
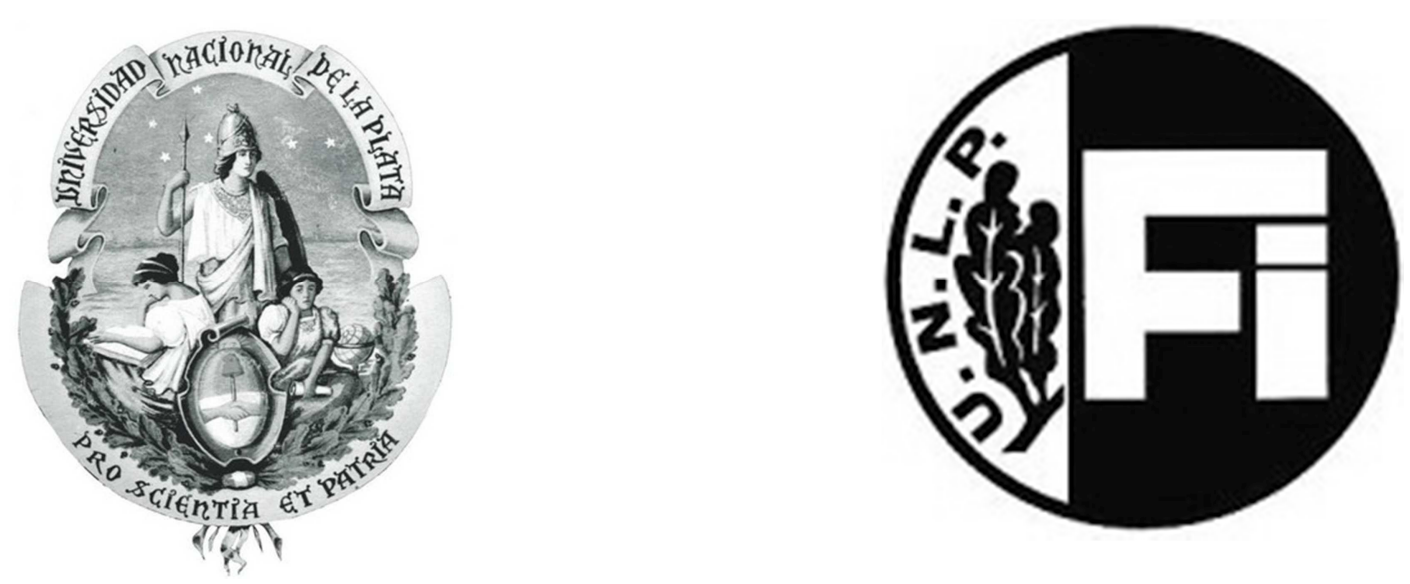

\title{
Desarrollo y evaluación de compositos cerámicos y recubrimientos a partir de arcillas nanoestructuradas
}

Tesis Doctoral presentada por:

Ing. Juan Manuel Martinez

Ante la

Facultad de Ingeniería de la Universidad Nacional de la Plata para acceder al grado académico de

DOCTOR EN INGENIERIA

Dirección de Tesis: Ing. Liliana B. Garrido

Codirección de Tesis: Dra. Ing. Cristina Volzone

Jurados de Tesis:

Dra. Elsa Farfán Torres (UNSA)

Mag. Mónica Trezza (FIO)

Dra. Irma Botto (UNLP)

Defensa Oral y Pública: 10 de Agosto de 2018 


\section{AGRADECIMIENTOS:}

Como muchos proyectos, este tiene un nombre en la portada, pero solo fue posible por la labor y apoyo de mucha gente que no está allí nombrada:

A mis mentoras y madres académicas, Cristina y Liliana, que, aparte de ser el bastión sobre el cual esta tesis se sostiene, demostraron ser guías de inmenso cariño y comprensión.

A mis viejos y a mi hermano, por su amor y apoyo, y por siempre alentarme a ser mejor persona.

A Malcom, mi compañero de ruta, por darme fuerzas cuando no las tenía, por el amor y la compañía (y la paciencia).

A Nacho, por su amistad, apoyo logístico y moral; pareciera que algo se empecino a condenarnos al éxito.

AI CETMIC, con toda su gente, abundante y variada, que me ayudo a disfrutar de mi profesión en un ambiente de calidez y apoyo mutuo (y comida, mucha).

A Pablo, por su ayuda con la granuladora; mucho de lo aquí realizado no hubiera podido hacerse sin su ayuda.

A Mati, por motivos varios y sobrados, en particular por su ayuda con el señor Rietveld.

A CONICET y YTEC, por las becas y el apoyo.

A todos los que de alguna manera, directa o indirecta, participaron de mi formación como doctor,

Gracias. 


\section{RESUMEN}

Las arcillas nanoestructuradas, AN, modificadas químicamente con especies polihidroxicatiónicas, tratadas térmicamente a temperatura de hasta $750{ }^{\circ} \mathrm{C}$, han sido objeto de muchos estudios por sus diversas propiedades (elevada superficie específica, tamaño de poro controlable, acidez, etc.), principalmente en el área de catálisis y adsorción. Sin embargo, son escasos los estudios de estos materiales tratados a mayores temperaturas, los cuales pueden desarrollar fases cristalinas en función del catión incorporado, otorgando propiedades adecuadas a la formación de compositos cerámicos de interés industrial.

El objetivo general de esta Tesis se basó en la preparación y caracterización de compositos cerámicos obtenidos con AN modificadas con especies hidroxialuminio (OHAl) e hidroxizirconio (OHZr). La arcilla utilizada para la preparación de las AN modificadas fue una bentonita, $\mathrm{B}$, de origen nacional. Se estudió la preparación de dos familias de compositos: sustratos recubiertos por inmersión en suspensiones de ANs y compositos tipo núcleo@cáscara-AN. Los sustratos en ambos casos fueron arcillas tipo caoliníticas.

Para los compositos obtenidos por recubrimiento de sustrato por inmersión en suspensiones de BOHAl, se hallaron las condiciones experimentales (cantidades y tiempo de inmersión, concentración de AN y aditivos en suspensión, condiciones de secado, sustrato, tratamiento térmico) que minimizaran el microagrietamiento superficial. Las condiciones óptimas para este tipo de AN fueron utilizadas para la preparación de compositos recubiertos por inmersión de sustrato en suspensión de BOHZr, determinando la importancia del catión intercalante de la AN en las propiedades del composito cerámico final.

Los compositos granulares tipo núcleo@cáscara se obtuvieron por rodamiento a partir de sustratos y recubrimiento de AN (natural y modificada por policationes de Al) en mezcladora de alta intensidad.

Las técnicas y ensayos utilizados para la caracterización de los materiales y la medición de sus propiedades fueron: difracción de rayos $\mathrm{X}$, fluorescencia de 
rayos $\mathrm{X}$, espectroscopia infrarroja, análisis térmicos, microscopía óptica y electrónica de barrido, movilidad electroforética y viscosidad en suspensión, distribución de tamaño de partícula, método de Arquímedes, porosimetría por intrusión de mercurio y dureza Vickers por indentación. Los materiales granulares fueron evaluados siguiendo los lineamientos de la norma API19C que se aplica para agentes de sostén en la industria de extracción del petróleo (entre ellos esfericidad y redondez; densidad de lecho, densidad aparente por picnometría y ensayo de resistencia a la rotura denominado ensayo crush).

Las AN intercaladas desarrollaron un menor contenido de fase amorfa, respecto a la AN sin tratar. La evolución de las fases cristalinas con la temperatura depende fuertemente de la composición química; a partir de BOHAl se determinó formación de espinela a $1000^{\circ} \mathrm{C}$ y progresivo aumento en el desarrollo de mullita y cristobalita hasta $1200^{\circ} \mathrm{C}$, coexistiendo con cordierita a $1300{ }^{\circ} \mathrm{C}$. Para $\mathrm{BOHZr}$, la formación de $\mathrm{t}-\mathrm{ZrO}_{2}$ comienza a $1000{ }^{\circ} \mathrm{C}$ que se transforma en $\mathrm{ZrSiO}_{4}$ a $1200{ }^{\circ} \mathrm{C}$. A $1300{ }^{\circ} \mathrm{C}$, predominan cordierita, $\mathrm{ZrSiO}_{4}$ y cristobalita. Mullita, $\mathrm{t}-\mathrm{ZrO}_{2}$ y $\mathrm{ZrSiO}_{4}$ son fases que presentan la ventaja de sus altos puntos de fusión y buenas propiedades mecánicas. La composición química, las fases presentes a alta temperaturas y mejoras en la estabilidad térmica resultan favorables para su utilización en cerámicos.

Se pudo establecer el uso de las arcillas nanoestructuradas (ANs) intercaladas con polihidroxicationes de $\mathrm{Al}$ o $\mathrm{Zr}$ como materias primas para el desarrollo de compositos cerámicos

La optimización de los sistemas sustrato-recubrimiento por inmersión derivó en compositos con recubrimientos de buena adherencia, en los cuales se minimizó el microagrietamiento superficial.

Pudo confirmarse que los compositos tipo nucleo@cáscara obtenidos por granulación y recubrimiento de AN modificada en polvo en mezcladora de alta intensidad, podrían ser utilizados como agentes de sostén cerámicos, desde el punto de vista de sus propiedades mecánicas y morfológicas de los mismos, según norma API19C. 


\section{ÍNDICE}

AGRADECIMIENTOS:

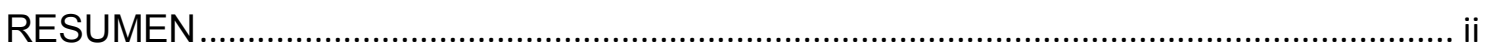

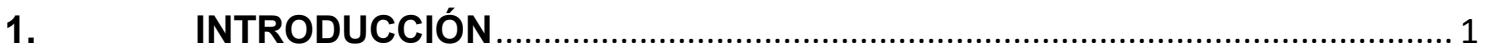

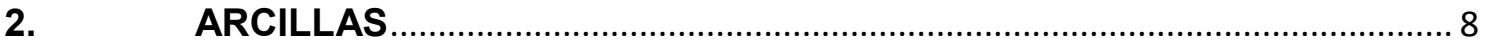

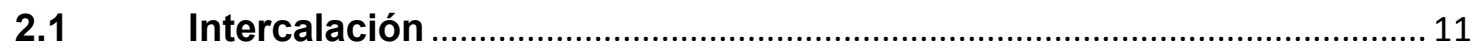

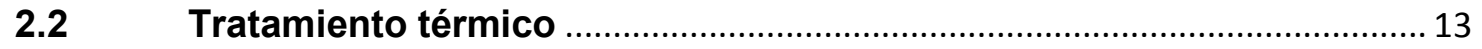

2.3 AN modificadas como materias primas de materiales cerámicos ........ 14

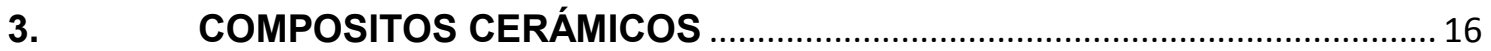

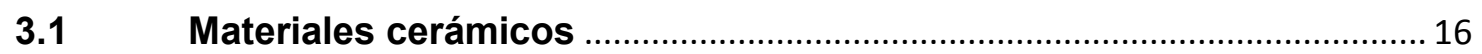

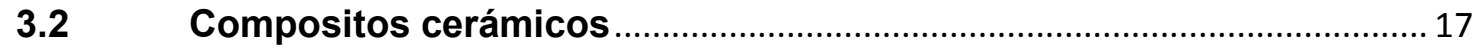

3.2.1 Recubrimiento por inmersión (dip-coating). ................................................. 18

3.2.1.1 Mecanismos de formación de recubrimientos por inmersión ......................... 19

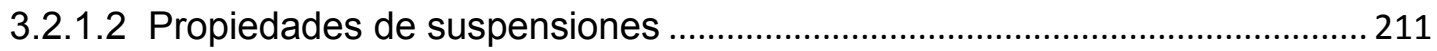

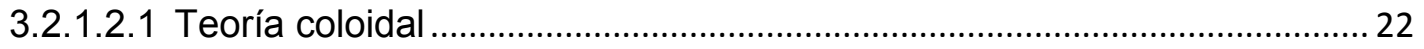

3.2.1.2.2 Propiedades de suspensiones de arcillas.................................................. 23

3.2.1.2.3 Efecto de agregado de poliacrilato de sodio en suspensión.......................23

3.2.2 Granulación y recubrimiento en mezcladora de alta intensidad ....................24

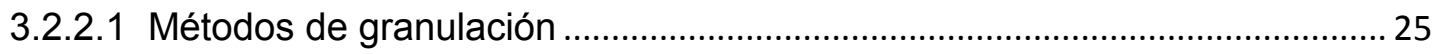

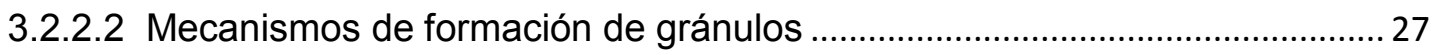

3.2.2.3 Recubrimiento en materiales granulares ....................................................... 28

4. MÉTODOS Y TÉCNICAS DE CARACTERIZACIÓN DE MATERIAS

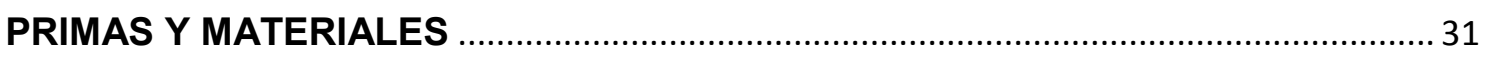

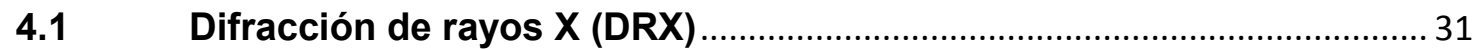

4.1.1 Cuantificación de fases cristalinas. Método de Rietveld ................................. 33

4.1.1.1 Semicuantificación de fase amorfa. Método de Ohlberg ……........................ 35

4.1.1.2 Cuantificación de fase amorfa. Método del patrón externo. ............................ 36

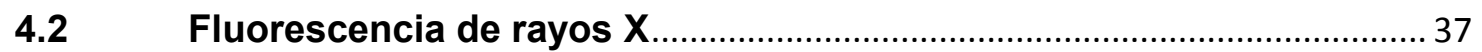

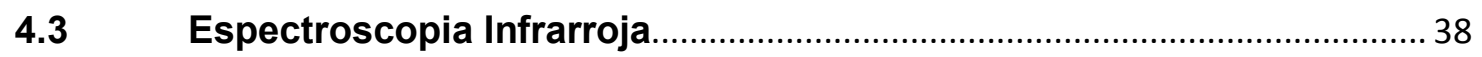

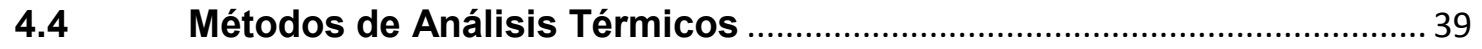

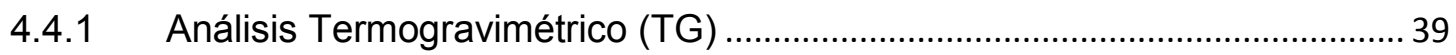

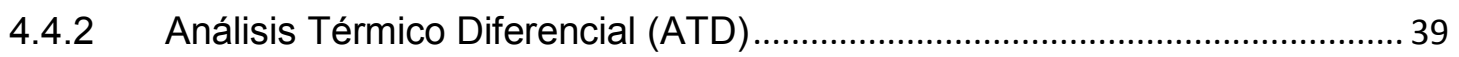


4.4.3 Microscopía de Calentamiento ........................................................................ 41

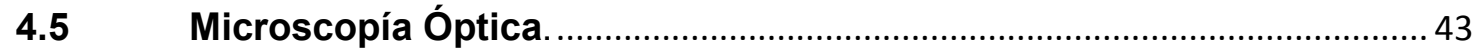

4.6 Microscopía electrónica de barrido (SEM) .................................................. 43

4.7 Movilidad electroforética en suspensión.................................................... 44

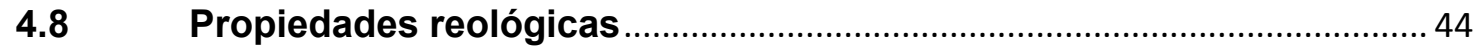

4.9 Distribución de tamaño de partícula ............................................................. 45

4.10 Método de Arquímedes para medición de densidad ................................ 46

4.11 Porosimetría por intrusión de mercurio ...................................................... 46

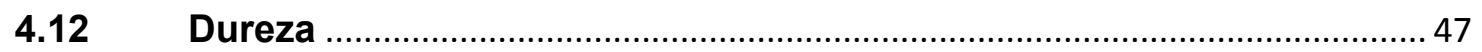

4.13 Caracterizaciones de materiales granulares............................................. 48

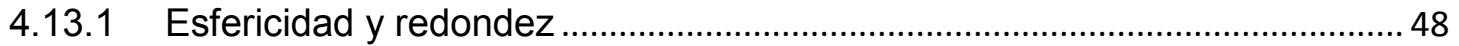

4.13.2 Densidad bulk o densidad de lecho de material granular .............................. 49

4.13.3 Densidad aparente por picnometría .............................................................. 50

4.13.4 Ensayo de resistencia a la rotura (crush) para materiales granulares......... 51

5. SÍNTESIS DE AN MODIFICADAS Y PROCESAMIENTO DE COMPOSITOS CERÁMICOS CON AN: SUSTRATOS RECUBIERTOS POR INMERSIÓN Y MATERIAL GRANULAR.

5.1 Síntesis de arcillas nanoestructuradas modificadas (BOHAl, BOHZr) 54

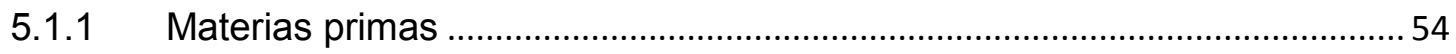

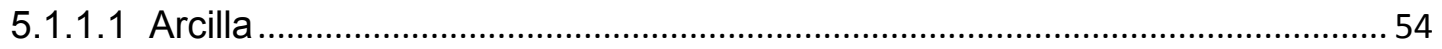

5.1.1.2 Solución con polihidroxicationes de aluminio $\mathrm{OH}-\mathrm{Al}$.........................................5 54

5.1.1.3 Solución con polihidroxicationes de zirconio $\mathrm{OH}-\mathrm{Zr}$...................................... 55

5.1.2 Método de síntesis de Arcillas Nanoestructuradas modificadas....................55

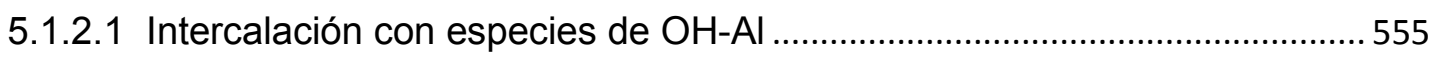

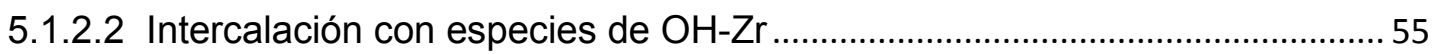

5.2 Procesamiento de compositos cerámicos .............................................. 56

5.2.1 Compositos obtenidos por recubrimientos por inmersión (Dip-coating) en suspensión de AN a partir de sustratos cerámicos............................................................. 57

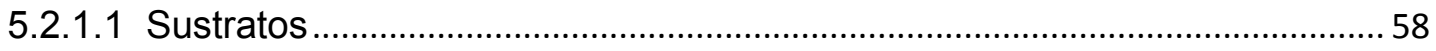

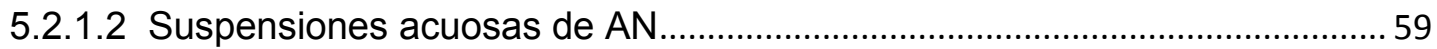

5.2.1.3 Procedimiento de recubrimiento de sustratos cerámicos por dip coating ... 59

5.2.2 Compositos cerámicos granulares por esferización ........................................ 60

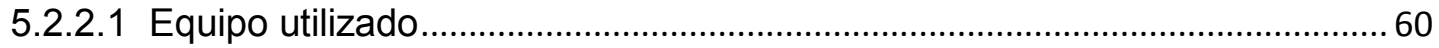


5.2.2.2 Materia prima para el conformado del sustrato

5.2.2.3 Procedimiento de pelletizado y recubrimiento en seco en granuladora de alta energía.

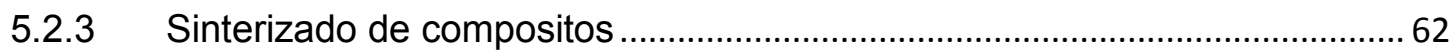

6. RESULTADOS

6.1 Caracterización de arcilla bentonítica B y arcillas nanoestructuradas modificadas

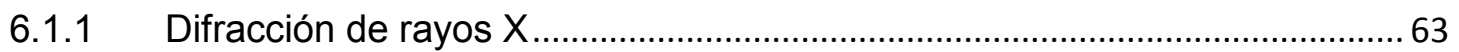

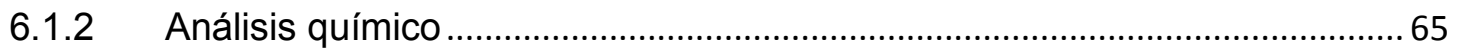

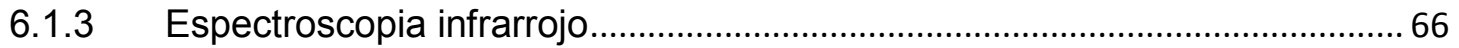

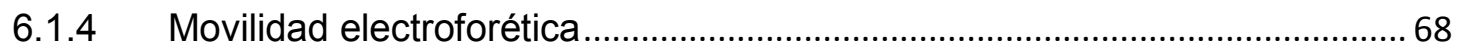

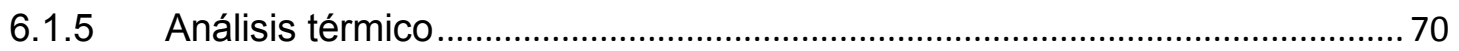

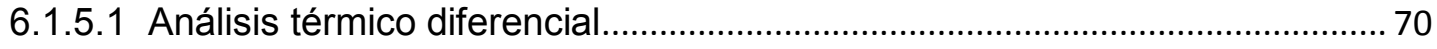

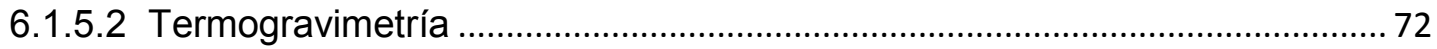

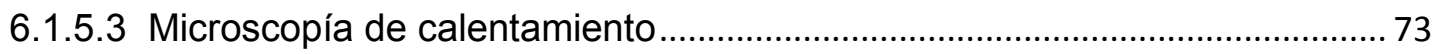

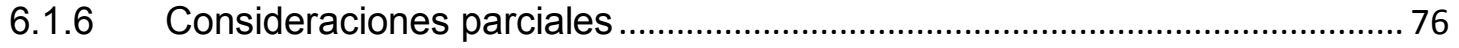

6.2 Propiedades de cerámicos obtenidos a partir de ANs naturales y

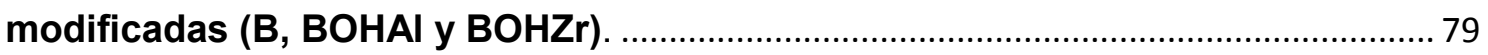

6.2.1 Composición de fases a diferentes temperaturas ......................................... 79

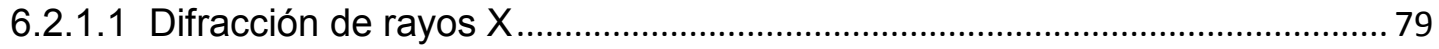

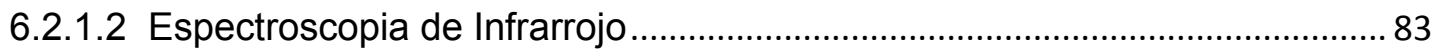

6.2.2 Comportamiento dilatométrico, propiedades microestructurales, físicas y

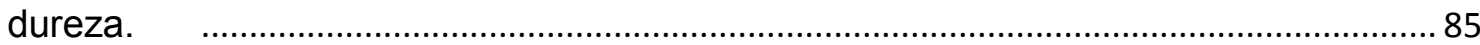

6.2.2.1 Efecto de pretratamiento de las ANs en las propiedades de los cerámicos

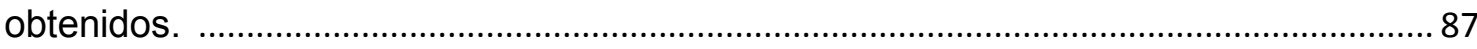

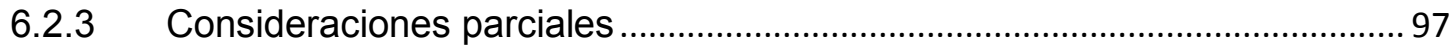

6.3 Compositos obtenidos por recubrimiento de sustratos con BOHAl por

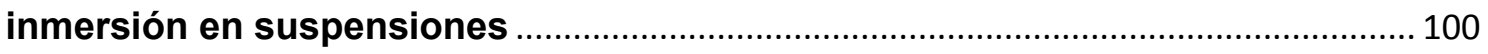

6.3.1 Recubrimiento de BOHAl sobre sustratos ................................................... 101

6.3.1.1 Evaluación de propiedades de suspensiones de BOHAl ............................ 101

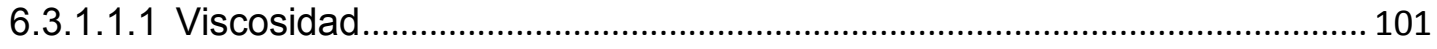

6.3.1.1.2 Efecto de NaPA en la movilidad electroforética ...................................... 103

6.3.1.2 Ensayos preliminares de recubrimientos por inmersión................................ 104 
6.3.1.2.1 Efecto del pretratamiento térmico del sustrato y temperatura del sustrato en la inmersión.

6.3.1.2.2 Efecto del tiempo de inmersión y propiedades de la suspensión precursora

6.3.1.2.3 Efecto de la temperatura de secado entre etapas sucesivas y de la temperatura de sinterizado

6.3.1.2.4 Ensayos de recubrimiento con suspensiones modificadas con diferentes aditivos

6.3.1.2.5 Ensayos de recubrimiento sobre sustratos PG ...................................... 126

6.3.2 Recubrimientos de BOHZr sobre sustratos PG .......................................... 131

6.3.3 Consideraciones parciales

6.4 Procesamiento y evaluación del material granular obtenido en mezcladora de alta intensidad con y sin aplicación de recubrimientos de AN. 136

6.4.1 Obtención y evaluación de cerámicos granulares a partir de arcilla PG y bentonita

6.4.2 Obtención y evaluación de cerámicos granulares derivados de arcilla PG con recubrimiento de arcilla nanoestructurada $\mathrm{BOHAl}$.

6.4.3 Correlación entre resistencia al crush y propiedades del material granular ...

6.4.4 Ensayo de resistencia al crush a $35 \mathrm{MPa}$ (5000 psi) de materiales PG1250, PG@B1200, PGm@BOHAl1250 y PGm@BOHAl1300................................................. 163

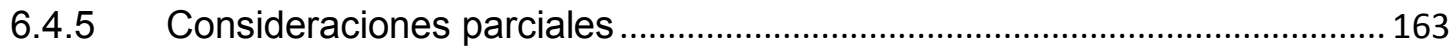

7. CONCLUSIONES

7.1 Acerca de las arcillas nanoestructuradas, AN, obtenidas y su caracterización

7.2 Acerca del procesamiento de cerámicos obtenidos a partir de AN modificadas ¡Error! Marcador no definido.

7.2 Acerca de los compositos obtenidos por recubrimiento de sustratos con AN por inmersión en suspensiones (dip coating) y caracterización .......... 167

7.3 Acerca de los compositos obtenidos por granulación y recubrimiento de BOHAl utilizando una mezcladora de alta intensidad y caracterización.......... 168

8. 


\section{INTRODUCCIÓN}

Las arcillas nanoestructuradas (AN) son materias primas de interés por su reactividad, derivada de su elevada superficie específica, así como por la posibilidad de modificarlas químicamente para obtener, por tratamiento térmico, materiales cerámicos con fases cristalinas de interés tecnológico. En la naturaleza las mismas se encuentran como minerales de arcilla constituidos por una estructura laminar con dimensiones nanométricas (Cap. 2 de la presente tesis), acompañadas por impurezas tales como feldespatos, cuarzo, carbonatos, óxidos, etc. Tradicionalmente, se han utilizado en diversas aplicaciones: barros de perforación en la industria de extracción de petróleo, (Al-Malki y col., 2016), como aglomerantes en arenas de moldeo para fundición (Paluszkiewicz y col., 2008), precursores de cerámicos refractarios y porosas (Vercauteren y col., 1998a); y como adsorbentes (Murray, 2000), por nombrar algunas de ellas. Asimismo, la inclusión de las nanoarcillas en membranas micro y nanofiltrantes mejora la hidrofilicidad y resistencia mecánica de las mismas (S y Joseph, 2018); así como aumenta la resistencia a la corrosión de materiales poliméricos de uso en la industria automotriz (Ganjaee Sari y col., 2015), en cementos para la industria de extracción de petróleo (Rahman y col., 2017), en las propiedades de retardo de llama en guantes de nitrilo (TingHsiang y col., 2018), demostrando el potencial de las mismas en adjudicar nuevas propiedades a materiales compuestos.

La modificación de AN naturales por intercalación con especies poliméricas inorgánicas ha sido objeto de estudio principalmente como precursor para la obtención de arcillas pilareadas o PILCs (del inglés, pillared interlayered clays) con control de superficie específica, acidez y tamaño de poros (Cap. 2). En general, los minerales arcillosos sobre los que se aplica este tipo de tratamiento son las esmectitas, componente principal de las bentonitas. Desde los trabajos iniciales de Vaughan y col (1980), diferentes especies catiónicas han sido incorporadas, tales como $\mathrm{Al}, \mathrm{Zr}, \mathrm{Ti}, \mathrm{Cr}, \mathrm{Si}$, y $\mathrm{Fe}$. Estos materiales poseen un adecuado tamaño de poro y elevada superficie específica, útil para su aplicación como adsorbentes, tamices moleculares y catálisis, entre otras, y son obtenidos a partir del tratamiento térmico de ANs intercaladas con las 
mencionadas especies a temperaturas no mayores a $750{ }^{\circ} \mathrm{C}$ (Mitra y Maitra, 2001).

El análisis bibliográfico realizado sobre la aplicación de AN intercaladas como materia prima para el desarrollo de materiales cerámicos por tratamiento térmico a temperaturas mayores a $1000{ }^{\circ} \mathrm{C}$, indica que no han sido estudiados en detalle para tal fin, y sólo se encuentra una investigación relacionada con su aplicación como recubrimiento de fibras de SiC estudio (Jagota y col., 1995). Así, en ese se utilizó una arcilla bentonítica enriquecida en policationes de aluminio para recubrir fibras de $\mathrm{SiC}$ que, posterior al tratamiento térmico, obtuvieron compositos cerámicos ( $\mathrm{SiC}$ recubiertas) en cuyo recubrimiento se desarrollaron fases cristalinas que produjeron el refuerzo de dichas fibras, mejorando las propiedades mecánicas del composito frente a la flexión.

Es sabido que los minerales arcillosos desarrollan con posterioridad a tratamientos térmicos, fases cristalinas de gran importancia tecnológica, tales como mullita, cordierita, ensteatita, etc. dependiendo de sus composiciones químicas y estructurales (Mackenzie y Caillere, 1979). Tanto en cerámica tradicional o para usos más actuales se recurre a estas fases porque confieren a los productos cerámicos buenas propiedades térmicas y mecánicas, necesarias para cumplir con los requerimientos de uso industrial (Kingery, 1976; Sadik y col., 2014).

Dentro de las fases cristalinas de interés industrial derivadas del tratamiento térmico de minerales arcillosos, se destaca la relevancia de la mullita $\left(3 \mathrm{Al}_{2} \mathrm{O}_{3} \cdot 2 \mathrm{SiO}_{2}\right)$, por múltiples propiedades tales como estabilidad térmica, buena resistencia mecánica, química y a la corrosión, y de la cordierita (2MgO $2 \mathrm{Al}_{2} \mathrm{O}_{3} \cdot 5 \mathrm{SiO}_{2}$ ) que presenta una menor resistencia mecánica, pero mejor resistencia al choque térmico (Tabla 1.1), con propiedades mecánicas que pueden ser mejoradas por incorporación de mullita. 
Tabla 1.1. Valores típicos de propiedades de cerámicos densos de cordierita y mullita (modificado de (Chlup y col., 2006))

\begin{tabular}{|c|c|c|}
\hline & Cordierita & Mullita \\
\hline Fórmula química & $2 \mathrm{MgO} \cdot 2 \mathrm{Al}_{2} \mathrm{O}_{3} \cdot 5 \mathrm{SiO}_{2}$ & $3 \mathrm{Al}_{2} \mathrm{O}_{3} \cdot 2 \mathrm{SiO}_{2}$ \\
\hline Densidad $\left(\mathrm{g} / \mathrm{cm}^{3}\right)$ & 2,6 & 2,8 \\
\hline Modulo elástico (GPa) & 70 & 150 \\
\hline Coeficiente de Poisson & 0,21 & 0,25 \\
\hline Resistencia a la compresión (MPa) & 350 & 551 \\
\hline Tensión de rotura (MPa) & 25,5 & 103,5 \\
\hline Resistencia a la flexión (MPa) & 117 & 170 \\
\hline Tenacidad a la fractura (MPa.m ${ }^{1 / 2}$ ) & - & 2 \\
\hline Coef. de expansión térmico lineal $\left(10^{-6}{ }^{\circ} \mathrm{K}^{-1}\right)$ & 1,7 & 5,3 \\
\hline Resistencia al choque térmico $\left({ }^{\circ} \mathrm{C}\right)$ & 500 & 300 \\
\hline Dureza Vickers (GPa) & 8,2 & 11 \\
\hline
\end{tabular}

Debido a que la intercalación de especies catiónicas inorgánicas en el mineral original lo enriquece en el tipo de catión incorporado y que, posterior al tratamiento térmico, dichas arcillas intercaladas pueden formar nuevas fases cristalinas, se considera que podría ser una alternativa para utilizarlas como recubrimiento $\mathrm{y}$, consecuentemente, en la obtención de compositos cerámicos (Cap. 3). Los antecedentes indican que el enriquecimiento en fase mullita es posible si se realizan tratamientos térmicos a arcillas intercaladas con especies policatiónicas de aluminio (Martinez y col., 2017a; Volzone y Garrido, 2012). Asimismo, se pueden obtener fases derivadas de otros elementos como el zirconio, por intercalado de ANs con especies policatiónicas de $\mathrm{Zr}$, para la obtención de fases de buenas propiedades mecánicas por tratamiento térmico (Martinez y col., 2017b). A temperaturas mayores a $1000^{\circ} \mathrm{C}$ se desarrollan fases como la zirconia en fase tetragonal $\left(\mathrm{t}-\mathrm{ZrO}_{2}\right)$, la cual es conocida por sus muy buenas propiedades mecánicas (elevada tenacidad a la fractura y resistencia al desgaste) que han fomentado su uso en aplicaciones diversas, desde materiales cerámicos refractarios hasta en implantes dentales (Hoggard y col., 1990; Özkurt y Kazazoğlu, 2011; Rendtorff Birrer, 2009). La t-ZrO $\mathrm{rO}_{2}$ es estable entre $1150-2250{ }^{\circ} \mathrm{C}$. A partir de esta temperatura y hasta el punto de fusión, la estructura del óxido es la cúbica. Debido a que a temperaturas inferiores la fase estable es la monoclínica; para estabilizar la fase tetragonal a temperatura ambiente, usualmente la $\mathrm{ZrO}_{2}$ se dopa con ciertos óxidos tales como $\mathrm{CaO}, \mathrm{MgO}, \mathrm{Y}_{2} \mathrm{O}_{3}$ y $\mathrm{CeO}_{2}$. La t- $\mathrm{ZrO}_{2}$ presenta buena resistencia mecánica 
que podría mejorarse por combinación con otra fase derivada del $\mathrm{Zr}$ tal como el zircón $\left(\mathrm{ZrSiO}_{4}\right)$. Este compuesto se caracteriza por un bajo coeficiente de dilatación térmica, baja conductividad térmica y elevada dureza (Kaiser y col., 2008; Suárez y col., 2015).

Sin embargo, las AN intercaladas son sistemas complejos, debido al carácter natural de las arcillas de partida, y es común que en su composición se encuentren impurezas típicas de minerales accesorios (cuarzo, feldespatos, filosilicatos, etc.). Es por ello que las propiedades y comportamiento del producto sinterizado dependerán no sólo de la AN (y las posibles impurezas), sino que también estarán relacionados con factores asociados al procesamiento. Por este motivo, es necesario caracterizar las AN y establecer los parámetros para su uso adecuado en la obtención de nuevos materiales cerámicos.

En los últimos años, para el diseño de nuevos materiales cerámicos, se ha propuesta una técnica que consiste en recubrir un sustrato cerámico con un compuesto y, a continuación, someterlo a un ciclo térmico (Moya y Requena, 1998). Esta es una técnica muy eficiente que permite obtener materiales compuestos, que posean propiedades distintas a las del sustrato.

Dos tipos de compositos cerámicos a partir de ANs son explorados en esta tesis: compositos de tipo sustrato-recubrimiento de AN y materiales granulares núcleo@cáscara de AN.

Respecto a los compositos cerámicos del tipo sustrato-recubrimiento obtenidos por recubrimiento de ANs, se reportan varios trabajos donde se aplica la técnica de inmersión de sustratos en suspensiones de AN (dip coating) y sinterización a temperaturas mayores a $1000{ }^{\circ} \mathrm{C}$, obteniendo compositos cerámicos de buenas propiedades mecánicas debido a las fases cristalinas desarrolladas por los mismos a alta temperatura (Blanton y col., 2000; Pisklak y col., 2011; Mishra y col., 2011). Sin embargo, existe escasa bibliografía respecto al desarrollo de recubrimientos de ANs modificadas por intercalación de policationes inorgánicos, siendo un aspecto interesante a analizar, ya que, como fuera antes mencionado, el enriquecimiento de las $A N$ en distintos 
elementos puede fomentar la formación de fases cristalinas de mejores propiedades mecánicas.

Respecto a los materiales granulares (pellets) derivados de arcillas naturales, los mismos tienen aplicaciones industriales de las más variadas, tales como materia prima en la producción de revestimientos, baldosas (Framinan y col., 2014), en el sellado de pozos (Koch, 2002), como coadyuvantes para la separación de suspensiones y adsorbentes (Miranda y col., 2015) por nombrar algunas. Asimismo, por tratamiento térmico de los mismos, estos pellets (cerámicos) poseen múltiples aplicaciones incluyendo en soportes de catalizadores, receptores de aire y elementos de molienda, entre otros.

Una aplicación interesante de los pellets cerámicos es su uso en la industria de extracción de hidrocarburos como agentes de sostén para la fractura hidráulica (Liang y col., 2016). En esta técnica denominada estimulación hidráulica o fracking, se realiza la inyección de un fluido formado por agua, agentes sostén y aditivos químicos en una perforación ya realizada. Dicha inyección a presión produce la fractura de la roca, abriendo fisuras en la formación, y el agente de sostén adquiere su nombre porque "sostiene" la fractura realizada, generando una red porosa por la cual puede fluir el hidrocarburo una vez comenzada la extracción (Fig. 1.1).

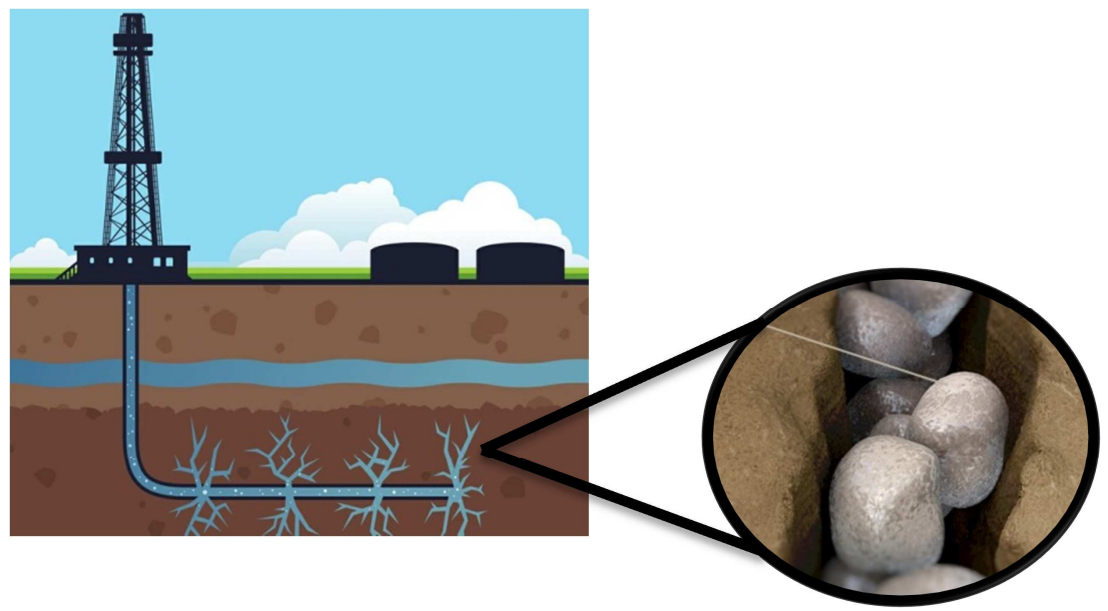

Fig. 1.1 Esquema de fractura hidráulica y agentes de sostén (modificado de (Roca 2013))

Esta práctica suele realizarse en pozos maduros y principalmente, en yacimientos de gas y petróleo no convencionales, donde el hidrocarburo se 
encuentra localizado en poros no interconectados entre sí, por lo que su explotación no es posible a menos de utilizar la técnica de estimulación (Hellmann y col., 2014; López Anadón y col., 2015; Lyle, 2011). Cabe destacar que en la Argentina, en los últimos años ha surgido la posibilidad de explotar los recursos de reservorios no convencionales con los que cuenta el país (López Anadón y col., 2015), lo cual permitiría aumentar considerablemente su aprovechamiento. Para esta finalidad, el lecho de pellets debe soportar elevadas presiones, así como ser térmica y químicamente estable, ser compatible con el líquido de fractura, y presentar valores adecuados de esfericidad y redondez, entre otros requerimientos. Los agentes de sostén cerámicos, sean de un solo material o compositos, son utilizados habitualmente en la industria. Así, el agente de sostén recubierto puede mejorar las propiedades mecánicas del lecho, habilitando su uso a mayores presiones de pozo.

El presente trabajo de tesis comprende el procesamiento y caracterización de compositos cerámicos utilizando arcillas nanoestructuradas naturales y modificadas como recubrimiento para mejorar la resistencia del composito a través del control de las fases formadas y su microestructura. La AN utilizada como materia prima es una bentonita; mineral natural procedente de nuestro país y su uso como materia prima en este trabajo contribuye a su valoración y a una aplicación más eficiente en la elaboración de nuevos productos cerámicos por recubrimiento de diversos sustratos (cerámicos porosos y granulares) utilizando dos tipos de técnicas: recubrimiento por inmersión del sustrato en suspensiones acuosas de AN y recubrimiento en seco del sustrato con AN en polvo en granuladora.

\section{Objetivos de la tesis}

- Síntesis de arcillas nanoestructuradas (AN) modificadas por intercalación de una arcilla nacional (bentonita) con especies poliméricas de aluminio y zirconio.

- Caracterización química, estructural, mineralógica y fisicoquímica. Comportamiento térmico de las ANs hasta $1300{ }^{\circ} \mathrm{C}$ evaluado por diversos análisis térmicos (análisis térmico diferencial, termogravimetría; microscopia de 
calentamiento; difracción de rayos $\mathrm{X}$ y espectroscopia infrarrojo de muestras tratadas térmicamente, etc.).

- Preparación y caracterización de cerámicos obtenidos a partir de ANs en polvo por prensado uniaxial y sinterización. Efecto de la distribución de tamaños de partícula y de la temperatura de sinterización en la densidad, porosidad y tamaño de poros, composición de fases y dureza Vickers de los cerámicos resultantes.

- Elaboración de compositos cerámicos constituidos de sustratos y recubrimiento de AN por inmersión en suspensiones (Dip coating) y sinterización a temperaturas mayores a $1000{ }^{\circ} \mathrm{C}$. Evaluación del efecto de las principales variables del proceso de dip coating sobre adherencia, cantidad retenida y grado de agrietamiento del recubrimiento.

- Desarrollo y caracterización de compositos cerámicos obtenidos a partir de sustratos granulares (pellets) por recubrimiento con ANs en polvo (natural y modificadas) por procesamiento en granuladora y sinterización a temperaturas mayores a $1000{ }^{\circ} \mathrm{C}$. Estudio de las reacciones a alta temperatura, densificación y sinterización, cuantificación de fases cristalinas y amorfas presentes en los compositos. Obtención del material granular en un equipo de granulación (tipo mezcladora de alta energía) a escala de laboratorio $(1 \mathrm{~kg})$. Determinación de las condiciones experimentales más adecuadas para obtener pellets esféricos con buena resistencia térmica y mecánica Evaluación de los compositos cerámicos granulares: propiedades físicas, morfología y resistencia mecánica siguiendo los lineamientos de la Norma API19C (Measurement of properties of proppants used in hydraulic fracturing and Gravel packing operations). 


\section{ARCILLAS}

La palabra arcilla se refiere al material "natural" compuesto fundamentalmente por "mineral de grano fino", el cual es generalmente "plástico" con apropiada cantidad de agua, que endurece cuando se lo seca al aire o calcina. Estos materiales están compuestos mayoritariamente por minerales arcillosos asociados a otros tales como cuarzo, yeso, y/o feldespato, etc. (Bergaya y Lagaly, 2013; Guggenheim y Martin, 1995).

Los minerales arcillosos pertenecen a la familia de los filosilicatos ya que en parte están constituidas por unidades estructurales de tetraedros de silicio $\left(\mathrm{SiO}_{4}\right)$ que polimerizan compartiendo tres oxígenos basales originando un retículo hexagonal en forma bidimensional (Brown, 1984), Fig. 2.1a. Esta estructura se encuentra acompañada por otra unidad formada por seis oxígenos coordinados en forma de octaedros con cationes $\mathrm{Al}, \mathrm{Mg}, \mathrm{Fe}$, etc. que polimerizan compartiendo cuatro oxígenos (Fig. 2.1b).

a)
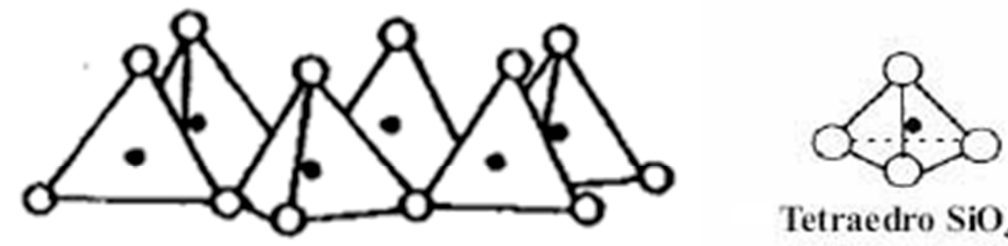

Oxígeno

Tetraedro $\mathrm{SiO}_{4}$

b)
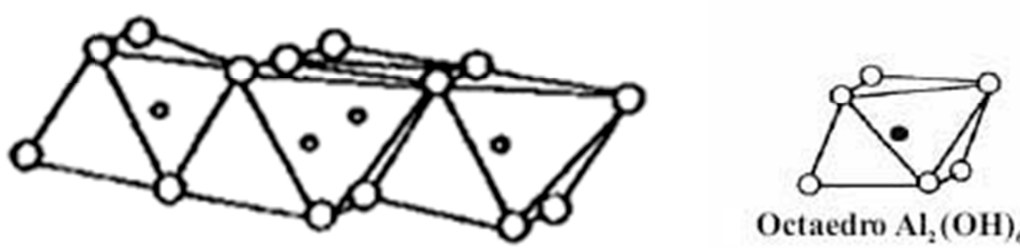

Oxígeno

Hidroxilos

Aluminio

- Magnesio

Figura 2.1: Estructura de las capas a) tetraédrica $(T)$ y b) octaédrica $(O)$ (extraído de Volzone (1997))

La capa conformada por los tetraedros de $\mathrm{SiO}_{4}$ es llamada "capa tetraédrica (T)" y la compuesta por los octaedros de Al, Mg o Fe, "capa octaédrica (O)". Existen dos tipos de capas O: cuando todos los octaedros están ocupados se denominan trioctaédricas, mientras que si solo dos tercios de los octaedros están ocupados son denominadas dioctaédricas. Las capas mencionadas se unen a través de los oxígenos, mientras que los vértices no compartidos contienen grupos $\mathrm{OH}$. 
a)

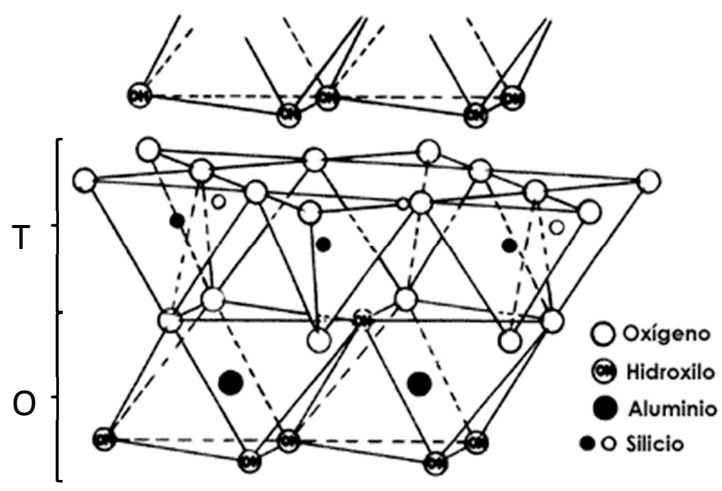

b)

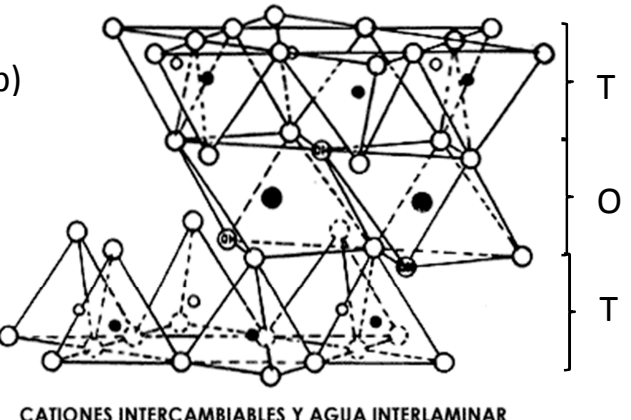

CATIONES INTERCAMBIABLES Y AGUA INTERLAMINAR

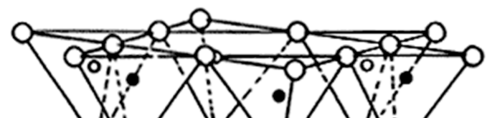

Fig. 2.2 Lámina a) tipo 1:1 y b) tipo 2:1(extraído de Volzone (1997))

La unión de una capa del tipo $\mathrm{T}$, con otra del tipo $\mathrm{O}$, genera una lámina T-O (Fig. 2.2.a), o lámina 1:1, en la cual la superficie de la capa octaédrica está constituida por grupos $\mathrm{OH}$. Asimismo, dos capas tetraédricas separadas por una capa octaédrica forman láminas T-O-T o tipo 2:1, (Fig. 2.2.b). En este tipo de estructura, los reemplazos isomórficos que pueden suceder en la capa tetraédrica (el $\mathrm{Si}^{4+}$ puede ser reemplazado por $\mathrm{Al}^{3+} \circ \mathrm{Fe}^{3+}$ ) y/o en la capa octaédrica $\left(\mathrm{Al}^{3+}\right.$ puede ser reemplazado por $\mathrm{Fe}^{2+}, \mathrm{Mg}^{2+}$, etc.) originan un exceso de cargas negativas, las cuales son neutralizadas por los cationes ubicados en el espacio interlaminar. La Tabla 2.1 muestra la clasificación de los minerales arcillosos donde se indican las principales características.

Tabla 2.1 Principales características de los minerales arcillosos y clasificación

\begin{tabular}{|c|c|c|c|c|}
\hline & Caolinita & Illita & Esmectita & Clorita \\
\hline Fórmula & $\begin{array}{c}\mathrm{Al}_{2} \mathrm{Si}_{2} \mathrm{O}_{5}(\mathrm{OH})_{4} \\
\mathrm{Al}_{4} \mathrm{Si}_{4} \mathrm{O}_{10}(\mathrm{OH})_{8} \cdot 4 \mathrm{H}_{2} \mathrm{O}\end{array}$ & $\begin{array}{c}\mathrm{K}_{0.8} \mathrm{Al}_{2}\left(\mathrm{Si}_{3.2} \mathrm{Al}_{0.8}\right) \\
\mathrm{O}_{10}(\mathrm{OH})_{2}\end{array}$ & $\begin{array}{c}\mathrm{Si}_{8} \mathrm{Al}_{4} \mathrm{O}_{20}(\mathrm{OH})_{4} \\
n \mathrm{H}_{2} \mathrm{O}\end{array}$ & $\begin{array}{c}(\mathrm{Mg}, \mathrm{Fe}, \mathrm{Mn}, \mathrm{Al})_{12}(\mathrm{Si}, \mathrm{Al})_{8} \\
\mathrm{O}_{20}(\mathrm{OH})_{16}\end{array}$ \\
\hline Estructura & 1:1 dioctaédrica & $\begin{array}{c}2: 1 \\
\text { mayormente } \\
\text { dioctaédrica }\end{array}$ & $\begin{array}{l}\text { 2:1 di- y } \\
\text { trioctaédrica }\end{array}$ & 2:1:1 trioctaédrica \\
\hline Espaciado (nm) & $0,71-1,0$ & 0,10 & $\begin{array}{l}\text { Variable, } \\
\text { gralmente } 1,5\end{array}$ & 1,42 \\
\hline $\begin{array}{l}\text { Catión } \\
\text { interlaminar }\end{array}$ & no & K & $\mathrm{Ca}$ y $\mathrm{Na}$ & No \\
\hline $\begin{array}{l}\text { Agua entre } \\
\text { láminas }\end{array}$ & $\begin{array}{c}1 \text { capa para } \\
\text { halloysita }\end{array}$ & & Variable & No \\
\hline $\mathrm{CIC}^{1}$ (meq/g) & 0,01 & $0,1-0,4$ & $0,8-1,5$ & \\
\hline
\end{tabular}


Las esmectitas son minerales arcillosos del tipo 2:1 (Figura 2.2b), las cuales son las principales constituyentes (80-90\%) de las bentonitas. Se caracterizan por poseer importante reemplazos isomórficos en las capas, los cuales originan una capacidad de intercambio catiónico del orden de 0,8-1,5 meq/g. La distancia entre estas láminas puede variar apreciablemente dependiendo del tipo de cationes de compensación interlaminar y de su grado de hidratación (Brown y Brindley, 1980). Este espaciado entre láminas es denominado espaciado basal o $\mathrm{d}_{001}$, y es del orden de los nanómetros (1,2 nm o mayores), hecho que le confiere la denominación de nanoarcillas 0 arcillas nanoestructuradas (AN) a este tipo de minerales.

Las principales aplicaciones de la bentonita natural están vinculadas al carácter tixotrópico de las suspensiones acuosas de la misma y su capacidad expansiva: entre ellas, su uso como lodo de perforación en la extracción de petróleo, espesante en cosméticos o pintura (Allo y Murray, 2004; Luckham y Rossi, 1999; Murray, 2000). Su gran área superficial, conferida por la nanoestructura antes mencionada y tamaño de partícula fino, posibilita uso adicional como adsorbente, catalizador, o medio filtrante entre otras aplicaciones (Lagaly y Dékány, 2013).

Los principales miembros de la familia de esmectitas son: montmorillonita, beidellita, nontronita, saponita y hectorita. La diferencia entre ellas radica en los reemplazos isomórficos que tienen lugar en las capas tetraédricas y/u octaédricas de las láminas, las cuales originan distintas deficiencias de cargas y propiedades fisicoquímicas. Esas deficiencias son compensadas por cationes tales como $\mathrm{Na}^{+}, \mathrm{Ca}^{2+}, \mathrm{Mg}^{2+}, \mathrm{K}^{+}$, etc. los cuales están acompañados por moléculas de agua ocupando el espaciado interlaminar. Las formulas estructurales ideales correspondientes a media celda unidad de las mismas se muestran en la Tabla 2.2. 
Tabla 2.2.: Fórmula estructural de las diferentes esmectitas

\begin{tabular}{lcccc}
\hline \multirow{2}{*}{ Esmectita } & Espacio interlaminar & \multicolumn{2}{c}{ Cationes } & \multirow{2}{*}{ Aniones } \\
\cline { 3 - 4 } & $(\mathrm{X}$ : catión interlaminar $)$ & capa octaédrica & \multicolumn{2}{c}{ capa tetraédrica } \\
\hline Montmorillonita & $\mathrm{X}_{0,35}^{+}$ & $\mathrm{Al}_{1,65} \mathrm{Mg} 0,35$ & $\mathrm{Si}_{4}$ & $\mathrm{O}_{10}(\mathrm{OH})_{2}$ \\
Beidellita & $\mathrm{X}_{0,40}^{+}$ & $\mathrm{Al}_{2,00}$ & $\mathrm{Si}_{3,60} \mathrm{Al}_{0,40}$ & $\mathrm{O}_{10}(\mathrm{OH})_{2}$ \\
Nontronita & $\mathrm{X}_{0,40}^{+}$ & $\mathrm{Fe}_{2,00}^{3+}$ & $\mathrm{Si}_{3,60}\left(\mathrm{Al}, \mathrm{Fe}^{3+}\right)_{0,40}$ & $\mathrm{O}_{10}(\mathrm{OH})_{2}$ \\
Saponita & $\mathrm{X}_{0,50}^{+}$ & $\mathrm{Mg}_{3,00}$ & $\mathrm{Si}_{3,50} \mathrm{Al}_{0,50}$ & $\mathrm{O}_{10}(\mathrm{OH})_{2}$ \\
Hectorita & $\mathrm{X}_{0,30}^{+}$ & $\mathrm{Mg}_{2,70} \mathrm{Li}_{0,30}$ & $\mathrm{Si}_{4}$ & $\mathrm{O}_{10}(\mathrm{OH})_{2}$ \\
\hline
\end{tabular}

Entre las esmectitas dioctaédricas, la más abundante en la naturaleza es la montmorillonita (Bergaya y Lagaly, 2013; Smykatz-Kloss y Warne, 2006) mineral arcilloso que deriva su nombre del francés Montmorillon, lugar de Francia en donde se encontraron arcillas de este tipo en 1874. Esta esmectita se caracteriza principalmente por sustituciones isomórficas del aluminio por el magnesio en la capa octaédrica. Se suele clasificar dos tipos de montmorillonitas, Cheto y Wyoming siendo la diferencia entre las mismas un mayor contenido de $\mathrm{Mg}$ en la del primer tipo respecto a la segunda.

Como se mencionara anteriormente, las bentonitas son las arcillas que contienen el mayor porcentaje de esmectita. La Argentina posee importantes yacimientos de bentonitas distribuidos principalmente en las provincias de Neuquén, Rio Negro, San Juan y Mendoza. Sus aplicaciones se distribuyen en diferentes tipos de industrias: en la extracción de petróleo (como lodo de perforación) en fundición de minerales de hierro (como ligante en arenas de moldeo y en la pelletización del mineral), en la industria de alimentos para animales (como binder en los pellets y pequeño aporte nutricional), por nombrar algunas (Hevia, 2007).

\subsection{Intercalación}

La estructura de las esmectitas puede ser modificada por diferentes métodos: intercambio iónico, intercalación con especies inorgánicas u orgánicas, activación física y química, tratamientos térmicos, etc.

El intercambio iónico, es decir, el reemplazo de los cationes interlaminares "naturales" del mineral arcilloso por otros, es posible debido a que los mismos están débilmente unidos a los oxígenos superficiales de las láminas y, 
principalmente, atraídos por el exceso de carga negativa de la lámina (producto de las sustituciones isomórficas), quedando prácticamente libres en medio acuoso. Esto le puede conferir nuevas propiedades a la AN así obtenida. Ejemplos de productos por intercambio catiónico son: con catión inorgánico de sodio para obtener suspensiones estables; con catión orgánico como aminas cuaternarias para adjudicarle propiedades organofílicas a la arcilla, posibilitando, por ejemplo, su uso en la remoción de compuestos orgánicos de aguas industriales de desecho (Groisman y col., 2004).

El uso de polímeros inorgánicos para el intercalado de esmectitas tuvo sus inicios con los trabajos de Lussier, Maggi y Vaughan (Lussier y col., 1980), cuyas patentes cubrían no sólo la metodología de intercalación de dichos polímeros en el espaciado interlaminar de la esmectita, sino también la deshidroxilación de las especies hidroxi-catiónicas introducidas, formando compuestos estables denominados arcillas pilareadas o PILCs. Se muestra un esquema de este proceso en la Fig. 2.3.

Respecto a las arcillas sin tratar, las arcillas intercaladas poseen una mayor porosidad y superficie específica, derivada de la expansión causada por las especies poliméricas en el espaciado interlaminar de la arcilla, que, posterior al tratamiento térmico, conserva sus láminas separadas por la formación de especies estables. De esta manera, la intercalación de arcillas con especies hidroxicatiónicas origina una mayor estabilidad térmica, ya que mantiene las láminas de las arcillas separadas a temperaturas que la arcilla natural no podría. Asimismo, se pueden preparar PILCs a partir de distintos cationes intercalantes, desarrollando por tratamiento térmico PILCs con pilares de $\mathrm{Al}, \mathrm{Zr}$, $\mathrm{Ti}, \mathrm{Fe}, \mathrm{Cr}, \mathrm{Ga}, \mathrm{V}$, Si y otros elementos, así como pilares de óxidos mixtos como $\mathrm{Fe} / \mathrm{Al}, \mathrm{Ga} / \mathrm{Al}, \mathrm{Si} / \mathrm{Al}, \mathrm{Zr} / \mathrm{Al}$, entre otros. (Bergaya y col., 2006; Kloprogge, 1998; Vaughan y Lussier, 1980; Volzone, 2001). 


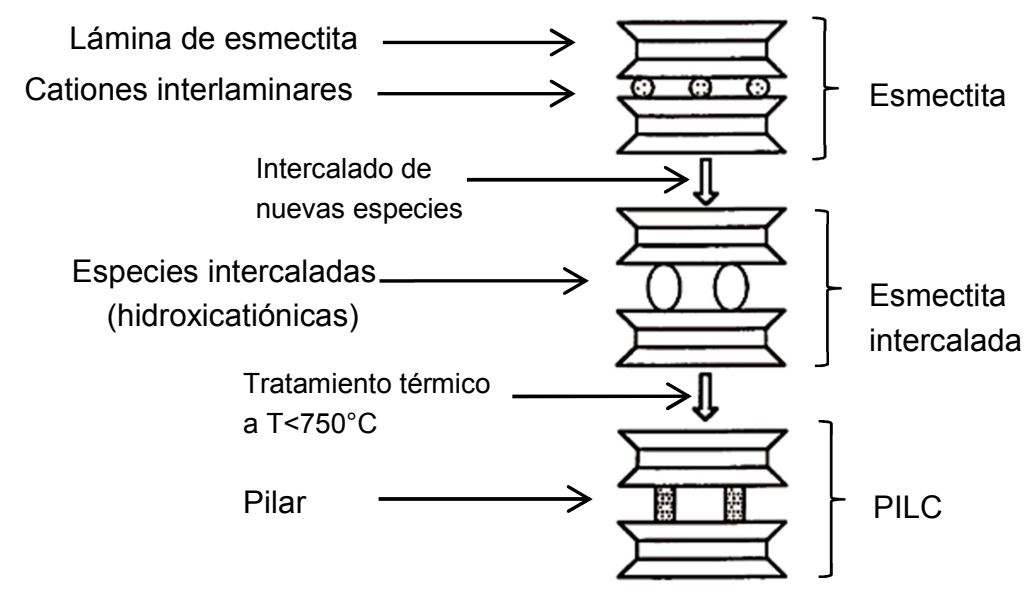

Fig. 2.3. Esquema de preparación de arcillas pilareadas a partir de esmectitas

\subsection{Tratamiento térmico}

Las esmectitas, así como en general las arcillas, desarrollan distintas fases cristalinas por tratamiento térmico a altas temperaturas (Mackenzie y Caillere, 1979). En una primera etapa, a temperaturas bajas de hasta $150^{\circ} \mathrm{C}$ pierden el agua interlaminar y la asociada a los cationes de intercambio. En el rango de 490-720 ${ }^{\circ} \mathrm{C}$ la pérdida de masa es atribuida a la remoción de los oxhidrilos estructurales, en tanto que a temperaturas mayores a $850{ }^{\circ} \mathrm{C}$, la estructura propiamente dicha comienza a destruirse. A partir de los constituyentes de la capa tetraédrica de $\mathrm{SiO}_{4}$ del mineral arcilloso original (y la presencia de álcalis), comenzando a aproximadamente $800-850^{\circ} \mathrm{C}$, se forma una fase líquida, rica en sílice, en tanto que la cristobalita cristaliza por encima de los $1000^{\circ} \mathrm{C}$. El desarrollo de nuevas fases tales como mullita, cordierita, ensteatita, etc. dependerá del tipo de esmectita presente, así por ejemplo, la cristalización de mullita comienza a $1050{ }^{\circ} \mathrm{C}$ a partir de montmorillonita tipo Wyoming, con cristales que crecen a medida que aumenta la temperatura de tratamiento térmico (McConville, 2005; Volzone y Cesio, 2004).

Estas observaciones son generales, y no siempre se cumplen, ya que, como se describió anteriormente, las esmectitas poseen una gran variabilidad respecto a su composición química y estructural (Tabla 2.2) y dependerá también de la presencia de impurezas que puedan acompañarla. Respecto a los dos tipos de montmorillonita mencionadas en punto 2.1 , el comportamiento al tratamiento 
térmico de la tipo Wyoming difiere de la del tipo Cheto. El mayor contenido en magnesio reemplazando al aluminio en la capa octaédrica en la montmorillonita tipo Cheto, origina la fase cristalina denominada cordierita a partir de los 1000 ${ }^{\circ} \mathrm{C}$, en tanto que en la tipo Wyoming se desarrolla la fase mullita (Grim y Kulbicki, 1961; Martinez y col., 2017a).

La presencia de impurezas, por ejemplo, de cuarzo y/o feldespatos altera el comportamiento térmico respecto al mineral arcilloso puro. El cuarzo remanente como impureza puede subsistir hasta altas temperaturas $(>1100$ ${ }^{\circ} \mathrm{C}$ ), mientras que la presencia de los feldespatos es detectada hasta temperaturas entre los $1000-1100{ }^{\circ} \mathrm{C}$, a temperaturas superiores no se observan, favoreciendo la formación de una fase líquida. Otro factor de relevancia es el tipo de cationes presentes en el espaciado interlaminar, que también participan de las fases desarrolladas a alta temperatura.

\subsection{AN modificadas como materias primas de materiales cerámicos}

El comportamiento térmico de las AN derivadas por intercalación de polihidroxicationes inorgánicos, PILCs, difiere de su arcilla original AN, debido a la formación de óxidos que actúan como pilares en el espaciado interlaminar en las primeras, haciendo que la estructura interlaminar se mantenga con la temperatura a valores mayores, de hasta $750^{\circ} \mathrm{C}$.

Existe escasa información sobre tratamientos térmicos de los PILCs a mayores temperaturas de las cuales generalmente se preparan, es decir, en el rango de 750 a $1350{ }^{\circ} \mathrm{C}$ (Jagota y col., 1995; Martinez y col., 2017a; Volzone y Cesio, 2004). En esos casos, como es de esperar, el "pilar" es destruido (por tratamiento a temperaturas por encima del colapso estructural del mineral arcilloso.) y nuevas fases cristalinas son obtenidas. De esta manera se llega a dilucidar que las fases desarrolladas son comunes a aquellas encontradas en productos cerámicos, resultando así de gran interés. Por lo tanto, arcillas intercaladas con especies poliméricas de hidroxi-cation ( $\mathrm{Al}, \mathrm{Zr}, \mathrm{Ti}, \mathrm{Cr}$, etc.) y posterior tratamiento térmico a alta temperatura podrían ser aplicables como materia prima de productos cerámicos y/o compositos cerámicos. 
En un estudio previo, Jagota y col (1995) utilizaron esmectitas intercaladas con polihidroxicationes de Al, encontrando evidencia de formación de mullita a 800 ${ }^{\circ} \mathrm{C}$, temperatura relativamente baja en comparación a las AN naturales. Estos autores lograron recubrir fibras de $\mathrm{SiC}$ con dichas $\mathrm{AN} \mathrm{y}$, por tratamiento térmico, formaron compositos cerámicos con mayor resistencia mecánica que las fibras sin recubrimiento.

Es importante resaltar que la composición estructural del mineral arcilloso de partida sigue siendo un factor determinante de las fases cristalinas desarrolladas (Martinez y col., 2017a). Se ha encontrado anteriormente que el contenido de fases cristalinas depende no sólo del método de intercalación sino además de la estructura del mineral arcilloso de partida (Martinez y col., 2017a; Volzone y Cesio, 2004). De la misma manera, se estudió el potencial uso de estas AN como recubrimiento sobre sustratos cerámicos, encontrando que los mismos desarrollan buena adherencia y presentan estructuras cristalinas multifásicas, destacándose entre las fases presentes la mullita (Martinez y col., 2017c).

La intercalación de polihidroxicationes de $\mathrm{Zr}$ en esmectitas y posterior calcinación a temperaturas mayores a $1000{ }^{\circ} \mathrm{C}$ puede producir fases derivadas de este elemento de gran interés en la industria cerámica, como la Zirconia $\left(\mathrm{ZrO}_{2}\right)$ o el Zircón $\left(\mathrm{ZrSiO}_{4}\right)$, por las propiedades antes mencionadas de dichas fases (Martinez y col., 2017b).

En base a lo discutido anteriormente, en este trabajo de Tesis se prepararon arcillas nanoestructuradas modificadas por intercalación de especies polinucleares de aluminio y zirconio en una arcilla bentonítica nacional, rica en contenido de esmectita, para su aplicación en la elaboración de recubrimientos para la obtención de compositos cerámicos. 


\section{COMPOSITOS CERÁMICOS}

\subsection{Materiales cerámicos}

La definición clásica de cerámicos los describe como materiales constituidos por compuestos inorgánicos no metálicos consolidados por tratamientos térmicos y que resisten a altas temperaturas tanto cristalinos como también vidrios, vitrocerámicos, esmaltes, cementos, etc. Además de la cerámica tradicional (productos estructurales de arcilla como ladrillos y tejas, alfarería, porcelana, refractarios, abrasivos), las cerámicas de avanzada o funcionales se usan como materiales dieléctricos, magnéticos, ferroeléctricos, ópticos, monocristales industriales y una amplia variedad de otros productos (Budworth y Arthur, 2016; Kingery, 1976). Las propiedades características de los cerámicos son altos puntos de fusión, elevada dureza, resistencia mecánica combinadas con resistencia al desgaste, buena estabilidad química y conductividad térmica.

El procesamiento de un material cerámico consiste de varias etapas. En general, se parte de una materia prima en polvo, y puede mezclarse con otros constituyentes y aditivos (líquidos, plastificantes, ligantes, etc.) a fin de posteriormente conferirle una determinada forma, mediante el conformado de la pieza utilizando diversas técnicas tales como prensado, extrusión, métodos coloidales a partir de suspensiones, etc. La pieza en verde así obtenida se somete a un tratamiento térmico a temperatura inferior a la de fusión para lograr el sinterizado del material, es decir, la consolidación del material con reducción de la porosidad y contracción (Kingery, 1976). El tratamiento térmico a altas temperaturas no sólo origina la densificación del material (eliminación de la porosidad de la pieza en verde) sino que además puede conducir a la transformación de fases, polimórficas o la aparición de nuevos compuestos, los cuales le confieren las propiedades deseadas al producto final.

Como fuera mencionado en el Capítulo 1, entre los materiales cerámicos de gran importancia industrial se destaca la mullita y se han desarrollado numerosos procesos con el propósito de obtenerla (Gonçalves y col., 2014; Magliano y Pandolfelli, 2010). La buena resistencia mecánica y química (ver Tabla 1.1) favorecen su uso como cerámica estructural de alta temperatura. Un 
método de preparación muy utilizado para obtener cerámicas con mullita es por tratamiento térmico de aluminosilicatos tales como caolinita y otras arcillas, pirofilita, silimanita, andalucita etc. La reacción de mullitización a partir de caolinita generalmente produce $\mathrm{SiO}_{2}$ en fase amorfa que se puede hacer reaccionar con alúmina para formar mullita secundaria o formar cristobalita. La cordierita presenta bajo coeficiente de expansión térmica y consecuentemente buena resistencia al choque térmico y relativamente baja resistencia mecánica que puede ser mejorada por la presencia de mullita.

Otros compuestos de interés tecnológico son los derivados del $\mathrm{Zr}$, entre ellos la zirconia en fase tetragonal $\left(\mathrm{t}-\mathrm{ZrO}_{2}\right)$ que presenta elevada tenacidad y el zircón $\left(\mathrm{ZrSiO}_{4}\right)$, que posee una buena combinación de propiedades tales como bajo coeficiente de dilatación térmica, elevada dureza, buena resistencia a la corrosión por álcalis y baja conductividad térmica. La presencia de zircón en composiciones de mullita y $\mathrm{ZrO}_{2}$ contribuye a mejorar la resistencia mecánica, dureza, resistencia al choque térmico, etc.

\subsection{Compositos cerámicos}

Los cerámicos monofásicos (es decir de un solo componente) no siempre cumplen con todas las propiedades mecánicas $y / u$ otras propiedades funcionales requeridas para el producto final. Por lo mismo, se están desarrollando y utilizando cada vez más materiales cerámicos compuestos, denominados compositos cerámicos. La estructura formada de capas superpuestas con geometría núcleo@cáscara es un sistema compuesto simple que puede proporcionar cerámicos con propiedades mecánicas y funcionales modificadas (Kastyl y col., 2015).

Los compuestos de núcleo@cáscara se pueden preparar en forma de estructuras axialmente simétricas como varillas y tubos o en forma de esferas, donde una capa exterior (capa externa) rodea concéntricamente un núcleo (capa interna). La cáscara y el núcleo se producen ya sea de diferentes compuestos cerámicos o del mismo material pero con una porosidad diferente (Chlup y Salamon, 2010). 
Este tipo de compositos puede ser utilizado en diversas aplicaciones, como membranas de separación de oxígeno (Moon, 2012), celdas de combustible sólidas (Huijsmans, 2001), en sistemas de transporte y liberación de fármacos (Arcos y Vallet-Regí, 2013), y agentes de sostén (Pisklak y col., 2011) entre otros.

Las propiedades mecánicas de un composito tipo núcleo@cáscara pueden ser modificadas ventajosamente para mejorar el desempeño del composito en aplicaciones donde los cerámicos monofásicos fallan. Por ejemplo, donde se requiere una superficie dura y resistente al desgaste, y a la vez un comportamiento de alta tenacidad, como en herramientas de corte (Wang y Zhang, 2014).

Existen muchos métodos para la producción de compositos cerámicos tipo núcleo@cáscara, por ejemplo, deposición electroforética (Kaya, 2003), extrusión o colada seguida de recubrimiento por inmersión (Chlup y Salamon, 2010), coextrusión (Kastyl y col., 2015), entre otros. Cada método tiene sus propias ventajas y limitaciones en la producción de este tipo de compositos.

Como se mencionara en la introducción, el presente trabajo de Tesis se centra en dos técnicas de obtención de compositos cerámicos: recubrimiento por inmersión (dip coating) de sustratos cerámicos y recubrimiento por rodamiento en polvo de sustratos granulares/pellets arcillosos cerámicos en mezcladora de alta intensidad. A continuación se describen dichos métodos y sus características.

\subsubsection{Recubrimiento por inmersión (dip-coating).}

El recubrimiento por inmersión (dip coating) es una técnica sencilla y de bajo costo para la aplicación de recubrimientos, basada en la inmersión del sustrato a recubrir en una suspensión del material que recubre, y la posterior extracción de éste a una velocidad controlada (Scriven, 1988).Este método puede ser utilizado para la formación de compositos cerámicos, y presenta diversas ventajas, entre ellas:

- Es un método que no requiere equipamiento sofisticado, en contraste con técnicas como deposición física (PVD) o química (CVD) en fase vapor (del 
inglés, physical vapor deposition y chemical vapor deposition respectivamente)

- Pueden recubrirse sustratos de formas irregulares.

- Las propiedades de la suspensión, tiempo de inmersión, la velocidad de extracción del sustrato pueden ser modificadas para obtener espesores variables de recubrimiento.

El proceso de recubrimiento por inmersión se puede dividir en cuatro etapas:

1. Inmersión del sustrato en la suspensión

2. Sustrato sumergido durante un tiempo definido

3. Extracción del sustrato a velocidad controlada, con la consiguiente formación de una capa húmeda de sólidos.

4. Formación de la capa de sólido mediante la evaporación del solvente (Fig. 2.1).

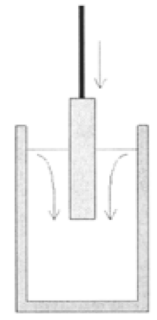

a)

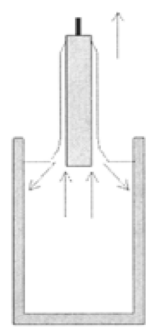

b)

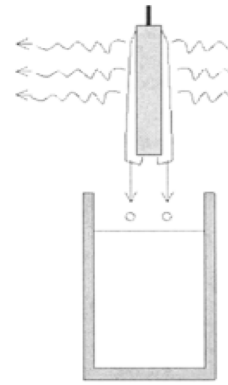

c)

Fig. 3.1 Esquema de las etapas del proceso dip-coating: a) inmersión del sustrato en la suspensión; b) extracción con formación de capa líquida en la superficie y c) evaporación del solvente (modificado de Scriven (1988)

\subsubsection{Mecanismos de formación de recubrimientos por inmersión}

Durante el recubrimiento por inmersión de un sustrato poroso tienen lugar dos posibles mecanismos de formación de la capa de recubrimiento, a saber, filtración capilar y recubrimiento por arrastre de película (Moon, 2012). 
Filtración capilar: cuando el sustrato seco entra en contacto con la suspensión de recubrimiento, la suspensión es absorbida por acción capilar de los poros del sustrato y las partículas se concentran en la superficie del sustrato, formando una capa compacta cuyo espesor aumenta con el tiempo de contacto hasta un valor límite.

Varios autores han postulado que el mecanismo de formación de películas puede describirse como el de colada en moldes de yeso (Moon, 2012). Este mecanismo se caracteriza por un aumento lineal del espesor del recubrimiento, $L$, en función de la raíz cuadrada del tiempo de inmersión, t, de acuerdo con:

$$
L=\frac{2 \gamma \cos \beta}{\eta} C(t)^{1 / 2}+L_{a}
$$

Donde $\gamma$ es la tensión superficial, $\beta$ el ángulo de contacto entre el líquido y la superficie sólida, $\mathrm{C}$ es una constante, $\eta$ es la viscosidad de la suspensión y $L_{a}$ es el espesor de la capa adherente inicial.

Recubrimiento por formación de película: durante la extracción, la capa se puede formar por efecto de arrastre del sustrato y la adhesión de la suspensión de recubrimiento sobre el sustrato. De acuerdo con este mecanismo, el espesor es independiente del tiempo de contacto. El espesor del recubrimiento aumenta al aumentar la velocidad de extracción del sustrato y modificando las propiedades reológicas de la suspensión (i.e con el aumento de la viscosidad de la suspensión de recubrimiento).

Según este mecanismo, el espesor del recubrimiento obtenido para velocidades de extracción no muy elevadas, se puede estimar con la expresión que fue establecida por Landau-Levich (1942) y es la siguiente:

$$
L=0,94 \frac{(\eta v)^{2 / 3}}{\sigma_{l v}^{1 / 6}(\rho g)^{1 / 2}}
$$

Donde $v$ es la velocidad de extracción del sustrato de la suspensión, $\sigma_{\mathrm{lv}}$ es la tensión superficial y $\rho$ la densidad de la suspensión.

Es importante remarcar que, cuanto mayor sea el espesor del recubrimiento, más influencia tendrán las propiedades del mismo y más efectivo será su 
efecto. Sin embargo, un espesor alto puede aumentar la probabilidad de que suceda un agrietamiento superficial (Murray, 2009) así como el aumento de tamaño de las grietas originadas. Esto se debe principalmente al aumento de las tensiones residuales en el seno del recubrimiento, generadas en las etapas de tratamiento térmico (secado y sinterizado). Los principales factores que pueden influir en la aparición del agrietamiento son: altos valores de espesor de recubrimiento, baja tenacidad de fractura del recubrimiento, alto módulo de elasticidad, fracción volumétrica elevada del disolvente y el desajuste de los coeficientes de dilatación térmica entre sustrato y recubrimiento (Galisteo, 2007).

El proceso de deposición conduce a la aparición de un mayor espesor de recubrimiento en los bordes inferiores del sustrato, debido al escurrimiento por gravedad del líquido al ser retirado de la suspensión. Si bien dicho efecto no puede ser evitado, al ser inherente a la técnica de recubrimiento por inmersión en batch, el mismo no sucede en el caso continuo (tiras sumergidas). En el caso del uso de la técnica en batch, como en este estudio, es importante observar que dicho aumento de espesor no resulte en el agrietamiento del recubrimiento en los bordes.

De los mecanismos mencionados se puede deducir la importancia de los parámetros de la suspensión en el espesor, integridad y microestructura de la capa consolidada sobre el sustrato. Así, el proceso requiere la preparación de suspensiones estables con un suficiente contenido de sólidos y adecuada viscosidad por lo que es necesario evaluar y controlar las propiedades electroforéticas y reológicas de la suspensión hasta alcanzar un alto grado de dispersión de las partículas suspendidas.

\subsubsection{Propiedades de suspensiones}

Las propiedades de las suspensiones resultan principalmente afectadas por factores tales como el tamaño y forma de partículas suspendidas, concentración de sólidos, grado de agregación de las partículas, $\mathrm{pH}$ y contenido de electrolitos de la solución incluyendo aditivos requeridos para el procesamiento. Los dispersantes se utilizan para ajustar el comportamiento al 
flujo de la suspensión, siendo su función alcanzar un alto grado de dispersión de las partículas, es decir, estabilizar la suspensión.

\subsection{Teoría coloidal}

Se conoce bien que las partículas suspendidas en un líquido polar se cargan superficialmente. Las reacciones superficiales, en particular la carga (signo y magnitud) del borde de la partícula arcillosa en suspensión acuosa depende del pH de la solución (Van Olphen, 1977). Las superficies cargadas generan un potencial eléctrico superficial, debido al cual atraen iones de signo contrario o contraiones. Según establece la teoría de Stern, alrededor de la partícula cargada se crea una doble capa eléctrica (DCE) constituida por una capa de contraiones fuertemente atraída y, otra capa difusa en donde se encuentran iones de ambos signos (Lagaly y Dékány, 2013; Van Olphen, 1977). En esta última, la concentración de contraiones es mayor cerca de la superficie de la partícula. De este modo se mantiene la neutralidad electroquímica del sistema, ya que el potencial desarrollado por la superficie arcillosa se compensa por el efecto de la DCE.

En general, la teoría coloidal de repulsión DLVO (Derjaguin, Landau, Verwey y Overbeek) considera que la estabilidad electroquímica de las partículas en medio acuoso está determinada por las interacciones entre partícula-líquido (DCE) y entre partícula-partícula (es decir, las interacciones o interferencias entre las DCE desarrolladas por las partículas). La estabilidad (partículas bien dispersas) se consigue si las fuerzas de repulsión entre partículas superan a las de atracción (London-Van de Waals, electrostáticas, etc.). En este caso, el solapamiento y repulsión entre DCE impide que las partículas se aglomeren y se mantienen separadas. Si las fuerzas de atracción predominan, se originan aglomerados de partículas (flóculos) cuyo tamaño es mayor que el de las partículas individuales (coagulación o floculación). Estos flóculos inmovilizan una gran proporción del volumen de líquido, que debido a ello no está disponible para el flujo. De modo que la concentración de sólidos efectiva será mayor que la nominal y, entonces, la fluidez de la suspensión se reduce. Cuando se trata de suspensiones concentradas, los flóculos pueden formar a 
su vez contactos entre si y dan lugar a la formación de una estructura continua tipo gel.

\subsection{Propiedades de suspensiones de arcillas}

En particular, para el caso de las arcillas en suspensión, las interacciones son más complejas debido a la forma de las partículas (Fig. 2.2), el origen distinto de las cargas de cara y borde de la partícula y la dependencia de la carga del borde con el pH. Para las mismas, existe la posibilidad de tres tipos de asociaciones entre partículas: por contactos cara-borde, cara-cara y bordeborde. El primer modelo de asociación representa la floculación en medio ácido entre dos superficies con cargas opuestas: la basal negativamente cargada y la superficie lateral que desarrolla carga positiva (aumento relativo de grupos $\mathrm{AlOH}_{2}{ }^{+}$). El modelo de asociación cara-cara se relaciona con el aumento de la fuerza iónica que da lugar a la compresión de la capa difusa de la DCE, reduciéndose la distancia de separación entre partículas. La atracción predomina entre ambas superficies cargadas negativamente resultando asociaciones borde-borde y cara-cara para baja y alta concentración de electrolitos, respectivamente (Lagaly y Dékány, 2013). La presencia de iones $\mathrm{Ca}^{2+}$ también promueve la formación de contactos por atracción electrostática entre superficies adyacentes con carga negativa. Resultados experimentales demostraron que altas concentraciones de ion $\mathrm{Ca}^{2+}$ promueven la transición entre estructura cara - borde a contactos cara- cara o borde-borde. Este resultado se manifiesta como un cambio importante del comportamiento al flujo (Lagaly, 1989).

Con respecto a las bentonitas sódicas, que poseen muy buena capacidad de formación de gel, es sabido que este proceso se relaciona con la hidratación de cationes intercambiables. $\mathrm{El}$ ion $\mathrm{Na}^{+}$promueve el fenómeno de hinchamiento, separación de las láminas, que da lugar a la delaminación de las partículas en medio alcalino.

\subsection{Efecto de agregado de poliacrilato de sodio en suspensión}

El mecanismo de adsorción del dispersante en la superficie arcillosa involucra interacciones electrostáticas y específicas. La adsorción del dispersante 
depende tanto de la carga superficial del sólido así como del grado de disociación y carga de la molécula del polielectrolito. Un dispersante que puede ser utilizado es el poliacrilato de sodio (NaPA), el cual logra un buen grado de dispersión para suspensiones de distintas arcillas, como caolines (Sjöberg y col., 1999) y esmectitas (Labanda y Llorens, 2005), mediante la disociación de los grupos COO-Na constituyentes de la molécula del dispersante y adsorción del anión poliacrilato en la superficie de la arcilla. Así, la viscosidad de las suspensiones conteniendo NaPA resulta menor que la correspondiente suspensión sin adición de dispersante (Labanda y Llorens, 2005; Sjöberg y col., 1999).

A su vez, la carga superficial del sólido y la de los grupos aniónicos $\mathrm{COO}^{-}$del dispersante dependen de las condiciones de $\mathrm{pH}$ y fuerza iónica del medio líquido. En soluciones alcalinas y con el aumento del $\mathrm{pH}$, el grado de disociación de la molécula del dispersante aumenta y el polielectrolito está negativamente cargado. A pH menores que 3-4, no ocurre disociación de los grupos COO-Na y la carga de la molécula es neutra. La conformación de las moléculas en solución también cambia con la fuerza iónica (presencia de electrolitos). Cuando el polielectrolito está completamente disociado, los grupos COO- negativos se repelen y la cadena polimérica adquiere una conformación extendida. Por otro lado, con un bajo grado de disociación, la molécula es neutra y resulta una cadena polimérica entrelazada (de menor área) por lo que será necesaria una mayor cantidad de moléculas para cubrir completamente una superficie.

\subsubsection{Granulación y recubrimiento en mezcladora de alta intensidad}

La granulación es el proceso en el cual las partículas pequeñas de un material en polvo forman un agregado multipartícula de tamaño mayor, de manera relativamente permanente, pero de forma que aún puedan distinguirse las partículas individuales (Perry y col., 1999). En la granulación en húmedo, esto se consigue incorporando un líquido como ligante a las partículas mientras éstas se agitan en el equipo. El líquido une las partículas por una combinación de fuerzas hasta que luego se desarrollen ligas permanentes por posterior secado y/o sinterizado (Iveson y col., 2001). 
El material así obtenido es denominado gránulo o pellet. El proceso de agregación, es decir, del aumento de tamaño de partícula puede resultar beneficioso para diversas aplicaciones en la industria cerámica, entre ellas:

- Mejora de las propiedades de flujo de polvos para prensado

- Eliminación de pérdida o riesgos en la operación con polvo, principalmente con arcillas

- Control de la porosidad y la relación superficie/volumen en soportes de catalizadores

- Mejoras de las características de intercambio de calor en minerales o vidrio para alimentación de hornos

Asimismo, el proceso de granulado puede ser utilizado para la conformación de productos, desde soportes para catalizadores, fertilizantes granulados, agentes de molienda (esferas de alúmina) productos químicos, solo para mencionar algunos. Una aplicación de interés en el proceso de granulado en la industria petrolera es el desarrollo de pellets de precursores cerámicos que, posterior a un tratamiento térmico a elevadas temperaturas, desarrollan una elevada densidad y resistencia mecánica a la compresión. Esto posibilita su uso como agentes de sostén en la industria petrolera

\subsubsection{Métodos de granulación}

Hay un gran número de equipos granuladores que pueden ser usados para este proceso. Las granuladoras de baja cizalla consiste en un lecho fluidizado o expandido, en el cual el movimiento de las partículas es inducido por una corriente de aire. Los granuladores de esfuerzo de corte medio y alto es donde el movimiento de las partículas se induce por movimiento mecánico de las piezas. Las granuladoras de cizalladura media son principalmente los tambores y discos rotativos. La granulación de alta cizalladura sucede en granuladores centrífugos (tipo Marumerizer ${ }^{\circledR}$ ) y en granuladores de alto esfuerzo de corte, también denominadas granuladoras o mezcladoras de alta intensidad. Las mismas poseen una cuba, generalmente de acero, en donde es cargado el polvo del material a granular, equipado con una boquilla para el ingreso del ligante. La rotación de las paletas, así como la rotación de la cuba, generalmente a contracorriente, favorece la colisión de las partículas, 
derivando en la formación de pellets. Se muestra un esquema general de este tipo de equipos en la Fig. 3.2.

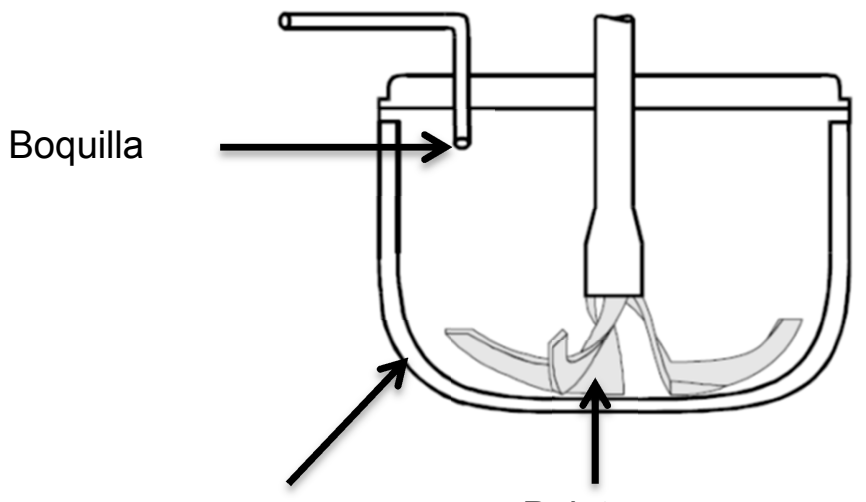

Cuba

Paletas

Fig. 3.2. Esquema de Mezcladora de alta intensidad

Si bien la granulación de pellets cerámicos puede lograrse en diversos tipos de granuladores (Tabla 3.1.), la densidad de los gránulos obtenidos es relativamente mayor en los granuladores de alto esfuerzo de corte. Esta mayor densidad deriva de la baja porosidad de los gránulos obtenidos, debido a la compactación de los gránulos por el alto esfuerzo ejercido. En general, una menor porosidad interna es conseguida por operaciones a mayor velocidad de rotación de tambor.

Tabla 3.1. Equipos de granulación batch y características, modificado de (Perry

$$
\text { y col., 1999) }
$$

\begin{tabular}{|c|c|c|c|c|}
\hline Método & $\begin{array}{c}\text { Tamaño del } \\
\text { producto }\end{array}$ & $\begin{array}{c}\text { Densidad del } \\
\text { granulo }\end{array}$ & $\begin{array}{c}\text { Escala de la } \\
\text { operación }\end{array}$ & $\begin{array}{c}\text { Aplicaciones } \\
\text { típicas }\end{array}$ \\
\hline \multicolumn{5}{|c|}{ Granuladores de volteo } \\
\hline $\begin{array}{l}\text { Tambores } \\
\text { Discos }\end{array}$ & 0,5 a $20 \mathrm{~mm}$ & Moderada & $0,5-800$ ton $/ \mathrm{h}$ & $\begin{array}{c}\text { Fertilizantes, } \\
\text { mineral de hierro, } \\
\text { agroquímicos }\end{array}$ \\
\hline \multicolumn{5}{|c|}{ Granuladores centrífugos } \\
\hline Marumerizer ${ }^{\circledR}$ & 0,3 a $3 \mathrm{~mm}$ & Moderada a alta & Hasta 200 kg/lote & $\begin{array}{c}\text { Productos } \\
\text { farmacéuticos y } \\
\text { agrícolas }\end{array}$ \\
\hline \multicolumn{5}{|c|}{ Granuladores mezcladores } \\
\hline $\begin{array}{l}\text { Mezclador de alto } \\
\text { esfuerzo de corte } \\
\text { por lotes }\end{array}$ & 0,1 a $2 \mathrm{~mm}$ & Alta & Hasta 500 kg/lote & $\begin{array}{c}\text { Productos } \\
\text { farmacéuticos, } \\
\text { agentes de } \\
\text { sostén cerámicos }\end{array}$ \\
\hline
\end{tabular}


Las granuladoras tipo Marumerizer pueden producir gránulos de alta densidad, aunque es un equipo diseñado para escala de laboratorio, con una capacidad máxima de producción de $200 \mathrm{~kg} / \mathrm{lote}$, principalmente utilizada para el desarrollo de productos en la industria farmacéutica (Tabla 3.1).

Las granuladoras de alto esfuerzo de corte presentan la posibilidad de producir gránulos de baja porosidad interna y alta densidad. Los mismos pueden escalarse a niveles de operación de hasta 500 kg/lote (Perry y col., 1999).

\subsubsection{Mecanismos de formación de gránulos}

Varios autores has estudiado el proceso de granulación, indicando que la misma se divide principalmente 3 etapas, como se muestra en la Figura 3.3

a)

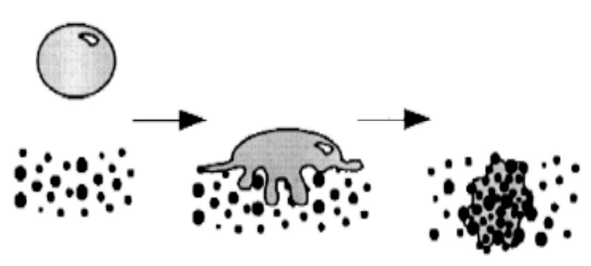

b)

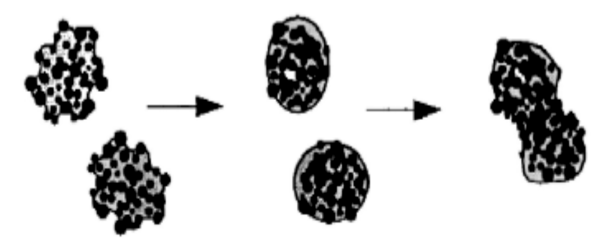

c)

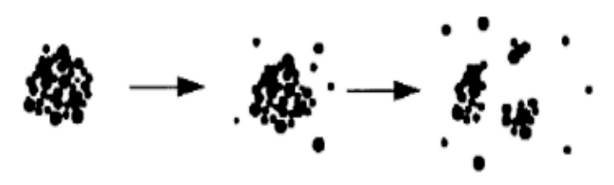

Fig. 3.3. Etapas de granulación: a) Humectación y nucleación b) Consolidación y coalescencia y c) Desgaste y rotura. Extraído de (Iveson y col., 2001)

a) Humectación y nucleación el líquido aglutinante entra en contacto con un "lecho" de polvo seco, y es distribuido a través del mismo, para dar una distribución de gránulos de núcleos;

b) Consolidación y coalescencia, donde las colisiones entre dos gránulos, gránulos con polvo primario, o gránulo y el equipo conducen a la compactación de los gránulos (densificación y disminución de la porosidad) y crecimiento;

c) Desgaste y rotura, donde los gránulos húmedos se rompen debido al impacto, el desgaste o la compactación en el granulador (o durante el manejo posterior del producto). 
Dentro de los mecanismos de consolidación y crecimiento, se han reportado tres tipos de mecanismos simultáneos; cuya influencia depende de las propiedades del polvo y aglutinante así como las variables del proceso. Los mismos se muestran en la Fig. 3.4.

a)

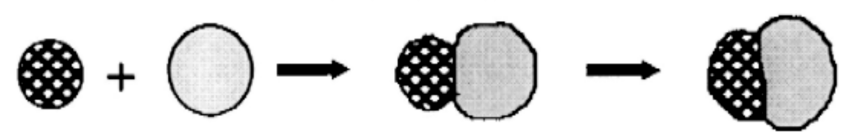

b)

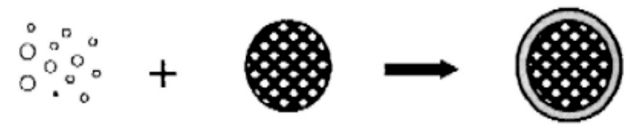

c)

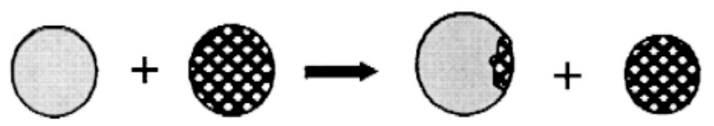

Fig. 3.4. Mecanismos de consolidación y crecimiento de pellets: a) Coalescencia, b) Recubrimiento y c) Transferencia por abrasión (Sastry y Fuerstenau, 1973)

a) Coalescencia: Se refiere a la producción de pellets de mayor tamaño mediante la aglutinación de dos o más gránulos colisionantes

b) Recubrimiento: material más fino es adherido a la superficie de un pellet de mayor tamaño

c) Transferencia por abrasión: Debido a la interacción y abrasión de los pellets en la granuladora, se transfiere una cierta masa de material de un pellet a otro

Las propiedades del material granular final, dependen del tamaño y la porosidad, así como de la microestructura del mismo. Estas dependen de dos tipos de factores: los propios al proceso de granulación, es decir, las variables operativas (velocidad de rotación de tambor, de las paletas, etc.) y las propias del material a alimentar, es decir, tamaño de partícula, medio aglutinante, etc.

\subsubsection{Recubrimiento en materiales granulares}

Es importante mencionar que el proceso de granulación posibilita la formación de compositos esféricos nucleo@cáscara: una vez formado el pellet crudo, en 
el mismo tambor se puede realizar el agregado de un material en polvo, por rodamiento dentro del mismo, recubrir dichos pellets. El tratamiento térmico (sinterizado) termina de adherir el recubrimiento al sustrato (pellet), formando de esta manera un nuevo composito con distintas propiedades al sustrato original.

Así como gránulos compuestos por un único polvo de partida, el procedimiento de granulación puede conllevar una etapa adicional de formación de recubrimiento con otro material sobre el mismo. Como fuera explicado en el inciso anterior, el mecanismo de formación de recubrimiento es la adhesión de partículas más pequeñas sobre núcleos (gránulos) de mayor tamaño, formando una capa sobre el mismo. Por un tratamiento térmico posterior, estos materiales pueden formar compositos cerámicos del tipo núcleo@cáscara.

En el caso de recubrimientos sobre agentes de sostén, la aplicación de un recubrimiento sobre los mismos puede tener diversas finalidades, entre ellas el mejoramiento de propiedades del mismo, como la flotabilidad para el transporte en fractura (Kincaid y col., 2013), disminución de la mojabilidad de la superficie para mejor conductividad (Palisch y col., 2015) o adquisición de nuevas propiedades, como el agregado de material radioactivo en resina para su trazabilidad (McDaniel y col, 2012).

Recientemente (Koep y col., 2017), se realizaron recubrimientos de $\mathrm{y}$-alúmina y zirconia sobre agentes de sostén en verde, logrando de esta manera evitar la aglomeración durante el sinterizado (formación de clústers de pellets adheridos) y previniendo la diagénesis de los mismos en su aplicación en la fracturación.

Otros autores (Pisklak y col., 2011) utilizaron un procedimiento similar, en el cual un material particulado de piedra pómez fue recubierto con una AN natural (bentonita) en una granuladora de alta intensidad, el cual, después del tratamiento térmico, desarrolló propiedades mecánicas superiores a los pellets de piedra pómez sin recubrimiento.

Tal como se mencionó, los compositos cerámicos requieren una etapa posterior a su conformado por granulación para conseguir la densificación de la 
pieza, así se consigue la consolidación final de partículas constitutivas para formar los compositos estables. Esto se logra mediante la sinterización a elevada temperatura. Por ello en el Capítulo 6.2 de la presente tesis se examina el efecto de las variables de sinterización en las propiedades de los compositos cerámicos puesto que la sinterización no sólo causa la densificación de la pieza, sino que también influye en el desarrollo de nuevas fases cristalinas y propiedades del composito final.

Por lo tanto, en la presente tesis se analizaron las propiedades de cerámicos obtenidos a partir de ANs naturales y modificadas. Asimismo, se estudió el uso de dichas ANs en el conformado de dos tipos de compositos cerámicos: materiales sustrato-recubrimiento de AN por inmersión en suspensión y material granular núcleo@cáscara, siendo la cáscara conformada por alguna de las ANs estudiadas. 


\section{MÉTODOS Y TÉCNICAS DE CARACTERIZACIÓN DE MATERIAS PRIMAS Y MATERIALES}

\subsection{Difracción de rayos $X$ (DRX)}

La difracción de rayos $\mathrm{X}$ es una de las técnicas más ampliamente difundidas y utilizadas en la identificación de fases en sólidos cristalinos. La difracción puede revelar indirectamente los detalles de la estructura interna de un material en el orden de los nanómetros y es posible la identificación de las fases cristalinas en todo tipo de materiales (Cullity y Stock, 2001).

Los rayos $\mathrm{X}$ se obtienen al irradiar un haz de electrones generado por un filamento contra un ánodo de un metal puro, logrando esto mediante la aplicación de una diferencia de potencial. Un filamento de $\mathrm{W}$ incandescente actúa de cátodo y provee los electrones, mientras que el ánodo es de $\mathrm{Cu}$. Se aceleran los electrones bajo vacío por una diferencia de potencial del orden de 30-100 kV entre cátodo y ánodo. La radiación generada está constituida por dos componentes:

- Radiación característica: es un conjunto de líneas de intensidad variable que proviene del reordenamiento de los electrones orbitales de los átomos del metal blanco (anticátodo) después de la expulsión de uno o más electrones durante la excitación

- Banda continua: es generada por los electrones del filamento al convertir su energía cinética en rayos $\mathrm{X}$ al colisionar con los átomos del anticátodo.

Para analizar sólidos policristalinos, uno de los dispositivos más utilizados es el difractómetro de polvos. En el mismo, se coloca la muestra policristalina pulverizada en un portamuestra, cuidando que la misma quede normalmente plana y pareja. El haz de rayos $X$ pasa a través de una ventana, usualmente de berilio $y$, a fin de obtener una radiación más monocromada, la misma atraviesa un filtro o cristal monocromador, a fin de reducir las líneas espectrales innecesarias. 


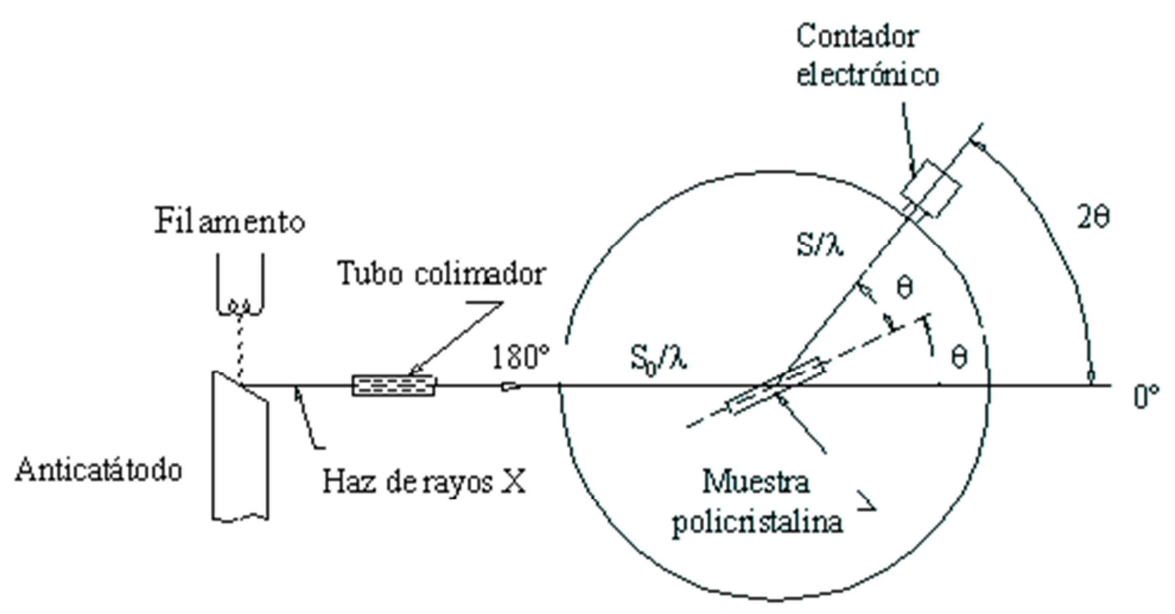

Fig. 4.1 Geometría de un difractómetro de polvo Extraído de (Busquets, 2009)

El haz incide sobre la muestra, y un contador electrónico recolecta la señal del haz difractado. Al estar equipado con un goniómetro, este detector puede formar un ángulo variable $(2 \Theta)$ con el haz incidente. En la práctica, para que el haz difractado focalice en la ventana del contador, el portamuestra gira un ángulo $\Theta$, mientras que el detector gira un ángulo $2 \Theta$ (Fig. 4.1).

Los rayos difractados por los cristales pueden ser tratados como reflexiones de planos atómicos en la estructura cristalina, la cual depende de la distancia interplanar y del ángulo de difracción para una longitud de onda dada. Para que una familia de planos paralelos separados regularmente en un cristal difracte un haz de rayos $X$ incidentes, se debe dar una condición de interferencia constructiva entre los haces difractados por los planos. La interferencia es constructiva cuando la diferencia de fase entre la radiación emitida es proporcional a $2 \pi$ (Fig. 4.2), y la ecuación que define estas condiciones fue expuesta por el físico británico William Henry Bragg (Bragg, 1913), y su forma es la siguiente:

$$
n \lambda=2 \mathrm{~d} \operatorname{sen} \theta
$$

Donde

$\mathrm{n}$ : número entero

$\lambda$ : longitud de onda de la radiación utilizada

$\mathrm{d}$ : distancia de separación entre planos paralelos de la red cristalina

$\theta$ : ángulo de incidencia del haz de rayos $X$ de la radiación utilizada 


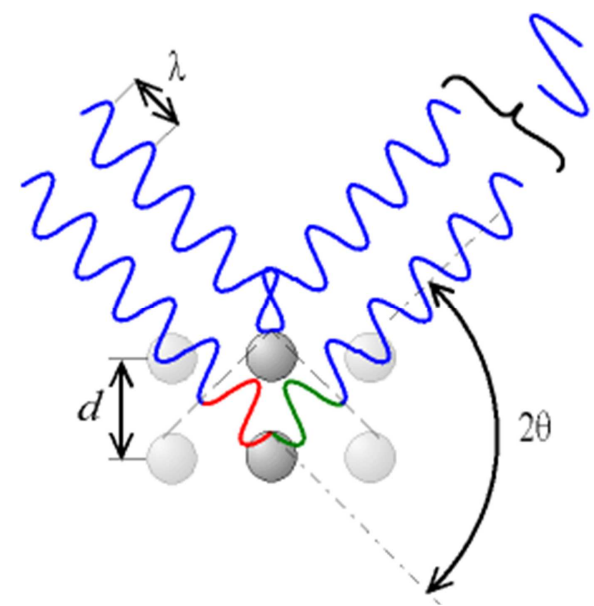

Fig. 4.2 Representación esquemática de la Ley de Bragg (Escarria y col, 2012)

Los resultados obtenidos por difracción de rayos $X$ de polvos se registran en gráficos en donde el eje de abscisas corresponde al ángulo $2 \Theta$ y el eje de ordenadas muestra la intensidad del haz difractado. Estos gráficos, denominados difractogramas, revelan una serie de picos correspondientes a las fases cristalinas presentes, los cuales sirven para determinar su presencia y, mediante diversas metodologías, su proporción.

Los difractogramas de las muestras en polvo (M: 100) se obtuvieron con un difractómetro (Philips 3020 modelo PW 3710) con radiación Ka-Cu $(\lambda=1.54 \AA)$ y filtro de Ni a $35 \mathrm{kV}$ y $40 \mathrm{~mA}$. El barrido se realizó entre $3^{\circ}$ y $70^{\circ} 2 \theta$ en pasos de $0.02^{\circ}(2 \theta)$ y $2 \mathrm{~s} /$ paso.

Cuando el material presenta algún grado de amorfización, i.e: presenta un ordenamiento interno de corto alcance y no periódico en su estructura, se genera una "banda" de difracción. En particular, en los sistemas derivados de la sílice, es común encontrar dicha banda centrada en los $26^{\circ} 2 \Theta$ (Gavin y col., 2013).

\subsubsection{Cuantificación de fases cristalinas. Método de Rietveld}

Desde la instauración de la cristalografía como una ciencia básica para el estudio de los materiales, se han desarrollado y utilizado técnicas para estudiar la estructura de los cristales que forman parte de los materiales. En lo que respecta a la cuantificación de fases cristalinas, los métodos más conocidos son el de RIR (del Inglés "Reference Intensity Ratio") y el de Rietveld. El 
primero se basa en la medida relativa de la intensidad del pico de difracción más intenso de la fase que se quiere cuantificar, con respecto una fase cristalina de referencia $\left(\mathrm{Ej} . \mathrm{Al}_{2} \mathrm{O}_{3}\right)$ en una proporción conocida, con respecto a la intensidad de esta misma fase en la muestra problema. Es una metodología muy simple para la cuantificación, aunque es poco precisa, teniendo en cuenta que los cálculos se llevan a cabo suponiendo mezclas binarias, además de no considerar la intensidad integrada (Área) del pico más intenso, lo cual acarrea un gran error en muestras donde existe ensanchamiento en las líneas de difracción por defectos cristalinos (tamaños de cristal y micro-deformaciones).

A fines de los años 60, H. Rietveld desarrolló un método (Rietveld, 1969) muy utilizado en la actualidad para cuantificar fases cristalinas que, a diferencia del anterior, utiliza todo el difractograma para la cuantificación, lo que lo hace muy robusto. Se basa en la obtención de un difractograma teórico, que modela los picos de difracción con respecto al difractograma experimental, generado por la siguiente ecuación:

Este difractograma teórico es generado por la siguiente ecuación, que modela los picos de difracción con respecto al difractograma experimental

$$
y_{i}^{c a l}=\mathrm{y}_{\mathrm{b}}\left(2 \theta_{i}\right)+\sum_{i} S_{i} \sum_{K} m_{k}\left|F_{k}\right|^{2} h\left(2 \theta_{i}-2 \theta_{k}\right) L_{p}\left(2 \theta_{i}\right) P_{k}
$$

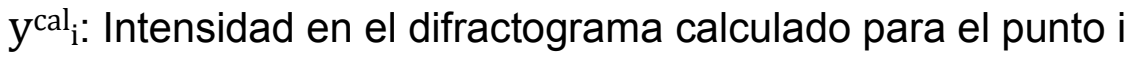

$\mathrm{y}_{\mathrm{b}}$ : Valor en $2 \theta$ de la línea de base.

$\mathrm{S}_{\mathrm{i}}$ : Factor de escala de la fase i.

$\mathrm{m}_{\mathrm{k}}$ : Multiplicidad de la reflexión $\mathrm{k}$.

$\mathrm{F}_{\mathrm{k}}$ : Factor de estructura.

$\mathrm{h}\left(2 \theta_{\mathrm{i}}-2 \theta_{\mathrm{k}}\right)$ : Función de distribución de intensidad alrededor de la reflexión i de Bragg.

Lp: Factor de polarización de Lorentz.

Pk: Factores de corrección adicionales (orientación preferencial, absorción, etc.)

El ajuste del difractograma calculado respecto al difractograma real se realiza por diferencia de cuadrados mínimos: 


$$
S y=\sum_{i} w_{i}\left(y_{i}^{o b s}-y_{i}^{c a l}\right)^{2}
$$

Donde:

$\mathrm{S}_{\mathrm{y}}$ : Función a minimizar

$\mathrm{y}_{\mathrm{i}}{ }^{\text {obs: }}$ Intensidad observada en el difractograma real para el punto $\mathrm{i}$

$\mathrm{w}_{\mathrm{i}}: 1 / \mathrm{y}$ obs: Peso estadístico.

Para la cuantificación de fases cristalinas, el enfoque más sencillo es la aproximación de que la muestra solo está compuesta por fases cristalinas de estructura conocida. Estas estructuras cristalinas obtenidas son incorporadas, y la relación entre el contenido en peso de una fase cristalina a para una muestra policristalina de $\mathrm{m}$ fases cristalinas estará dado por la siguiente ecuación:

$$
W_{\alpha}=\frac{s_{\alpha} \rho_{\alpha} V_{\alpha}^{2}}{\sum_{i=1}^{m} S_{i} \rho_{i} V_{i}^{2}}
$$

$\mathrm{W}_{\alpha}$ : contenido en peso de la fase $\mathrm{i}$

$\rho_{\alpha}$ : Densidad cristalográfica de la fase i.

$\mathrm{V}_{\alpha}$ : Volumen de la celda unidad.

Debido a que este método normaliza las fracciones másicas analizadas a uno, si la muestra posee fases amorfas o fases cristalinas no identificadas, el contenido en peso calculado para las fases cristalinas estará sobreestimado.

\subsubsection{Semicuantificación de fase amorfa. Método de Ohlberg}

El análisis de los difractogramas, además de la información de las fases cristalinas, puede ser útil para el análisis de contenido de fase amorfa de la muestra. Uno de los métodos empleados para el análisis semicuantitativo de dicha fase es el método de Ohlberg modificado (Conconi y col., 2011), el cual determina el porcentaje de fase amorfa en la muestra por interpolación de la línea de base del difractograma entre las correspondientes a muestras patrones $100 \%$ amorfa y $100 \%$ cristalina:

$$
A \%=\frac{\mathrm{I}_{m}-\mathrm{I}_{c}}{\mathrm{I}_{v}-I_{c}} * 100
$$


Donde $I_{v}, I_{m}$ e $I_{c}$ son las intensidades del fondo a $22,5^{\circ}$ correspondientes a una muestra $100 \%$ vítrea, la muestra de interés y una muestra patrón $100 \%$ cristalina, respectivamente. Se utilizaron como patrones cristalinos y amorfos cuarzo cristalino y vidrio de sílice, respectivamente.

\subsubsection{Cuantificación de fase amorfa. Método del patrón externo.}

Respecto a la cuantificación absoluta de fases cristalinas, el factor de escala de una determinada fase en una muestra está directamente relacionado con su contenido en masa (Aranda y col., 2012):

$$
W_{i}=S_{i} \frac{\rho_{i} V_{i}^{2} \mu_{i}}{G}
$$

Donde:

$\mathrm{W}_{\mathrm{i}}$ : contenido en peso de la fase $\mathrm{i}$

$\rho_{\mathrm{i}}$ : Densidad cristalográfica de la fase i.

$\mathrm{V}_{\mathrm{i}}$ : Volumen de la celda unidad.

$\mu_{\mathrm{i}}$ : Coeficiente de absorción másica.

G: Constante característica del difractómetro

Para poder utilizar esta ecuación y cuantificar en forma absoluta los contenidos en peso de cada fase cristalina presente, es necesario caracterizar el difractómetro y determinar su constante característica $(G)$. El valor de $G$ se calcula utilizando las mismas condiciones de difracción (potencia, tiempo de integración, slits, paso) que en las muestras problema, analizando una sustancia de referencia de composición conocida.

$$
G=S_{r} \frac{\rho_{r} V_{r}^{2} \mu_{r}}{W_{r}}
$$

Donde:

G: Constante característica del difractómetro

$\mathrm{W}_{\mathrm{i}}$ : contenido en peso de la fase $\mathrm{i}$

$\rho_{\mathrm{i}}$ : Densidad cristalográfica de la fase i.

$\mathrm{V}_{\mathrm{i}}$ : Volumen de la celda unidad.

$\mu_{\mathrm{i}}$ : Coeficiente de absorción másica. 
En esta tesis se utilizó $\mathrm{Al}_{2} \mathrm{O}_{3}$ como referencia. Los coeficientes de absorción másica de cada fase involucrada fueron calculados por una suma pasada de los coeficientes de los respectivos óxidos que la conforman, los cuales fueron extraídos como dato del trabajo llevado a cabo por Alvarez Pinazo y col ( 2012). El software utilizado para el ajuste por el método de Rietveld fue Fullprof ${ }^{\circledR}$. Los datos cristalográficos necesarios para obtener los patrones de difracción teóricos fueron extraídos de la página web de acceso libre http://crystallography.net.

\subsection{Fluorescencia de rayos $X$}

Cuando se hacen incidir rayos $X$ sobre una muestra suceden varios fenómenos. El haz de rayos $X$ chocará con un electrón de las capas internas del átomo, el cual absorbe energía y será expulsado a niveles superiores (de mayor energía). El espacio vacante generado hará que uno de los electrones de un orbital más externo ocupe el hueco generado por el electrón expulsado. Este salto producirá una liberación de energía en forma de radiación electromagnética característica (Fig. 4.3).

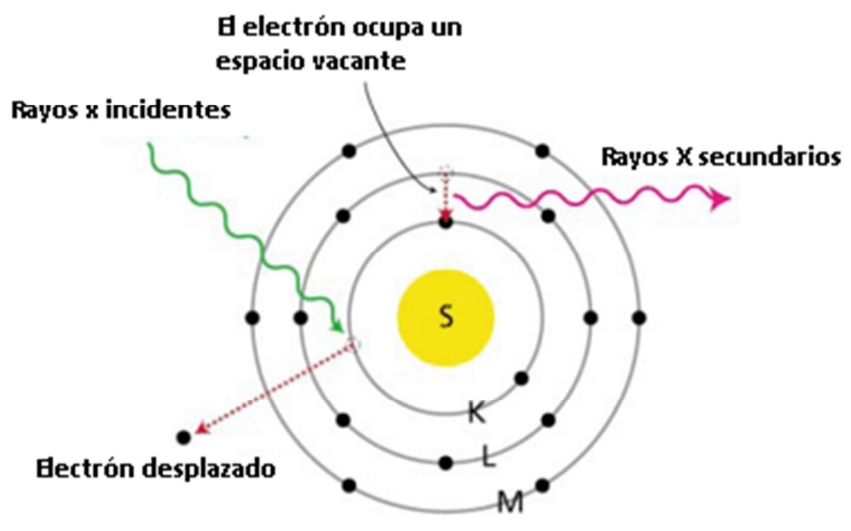

Fig. 4.3 Fenómeno de fluorescencia producido por bombardeo de rayos $\mathrm{X}$.

La técnica de fluorescencia de rayos $X$ posibilita la identificación y cuantificación de los elementos presentes en las muestras mediante la medición de las emisiones de fluorescencia de estos electrones excitados, ya que estás poseen una determinada longitud de onda característica asociada al elemento, realizando la cuantificación a partir de la intensidad de la emisión de dicho emisión (Beckhoff y col., 2007). 
Muestras en polvo de bentonita intercalada con policationes de zirconio (BOHZr, como precursora de recubrimiento) y de la bentonita original $\mathrm{B}$ (M: 100) fueron analizadas por fluorescencia de rayos $X(X R F)$ utilizando un espectrómetro dispersivo en energía marca Shimadzu (modelo EDX800-HD)

\subsection{Espectroscopia Infrarroja}

La espectrometría en el infrarrojo (IR) trabaja en el rango infrarrojo del espectro electromagnético. Esta técnica, se basa en la espectroscopia de absorción. Puede utilizarse para identificar un compuesto e investigar la composición de la muestra ya que cada molécula presenta un IR característico.

Aunque el espectro infrarrojo se extiende de 10 a $14300 \mathrm{~cm}^{-1}$, desde un punto de vista funcional se divide en tres zonas: IR lejano e IR medio (MIR o IR) con bandas que corresponden a vibraciones fundamentales (stretching o bending), sobretonos y combinaciones.

La absorción de radiación en la región infrarroja es consecuencia de la excitación por deformaciones de enlaces, ya sean de estiramiento (stretching) o de flexión o deformación (bending) (Fig. 4.4).

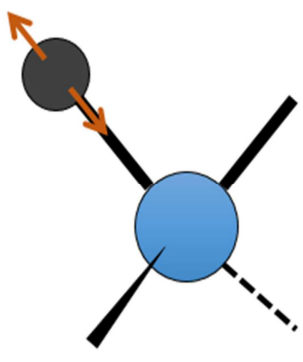

a)

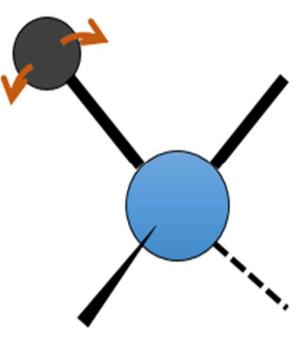

b)

Fig. 4.4. a) Modo de vibración de estiramiento o stretching; b) modo de vibración de flexión o deformación, bending o cambio de ángulo.

La cantidad de energía requerida para excitar los modos stretching y bending depende de las masas de los átomos, por lo tanto de qué tipo de enlace se esté excitando dependerá de la longitud de onda del infrarrojo que será absorbida por la sustancia a analizar, que dependerá de sus constituyentes. 
En este trabajo los espectros por infrarrojo fueron obtenidos utilizando un equipo Spectrum One Perkin Elmer en el rango de $4000-380 \mathrm{~cm}^{-1}$. La muestras fueron dispersadas en $\mathrm{KBr}$ al $1 \% \mathrm{~m} / \mathrm{m}$ y compactadas en finas pastillas para su análisis. Se realizó la caracterización de las muestras $\mathrm{B}, \mathrm{BOHAl}, \mathrm{BOHZr}$ antes y después de la calcinación entre 1000 y $1300{ }^{\circ} \mathrm{C}$

\subsection{Métodos de Análisis Térmicos}

El análisis térmico se refiere a las técnicas en las cuales se realiza la medida de la propiedad de un material y sus productos de reacción como una función de la temperatura, mientras este se somete a un programa de calentamiento definido (Gallagher y col., 1998).

\subsubsection{Análisis Termogravimétrico (TG)}

El análisis termogravimétrico, comúnmente denominado TGA (del inglés, thermogravimetric analysis) es una técnica que permite estudiar la evolución de la muestra a analizar con la temperatura. Se observan los cambios de masa de la muestra frente a la temperatura, midiendo las ganancias y/o pérdidas de masa causadas por diferentes fenómenos.

El equipo utilizado para este tipo de análisis es una termobalanza, compuesta básicamente por una balanza y un horno programable que actúa en un rango de temperaturas hasta los $1500{ }^{\circ} \mathrm{C}$. En el gráfico obtenido, llamado termograma, se halla representada la masa (o masa \% de la muestra) en el eje de las ordenadas y la temperatura en el eje de las abscisas. La curva termogravimétrica (TG) y su derivada (DTG) permiten la observación de la pérdida y/o ganancia de masa de la muestra, la segunda permite tener una definición más clara de los procesos.

\subsubsection{Análisis Térmico Diferencial (ATD)}

El análisis térmico diferencial consiste en la medición de la diferencia de temperatura $(\Delta \mathrm{T})$ entre la muestra a analizar y una sustancia llamada de referencia al someterla a un tratamiento térmico controlado. El material de referencia debe ser térmicamente inerte, es decir, no debe presentar cambios en el rango de temperaturas estudiado (Gallagher y col., 1998). 
La medida de $\Delta \mathrm{T}$ adquiere importancia cuando el material estudiado presenta transformaciones físicas o químicas con intercambio de calor durante el tratamiento térmico. Cuando, a determinada temperatura, se produce una reacción exo o endotérmica, la muestra se calentará o enfriará respecto a la de referencia hasta que, terminada la reacción, volverán a equilibrarse.

En el sistema clásico, los cambios de temperatura se detectan de manera diferencial (Fig. 4.5) la diferencia de las temperaturas de la muestra $\left(T_{m}\right)$ y la de la referencia $\left(T_{r}\right)$ es la función que mide el equipo $\left(\Delta T=T_{m}-T_{r}\right)$.

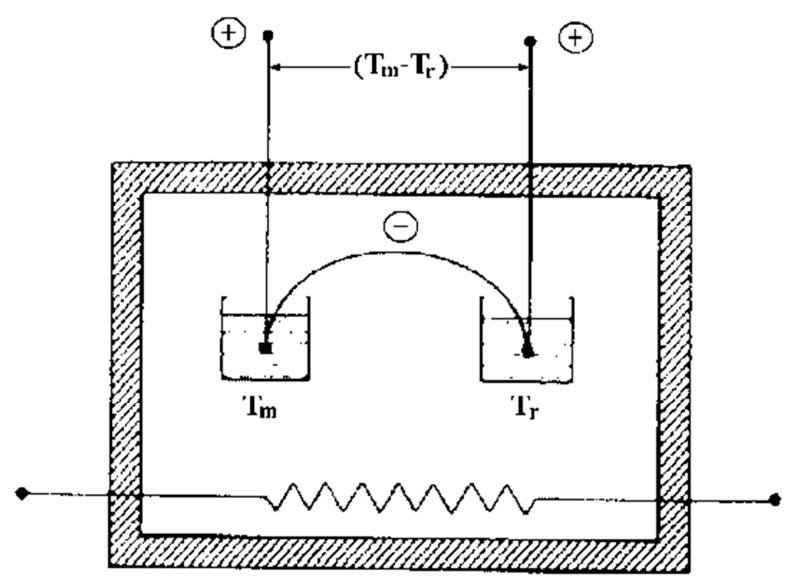

Fig. 4.5 Sistema básico de ATD (Gallagher y col., 1998)

La curva del ATD grafica en el eje de las ordenadas a $\Delta T$ y en el eje de las abscisas a la temperatura. Las reacciones endotérmicas, por convención, se observan como picos hacia la parte negativa de la escala $\Delta T<0$ y los exotérmicos hacia la positiva $\Delta \mathrm{T}>0$.

El equipo de ATD consiste en un horno programable, un soporte para colocar ambas muestras (patrón y muestra problema) con termocuplas para medir su temperatura, un sistema para controlar la atmósfera en el equipo, un sistema de recolección de medidas de las termocuplas y un graficador.

Tanto la muestra como la sustancia de referencia deben ser introducidas en crisoles antes de ser colocadas en el equipo. Dichos crisoles no deben reaccionar con las muestras, siendo común que estén hechos de platino, aluminio y otros materiales. El conjunto de ambos crisoles con las muestras se ubican en los portamuestras dentro del horno del equipo. Dicha cámara suele 
estar equipada para permitir la circulación de gases como nitrógeno, aire u oxígeno.

Existen equipos que unifican las técnicas de ATD y TG en el mismo ensayo, realizando la medida de la variación de masa y $\Delta \mathrm{T}$ con un inerte al mismo tiempo durante un programa de calentamiento. Este tipo de equipos es denominado de Análisis Térmico Simultaneo (ATD-TG). En la Fig. 4.6 se muestra un esquema de un equipo comercial

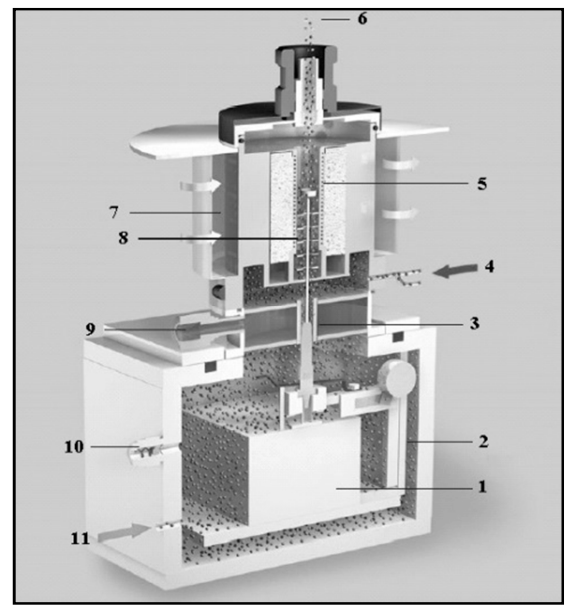

1. Microbalanza

2. Cámara de pesado.

3. Regulador de altura del portamuestras.

4. Gases de purga.

5. Muestra.

6. Salida de gases.

7. Refrigeración del horno.

8. Disipador de calor.

9. Control termostático.

10. Alivio de presión.

11. Gas protector.

Fig. 4.6 Esquema de equipo comercial de ATD-TG

Para las caracterizaciones se ha utilizado un equipo de Análisis Térmico Simultáneo marca RIGAKU (Serie Thermo Plus Evo, 220V $50 \mathrm{~Hz}$ ). El mismo puede operar hasta una temperatura máxima de $1500^{\circ} \mathrm{C}$, y posee una resolución de $0,1 \mu \mathrm{g}$ para el análisis termogravimétrico. Las mediciones fueron realizadas en atmosfera de aire a una velocidad de calentamiento de 10 ${ }^{\circ} \mathrm{C} / \mathrm{min}$, utilizando un crisol de platino para la muestra y una referencia de $\alpha$ $\mathrm{Al}_{2} \mathrm{O}_{3}$. Las medidas realizadas se almacenaron digitalmente mediante computadora conectada al equipo, utilizando el software Thermo Plus2

\subsubsection{Microscopía de Calentamiento}

La microscopía de calentamiento permite el análisis de la variación dimensional de una muestra al someterla a un ciclo térmico posibilitando la observación de cambios morfológicos y dimensionales que suceden en el material al ser calentado. Mediante esta técnica se pueden determinar los intervalos de 
temperatura en los que se producen contracciones y/o la fusión del material (Stábile y col., 2015).

El equipo utilizado para esta técnica consta de un portamuestra de material inerte donde se coloca la probeta cilíndrica de la muestra a estudiar. La misma se somete a un régimen de calentamiento en un horno tubular, mientras que una fuente de luz ilumina la muestra y una cámara registra las imágenes desde el fondo del horno (Fig. 4.7). Dichas imágenes son registradas mediante software y se asignan a la temperatura de la muestra, medida mediante una termocupla instalada en el interior del horno.

a)
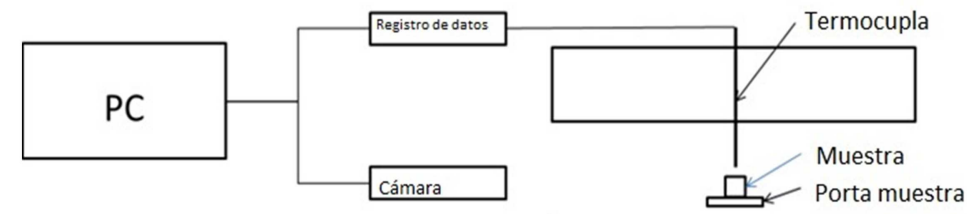

b)

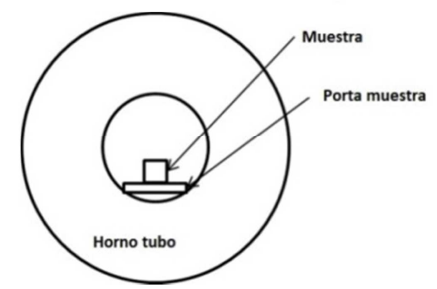

Fig. 4.7 Esquemas del microscopio térmico: a) Corte paralelo al horno tubo; b) corte transversal al horno tubo (Stábile y col., 2015).

Para realizar el ensayo se prepararon probetas cilíndricas $(5 \mathrm{~mm}$ de alto y 3 $\mathrm{mm}$ de diámetro) por prensado uniaxial de las muestras en polvo $\mathrm{B}, \mathrm{BOHAl}$, $\mathrm{BOHZr}$ y arcillas usadas como sustratos (LG y PG). Las mismas se colocaron verticalmente sobre el portamuestra del horno del microscopio de calentamiento (L74 Linseis) y se sinterizaron con una rampa de calentamiento de $10^{\circ} \mathrm{C} \mathrm{min}^{-1}$ hasta $1300^{\circ} \mathrm{C}$. Los cambios de altura y diámetro de los compactos con la temperatura son registrados en fotografías con la cámara digital del microscopio, y el software del equipo permite realizar las evaluaciones a partir de las imágenes tomadas de la muestra.

Asimismo, se realizaron análisis dilatométricos de piezas sinterizadas de ANs y sustratos, también preparados por prensado uniaxial. Dicho análisis, comparando con un blanco de alúmina sometida simultáneamente al 
tratamiento térmico, permite obtener el coeficiente de expansión térmica de la muestra.

\subsection{Microscopía Óptica.}

La microscopía óptica por reflexión permite la observación de las muestras a nivel superficial. La examinación de la superficie de las muestras analizadas por esta técnica fue realizada mediante el uso de un microscopio Olympus BX60.

\subsection{Microscopía electrónica de barrido (SEM)}

Cuando un haz de electrones incidente impacta la superficie de la muestra, interactuará con los átomos de la muestra por dispersión elástica e inelástica, generando diversas emisiones (Fig. 4.7).

Los electrones secundarios tienen poca penetración y dan buena información superficial de la muestra, mientras que las imágenes formadas por los electrones retrodifundidos llevan información de la composición (cualitativa) dela muestra, ya que su intensidad depende de $Z^{2}$ de la muestra. Adicionalmente, los rayos $X$ dan información cuali/cuantitativa de la composición elemental, ya que su intensidad depende de Z. (Jenei, 2012).

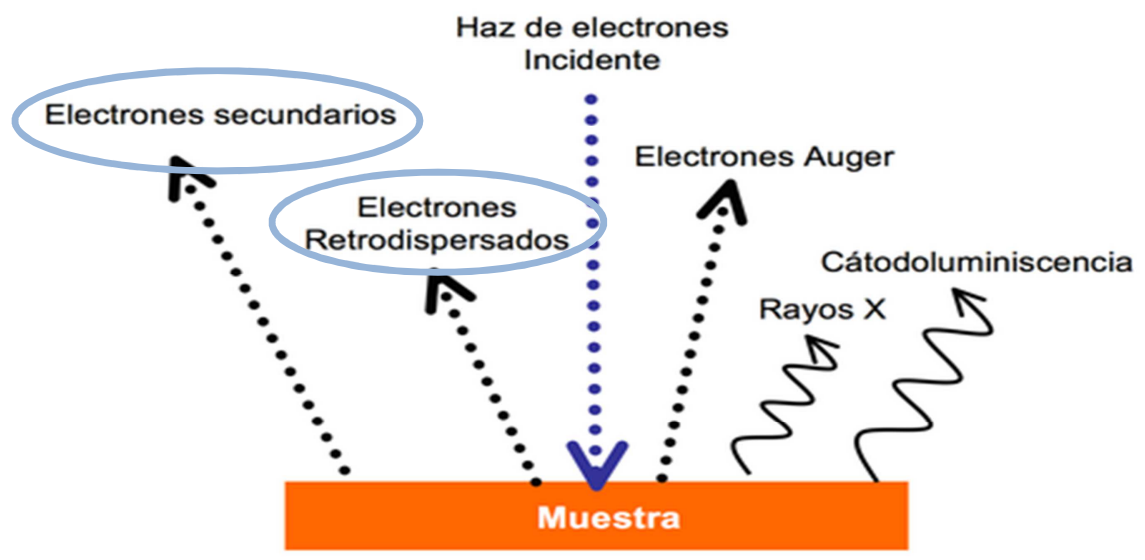

Fig. 4.7 Interacciones del haz de electrones con la muestra

Las muestras en este trabajo fueron observadas con un microscopio electrónico de barrido de 15 kV de potencia marca JEOL (modelo JCM-6000). 


\subsection{Movilidad electroforética en suspensión.}

Las partículas en suspensiones coloidales suelen estar cargadas. El signo y la magnitud de la carga en la superficie de la partícula determinan la estabilidad de dichos coloides en suspensión. El potencial zeta es un parámetro indicativo de la estabilidad de la partícula suspendida por lo que es un valor de particular importancia en la caracterización de partículas en suspensión. El potencial zeta se calcula a partir de la movilidad electroforética (determinada experimentalmente) de la partícula en suspensión, la cual es eléctricamente neutra, debido a que las cargas superficiales de cada partícula están contrarrestadas por iones de cargas opuestas (contraiones) disueltos en la solución. Sin embargo, la forma no esférica de las partículas de minerales arcillosos, entre otros efectos, proporciona una complicación para el cálculo porque no se han podido derivar formulaciones matemáticas para la relación entre la movilidad y el potencial zeta. Por ello, en los estudios de comportamiento coloidal de las arcillas, se recomiendo informar los valores de movilidad electroforética en lugar de los valores de potencial zeta (Lagaly y Dékány, 2013).

Para la medición de la movilidad electroforética se ha utilizado el equipo Zeta Plus, Brookhaven Inc, USA que utiliza la técnica de dispersión de luz electroforética para realizar las determinaciones (también conocida como velocimetría láser por efecto Doppler). El mismo opera en un rango que posibilita la medición de potencial Zeta de $-150 \mathrm{a}+150 \mathrm{mV}$, utilizando un láser rojo $(\lambda=660 \mathrm{~nm}$ de $35 \mathrm{~mW}$ ) para incidir en la muestra en suspensión. La movilidad electroforética depende fuertemente de los valores de $\mathrm{pH}$ y fuerza iónica de la suspensión. En este estudio, las medidas se llevaron a cabo con suspensiones diluidas con un contenido de solidos de $0,1 \%$ en masa en solución $\mathrm{KCl} 10^{-3} \mathrm{M}$. El pH de las suspensiones se ajustó en un rango entre $3 \mathrm{y}$ 10 mediante $\mathrm{HCl}$ y $\mathrm{KOH}$ manteniendo la agitación.

\subsection{Propiedades reológicas}

La medición de la viscosidad de la suspensión, es decir, la resistencia interna al flujo que ofrece la suspensión, es necesaria para la correcta evaluación y 
aplicación de dichas suspensiones. El viscosímetro rotacional fue el equipo utilizado para la determinación de la viscosidad. El sistema de medida de cilindros concéntricos se compone de un cilindro interior que rota (rotor) y uno exterior que permanece fijo donde se ubica a la suspensión o líquido. Cuando se introduce el rotor, que al girar, provoca el fluir del líquido localizado en el espacio anular entre ambos cilindros, la resistencia generada sobre el rotor se transmite como un momento de giro que es proporcional a la viscosidad de la suspensión analizada. La velocidad de deformación aplicada y el esfuerzo de corte resultante se determinan como en un sistema de flujo de corte simple.

La relación entre el esfuerzo de corte y la velocidad de deformación se registra en forma de curva de flujo. La medición de dicha curva se llevó a cabo con un viscosímetro rotacional Vt 550 , Haake y un sensor de cilindros coaxiales a 25 ${ }^{\circ} \mathrm{C}$, en condición de velocidad controlada, y se mide el esfuerzo de corte. Para la determinación se aplica un ciclo de velocidad de deformación en el que primero se aumenta la velocidad hasta una velocidad máxima de $550 \mathrm{~s}^{-1}$ partir de la cual la velocidad se desciende punto a punto en condiciones estacionarias. Partiendo de estos datos se puede obtener la viscosidad aparente que es valor de viscosidad que corresponde a una velocidad de deformación dada y a veces se emplea para describir el comportamiento observado, en nuestro caso se usó la viscosidad aparente a la velocidad máxima estudiada.

\subsection{Distribución de tamaño de partícula}

El análisis de la distribución de tamaño de partícula de diferentes muestras en polvo fue realizado en un equipo Mastersizer 2000 con unidad de dispersión Hydro 2000G, Malvern permite medir tamaños de partícula desde 0,02 hasta $2000 \mu \mathrm{m}$.

El método de medida se fundamenta en la determinación de tamaño de partícula por dispersión de luz láser. Las partículas dispersan luz en todas las direcciones con un patrón de intensidad que depende de su tamaño y del ángulo de observación. A la vez, cada partícula presenta la propiedad de dispersar la luz frontalmente con un ángulo de difracción inversamente 
proporcional a su tamaño. A partir de la distribución de la intensidad de la luz dispersada es posible calcular la distribución de tamaño de partícula.

Para el ensayo, las muestras se dispersaron en suspensiones acuosas diluidas con aplicación de ultrasonido

\subsection{Método de Arquímedes para medición de densidad}

El método de Arquímedes es muy utilizado en cerámica para evaluar la densidad aparente y porosidad abierta de una probeta. El mismo consiste en la medición de la masa de la muestra seca $\left(\mathrm{P}_{\mathrm{s}}\right)$, la masa de la muestra con sus poros ocupados por líquido $\left(\mathrm{P}_{\text {sat }}\right)$ y el empuje de la muestra sumergida en el líquido $\left(\mathrm{P}_{\text {sum }}\right)$. A partir de estos tres parámetros, y conocida la densidad del líquido $\left(\delta_{\text {liq }}\right)$ se calculan los siguientes valores:

Volumen aparente: $V_{a p}=\frac{\left(P_{\text {sat }}-P_{\text {sum }}\right)}{\delta_{\text {liq }}}$

Porosidad abierta: $P_{a}=\frac{\left(P_{s a t}-P_{s}\right) / \delta_{l i q}}{V_{a p}}$

Densidad aparente: $\delta_{a p}=\frac{P_{s}}{\left(P_{\text {sat }}-P_{\text {sum }}\right) / \delta_{\text {liq }}}$

\subsection{Porosimetría por intrusión de mercurio}

La porosimetría por intrusión de mercurio (MIP) se basa en la premisa de que un líquido no mojante, i.e: que tiene un ángulo de contacto mayor a $90^{\circ} \mathrm{C}$, sólo penetrará en un sistema poroso bajo presión. La relación entre la presión necesaria para que el líquido penetre y el tamaño del poro (diámetro) está dada por la ecuación de Washburn que, suponiendo poros de geometría cilíndrica, toma la siguiente forma (Washburn, 1921):

$$
P=-\frac{4 \gamma \cos \theta}{d}
$$

Dónde: 


\section{P: presión \\ $\gamma$ : tensión superficial del líquido \\ $\theta$ : ángulo de contacto del líquido \\ d: diámetro del poro}

El mercurio debe ser forzado usando presión para que penetre en los poros del material. La distribución de tamaño de poro se determina a partir del volumen de mercurio intruido a cada presión; mientras que la porosidad abierta total se determina con el volumen total intruido. El poro más pequeño registrado está limitado por la presión máxima que pueda alcanzar el instrumento. Con esta técnica se puede calcular la distribución de diámetros de poro al derivar la curva acumulada con respecto al diámetro.

La porosidad de los cerámicos es una de las propiedades más importantes desde el punto de vista de sus propiedades mecánicas (Wachtman y col., 2009). La técnica MIP tiene limitaciones, puesto que considera poros cilíndricos, no tiene en cuenta los poros no conectados. En algunos casos resulta destructiva produciendo grietas en las muestras, o si la misma es compresible, da resultados erróneos. A pesar de ello, da información muy valiosa sobre la caracterización textural de los cerámicos.

Los ensayos de MIP fueron realizados en un porosímetro por intrusión de $\mathrm{Hg}$ automático PASCAL 440, Thermo Fisher Scientific. El mismo opera en un rango de presiones que posibilita la medición del volumen y tamaño de poros entre 3,6 y $15000 \mathrm{~nm}$.

\subsection{Dureza}

La dureza es una propiedad mecánica relevante en los materiales cerámicos, medida usualmente por ensayos de indentación. Mediante la inserción de una punta de forma definida a determinada presión y durante cierto tiempo, se deja una marca o impronta sobre el material a ensayar al remover la carga. El valor de dureza se calcula a partir de las dimensiones de la impronta realizada. Para los materiales cerámicos, uno de los ensayos más utilizados es el de dureza Vickers. En el mismo, se utiliza una punta de diamante de forma piramidal cuadrada para realizar la indentación. 
La dureza Vickers (HV) se calcula por medio de la siguiente expresión (Carter y Norton, 2007):

$$
H V=\frac{1,8544 P}{d^{2}}
$$

Dónde: $\mathrm{P}$ es la carga aplicada y $\mathrm{d}$ es la longitud promedio de las diagonales de la impronta. En la presente tesis se evaluó la dureza de los materiales utilizando un durómetro Buehler modelo Indentamet 1100.

Para realizar la medición, piezas sinterizadas fueron incluidos en resina (marca Enaldite), y su superficie pulida con pastas diamantadas hasta $1 \mu \mathrm{m}$. La medición de la dureza Vickers se realizó con una carga de 3N, durante $10 \mathrm{~s}$. Se realizaron 20 indentaciones por pieza, obteniendo de la medición de las diagonales de la impronta resultante el valor de dureza. La dureza Hv informada corresponde al promedio y el error informado es la desviación estándar.

\subsection{Caracterizaciones de materiales granulares}

La caracterización de las propiedades de los materiales granulares nombradas a continuación se realizaron siguiendo los lineamientos de la norma API19C.

\subsubsection{Esfericidad y redondez}

El propósito de este ensayo es caracterizar y evaluar la forma de los agentes de sostén. Como fuera antes mencionado, la resistencia del lecho granular que forman, depende de varios factores, entre ellos la forma de los pellets; lo cual produce empaquetamientos más o menos eficientes, modificando en última instancia la resistencia a la compresión del mismo. Según la norma, Los parámetros de forma más comunes de utilidad para describir los agentes de sostén son la esfericidad y la redondez. 


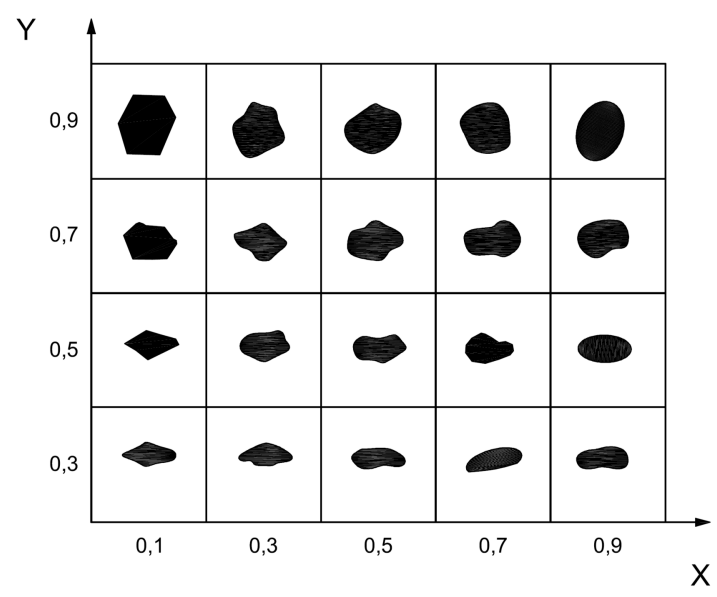

Fig. 4.8 Diagrama de Krumbein / Sloss para la evaluación visual de esfericidad (X) y redondez (Y) (extraído de API19C)

El método más utilizado para determinar redondez y esfericidad es el uso de la tabla Krumbein/Sloss (ver Fig. 4.8). La esfericidad es una medida de cuán cerca se aproxima una partícula a la forma de una esfera, mientras que la redondez es una medida de la "suavidad" relativa de las esquinas o de la curvatura.

Para la determinación de la esfericidad y redondez de los pellets, muestras de los mismos se depositaron en un fondo adecuado, separándolas para formar una capa de una partícula de espesor, y se toma la imagen por una lupa digital. Como indica la norma, se toman veinte partículas al azar de dicha imagen, evaluando visualmente por comparación con la tabla Krumbein/Sloss la redondez y esfericidad de las mismas. El valor de redondez y esfericidad informado corresponde al promedio de las veinte medidas.

\subsubsection{Densidad bulk o densidad de lecho de material granular}

Según la norma API19C, se define a la densidad bulk como la masa de agente de sostén requerida para llenar un volumen unitario, incluyendo tanto al agente de sostén como a la porosidad del lecho, utilizando un equipo como el que se muestra en la Fig. 4.9. Esta medida es utilizada para determinar la masa de agentes de sostén necesaria para rellenar una fractura 0 un tanque de almacenamiento. 


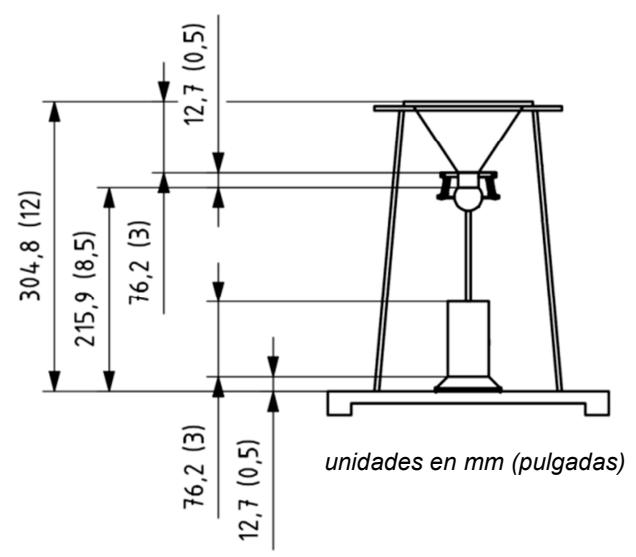

Fig. 4.9 Dispositivo para medición de densidad bulk (extraído de API19C); unidades en $\mathrm{mm}$ (pulgadas)

El procedimiento consiste en la carga del embudo superior (cerrado) con $150 \mathrm{~g}$ de agente de sostén. Al mover la bola que mantiene cerrado el embudo, se permite al agente de sostén rellenar el cilindro (hueco) inferior. Una vez vaciado el embudo, se pasa suavemente una superficie lisa en contacto con el borde del cilindro para nivelar la superficie del agente de sostén, evitando vibraciones y golpes. El cilindro relleno con los agentes de sostén se pesa, y, conocidas las masas del cilindro vacío y el volumen hueco del mismo, la densidad bulk $\left(\rho_{\text {bulk }}\right)$ se determina mediante la siguiente ecuación:

$$
\rho_{\text {bulk }}=\frac{m_{p}}{V_{c y l}}
$$

\section{Donde}

$\mathrm{m}_{\mathrm{p}}$ : masa de cilindro lleno - masa de cilindro vacío

$\mathrm{V}_{\text {cyl }}$ : volumen del cilindro hueco

La medida se realiza por triplicado, y se informa el promedio de la misma.

\subsubsection{Densidad aparente por picnometría}

En este ensayo se determina la densidad aparente del material granular, definida en la norma API19C como aquella que incluye al material granular así como a la porosidad inaccesible al fluido que moja la superficie de la partícula, utilizado para la medida. 
La medida consiste en el llenado de un picnómetro de masa conocida $\left(\mathrm{m}_{\mathrm{f}}\right)$ con un fluido de densidad conocida $\left(\rho_{\mathrm{l}}\right)$, registrando dicha masa $\left(\mathrm{m}_{\mathrm{f}+\mathrm{l}}\right)$ en una balanza analítica. Posteriormente, se vacía parte del líquido y se agrega una cantidad previamente pesada del material granular seco $\left(\mathrm{m}_{\mathrm{p}}\right)$, llenando el picnómetro nuevamente con el fluido. La masa del picnómetro con el material granular y el fluido $\left(\mathrm{m}_{\mathrm{f}+\mathrm{l}+\mathrm{p}}\right)$ es registrado, y la densidad aparente del material granular $\left(\rho_{\text {app }}\right)$ es calculada mediante la siguiente ecuación.

$$
\rho_{\text {app }}=\frac{m_{p} \rho_{l}}{m_{f+l}+m_{p}-m_{f+l+p}}
$$

\subsubsection{Ensayo de resistencia a la rotura (crush) para materiales granulares}

Este ensayo se utiliza para determinar la resistencia a la compresión de un lecho de material granular confinado. El mismo consiste en someter a un lecho de partículas a presión por determinado tiempo y evaluar la cantidad de material granular que se fractura respecto a la cantidad de material total.

La celda de crush tiene un diámetro de 50,8 $\mathrm{mm}$ con un espesor de pared de $0,5 \mathrm{~mm}$ y una altura de $85,8 \mathrm{~mm}$. El pistón de carga tiene un diámetro de 50,7 $\mathrm{mm}$, y una altura de $88,9 \mathrm{~mm}$, son de acero de aleación 4340 con dureza mínima de Rockwell C 43. Estas especificaciones están de acuerdo con las normas API 19C (API). La celda se carga con un volumen de material granular de $24,7 \mathrm{~cm}^{3}$. Se muestra un esquema de la celda de carga con el pistón de carga montado en la Fig. 4.10 


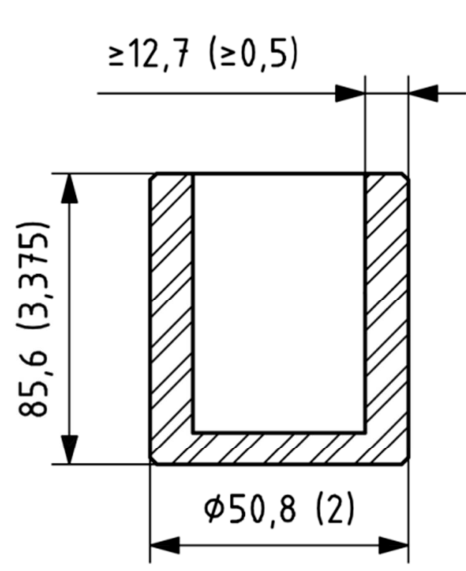

a)

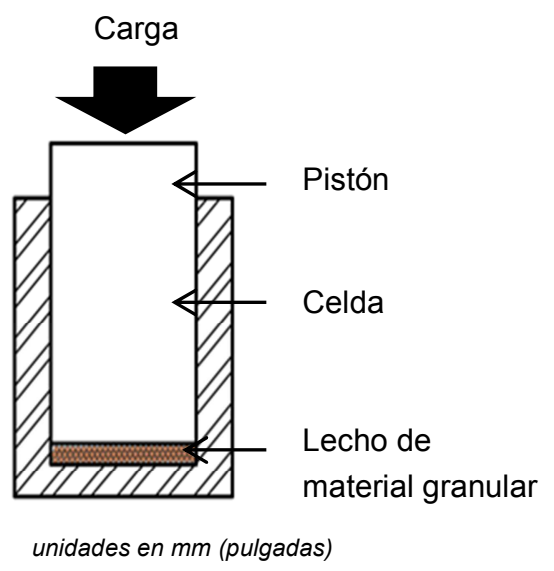

b)

Fig. 4.10. a) Esquema de celda de crush b) disposición de celda cargada con material granular para ensayo de crush (extraído de Norma API19C)

Las pruebas se realizan en una prensa hidráulica Carver modelo 3925. La carga se aplica hidráulicamente y se controla manualmente. A medida que el pistón se desplaza, el empaquetamiento granular es comprimido y el material granular comienza a fracturarse. La presión máxima se sostiene durante 2 min, y luego la prensa se libera. El ensayo se considera satisfactorio (para una presión máxima dada) si el porcentaje de finos pasante la malla que retiene el menor tamaño de material granular sin fracturar es menor que el $10 \%$ del peso total de material granular del lecho.

En particular se evaluaron pellets cerámicos de tamaño comprendido entre tamices M: 20 (diámetro equivalente $850 \mu \mathrm{m}$ ) y M: 40 (diámetro equivalente $400 \mu \mathrm{m}$ ); siendo satisfactorio el ensayo si el porcentaje de finos pasantes M: 40 resulta menor al $10 \%$. 


\section{SÍNTESIS DE AN MODIFICADAS Y PROCESAMIENTO DE COMPOSITOS CERÁMICOS CON AN: SUSTRATOS RECUBIERTOS POR INMERSIÓN Y MATERIAL GRANULAR.}

Se ha mencionado anteriormente que la obtención y evaluación arcillas nanoestructuradas modificadas ha recibido especial atención debido a importantes aplicaciones tecnológicas que presentan y es cada vez más frecuente recurrir a su empleo para la formulación de diversos nanocompositos. No obstante, cabe destacar que los estudios previos sobre el proceso de obtención, la incorporación y la transformación de AN a elevadas temperaturas para el desarrollo de compositos cerámicos con fases tales como mullita, zirconia, zircón son muy limitados. Las AN intercaladas con especies de aluminio se utilizaron para recubrir fibras de SiC y, posteriormente tratadas térmicamente, incluyendo las mismas en una matriz de vidrio de borosilicato; encontrándose que dicho recubrimiento genero un refuerzo mayor en el composito obtenido que material con fibras de $\mathrm{SiC}$ sin recubrimiento (Jagota y col., 1995; McCarron III y col., 2000).

Respecto a las ANs intercaladas con especies de $\mathrm{Zr}$, si bien no se han reportado trabajos acerca de la obtención de compositos cerámicos a partir de ellas, existen trabajos previos acerca del uso de ANs sintéticas (laponita) como recubrimiento sobre cerámicos de zirconia que, por tratamiento térmico, desarrollan zircón, mejorando la dureza del composito en comparación a la pieza sin recubrir (Blanton y col., 2000).

En este Capítulo se describe el método empleado para la síntesis de AN modificadas, las materias primas utilizadas y su uso como precursores en la formulación de compositos cerámicos. El procedimiento utilizado para la obtención de ANs modificadas así como la caracterización de la bentonita utilizada son descriptos en el inciso 5.1.

Asimismo, en el inciso 5.2 se detalla el procesamiento seguido para el desarrollo de dos tipos de compositos mediante la aplicación de recubrimientos de $\mathrm{AN}$ en sustratos arcillosos: piezas cerámicas recubiertas con AN y material granulado tipo núcleo cerámico@recubrimiento de AN. Se presentan las 
principales características de las técnicas utilizadas para aplicar el recubrimiento por inmersión en suspensiones y granulación de polvos finos, y el proceso de sinterizado. El uso de estas dos técnicas permite evaluar el efecto del grado de agregación de las partículas en las características del recubrimiento y en las propiedades microestructurales y resistencia del composito

\subsection{Síntesis de arcillas nanoestructuradas modificadas (BOHAl, BOHZr)}

\subsubsection{Materias primas}

\subsubsection{Arcilla}

Previamente a la selección de la arcilla se realizó una evaluación mineralógica de diferentes tipos de bentonitas nacionales, provenientes de Neuquén, Rio Negro, Mendoza y San Juan. La selección quedó acotada a la bentonita natural proveniente de San Juan debido a su mayor contenido en mineral arcilloso tipo esmectítico, cuya caracterización se incluye en el Capítulo 6.1. El yacimiento de esta bentonita se encuentra ubicado al noreste de la provincia de San Juan a una distancia de $100 \mathrm{~km}$ de la ciudad capital. En el presente trabajo esta arcilla bentonítica fue denominada $B$.

\subsubsection{Solución con polihidroxicationes de aluminio $\mathrm{OH}-\mathrm{Al}$}

La adición de aluminio a la bentonita se realizó mediante el tratamiento de la misma con solución polimérica de especies hidroxialuminicas $\mathrm{OH}-\mathrm{Al}$ obtenida en el laboratorio. Se preparó esta solución de $\mathrm{OH}-\mathrm{Al}(0,10 \mathrm{M}$ en $\mathrm{Al})$ diluyendo una solución comercial de clorohidroxialuminio $(6,0 \mathrm{M})$ que se envejeció durante 7 días a temperatura ambiente (Volzone y Garrido, 2008). Dicha solución se preparó a fin de modificar químicamente la bentonita mediante la intercalación de las especies policatiónicas de aluminio en el mineral arcilloso. La mayoría de las especies polinucleares de Al en esta solución tienen una estructura tipo Keggin, de formula estructural $\left(\mathrm{Al}_{13} \mathrm{O}_{4}(\mathrm{OH})_{24}\left(\mathrm{H}_{2} \mathrm{O}\right)_{12}\right)^{7+}(\mathrm{Hsu}$, 1989; Volzone y Garrido, 2001). 


\subsubsection{Solución con polihidroxicationes de zirconio $\mathrm{OH}-\mathrm{Zr}$}

El agregado de zirconio a la arcilla fue realizado mediante el tratamiento con una solución a base de $\mathrm{Zr}$, la cual fue preparada a partir de la hidrolisis parcial de $0,1 \mathrm{M}$ de $\mathrm{ZrOCl}_{2}$ y envejecida durante 1 día a $60^{\circ} \mathrm{C}$. Esta solución contiene especies de $\mathrm{Zr}$ en forma de tetrámeros, con una fórmula $\left[\mathrm{Zr}_{4}(\mathrm{OH})_{24}\left(\mathrm{H}_{2} \mathrm{O}\right)_{10}\right]^{2+}$, en la cual dos de los iones de $\mathrm{Zr}$ tienen una carga positiva y los otros dos son neutros (Volzone y Hipedinger, 1999).

\subsubsection{Método de síntesis de Arcillas Nanoestructuradas modificadas}

La metodología empleada en la modificación de la bentonita para su enriquecimiento en aluminio y zirconio, consistió en la incorporación de especies policatiónicas de $\mathrm{OH}-\mathrm{Al}$ y/o OH-Zr, vía intercambio catiónico, conocido y extensivamente reportado por (Figueras, 1988; Li y col., 2017; Vaughan y Lussier, 1980; Volzone y Garrido, 2008), entre otros, cuyo objetivo era la obtención de arcillas pilareadas por tratamiento térmico de éstas a temperaturas menores a $750{ }^{\circ} \mathrm{C}$, como fuera mencionado en el Capítulo 2.

\subsubsection{Intercalación con especies de $\mathrm{OH}-\mathrm{Al}$}

La intercalación con especies de OH-Al se realizó dispersando la bentonita en agua destilada hasta obtener una suspensión al $10 \% \mathrm{~m} / \mathrm{m}$ y luego la solución de $\mathrm{OH}-\mathrm{Al}$ se añadió lentamente manteniendo una agitación constante. La cantidad de Al añadida total fue de $2,5 \mathrm{mmol} \mathrm{Al} / \mathrm{g}$ de bentonita. Después de 24 h en contacto, el sólido fue separado por centrifugación y se realizaron lavados con agua destilada hasta eliminar el exceso de electrolitos. La arcilla intercalada así obtenida fue secada a temperatura ambiente, molida y tamizada hasta pasar M: 100 (<149 $\mu \mathrm{m})$. La AN modificada así obtenida fue denominada BOHAl.

\subsubsection{Intercalación con especies de $\mathrm{OH}-\mathrm{Zr}$}

El proceso de intercalación de las especies $\mathrm{OH}-\mathrm{Zr}$ en la arcilla fue realizado dispersando la bentonita en agua $(10 \% \mathrm{~m} / \mathrm{m})$, y posteriormente agregando la solución de especies $\mathrm{OH}-\mathrm{Zr}$ mencionada manteniendo la agitación. La cantidad de $\mathrm{Zr}$ total fue de $2,5 \mathrm{mmol} \mathrm{Zr} / \mathrm{g}$ bentonita. La suspensión así obtenida fue 
dejada a temperatura ambiente durante $24 \mathrm{~h}$, período después del cual, el sólido obtenido se lavó con agua destilada hasta la remoción completa de electrolitos. Posteriormente se dejó secar a temperatura ambiente, fue molida y tamizada M: 100 (<149 $\mu \mathrm{m})$. El material obtenido se denominó BOHZr.

\subsection{Procesamiento de compositos cerámicos.}

Como se mencionó anteriormente, en la presente tesis se prepararon dos tipos de compositos cerámicos. Ambos compositos cerámicos están constituidos de un núcleo (sustrato) y un recubrimiento de $\mathrm{AN}$, éstos son:

- Placas de sustratos cerámicos obtenidas por prensado uniaxial, recubiertos por inmersión en suspensiones de AN

- Material granular (pellets) de arcilla conformados por granulación en mezcladora de alta energía, recubiertos por AN en polvo.

En la Fig. 5.1 se muestra el esquema del procesamiento seguido para la preparación de los composito cerámicos en esta tesis

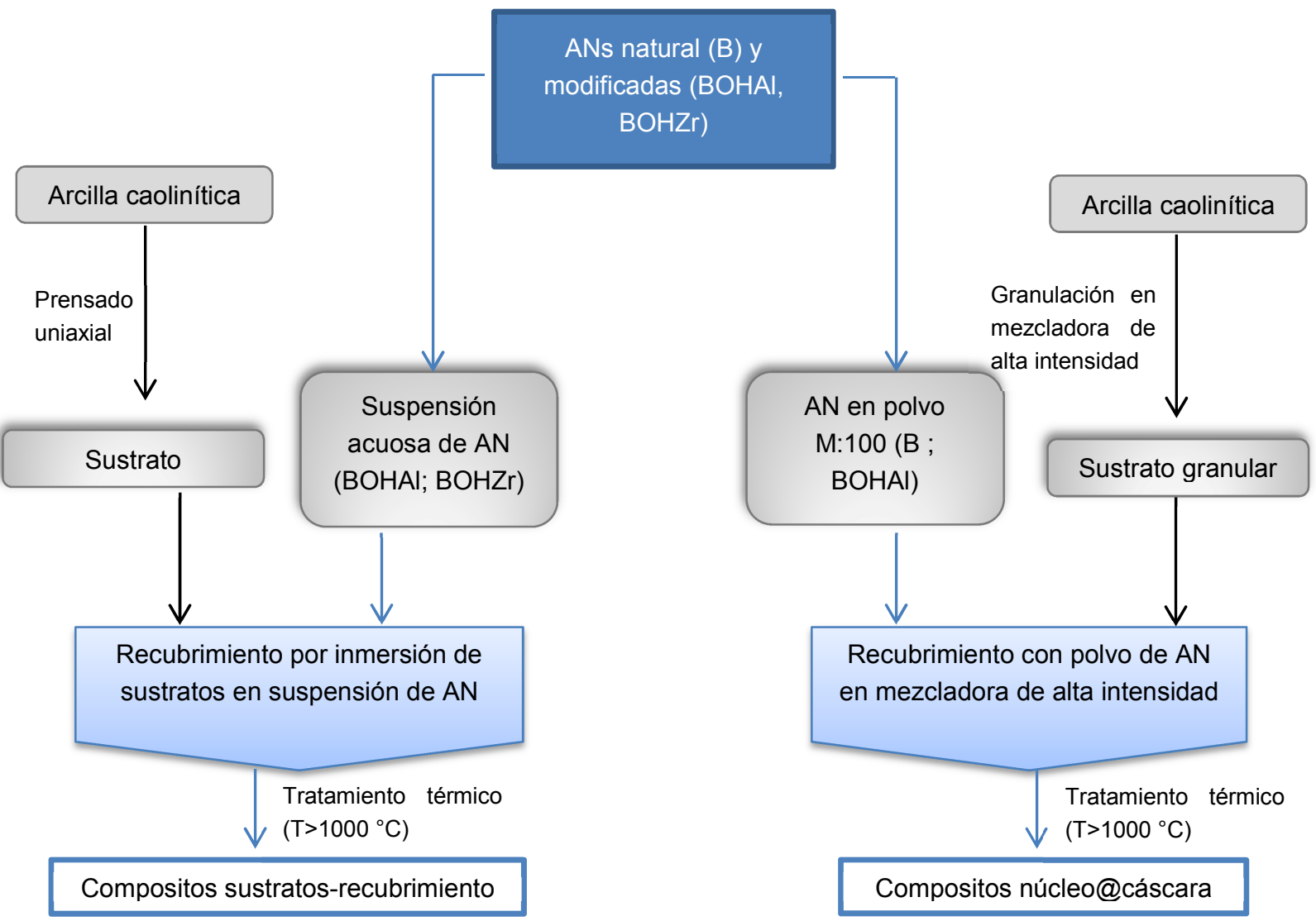


Fig. 5.1 Esquema del procesamiento seguido para la preparación de los composito cerámicos

La preparación del composito comprende la obtención de diferentes sustratos y la subsecuente aplicación de un recubrimiento con BOHAl o BOHZr estudiadas, la incorporación de las AN fue realizada por dos tipos de técnicas distintas:

- Recubrimiento por inmersión (dip coating) en suspensiones de BOHAl y $\mathrm{BOHZr}$ de los sustratos cerámicos obtenidos por prensado.

- Recubrimiento de AN en polvo en mezcladora de alta intensidad: El recubrimiento se obtiene durante el procesado del material granular en mezcladora de alta intensidad. Al material granular preformado en la cuba de la granuladora se lo recubre por agregado de BOHAI precalcinada y molida en polvo fino y posterior rodado en el tambor.

Posterior al conformado, ambos tipos de compositos fueron sometidos a tratamiento térmico a altas temperaturas para su sinterizado.

\subsubsection{Compositos obtenidos por recubrimientos por inmersión (Dip- coating) en suspensión de AN a partir de sustratos cerámicos}

El recubrimiento por inmersión, o dip coating, es una forma sencilla de depositar sobre un sustrato, especialmente en piezas pequeñas, una película fina e uniforme de una suspensión la cual, una vez evaporado el solvente, solidifica en un recubrimiento (Scriven, 1988). El espesor de la película formada se establece por la competencia entre fuerzas viscosas, capilares, y gravedad dependiendo del mecanismo de formación de la película, i.e: por succión capilar del sustrato poroso y/o arrastre viscoso (ver Capítulo 3). Este método ha sido utilizado para obtener piezas recubiertas que, al sinterizar a altas temperaturas, producen compositos con propiedades mecánicas mejoradas (Díaz-Parralejo y col., 2010; Mishra y col., 2011).

Como fuera discutido en el Capítulo 3, un requerimiento básico de este método es la preparación de suspensiones estables y fluidas. Para lograr estas características, la etapa de dispersión de las partículas en el medio líquido y el control de las propiedades reológicas de la suspensión son críticas. Por lo mismo, se estudian las propiedades reológicas y electrocinéticas de las 
partículas de AN en suspensión, a fin de acondicionar las mismas para su uso en dip coating de los sustratos. Dichos resultados se presentarán en el Capítulo 6.3.

\subsubsection{Sustratos}

El conformado de sustratos (4 $\mathrm{cm}^{2}$ de área y $0,5 \mathrm{~cm}$ de espesor) para ser utilizados como sustrato en el proceso de dip coating se realizó por prensado uniaxial de dos arcillas caoliníticas de origen nacional. Los difractogramas de ambas muestras se muestran en la Fig. 5.2.

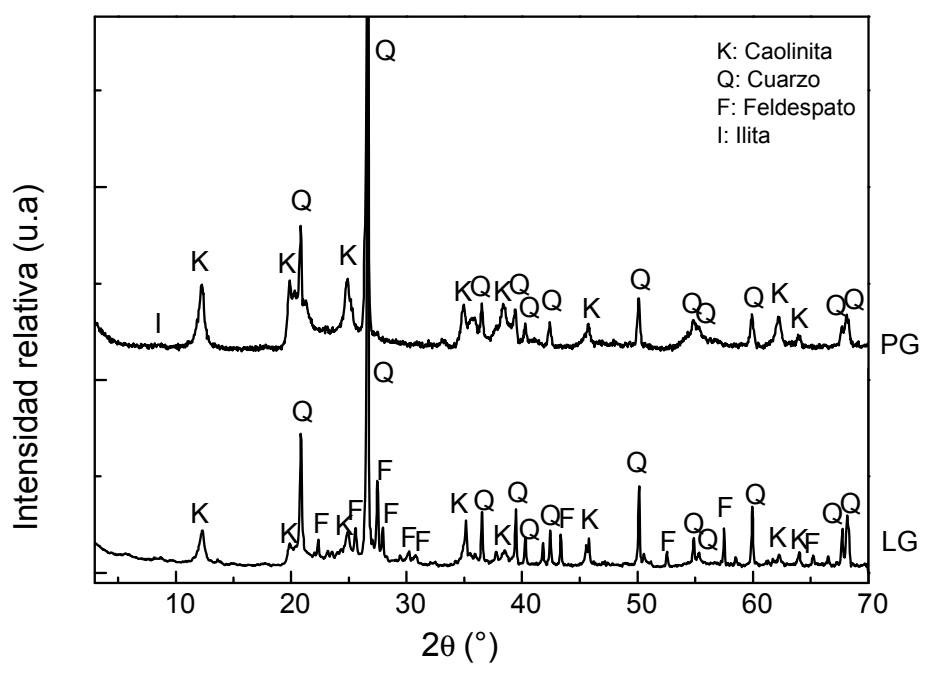

Fig. 5.2. Difractogramas de LG y PG

La primera arcilla utilizada, denominada LG, está mayoritariamente constituida por caolinita, con cuarzo y feldespato como principales minerales secundarios según el análisis por DRX de la misma.

La segunda arcilla fue provista por la empresa Piedra Grande, y es denominada PG en el presente trabajo. La misma posee la composición química que se indica en la Tabla 5.1. A través de un análisis racional con los resultados de DRX y del análisis químico se calculó la siguiente composición mineralógica: caolinita $66 \%$; illita $8 \%$, cuarzo $26 \%$.

Tabla 5.1 Análisis químico de arcilla PG calcinada a $1000^{\circ} \mathrm{C}(\% \mathrm{~m} / \mathrm{m})$ 


\begin{tabular}{ccccccccc}
\hline Arcilla & $\mathrm{SiO}_{2}$ & $\mathrm{Al}_{2} \mathrm{O}_{3}$ & $\mathrm{Fe}_{2} \mathrm{O}_{3}$ & $\mathrm{MgO}$ & $\mathrm{K}_{2} \mathrm{O}$ & $\mathrm{Na}_{2} \mathrm{O}$ & $\mathrm{TiO}_{2}$ & $\mathrm{CaO}$ \\
\hline PG & 63,7 & 30,7 & 3,49 & 0,27 & 0,95 & 0,15 & 0,17 & 0,2 \\
\hline
\end{tabular}

La arcilla en polvo (M: 40) fue humectada con $3 \% \mathrm{~m} / \mathrm{m}$ de agua para asegurar una buena compactación y resistencia en verde de las piezas prensadas. La muestra fue sometida a una presión de $150 \mathrm{MPa}$ durante 1 min.

El tratamiento térmico de los sustratos secos $100{ }^{\circ} \mathrm{C}$ se realizó en una mufla programable eléctrica a una velocidad de calentamiento de $5{ }^{\circ} \mathrm{C} / \mathrm{min}$ a temperaturas de hasta $1200^{\circ} \mathrm{C}$. Las precalcinación de las muestras a distintas temperaturas permitió obtener sustratos con diferentes propiedades texturales, a fin de evaluar la influencia del volumen y tamaño medio de poros en las características de piezas recubiertas con las AN estudiadas.

\subsubsection{Suspensiones acuosas de AN}

Las suspensiones acuosas de AN utilizadas para el recubrimiento por inmersión de los sustratos fueron preparadas por dispersión del sólido en agua destilada, manteniendo agitación constante por agitador magnético, hasta alcanzar la concentración de sólidos deseada. Posteriormente fueron sometidas a tratamiento por ultrasonido durante $15 \mathrm{~min}$ para favorecer la ruptura de los flóculos formados, si los hubiese.

\subsubsection{Procedimiento de recubrimiento de sustratos cerámicos por dip coating}

El procedimiento usado para la aplicación del recubrimiento por dip coating, consistió en sumergir los discos del sustrato en suspensiones de AN un tiempo determinado, posterior extracción a velocidad controlada y secado para la formación de recubrimiento; repitiendo estas etapas hasta la formación de un espesor de recubrimiento adecuado. El sistema sustrato-recubrimiento fue sinterizado a diferentes temperaturas.

Se analizaron diversas condiciones experimentales para los ensayos de recubrimiento por inmersión. Dichos estudios se presentarán en el Capítulo 6.3. 


\subsubsection{Compositos cerámicos granulares por esferización}

La elaboración del composito cerámico tipo núcleo@cáscara constituido por el sustrato PG y recubrimiento de AN se realizó por granulación en una mezcladora de alta intensidad (Fig. 5.3). La misma cuenta con un recipiente cilíndrico, en el cual se carga la materia prima en polvo. El equipo posee un rotor con paletas que llegan hasta el fondo del recipiente. La boquilla en el orificio de la tapa superior es utilizada para el agregado del medio ligante, agua en el caso particular de la presente tesis.

Las propiedades del material granular obtenido en este equipo dependerán de varios factores, siendo los más importantes entre ellos: las propiedades del material de partida, el tipo de mezclador utilizado y las variables operativas del proceso de pelletizado.

\subsubsection{Equipo utilizado}

El equipo utilizado en esta tesis fue una mezcladora de alta intensidad (Fig. 5.3)

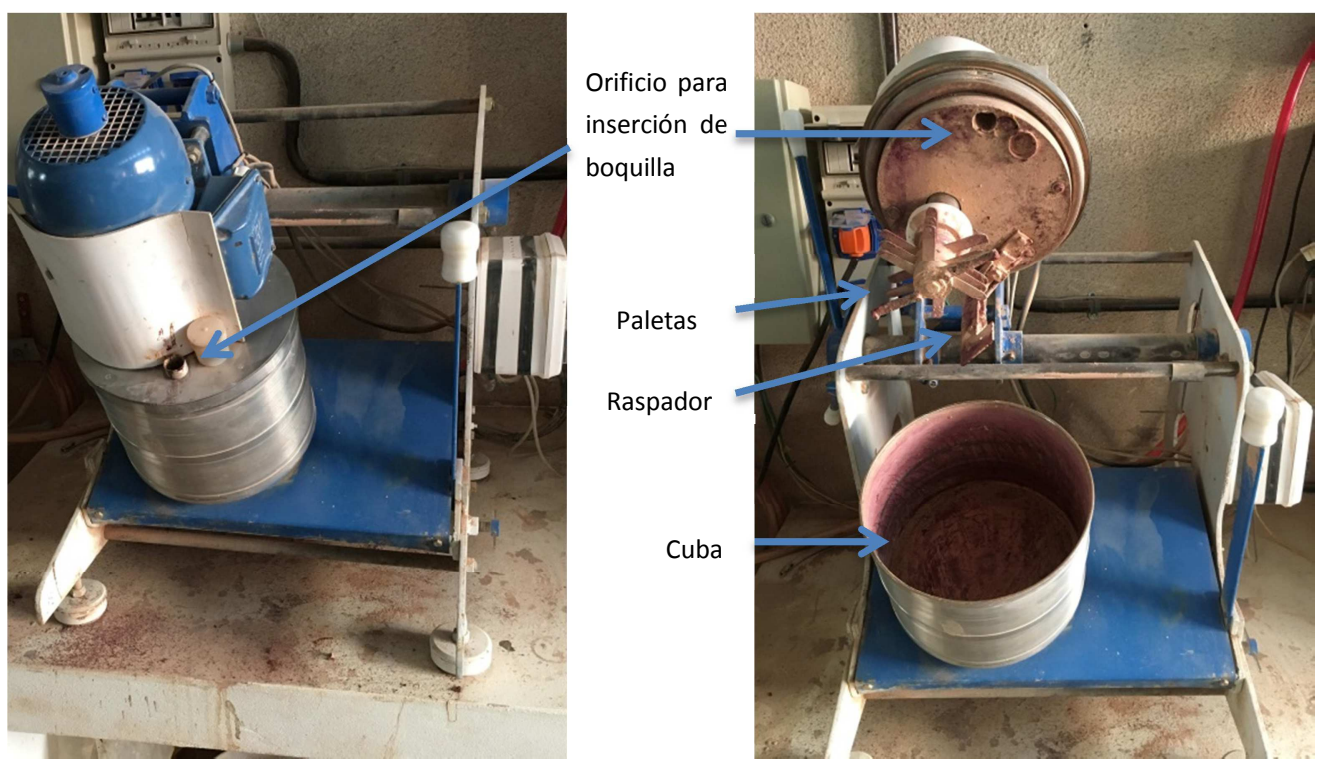

Fig. 5.3 Fotos de la mezcladora de alta intensidad utilizada

El equipo que fue construido en los laboratorios del CETMIC, consta de una cuba de acero de $20 \mathrm{~L}$, velocidad de rotación de paletas variable (hasta 4800 rpm) y velocidad de rotación de tambor (cuba) fija, de $120 \mathrm{rpm}$ como características principales. El alto esfuerzo de corte imprimido por las paletas 
girando a alta velocidad y el agregado de ligante favorecen la colisión y unión entre partículas del polvo, provocando la formación de los pellets. Posee un raspador, cercano a la pared del tambor para evitar la formación de una capa de arcilla que se adhiera sobre el tambor durante el procesamiento.

\subsubsection{Materia prima para el conformado del sustrato}

Para el conformado del material granular en la mezcladora de alta intensidad que será usado como sustrato de los pellets, se utilizó la arcilla PG descripta en el inciso 5.2.1.1, pasante M: 100 y con $3 \%$ de humedad.

\subsubsection{Procedimiento de pelletizado y recubrimiento en seco en granuladora de alta energía}

En función de lo establecido en pruebas preliminares, se utilizó el siguiente procedimiento para el conformado de los pellets de PG.

1. Se realizó el llenado manual de la cuba con $1 \mathrm{~kg}$ de arcilla $P G$, y cerrado del equipo mediante descenso de la tapa del mismo.

2. Se inició la rotación del tambor $(120 \mathrm{rpm})$ y el rotor con paletas a alta velocidad (4800 rpm). Inmediatamente, se realizó el agregado de agua por la boquilla, hasta alcanzar los $180 \mathrm{~mL}$ de agua. El proceso de pelletizado se mantuvo durante $5 \mathrm{~min}$.

3. Posteriormente se redujo velocidad de rotación de paletas (1200 rpm), manteniendo la rotación de la cuba, para favorecer el redondeo de los pellets.

El recubrimiento en seco de los pellets de arcilla PG, usados como sustrato, se realizó en el mismo equipo en el que fueron conformados. Al pellet en verde aún en el recipiente, se le realizó el agregado de la BOHAl en polvo. La rotación de esta cuba y el esfuerzo adicionado por las paletas imprime la energía suficiente para que las partículas de AN se adhieran a la superficie del pellet. En esta etapa, la rotación de las paletas se mantiene a baja velocidad (1200 rpm) a fin de mejorar el contacto entre las partículas de BOHAl y los pellets, sin llegar a romper los mismos. La rotación se mantuvo durante 3 min. 
Una vez obtenido el material granular recubierto, el mismo fue tratado térmicamente en horno eléctrico. El material así sinterizado fue clasificado por tamizado, obteniéndose la fracción comprendida entre los tamices M: 20 y M: 40 para la realización de los ensayos de caracterización.

\subsubsection{Sinterizado de compositos}

La sinterización es esencialmente el proceso físico que consiste en el tratamiento térmico de un polvo o compacto de partículas finas, con o $\sin$ aplicación de presión externa de modo de producir un cuerpo cerámico denso y resistente. La fuerza impulsora para el sinterizado es el transporte o difusión de materia por lo que la temperatura constituye la principal variable. La temperatura debe ser eficaz para estimular los mecanismos de transporte que conducen a la densificación requerida y a la vez debe ser lógicamente inferior al punto de fusión del material. En el caso de la arcillas durante dicho proceso ocurre también la formación de fases cerámicas a altas temperaturas debido a la reacción química entre los componentes del sistema (Kingery, 1976).

Previo al sinterizado, tanto los discos como los pellets recubiertos fueron secados en estufa a $90{ }^{\circ} \mathrm{C}$ hasta peso constante. El tratamiento térmico se efectuó en horno eléctrico (Thermolyne modelo F46200) a temperaturas entre $1000-1300^{\circ} \mathrm{C}$, a fin de estudiar la influencia de dichas temperaturas en las propiedades del material resultante. 


\section{RESULTADOS}

\subsection{Caracterización de arcilla bentonítica B y arcillas nanoestructuradas modificadas}

\subsubsection{Difracción de rayos $\mathrm{X}$}

El análisis de los difractogramas de la bentonita, precursora de las AN (BOHAI y $\mathrm{BOHZr}$ ), muestra la composición mineralógica de la misma que está principalmente formada por el mineral arcilloso montmorillonita con escaso contenido de cuarzo y feldespato sódico (Fig. 6.1).

El pico ubicado en $6{ }^{\circ}(2 \theta)$ de la bentonita original corresponde al espaciado basal $d_{001}$ de la montmorillonita. Esta distancia, de 14,8 $\AA$ para esta muestra, informa sobre la distancia entre una lámina y la siguiente de la montmorillonita; incluyendo tanto las capas de mineral arcilloso como su espaciado entre láminas (Fig. 2.2), donde se ubican los cationes interlaminares (Bergaya y Lagaly, 2013; Moore y Reynolds, 1989). El valor calculado del espaciado interlaminar (i.e. el espaciado basal menos el espesor de la lámina de mineral arcilloso de $\approx 9,6 \AA$ ) resultante es de $5,2 \AA$.

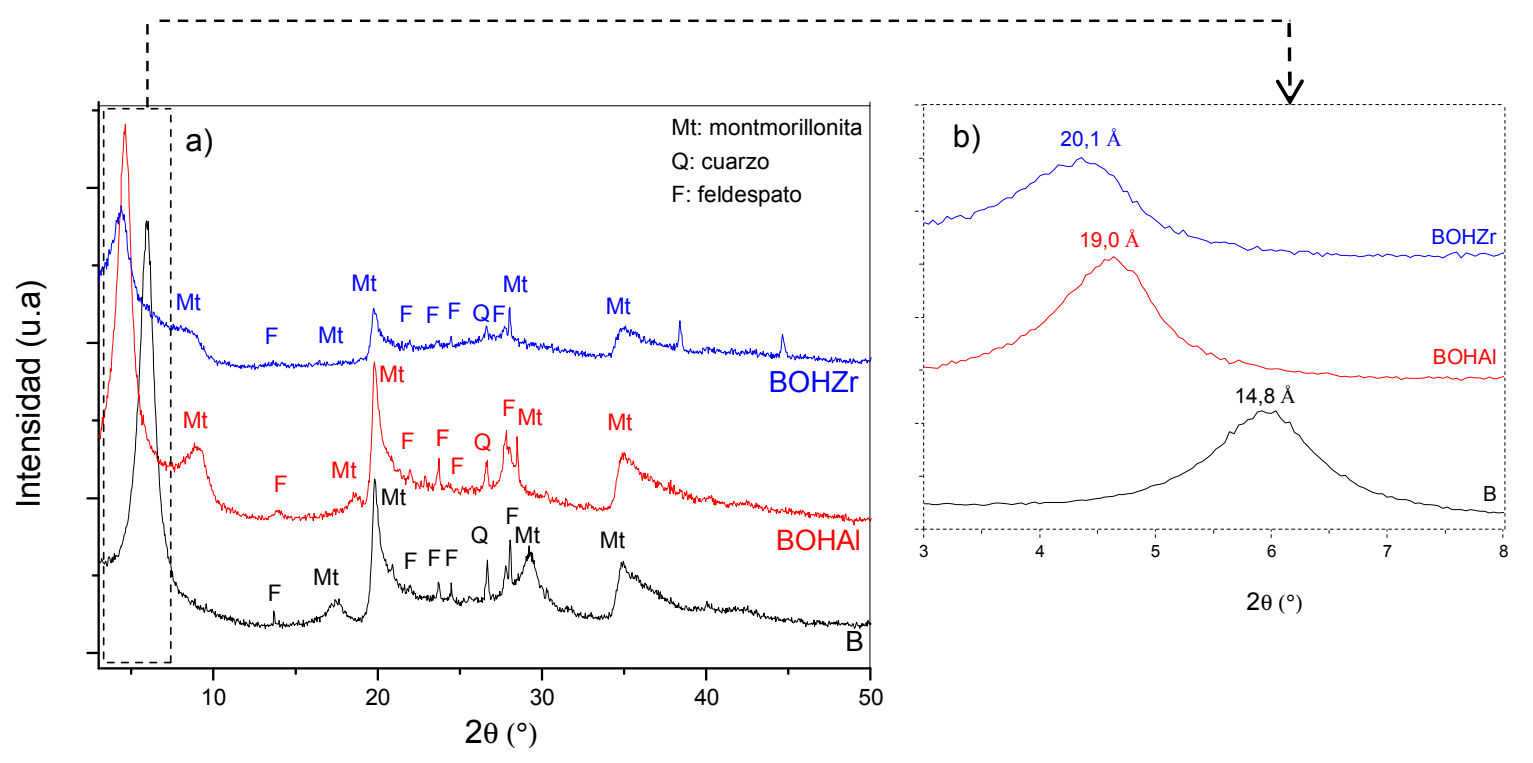

Fig. 6.1.a) Difractogramas de B, BOHAl y BOHZr; b) comparación del espaciado $\mathrm{d}_{001}$

Los difractogramas de BOHAl y $\mathrm{BOHZr}$ demuestran la presencia de las mismas fases cristalinas que la bentonita precursora. Sin embargo, en la Fig. 6.1.b se 
observa un corrimiento del espaciado basal a un valor de $2 \theta\left(^{\circ}\right)$ menor que el de la bentonita original. Esto implica un aumento del $\mathrm{d}_{001}$, alcanzando valores de 19,0 A para BOHAl y de 20,1 A para BOHZr, y se debe al ensanchamiento del espaciado interlaminar con respecto al del mineral arcilloso precursor.

En la muestra BOHAl, es decir en la montmorillonita de la bentonita intercalada con policationes de aluminio, esto implica un valor calculado de espaciado interlaminar de 9,4 A. Este espaciado, según lo indicado por bibliografía (Ma y col., 2015; Plee y col., 1985; Vaughan y Lussier, 1980), es del orden del tamaño del ión tipo Keggin $\mathrm{Al}_{13} \mathrm{O}_{4}(\mathrm{OH})_{24}\left(\mathrm{H}_{2} \mathrm{O}\right)_{12}{ }^{7+}$ (Fig. 6.2.), el cual posee una dimensión de $\sim 9,0$ A confirmando que las especies ubicadas en el espacio interlaminar son mayoritariamente de este tipo (Volzone y Garrido, 2001).

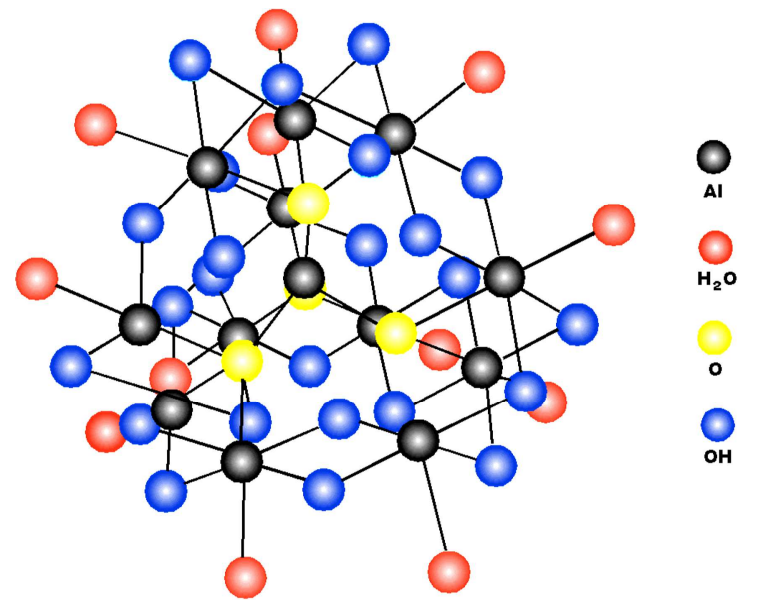

Fig. 6.2. Complejo de $\left(\mathrm{Al}_{13} \mathrm{O}_{4}(\mathrm{OH})_{24}\left(\mathrm{H}_{2} \mathrm{O}\right)_{12}\right)^{7+}$

La muestra de $\mathrm{BOHZr}$, es decir, la obtenida por intercalación de la montmorillonita con especies poliméricas de zirconio, posee un espaciado interlaminar calculado de 10,5 A. El Zr presente en la solución intercalante, con la que se obtuvo esta muestra, se encuentra principalmente en forma de tetrámeros. De acuerdo con lo reportado previamente (Jung y col., 2007), dichas especies son identificadas como cationes de fórmula $\left[\mathrm{Zr}_{4}(\mathrm{OH})_{14}\left(\mathrm{H}_{2} \mathrm{O}\right)_{10}\right]^{2+}$. 


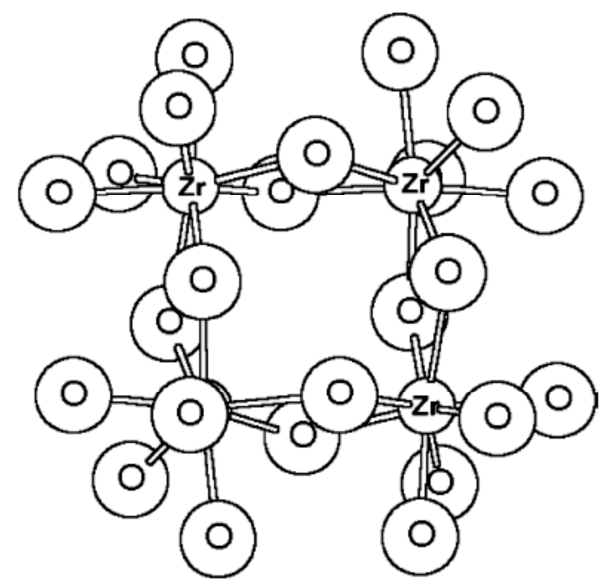

Fig. 6.3. Complejos de $\left[\mathrm{Zr}_{4}(\mathrm{OH})_{14}\left(\mathrm{H}_{2} \mathrm{O}\right)_{10}\right]^{2+,}$ (Jung y col., 2007)

Según lo estimado a partir de su información estructural, estos tetrámeros poseen una dimensión molecular de $10 \times 10 \AA^{2}$ para una configuración cuadrada promedio y 4,5 $\AA$ de espesor (Clearfield y Vaughan, 1956). Con estas dimensiones puede ser introducido en el espacio interlaminar, desplazando a los cationes de intercambio de la montmorillonita formando una monocapa de complejos normal a la lámina del mineral arcilloso o como una doble capa de complejos planos; en ambos casos dando un espaciado interlaminar calculado de aproximadamente $\sim 10 \AA$.

\subsubsection{Análisis químico}

Los análisis químicos de las muestras estudiadas obtenidos por ICP y XRF se presentan en la Tabla 6.1. En la misma se observa que la bentonita (precursora de las AN) se compone principalmente de $\mathrm{SiO}_{2}(65,7 \% \mathrm{~m} / \mathrm{m})$ y $\mathrm{Al}_{2} \mathrm{O}_{3}(20,0$ $\% \mathrm{~m} / \mathrm{m}$ ). Los porcentajes de $\mathrm{Na}_{2} \mathrm{O}, \mathrm{K}_{2} \mathrm{O}$ y $\mathrm{CaO}$ corresponden a los cationes interlaminares del mineral arcilloso y a la presencia de feldespato, según lo indicado por el DRX de la muestra (Fig. 6.1a). Los aportes de $\mathrm{Fe}_{2} \mathrm{O}_{3}$ y $\mathrm{MgO}$ provienen de los reemplazos isomórficos del mineral arcilloso (Brigatti y col., 2013). La fórmula estructural de esta montmorillonita es $\left[\left(\mathrm{Si}_{3,94} \mathrm{Al}^{\mathrm{IV}}{ }_{0,06}\right)\left(\mathrm{Al}^{\mathrm{VI}}{ }_{1,36} \mathrm{Fe}_{0,06} \mathrm{Mg}_{0,60}\right) \mathrm{O}_{10}(\mathrm{OH})_{2}\right]$ (Vidal y Volzone, 2012). 
Tabla 6.1. Análisis químico de $\mathrm{B}, \mathrm{BOHAl}$ y $\mathrm{BOHZr}(\% \mathrm{~m} / \mathrm{m})$

\begin{tabular}{lcccccccccc}
\hline & $\mathbf{S i O}_{2}$ & $\mathbf{A l}_{2} \mathbf{O}_{3}$ & $\mathbf{F e}_{2} \mathbf{O}_{3}$ & $\mathrm{TiO}_{2}$ & $\mathbf{M g O}$ & $\mathbf{K}_{\mathbf{2}} \mathbf{O}$ & $\mathbf{C a O}$ & $\mathbf{N a}_{2} \mathbf{O}$ & $\mathbf{Z r O}_{2}$ & $\mathbf{A l}_{2} \mathrm{O}_{3} / \mathrm{SiO}_{2}$ \\
\hline B (ICP) & 65,7 & 20,0 & 1,5 & 0,3 & 6,6 & 0,8 & 1,6 & 3,4 & -- & 0,3 \\
BOHAI (ICP) & 59,8 & 30,5 & 1,5 & 0,3 & 6,0 & 0,6 & 0,6 & 0,6 & -- & 0,5 \\
BOHZr (XRF) & 61,7 & 20,4 & 1,2 & 0,3 & 5,8 & 0,5 & 0,4 & $<0,1$ & 9,6 & 0,3 \\
\hline
\end{tabular}

Los análisis químicos de $\mathrm{BOHZr}$ y $\mathrm{BOHAl}$ muestran una reducción en sus contenidos en $\mathrm{Na}_{2} \mathrm{O}, \mathrm{K}_{2} \mathrm{O}$ y $\mathrm{CaO}$ así como un aumento de $\mathrm{ZrO}_{2}$ y $\mathrm{Al}_{2} \mathrm{O}_{3}$, respectivamente. Esto es causado por el proceso de preparación de estas arcillas, en el cual los cationes interlaminares $\left(\mathrm{Na}^{+}, \mathrm{K}^{+}, \mathrm{Ca}^{2+}\right.$ principalmente) son intercambiados por especies poliméricas de $\mathrm{Zr}$ y Al (Vaughan y Lussier, 1980; Volzone y Garrido, 2001; Volzone y Hipedinger, 1999) puesto que los cationes con carga elevada resultan preferencialmente retenidos por intercambio iónico en el espacio interlaminar de la montmorillonita. La relación $\mathrm{Al}_{2} \mathrm{O}_{3} / \mathrm{SiO}_{2}$ confirma la mayor presencia de $\mathrm{Al}$ en la muestra $\mathrm{BOHAl}$

\subsubsection{Espectroscopia infrarrojo}

En la Fig. 6.4 se muestra el espectro de infrarrojo (IR) de la bentonita $B$ en condiciones de humedad relativa de $55 \%$.

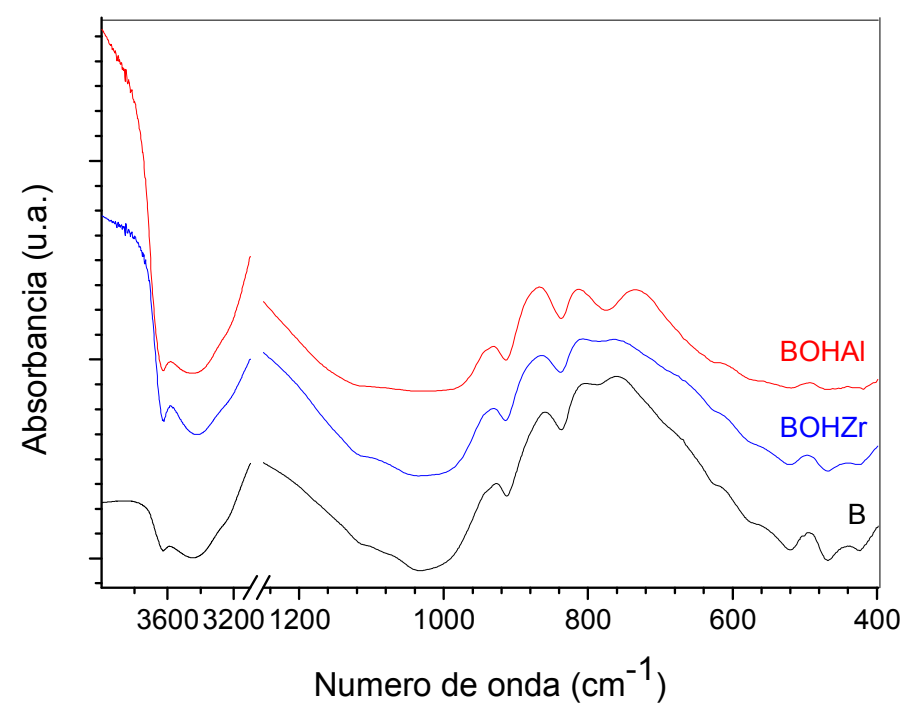

Fig. 6.4. Espectroscopia infrarroja de B, BOHAl y BOHZr 
La banda de absorción ubicada en el rango de $3620-40 \mathrm{~cm}^{-1}$ es típica de las esmectitas que poseen aluminio o magnesio en la capa octaédrica, siendo la especie característica $\mathrm{Al}_{2} \mathrm{OH} / \mathrm{Al}-\mathrm{Mg}-\mathrm{OH}$ (Farmer, 1968). Las características de los cationes de intercambio en cada esmectita natural (radio, carga, energía de hidratación) pueden influir en la posición de esta banda (Madejová, 2003)

Una banda alrededor de los $3440 \mathrm{~cm}^{-1}$ se observa en la misma y es atribuida a la vibración-stretching del enlace $\mathrm{H}-\mathrm{O}-\mathrm{H}$ del agua adsorbida en la esmectita. La banda a $1640 \mathrm{~cm}^{-1}$ también corresponde al agua adsorbida representando el modo vibración-bending del grupo $\mathrm{OH}$

La banda cercana a $1040 \mathrm{~cm}^{-1}$ corresponde al modo de vibración-stretching del enlace Si-O-Si con un hombro cercano a $1110 \mathrm{~cm}^{-1}$ asignado al stretching perpendicular del enlace Si-O (Ma y col., 2010). Las bandas observadas alrededor de $914 \mathrm{~cm}^{-1}\left(\mathrm{Al}_{2} \mathrm{OH}\right)$ y $837 \mathrm{~cm}^{-1}(\mathrm{Al}-\mathrm{Mg}-\mathrm{OH})$ corresponden a la región $\mathrm{OH}$ vibración bending y reflejan el reemplazo parcial del Al octaédrico por el $\mathrm{Mg}$ en la esmectita (Madejová, 2003). Finalmente, las bandas en $520 \mathrm{~cm}^{-1}$ y 467 $\mathrm{cm}^{-1}$ son generadas por la vibración tipo bending de las especies Si-O-Al y SiO-Si, respectivamente.

El análisis por IR permitió comprobar que las bandas se corresponden con esmectitas tipo montmorillonitas, debido a posiciones e intensidades relativas de las vibraciones stretching de $\mathrm{Si}-\mathrm{O}-\mathrm{Si}$ y bending de las uniones $\mathrm{Al}_{2} \mathrm{OH}, \mathrm{Al}-\mathrm{Mg}$ $\mathrm{OH}$, Si-O-Al y Si-O-Si.

El tratamiento con las especies poliméricas de $\mathrm{OH}-\mathrm{Al}$ y $\mathrm{OH}-\mathrm{Zr}$ no originó cambios relevantes en las bandas características de la montmorillonita, observándose solo un desplazamiento de la banda de 3440 a $3420 \mathrm{~cm}^{-1}$ luego del tratamiento con Zr. Sin embargo, la relación de las bandas $3440 / 3620$ se modificó, pasando de un valor de 0,38 en la muestra $B$ a 0,52 y 0,77 luego de las intercalaciones con $\mathrm{Zr}$ y Al respectivamente. Esto indicaría un mayor aporte de $\mathrm{OH}$ por parte de la especies Al respecto a las de $\mathrm{Zr}$. 


\subsubsection{Movilidad electroforética}

La variación de la movilidad electroforética de las partículas en suspensión en función del pH para la bentonita natural y las intercaladas se muestran en la Fig. 6.5 .

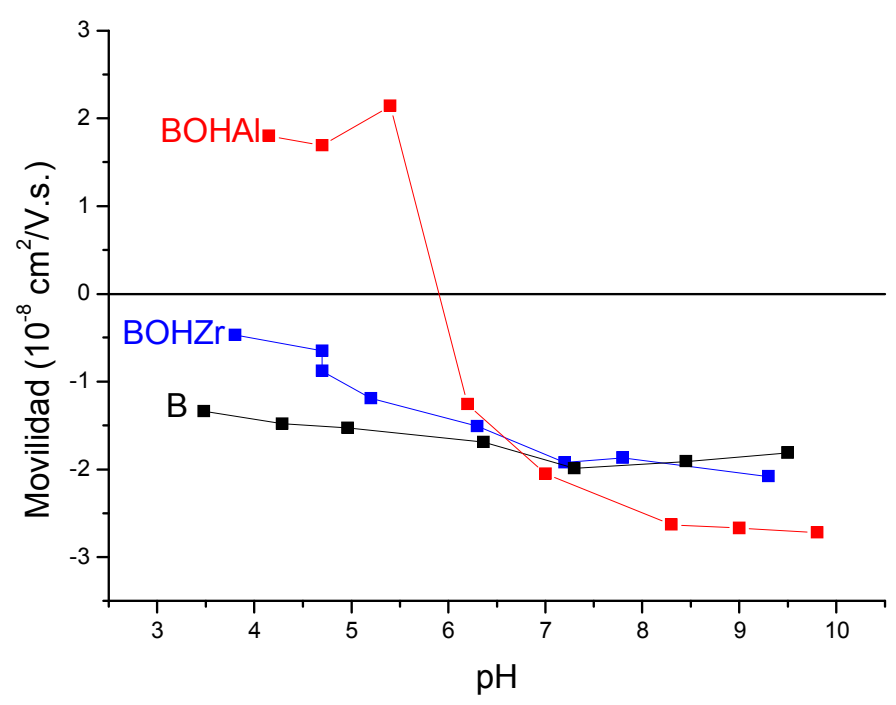

Fig. 6.5. Movilidad electroforética en suspensión de las muestras

Los valores para la bentonita $\mathrm{B}$ fueron negativos para todo el rango del $\mathrm{pH}$ estudiado (4-10,5), observando que su magnitud se vio ligeramente incrementada, de -1 a $-1.5 \times 10^{-8} \mathrm{~cm}^{2}(\mathrm{~V} . \mathrm{s})^{-1}$, con el aumento del pH. Este resultado demuestra que las partículas arcillosas poseen una carga (neta) negativa permanente, que está en concordancia con lo reportado para este tipo de arcillas (Avena y col., 1990; Delgado y col., 1986; Lagaly y Dékány, 2013; Martinez y col., 2017c). Esta carga negativa permanente es consecuencia del alto grado de sustitución isomórfica en la montmorillonita constituyente de la bentonita, como indica su formula estructural. Los iones $\mathrm{Al}^{3+}$ en la lámina

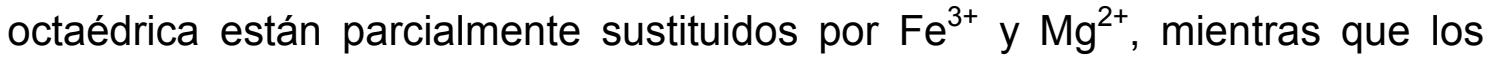
iones de $\mathrm{Si}^{4+}$ en la lámina tetraédrica están parcialmente sustituidos por $\mathrm{Al}^{3+}$. No obstante, a medida que el pH de la suspensión aumenta ocurre la neutralización progresiva de los grupos de silanol y $\mathrm{Al}-\mathrm{OH}_{2}{ }^{+}$localizados en los sitios expuestos de la superficie del borde de las partículas del mineral 
arcilloso, con lo que se produce un ligero aumento de la carga negativa superficial.

Las partículas de BOHAI mostraron un comportamiento marcadamente distinto al de la bentonita original. La movilidad electroforética exhibe valores positivos hasta $\mathrm{pH} 6$, donde la curva cambia abruptamente hacia valores negativos. En este caso, la movilidad electroforética nula está indicando la existencia de un punto isoeléctrico a $\mathrm{pH} \sim 6$. El punto isoeléctrico representa el $\mathrm{pH}$ donde la carga neta de la superficie de la partícula es neutra (Avena y col., 1990; Cleaves, 2011; Van Olphen, 1977), es decir que el número de sitios superficiales positivamente cargados es igual al número de sitios que presentan carga negativa. Este resultado muestra que las partículas de BOHAl desarrollan una carga superficial positiva entre $\mathrm{pH} 4$ y 6 , debido a la contribución de las especies poliméricas de $\mathrm{OH}-\mathrm{Al}$ intercaladas, las cuales adquieren carga positiva en medio ácido (Bottero y col., 1988).

A $\mathrm{pH}>6$, se observa que la movilidad electroforética se vuelve negativa; con una magnitud que aumenta gradualmente con el aumento del $\mathrm{pH}$. Esto se debe a que las especies de Al intercaladas son anfóteras, y debido a la reacción de asociación y disociación de $\mathrm{H}^{+}$con los grupos $\mathrm{OH}-\mathrm{Al}$, presentan una carga que es variable dependiendo del pH de la solución. Así, desarrollan carga positiva en medio ácido, la cual se neutraliza gradualmente con el aumento de pH. Este aporte adicional de carga negativa de las especies de Al en medio alcalino explica el aumento en magnitud de la movilidad electroforética negativa de BOHAl en comparación con la bentonita original (Avena y col., 1990).

La muestra $\mathrm{BOHZr}$ demostró un comportamiento similar al de la bentonita original; siendo su movilidad electroforética negativa para todo el rango de $\mathrm{pH}$ estudiado. Sin embargo, se observa que la movilidad es ligeramente más positiva a pH ácidos que el valor correspondiente para B. Tal como se describió anteriormente para $\mathrm{BOHAl}$, este comportamiento evidencia la adsorción de especies policatiónicas de $\mathrm{Zr}$ en el mineral arcilloso en el proceso de intercalación de la arcilla (Zhou y col., 2010). En tanto que movilidad se vuelve más negativa que la de $\mathrm{B}$ entre $\mathrm{pH} 8$ y 9,5 por el aporte de las especies poliméricas de $\mathrm{Zr}$, negativamente cargadas en medio alcalino. 


\subsubsection{Análisis térmico}

\subsubsection{Análisis térmico diferencial}

Las curvas obtenidas por ATD de las muestras estudiadas se observan en la Fig. 6.6.

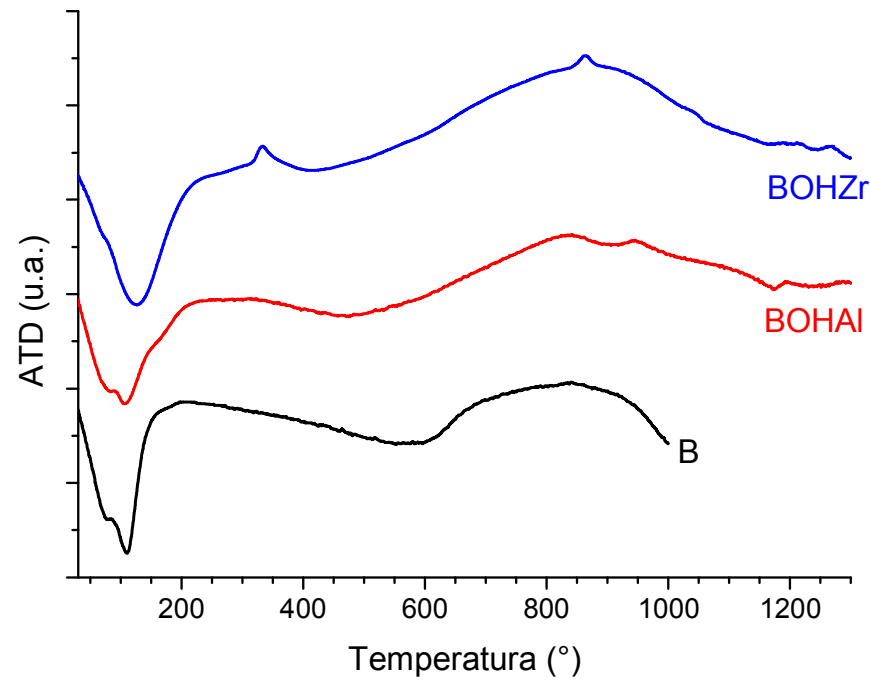

Fig. 6.6. Análisis térmicos diferenciales de $\mathrm{B}, \mathrm{BOHAl}$ y $\mathrm{BOHZr}$

Para la bentonita se aprecia la curva térmica característica de la montmorillonita que es el constituyente principal de dicha muestra, con dos picos endotérmicos centrados a $\sim 100{ }^{\circ} \mathrm{C}$ y $600{ }^{\circ} \mathrm{C}$, indicando la deshidratación y deshidroxilación de la estructura del mineral arcilloso respectivamente. Los picos endo-exotérmico (en forma de S) a $813-838^{\circ} \mathrm{C}$ (Fig. 6.6) se asocian al colapso de dicha estructura, acompañado con la aparición de nuevas fases cristalinas (Mackenzie y Caillere, 1979). Según (Grim y Kulbicki, 1961), la primera parte de estos picos corresponde a la pérdida del agua estructural de la montmorillonita que persiste hasta mayores temperaturas, pérdida que ocurre sin la destrucción de la red cristalina, mientras que el pico exotérmico al desarrollo de una nueva fase cristalina de cordierita y/o mullita.

La intercalación de las especies $\mathrm{OH}-\mathrm{Al}$ y $\mathrm{OH}-\mathrm{Zr}$ originó cambios importantes en la curva ATD de las muestras con respecto a la arcilla precursora. El primer pico endotérmico se ensanchó ligeramente, para ambas muestras, mientras que el segundo se desplazó a temperaturas más bajas $\left(480-500^{\circ} \mathrm{C}\right)$. Estas 
temperaturas menores se explican por la superposición de la reacción de deshidroxilación del mineral arcilloso y de las especies poliméricas intercaladas. La calcinación de las especies en el espacio interlaminar afecta la estabilidad térmica de los grupos $\mathrm{OH}$ de las capas de la montmorillonita (Gandía y col., 2005; Sun Kou y col., 1998). Algunos autores atribuyen la debilitación de la estructura del mineral arcilloso al $\mathrm{pH}$ ácido de las soluciones utilizadas para la preparación de ambas muestras. La acidez de la solución intercalante puede favorecer la protonación y disociación de grupos estructurales o disolución de la estructura de la montmorillonita con liberación de iones metálicos (Al, Mg) de la capa octaédrica (Sun Kou y col., 1998). Este efecto podría favorecer la deshidroxilación de la estructura de montmorillonita en las muestras intercaladas a menores temperaturas.

Varios autores (Aceman y col., 1997; Lussier y col., 1980) establecen que la deshidroxilación del ión Keggin $\left.\mathrm{Al}_{13} \mathrm{O}_{4}\left(\mathrm{OH}_{24}\right)\left(\mathrm{H}_{2} \mathrm{O}\right)_{12}\right)^{7+}$, también denominado $\mathrm{Al}_{13}$, comienza a $350{ }^{\circ} \mathrm{C}$. Con el aumento de la temperatura a $500-600{ }^{\circ} \mathrm{C}$ el policatión condensa con las láminas de montmorillonita (Aceman y col., 2000).

El ATD de la muestra BOHZr mostró además un pico exotérmico a los $360{ }^{\circ} \mathrm{C}$, probablemente asociado a la deshidroxilación de las especies intercaladas de $\mathrm{Zr}$.

Los cambios en el comportamiento térmico están asociados a la formación de enlaces químicos entre las especies poliméricas de $\mathrm{OH}-\mathrm{Al}$ y $\mathrm{OH}-\mathrm{Zr}$ con las capas de montmorillonita (Aceman y col., 2000; Sun Kou y col., 1998; Volzone y Garrido, 2001). Los picos en forma de S (endo-exotérmico) se aprecian con mayor intensidad para ambas muestras intercaladas, centrándose el pico exotérmico a mayores temperaturas $\left(865{ }^{\circ} \mathrm{C}\right.$ para $\mathrm{BOHZr}$ y $948{ }^{\circ} \mathrm{C}$ para $\mathrm{BOHAl}$ ). Estas modificaciones en el comportamiento térmico se asocian a la mayor estabilidad térmica de la estructura cristalina del mineral arcilloso intercalado con especies de $\mathrm{Al}$ y $\mathrm{Zr}$, las cuales se han convertido en óxidos durante el tratamiento térmico. La temperatura a la cual sucede esta reacción depende de la composición química y la estructura de las especies precursoras (Bergaya y col., 2006). Los picos exotérmicos observados a $>1000{ }^{\circ} \mathrm{C}$ están asociados a la formación de nuevas fases cristalinas. 


\subsubsection{Termogravimetría}

La Fig. 6.7. muestra las curvas termogravimétricas (TG) de B, BOHAl y BOHZr, es decir, las pérdidas de masa (\%) observadas por tratamiento térmico hasta $1000^{\circ} \mathrm{C}$.

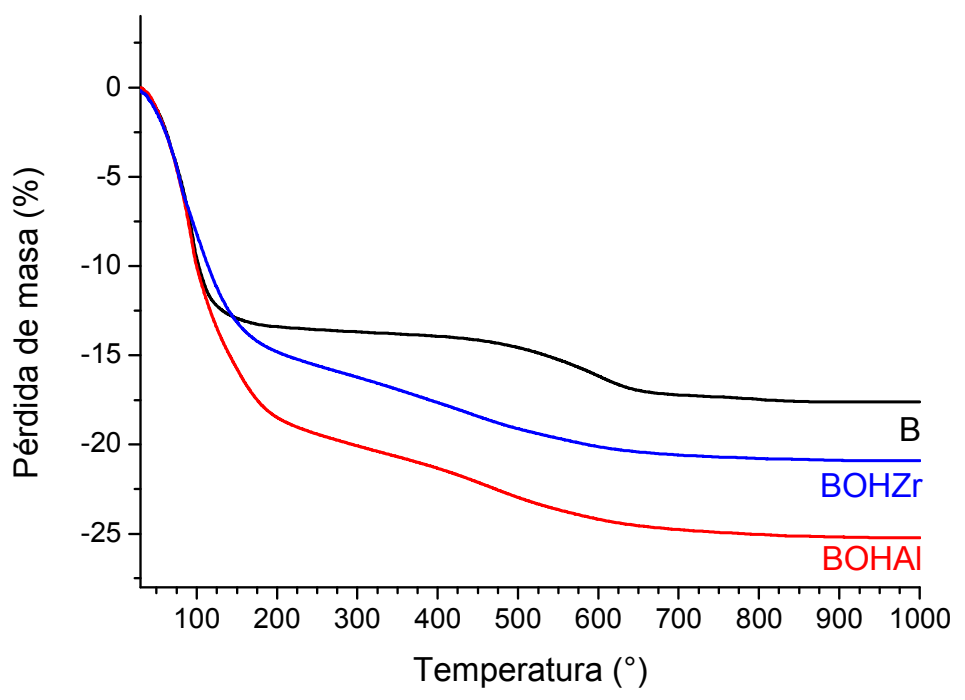

Fig. 6.7 Curvas termogravimétricas de $\mathrm{B}, \mathrm{BOHAl}$ y $\mathrm{BOHZr}$

La curva TG de B mostró una pérdida de masa de $13,3 \%$ hasta $200{ }^{\circ} \mathrm{C}$ atribuida a la pérdida de agua absorbida y al agua de hidratación de los cationes intercambiables tal como se mencionó anteriormente. La pérdida de masa de BOHAl y BOHZr, en el mismo rango de temperatura, fue $18,4 \%$ y $14,8 \%$, respectivamente. Estos valores, mayores que el determinado para B, están relacionados con las especies intercaladas, es decir; a las especies poliméricas de OH-Al y OH-Zr (De León y col., 2014; Volzone y Garrido, 2001), las cuales poseen un alto contenido de grupos $\mathrm{OH}^{-}$y moléculas de agua (Fig. 6.2 y 6.3) en comparación con los cationes interlaminares $\left(\mathrm{Na}^{+}, \mathrm{K}^{+}, \mathrm{Ca}^{2+}\right)$ de la bentonita original. La deshidratación-deshidroxilación de las especies poliméricas con el tratamiento térmico se refleja en estas mayores pérdidas de masa para las AN.

La eliminación de los oxidrilos estructurales para $B$, asociada a una pérdida de masa del $4,2 \%$, se produjo en un intervalo de temperatura relativamente estrecho $\left(500-700{ }^{\circ} \mathrm{C}\right)$ mientras que la deshidroxilación correspondiente a las 
muestras BOHAl y BOHZr, fue de 8,6 \% y 10,1 \%, y ocurrió de forma más gradual, en un intervalo más amplio de temperaturas $\left(200-700^{\circ} \mathrm{C}\right)$. No se registraron cambios de masa significativos por encima de $800^{\circ} \mathrm{C}$ en ninguna de las muestras. La pérdida de masa total hasta $1000^{\circ} \mathrm{C}$ para $\mathrm{B}, \mathrm{BOHAl}$ y $\mathrm{BOHZr}$ fue 17,$6 ; 25,2$ y $20,9 \%$, respectivamente.

\subsubsection{Microscopía de calentamiento}

En la Fig. 6.8 se presentan las curvas de $H_{r}$ (Altura relativa) versus temperatura, obtenidas por microscopía de calentamiento de las probetas preparadas con $\mathrm{B}$ y con las muestras intercaladas (BOHAl y $\mathrm{BOHZr}$ ) hasta $1300^{\circ} \mathrm{C}$. En la misma se puede observar una clara semejanza entre las curvas hasta los $800^{\circ} \mathrm{C}$ para los tres materiales.
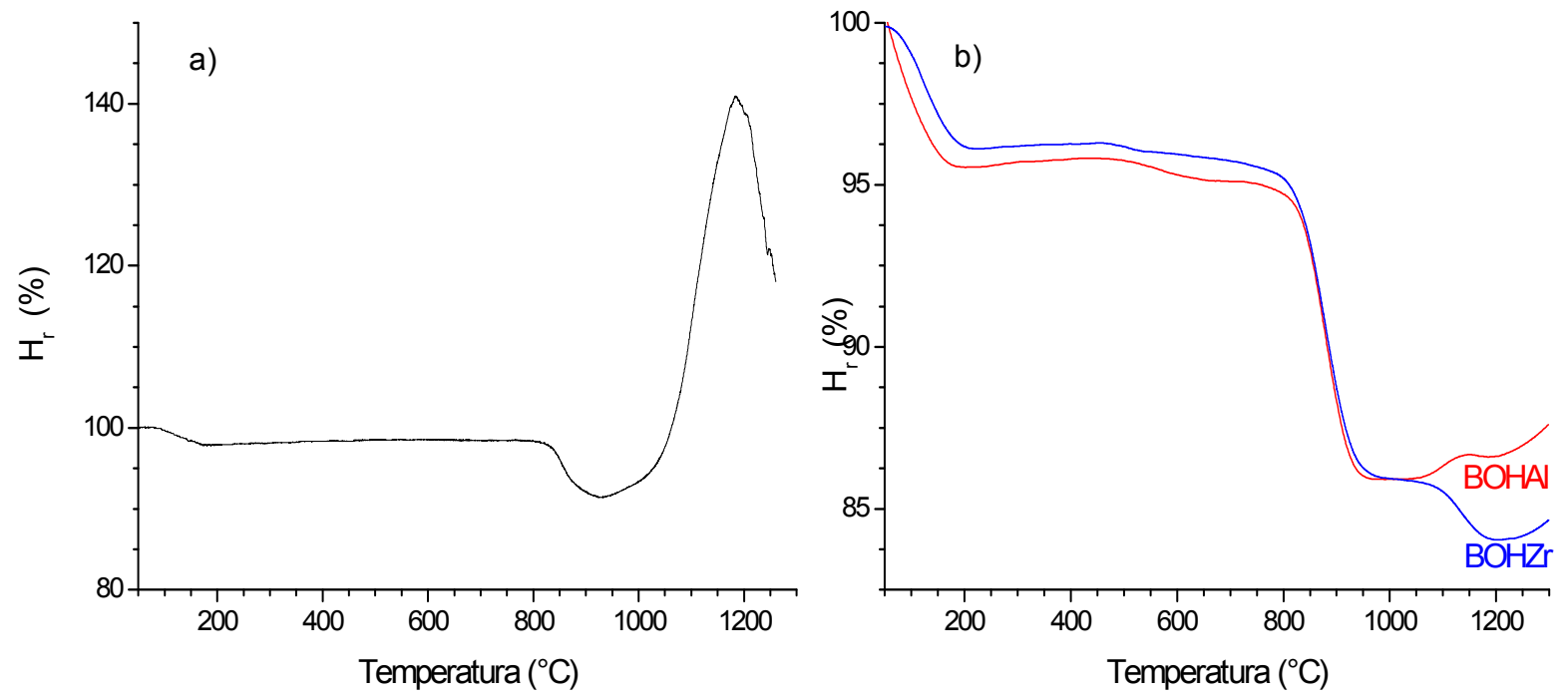

Fig.6.8. Evolución de $H_{r}$ vs temperatura de probetas preparadas con a) $B$, b)

BOHAl y BOHZr, registrado por microscopía de calentamiento

La bentonita $B$ presenta una reducción de $\mathrm{H}_{r}$ (contracción) de aproximadamente $3 \%$ hasta $200{ }^{\circ} \mathrm{C}$ que se asocia a la pérdida de agua absorbida del mineral arcilloso. No se determinaron cambios de dimensión adicionales hasta los $800{ }^{\circ} \mathrm{C}$. A partir de esta temperatura se observa el comienzo de una rápida contracción, que aumenta hasta un valor de $\mathrm{H}_{\mathrm{r}}$ de 90,0 $\%$ a $930{ }^{\circ} \mathrm{C}$, contracción atribuible al colapso estructural de la montmorillonita y al comienzo de la sinterización. A temperaturas superiores a $930{ }^{\circ} \mathrm{C}$ se observa 
un proceso de expansión hasta $1200{ }^{\circ} \mathrm{C}$, temperatura a la cual comienza un descenso del valor de $\mathrm{Hr}$.

Para las muestras intercaladas ( $\mathrm{BOHZr}$ y $\mathrm{BOHAl})$ se aprecia una contracción inicial de $5 \%$ a temperaturas bajas (similar a la de $B$ ); que se intensifica a partir de $800{ }^{\circ} \mathrm{C}$ llegando al $10 \%$ para $1000{ }^{\circ} \mathrm{C}$. Los valores $\mathrm{H}_{\mathrm{r}}$ correspondientes a la contracción máxima a $1200{ }^{\circ} \mathrm{C}$ son similares $(84,1 \%$ para $\mathrm{BOHZr}$ y $86,8 \%$ para $\mathrm{BOHAl}$ ). El análisis de las curvas de las muestras intercaladas y sus respetivas derivadas con respecto a la temperatura (Fig. 6.9) confirma que las mismas poseen una primera etapa de contracción más acentuada entre 800 y $1000{ }^{\circ} \mathrm{C}$.

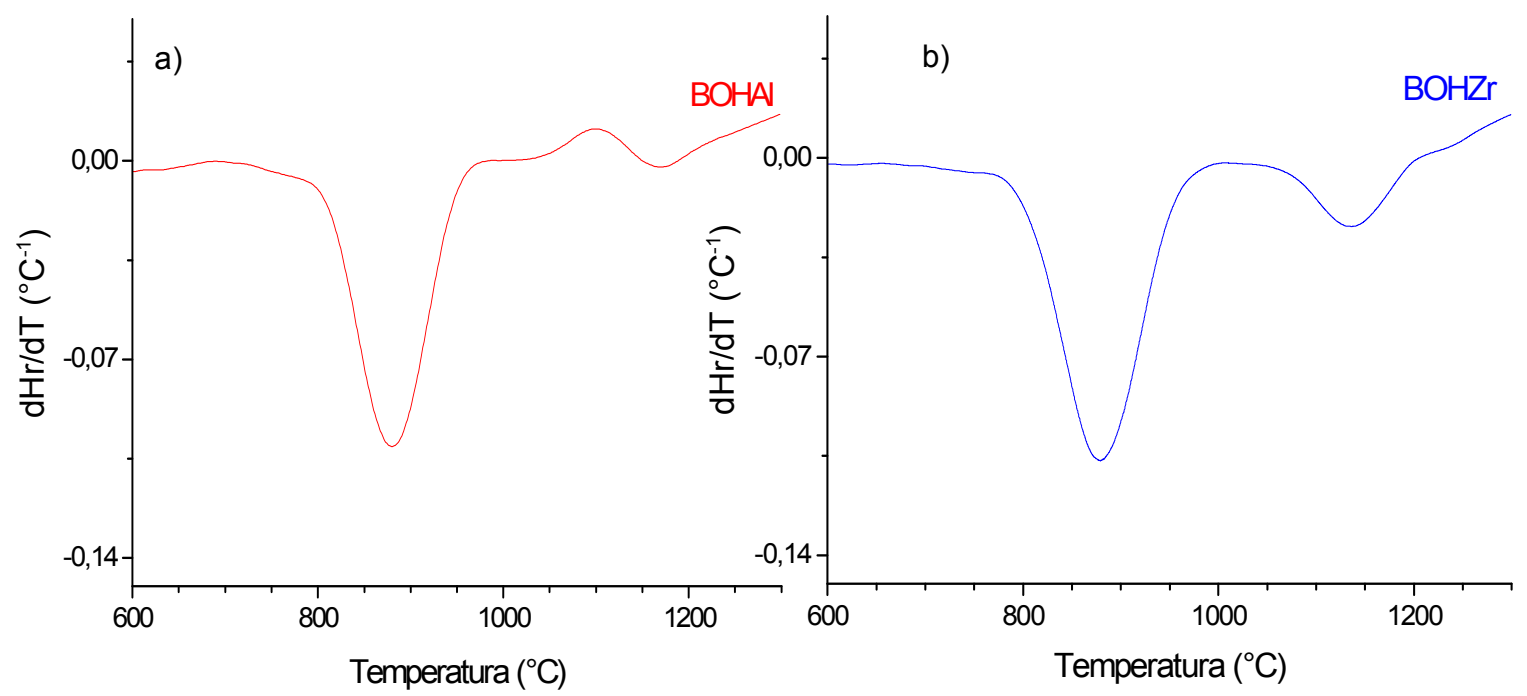

Fig. 6.9. Derivadas de curvas de sinterización de a) BOHAl y b) $\mathrm{BOHZr}$

Dichas curvas, que reflejan la velocidad a la cual las muestras se contraen o se expanden, en este caso permiten observar más claramente los efectos que suceden a elevadas temperaturas. Para $\mathrm{BOHZr}$, la curva a mayores temperaturas posee una segunda etapa de contracción (sinterizado), alcanzando $\mathrm{Hr} 84 \%$, mientras que la muestra BOHAl se expande ligeramente entre los $1100-1200{ }^{\circ} \mathrm{C}$, y así la relación $\mathrm{Hr}$ experimental sólo fue de 87,5 \%.

El análisis de las curvas termogravimétricas para ambas muestras en este rango de temperatura no revelo pérdida de masa (Fig. 6.7.), de modo que la diferencia de comportamiento de las muestras intercaladas entre 1000 y 1200 
${ }^{\circ} \mathrm{C}$ se puede atribuir a la combinación (o superposición) de varios fenómenos tales como la destrucción estructural, el inicio de la formación de nuevas y diferentes fases cristalinas, así como a la formación de cantidades diferentes de fase líquida dado que pueden actuar en forma simultánea. En ese sentido, estudios previos (Speyer, 1993) indican que la reacción de formación de mullita que ocurre a esas temperaturas es expansiva y por eso la muestra BOHAl se seguiría expandiendo.

Observando las imágenes donde se muestra la evolución de la sección de las probetas cilíndricas con la temperatura durante el ensayo (Tabla 6.2), se denota que las muestras intercaladas conservan su forma hasta la máxima temperatura de ensayo de $1300{ }^{\circ} \mathrm{C}$. Por otra parte, la muestra B a $1200{ }^{\circ} \mathrm{C}$ experimentó un proceso de expansión con posterior esferización. Panna y col. (2016) observaron comportamientos similares para arcillas con alto contenido de esmectita, asociando este comportamiento a la formación de líquido por el tratamiento térmico a alta temperatura de este mineral. Las temperaturas $>900$ ${ }^{\circ} \mathrm{C}$ contribuyen al desarrollo de una fase líquida rica en sílice de alta viscosidad, la cual tiene la capacidad de retener aire generado durante el sinterizado del material, produciendo la expansión del mismo ("bloating"). Un aumento de temperatura produce la disminución de la viscosidad de la fase líquida, lo cual conlleva al escape de los gases generados, y el colapso de la estructura y, a mayores temperaturas, la fusión completa del material. 
Tabla 6.2 Evolución de la sección transversal de muestras de B, BOHAl y $\mathrm{BOHZr}$ durante el tratamiento térmico en microscopio de calentamiento

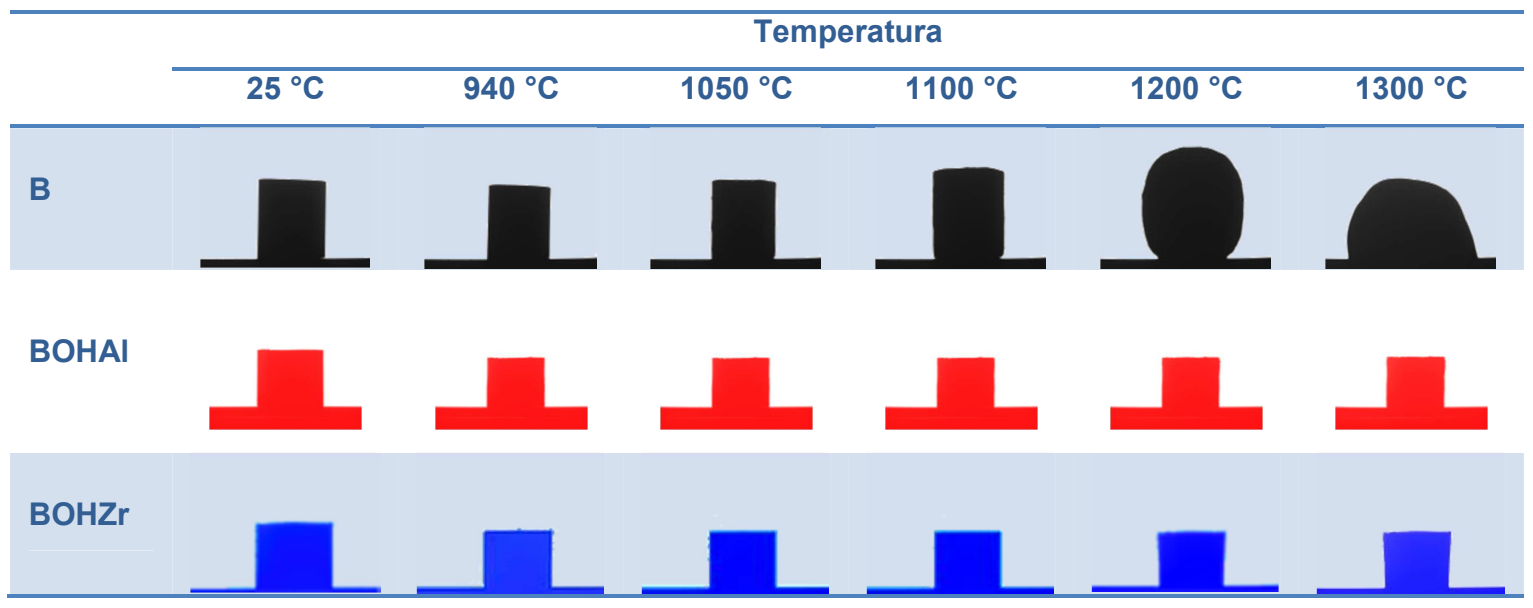

Esta formación de fase líquida, la cual vitrifica durante el enfriamiento a temperatura ambiente, imposibilita el uso de B para el conformado de piezas por sinterizado a altas temperaturas, ya que las mismas se deforman a temperaturas mayores a $1050{ }^{\circ} \mathrm{C}$, como se observa en la Tabla 6.2. Sin embargo, el proceso de intercalado dio a la estructura cristalina de la arcilla una mayor estabilidad térmica, posibilitando el uso de este tipo de material en el conformado de compositos por sinterización a alta temperatura.

Comparando la composición química (Tabla 6.1), se observa un enriquecimiento en $\mathrm{Al}$ y $\mathrm{Zr}$, cuyos óxidos poseen altos puntos de fusión $\left(\mathrm{Al}_{2} \mathrm{O}_{3}\right.$, $\left.\mathrm{ZrO}_{2}\right)$ y la reducción notable del contenido de óxidos fundentes $\left(\mathrm{Na}_{2} \mathrm{O}, \mathrm{K}_{2} \mathrm{O}\right.$, $\mathrm{CaO}$ ) debido a la reacción de intercambio con las especies policatiónicas, que deriva en una mayor estabilidad térmica de las muestras.

\subsubsection{Consideraciones parciales}

$\checkmark$ Se determinó por DRX que la bentonita utilizada como materia prima se compone principalmente de esmectita acompañada de escaso contenido de cuarzo y feldespato. Composición química y formula estructural similares a la de montmorillonita rica en $\mathrm{Mg}$ (tipo Cheto)

$\checkmark$ Se sintetizaron arcillas nanoestructuradas modificadas con aluminio (BOHAl) y con zirconio (BOHZr) como precursores de compositos cerámicos, por intercalación (reacción de intercambio iónico) de la 
especies alumínicas y polímeros de zirconio en la montmorillonita. EI AQ verificó la retención de policationes de aluminio o de zirconio en AN y el reemplazo de los cationes intercambiables resultando un material calcinado con $30.5 \%$ de $\mathrm{Al}_{2} \mathrm{O}_{3}$ y $9.6 \% \mathrm{ZrO}_{2}$, respectivamente. Dichas especies alumínicas y de zirconio se ubican en el espacio interlaminar de la esmectita.

$\checkmark$ El estudio estructural por IR de la bentonita, B, indicó presencia de bandas características de montmorillonita. La modificación de $\mathrm{B}$ con especies $\mathrm{OH}-\mathrm{Al}$ y $\mathrm{OH}-\mathrm{Zr}$ no originó cambios relevantes en la estructura de la montmorillonita, a excepción de un pequeño aumento de la banda a $3440 \mathrm{~cm}^{-1}$ indicando mayor aporte de $\mathrm{OH}^{-}$por las especies intercaladas.

$\checkmark$ La movilidad electroforética de ambas BOHAl y BOHZr indicó la retención de especies catiónicas. Los resultados mostraron que las partículas de BOHAl desarrollan una carga superficial positiva entre $\mathrm{pH} 4$ y 6 , debido a la contribución de carga positiva que adquieren las especies poliméricas de $\mathrm{OH}-\mathrm{Al}$ intercaladas en medio ácido. La muestra $\mathrm{BOHZr}$ presentó movilidad electroforética negativa para todo el rango de $\mathrm{pH}$ estudiado aunque de magnitud levemente menor (carga superficial más positiva) que la de esmectita original.

Los ATD/TG mostraron dos picos endotérmicos característicos de la deshidratación en dos etapas y de la deshidroxilación a entre 700 y 800 ${ }^{\circ} \mathrm{C}$, y un efecto endo -exotérmico a $\sim 840{ }^{\circ} \mathrm{C}$ típicos de la esmectita. En BOHAl y BOHZr (AN intercaladas) la deshidroxilación fue progresiva y ocurre a menores temperaturas. La deshidratación-deshidroxilación de las especies poliméricas con el tratamiento térmico se reflejó en mayores pérdidas total de masa para las $\mathrm{AN}$ con respecto a la $\mathrm{B}$ original. En ambas muestras el pico endo-exotérmico se observó a mayor temperatura ( 880 y $945{ }^{\circ} \mathrm{C}$ ) asociado a la formación de nuevas fases y resultó más definido en $\mathrm{BOHZr}$. En esta última se distinguió un pico 
exotérmico a $360{ }^{\circ} \mathrm{C}$ atribuido a la deshidroxilación de las especies intercaladas.

$\checkmark$ La microscopia de calentamiento demostró que piezas de B se contraen y se deforman a temperaturas mayores de $1050{ }^{\circ} \mathrm{C}$ debido a la formación de fase líquida, en tanto que la intercalación dio a la estructura cristalina de la arcilla una mayor estabilidad térmica, posibilitando el uso de este tipo de material en el conformado de compositos por sinterización hasta $1300{ }^{\circ} \mathrm{C}$. Este comportamiento se explicaría por el enriquecimiento de óxidos/compuestos con altos puntos de fusión $\left(\mathrm{Al}_{2} \mathrm{O}_{3}, \mathrm{ZrO}_{2}\right)$ y la reducción notable del contenido de óxidos fundentes $\left(\mathrm{Na}_{2} \mathrm{O}, \mathrm{K}_{2} \mathrm{O}, \mathrm{CaO}\right)$ debido a la reacción de intercambio con las especies policatiónicas. 


\subsection{Propiedades de cerámicos obtenidos a partir de ANs naturales y modificadas (B, BOHAl y BOHZr).}

En el presente apartado se estudia el comportamiento térmico de la AN natural (B), así como de las AN modificadas con policationes de $\mathrm{Al}$ (BOHAl) y $\mathrm{Zr}$ $(\mathrm{BOHZr})$.

Para ello, se trató térmicamente polvos de las mismas a distintas temperaturas entre los 1000-1300 ${ }^{\circ} \mathrm{C}$, analizando la influencia de la temperatura de calcinación en las fases cristalinas desarrolladas por DRX y espectroscopia IR. Esto se incluye en el inciso 6.2.1.

En el inciso 6.2.2 se examina la influencia del precalcinado de las ANs y de la molienda en molino planetario de las mismas en las propiedades de cerámicos preparadas por sinterizado de polvos de AN compactados por prensado uniaxial. La reducción del tamaño de partícula de las ANs fue evaluado por la medida de su distribución de tamaño partícula (ver inciso 4.9.). Se analizó la influencia del tratamiento térmico por microscopía de calentamiento, difracción de rayos X y SEM. Asimismo, se midió la porosidad y densidad aparente de los cerámicos obtenidos por el método de Arquímedes (ver inciso 4.10.), así como la dureza Vickers de los mismos, comparando los valores obtenidos de agentes de sostén cerámicos en la bibliografía consultada.

\subsubsection{Composición de fases a diferentes temperaturas}

\subsubsection{Difracción de rayos $X$}

Las transformaciones de fase a alta temperatura de la montmorillonita presentan grandes variaciones dependiendo de la composición y estructura del mineral original. La presencia de impurezas (y su concentración) ejercen una influencia importante en la formación de fases y su evolución con el tratamiento térmico.

Los resultados sobre el efecto del tratamiento térmico entre 1000 y $1300^{\circ} \mathrm{C}$ en los difractogramas de B (Fig. 6.10) indican que no se observan reflexiones de montmorillonita, debido a que de acuerdo a los ATD (ítem 6.1.5) y lo previamente reportado por Grim y Kulbicki (1961) la estructura de este mineral 
arcilloso colapsa y se deshidroxila a $850-900{ }^{\circ} \mathrm{C}$, alterando irreversiblemente la estructura de la lámina.

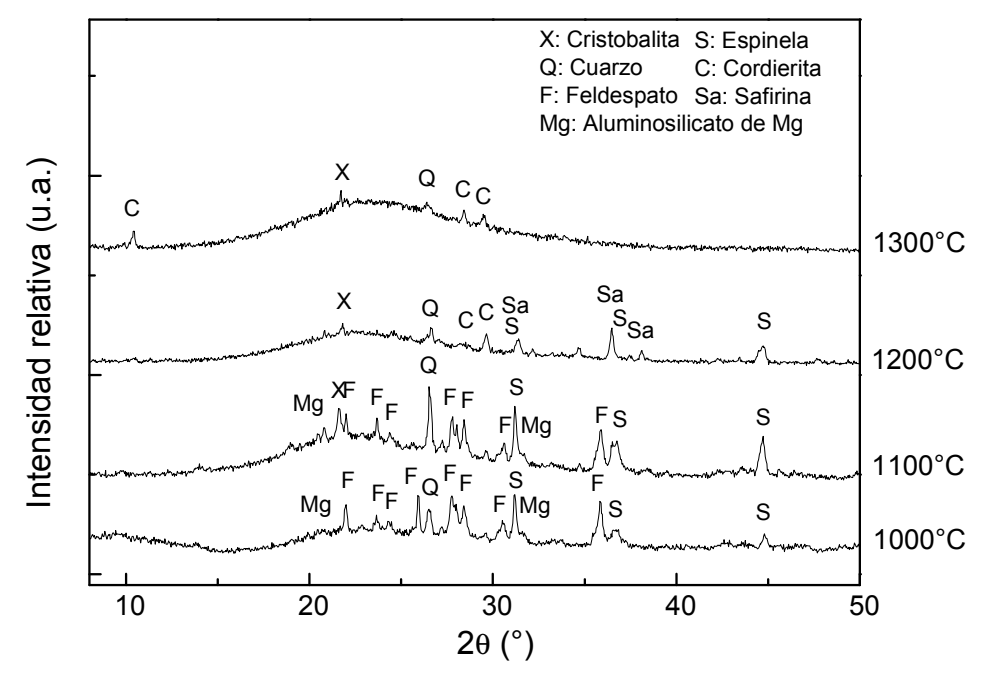

Fig. 6.10. Difractogramas de B calcinada entre 1000 y $1300^{\circ} \mathrm{C}$.

El aumento de temperatura de calcinación causó el crecimiento de una banda ancha centrada a alrededor de los $22^{\circ} 2 \Theta$. La intensidad de la misma está asociada al desarrollo de una fase amorfa (no cristalina) rica en sílice (Gavin y col, 2013), corroborando así la presencia de la fase líquida a altas temperaturas. Esta fase amorfa se origina a partir de la fase líquida presente a elevada temperatura durante el enfriamiento desde la temperatura de calcinación.

A $1000^{\circ} \mathrm{C}$ se formaron nuevas fases cristalinas, entre ellas aluminosilicato de magnesio $\left((\mathrm{Mg}, \mathrm{Al}) \mathrm{SiO}_{3}\right)$ y espinela $\left(\mathrm{MgAl}_{2} \mathrm{O}_{4}\right)$; con pequeñas cantidades de cuarzo y feldespato (presentes en la bentonita original Fig. 6.1.a). A $1100{ }^{\circ} \mathrm{C}$, la intensidad de los picos de feldespato disminuye, en tanto aumenta la intensidad de los picos de espinela y la formación de cristobalita $\left(\mathrm{SiO}_{2}\right)$. A $1200{ }^{\circ} \mathrm{C}$ desaparecieron las reflexiones del feldespato, y se observa el desarrollo de nuevas fases de safirina $\left(\left(\mathrm{Al}_{5} \mathrm{Mg}_{4}\right)\left(\mathrm{Al}_{4} \mathrm{Si}_{2}\right) \mathrm{O}_{20}\right)$ y cordierita $\left(\mathrm{Mg}_{2} \mathrm{Al}_{4} \mathrm{Si}_{5} \mathrm{O}_{18}\right)$.

Estas transformaciones de fases y la evolución de las fases con la temperatura han sido discutidas previamente. En montmorillonitas con alto contenido de $\mathrm{Mg}$ en su capa octaédrica, generalmente tiene lugar la formación de cristobalita por 
calcinación a $1100^{\circ} \mathrm{C}$ (Grim y Rowland, 1942). Esta fase se desarrolla rápidamente en tanto que el cuarzo desaparece a medida que aumenta la formación de cristobalita. Con estas montmorillonitas ricas en $\mathrm{Mg}$ se origina cordierita entre 1200 y $1300{ }^{\circ} \mathrm{C}$. La montmorillonita utilizada en la presente tesis corresponde a este tipo.

En ciertas esmectitas con mayor contenido de Al se ha observado el desarrollo simultáneo de cristobalita y mullita por calcinación a 1100-1150 ${ }^{\circ} \mathrm{C}$ (Grim y Kulbicki, 1961). La calcinación a mayores temperaturas favorece el incremento continuo de estas fases, las cuales permanecen hasta $1400-1500^{\circ} \mathrm{C}$, donde ocurriría la fusión del material.

En la Fig. 6.11 se muestran los difractogramas de la muestra BOHAl tratada térmicamente entre 1000 y $1300^{\circ} \mathrm{C}$.

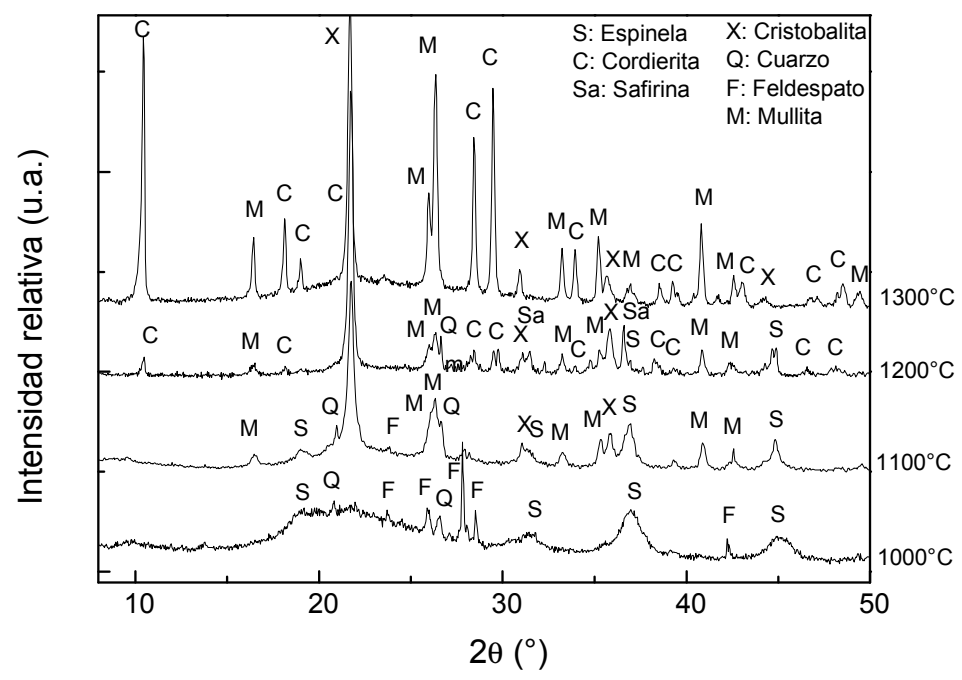

Fig. 6.11. Difractogramas de BOHAl calcinada entre 1000 y $1300{ }^{\circ} \mathrm{C}$

Como principal diferencia respecto a la bentonita, B, se observa que en esta muestra calcinada a $1000{ }^{\circ} \mathrm{C}$ ocurre la formación de espinela en tanto no se detecta aluminosilicato de magnesio. A $1100{ }^{\circ} \mathrm{C}$, se observa la aparición de picos correspondientes a la fase mullita $\left(26,2^{\circ} 2 \theta\right)$ y un crecimiento importante de los picos de la cristobalita. Así como en la bentonita sin tratar, a $1200{ }^{\circ} \mathrm{C}$ desaparecen los picos de feldespato. En este caso, se aprecia la formación de cordierita y safirina, y continúa aumentando la intensidad de los picos de mullita mientras que se reducen los de espinela. A $1300{ }^{\circ} \mathrm{C}$, se intensifica el 
crecimiento de los picos correspondientes a mullita, convirtiéndose en la fase mayoritaria, siendo las fases restantes cristobalita y cordierita.

Se resalta el hecho de que, si bien existe una banda correspondiente a la fase amorfa, su intensidad se reduce con el aumento de la temperatura hasta 1200 ${ }^{\circ} \mathrm{C}$, inversamente a lo observado para la bentonita sin tratar.

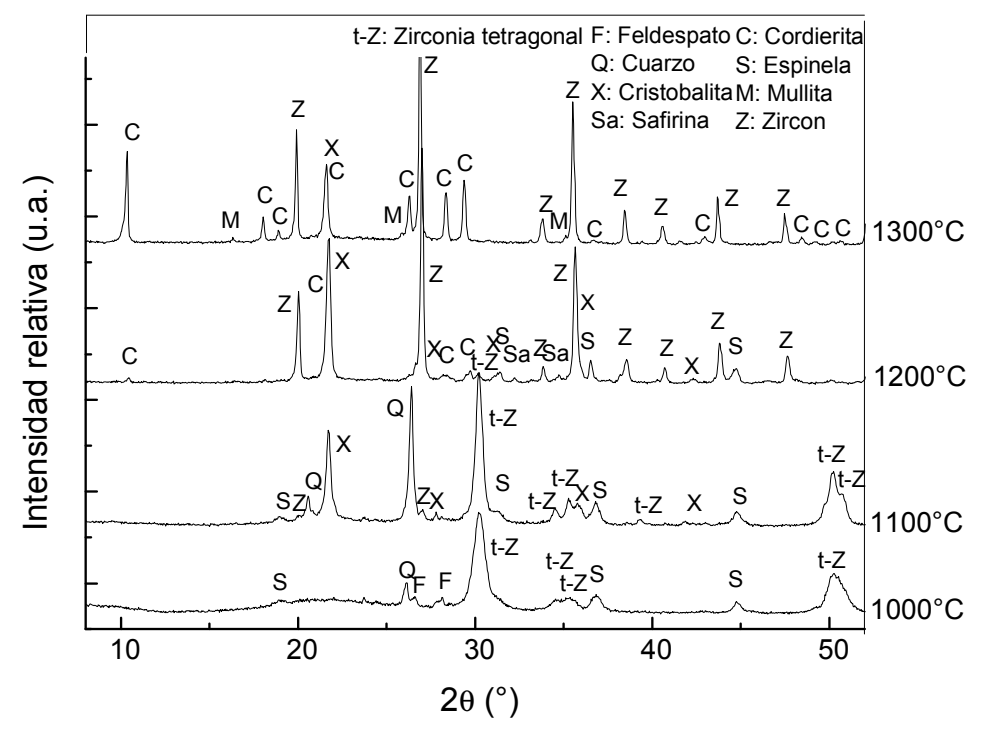

Fig. 6.12 DRX de BOHZr calcinada a diferentes temperaturas

Las fases cristalinas presentes en $\mathrm{BOHZr}$ calcinada a $1000{ }^{\circ} \mathrm{C}$ son cuarzo, feldespato y espinela (Fig. 6.12), comparables con la bentonita original. Se destaca el importante desarrollo de óxido de zirconio en fase tetragonal (t$\mathrm{ZrO}_{2}$ ), fase de interés por su uso en cerámicos tenaces (Basu, 2005). Igualmente que en BOHAI, no se determinó la presencia de aluminosilicato de magnesio observado en la bentonita original.

En el difractograma de $\mathrm{BOHZr}$ tratada térmicamente a $1100{ }^{\circ} \mathrm{C}$ se observan bajas intensidades en las reflexiones de cuarzo, cristobalita y espinela, y no se identifican los picos de feldespato. Respecto a las fases cristalinas con contenido de $\mathrm{Zr}$, se observó un aumento en la intensidad de los picos de $\mathrm{t}-\mathrm{ZrO}_{2}$, y además se distinguen picos correspondientes a Zircón $\left(\mathrm{ZrSiO}_{4}\right)$. Esta fase es reconocida por sus buenas propiedades mecánicas, alta resistencia al choque térmico y buenas propiedades químicas (Garrido y Aglietti, 2001). Del mismo modo que en $\mathrm{BOHAl}$, en los difractogramas de $\mathrm{BOHZr}$ se observó una 
reducción de la banda centrada a los $22^{\circ} 2 \Theta$ a partir de la calcinación a 1100 ${ }^{\circ} \mathrm{C}$, indicando la mayor cristalinidad de las muestras intercaladas respecto a la bentonita original.

El difractograma de $\mathrm{BOHZr}$ calcinada a $1200{ }^{\circ} \mathrm{C}$ presenta principalmente las reflexiones de zircón y cristobalita. Un aspecto interesante respecto a las fases conteniendo $\mathrm{Zr}$ es que los picos de Zircón se volvieron más intensos a expensas de la reducción de intensidad de los picos de Zirconia. El tratamiento térmico produjo también la aparición de safirina y escasa cordierita, aunque no se observaron picos correspondientes al cuarzo. La muestra también conservó una cristalinidad mayor respecto a la arcilla precursora (i.e.: menor cantidad de fase amorfa) y respecto a las muestras de $\mathrm{BOHZr}$ tratadas a menor temperatura. Probablemente el silicio presente en la fase amorfa haya dado paso a la formación de Zircón $\left(\mathrm{ZrSiO}_{4}\right)$ por reacción con el $\mathrm{Zr}$ incorporado en la muestra, explicando así el aumento de la intensidad de los picos de Zircón, así como la disminución en intensidad de los picos de $\mathrm{t}-\mathrm{ZrO}_{2}$ y del contenido de fase amorfa.

A $1300{ }^{\circ} \mathrm{C}$, se intensificaron los picos de zircón y cordierita, a expensas de la desaparición de los picos de espinela y safirina (compuestos con $\mathrm{Mg}$ ), indicando que la formación de cordierita tiene lugar a expensas de estas fases, y de cristobalita. Se observó la aparición de picos muy pequeños asociados a un bajo contenido de mullita.

\subsubsection{Espectroscopia de Infrarrojo}

En la Fig. 6.13 se muestran los espectros IR de las muestras de AN posterior al tratamiento térmico a 1000,1100 y $1200{ }^{\circ} \mathrm{C}$. 

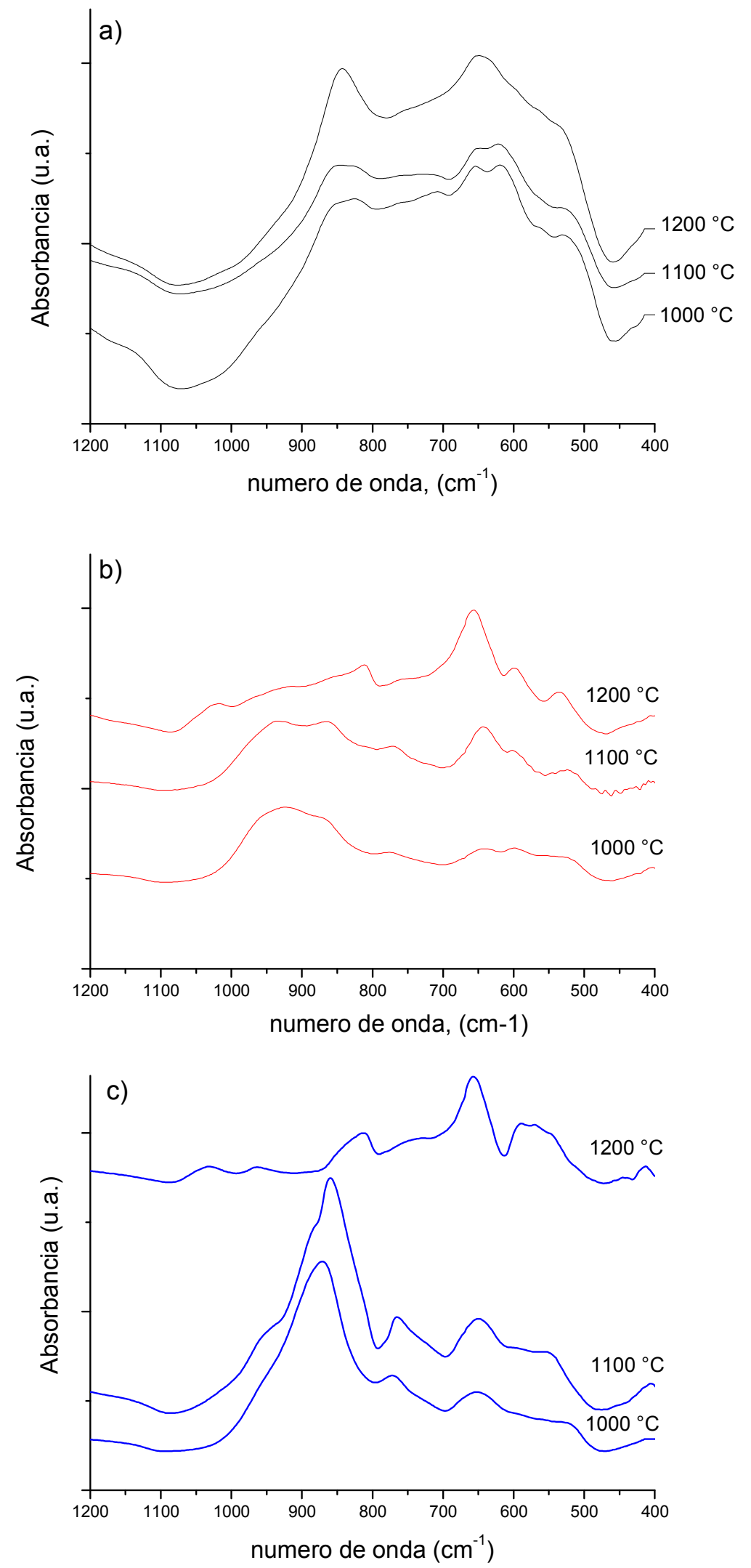

Fig. 6.13 Espectro IR de ANs a) B, b) BOHAl y c) BOHZr calcinadas a 1000,

$$
1100 \text { y } 1200^{\circ} \mathrm{C}
$$


El tratamiento térmico a 1000,1100 y $1200^{\circ} \mathrm{C}$ de la bentonita ha provocado un cambio importante en el espectro de IR (Fig. 6.13a) respecto a su condición natural (Fig. 6.4). Las bandas propias del mineral arcilloso montmorillonita han desaparecido. Por tratamiento térmico a $1000^{\circ} \mathrm{C}$ se hacen intensas las bandas de Si-O-Si $\left(1074,780\right.$ y $455 \mathrm{~cm}^{-1}$ ) y el tratamiento hasta $1200{ }^{\circ} \mathrm{C}$ se hacen más intensas bandas de uniones del tipo Al-O: 840 (hombro), 790, 740, 620 y 550 $\mathrm{cm}^{-1}$, atribuidas a nuevas fases originadas de acuerdo a los análisis por DRX (espinelas, safirinas). La Fig. 6.13b, correspondiente a las muestras BOHAI calcinadas marcan diferencia entre el IR respecto a la bentonita sin tratamiento con aluminio (Fig. 6.4.), en donde las bandas a 700, 620 y $557 \mathrm{~cm}^{-1}$ incrementan a $1000^{\circ} \mathrm{C}$, atribuido fundamentalmente a la presencia de espinela, en tanto que luego del tratamiento a 1100 y $1200{ }^{\circ} \mathrm{C}$ se hacen evidentes bandas propias de la mullita $557,620,740,850 \mathrm{~cm}^{-1}$, correspondiente a bending $\mathrm{Al}-\mathrm{O}\left(\mathrm{AlO}_{6}\right)$, bending $\mathrm{O}-\mathrm{Al}-\mathrm{O}\left(\mathrm{AlO}_{4}\right)$; bending $\mathrm{Al}-\mathrm{O}\left(\mathrm{AlO}_{4}\right)$, stretching $\mathrm{Al}-$ $\mathrm{O}\left(\mathrm{AlO}_{4}\right)$, respectivamente. (Dietmar y col., 2001).

La intercalación de especies de $\mathrm{OH}-\mathrm{Zr}$ en la montmorillonita con posterior tratamiento a $1000{ }^{\circ} \mathrm{C}$ y $1100{ }^{\circ} \mathrm{C}$ evidenció en el espectro IR de la misma (Fig. 6.13.c), bandas características de zirconia tetragonal $\left(695,466 \mathrm{~cm}^{-1}\right)$. Con el tratamiento a $1200{ }^{\circ} \mathrm{C}$ pudo observarse una marcada diferencia debido a la aparición de bandas propias de zircón $\left(400,431,471\right.$ y $\left.900 \mathrm{~cm}^{-1}\right)$.

\subsubsection{Comportamiento dilatométrico, propiedades microestructurales, físicas y dureza.}

A fin de estudiar comportamiento a la sinterización de BOHAl y $\mathrm{BOHZr}$, se prepararon piezas cerámicas tras un proceso de acondicionamiento de las muestras consideradas. Como fuera explicado en el inciso anterior, la bentonita y las AN derivadas experimentaron una fuerte contracción por la deshidratación y deshidroxilación durante el calentamiento (ver inciso 6.1.5). Este comportamiento puede ser perjudicial para la obtención de cerámicos densos, favoreciendo el desarrollo de una alta porosidad y/o defectos como agrietamiento durante el sinterizado.

Varios aspectos adquieren particular relevancia en el conformado por vía seca de cerámicos y materiales granulares, donde se debe tener en cuenta la 
influencia de distintas variables que son determinantes de las propiedades del cerámico resultante. En particular, la distribución granulométrica del material en polvo se vuelve relevante en la formación de un recubrimiento en seco. En función de diseñar y/o mejorar la resistencia a la compresión de lechos granulares, algunos autores (Koseski, 2008; Luscher y col., 2006) resaltan la importancia de medidas de propiedades mecánicas de los materiales constituyentes, como la dureza y la tenacidad, a fin de predecir y explicar el comportamiento del lecho de pellets frente a la compresión, como el caso del ensayo de resistencia al crush según norma API 19C.

A fin de optimizar el proceso de sinterización y disminuir la porosidad de los cerámicos, se estudió el efecto de la precalcinación a baja temperatura de $\mathrm{BOHAl}$ y $\mathrm{BOHZr}$ y posterior molienda (en molino planetario) en las propiedades físicas, microestructura y dureza de cerámicos sinterizados, previo al uso como material de partida para el conformado del material granular.

Para ello, las muestras en polvo de BOHAl y BOHZr, así como de la bentonita precursora $\mathrm{B}$, fueron precalcinadas hasta $800^{\circ} \mathrm{C}$ durante $1 \mathrm{~h}$. Posteriormente, se tomó una fracción de las muestras precalcinadas para someterlas a molienda. La misma se realizó en húmedo, en un molino planetario (Fritz) utilizando esferas de zirconia de diámetro nominal de $1 \mathrm{~mm}$ como elementos de molienda. La molienda fue realizada a $500 \mathrm{rpm}$ por un tiempo total de $5 \mathrm{~h}$. El material obtenido fue secado en estufa a $90^{\circ} \mathrm{C}$, posteriormente disgregado manualmente en mortero y tamizado (M: 100).

La evaluación del grado de dilatación se realizó por microscopia de calentamiento (ver inciso 4.4.3.) Como fuera explicado previamente, mediante esta técnica es posible determinar la contracción o expansión de la probeta durante el tratamiento térmico.

Se prepararon cerámicos en forma de discos de $30 \mathrm{~mm}$ de diámetro y $5 \mathrm{~mm}$ de espesor por prensado uniaxial y posterior sinterizado en horno eléctrico. La elección de la temperatura final de sinterizado se realizó en función de los resultados de los análisis de las muestras por microscopía de calentamiento. Se obtuvieron los valores de densidad aparente y porosidad abierta de las muestras. El análisis estructural de las mismas fue realizado por DRX y la 
microestructura se examinó por SEM, realizando posteriormente la medición de la dureza Vickers.

\subsubsection{Efecto de pretratamiento de las ANs en las propiedades de los cerámicos obtenidos.}

La Fig. 6.14 muestra la distribución de tamaño de partícula de las muestras precalcinadas a $800{ }^{\circ} \mathrm{C}(\mathrm{B}-\mathrm{C}$; BOHAl-c, BOHZr-C) y con posterior molienda (Bcm; BOHAl-cm, BOHZr-cm).

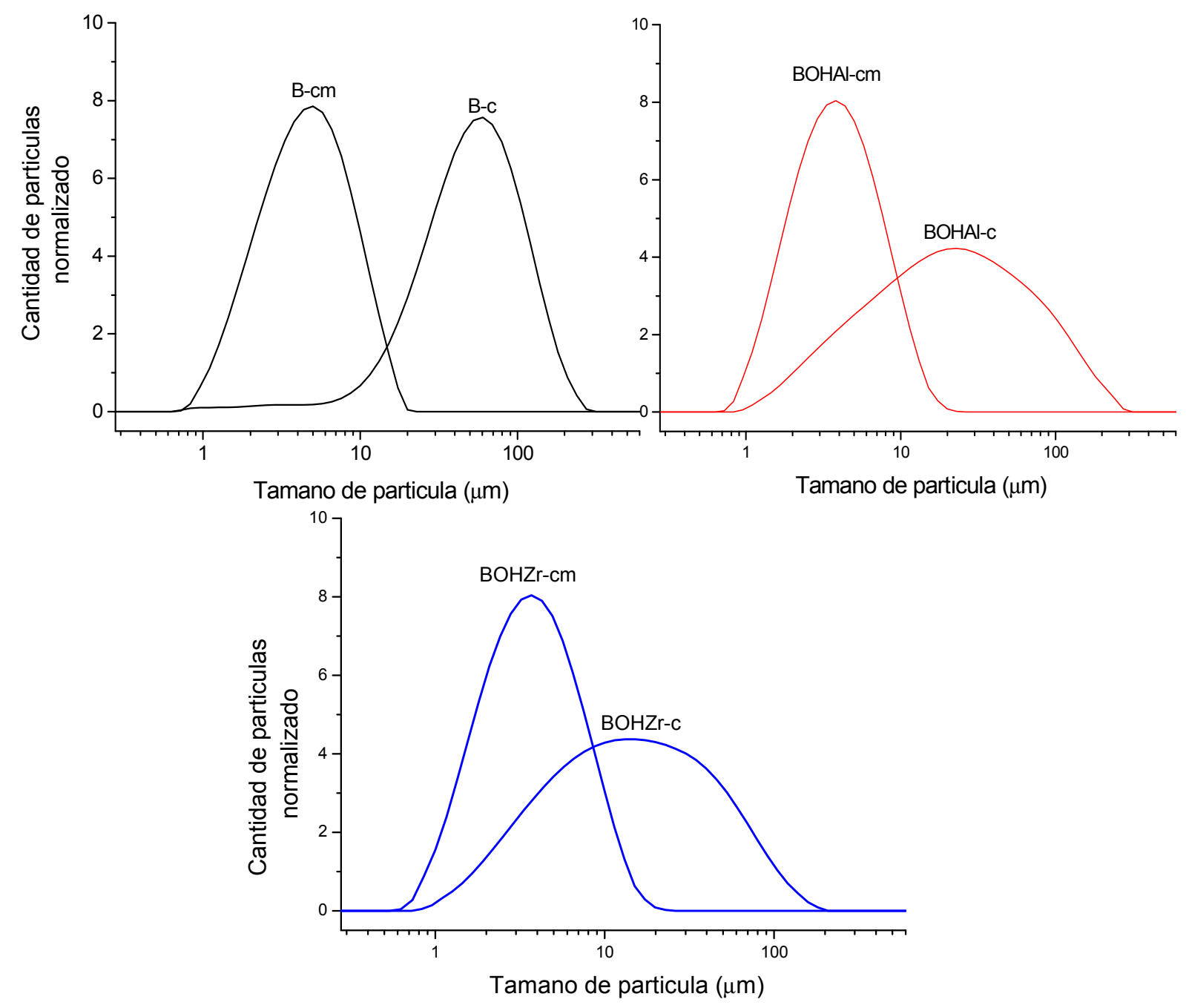

Fig. 6.14 Distribución de tamaño de partícula y $\mathrm{d}_{50}$ de polvos precalcinados (c)

$$
\text { y molidos (cm) de a) B, b) BOHAl y c) BOHZr }
$$

Todas las muestras denotan una distribución de tamaño de partícula unimodal. Se observa en la misma que la bentonita calcinada, B-c, posee un $d_{50}$ mayor $(58,2 \mu \mathrm{m})$ que las muestras intercaladas calcinadas $(23,3 \mu \mathrm{m}$ para BOHAl-c y 
14,0 $\mu \mathrm{m}$ para $\mathrm{BOHZr}$ ); aunque estas últimas presentaron una distribución de tamaño de partícula más amplia. Se observa además que la molienda en molino planetario produjo un efecto de reducción de tamaño de partícula en las tres muestras; disminuyendo el $d_{50}$ en un orden de magnitud (entre 5 y $3,8 \mu \mathrm{m}$ ) y distribuciones de tamaño más acotadas y de valores similares, en las muestras BOHAl-cm y BOHZr-cm.

La Fig. 6.15 muestra las curvas de $\mathrm{Hr}$ (altura relativa) vs temperatura de las muestras de bentonita pretratadas $(\mathrm{Bc}, \mathrm{Bcm})$, así como la curva para la bentonita original, $\mathrm{B}$, correspondientes de los ensayos de microscopia de calentamiento. Se observa que la reducción de altura relativa (contracción) de aproximadamente $3 \%$ hasta $200{ }^{\circ} \mathrm{C}$ de la muestra $\mathrm{B}$ no se encuentra en la muestras precalcinadas. Esta contracción, asociada a la pérdida de agua absorbida del mineral arcilloso habría sido eliminada en el proceso de precalcinado.

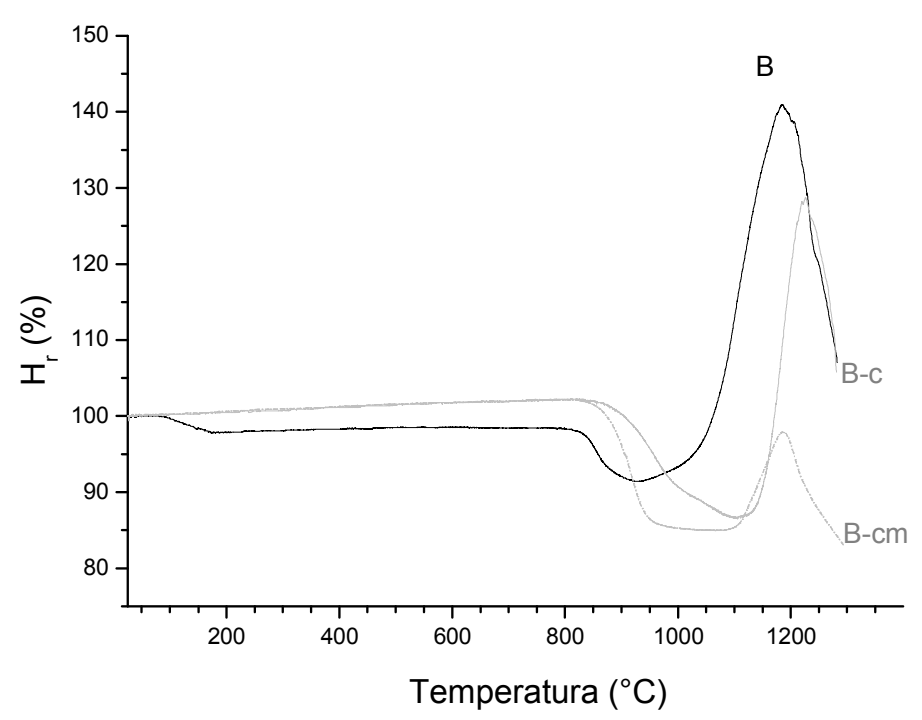

Fig. 6.15. Evolución de altura relativa $(\mathrm{Hr})$ vs temperatura de probetas de B, B-c y B-cm

El comportamiento térmico de ambas muestras $B$ pretratadas fue similar hasta $\sim 850{ }^{\circ} \mathrm{C}$. A mayores temperaturas, la muestra B-c denota una contracción progresiva, hasta un mínimo de $\mathrm{H}_{\mathrm{r}}$ de $86,9 \%$ a $1100{ }^{\circ} \mathrm{C}$, mientras que la reducción de B-cm fue más abrupta y alcanzó el valor mínimo de 85,2 \% a $1000{ }^{\circ} \mathrm{C}$. Este menor valor de $\mathrm{H}_{\mathrm{r}}$, así como la mayor velocidad de contracción 
de la muestra B-cm con respecto a B-c, es indicativo de la influencia de la reducción del tamaño de partícula, lo cual permite una mayor eficiencia en la compactación e incide sobre el sinterizado del material, aumentando la velocidad con la que el cuerpo densifica al disminuir el tamaño de partícula (Rahaman, 2003).

El proceso de expansión registrado las curvas de sinterización, a partir de 1000 ${ }^{\circ} \mathrm{C}$ sucedió acompañado de la deformación de las piezas (Tabla 6.3), atribuida a la formación de una fase liquida rica en sílice y álcalis originada a partir del mineral arcilloso. Esta fase líquida de alta viscosidad tiene la capacidad de retener los gases generados en el producto, causando una expansión en su volumen (Panna y col., 2016). Como se observa en las imágenes de secciones transversales obtenidos durante el mismo ensayo de dilatométrico por microscopía de calentamiento (Tabla 6.3), las muestras B-c y B-cm se expanden a $\sim 1100{ }^{\circ} \mathrm{C}$ en tanto la expansión para $\mathrm{B}$ fue a partir de $1000^{\circ} \mathrm{C}$. La mayor expansión observada en la muestra $B$ respecto a la muestra precalcinada (B-C) podría ser atribuido al aire o vapores retenidos en los poros que se expanden con la temperatura (Panna y col., 2016).

Tabla 6.3 Evolución de la sección transversal de muestras pretratadas de B durante el tratamiento térmico en microscopio de calentamiento

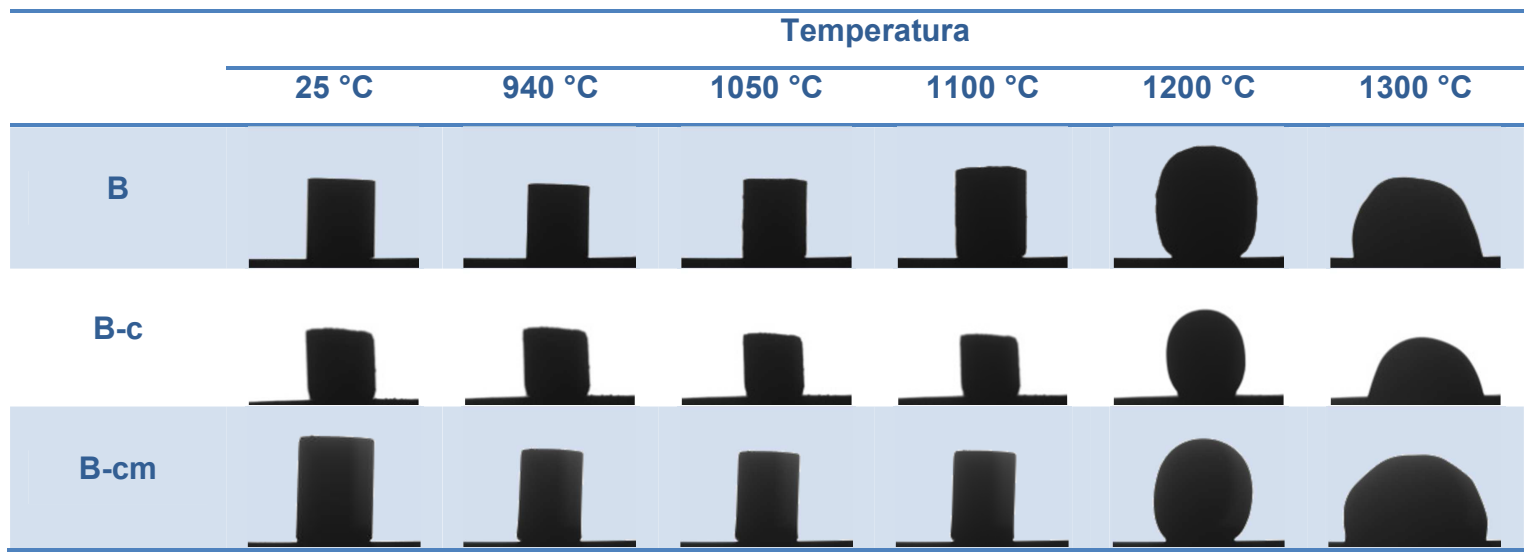

Asimismo, cabe recordar que la muestra B posee una pérdida de masa durante el tratamiento térmico entre los $200-800{ }^{\circ} \mathrm{C}$ de $4,4 \%$ debido a la deshidroxilación de la esmectita (Ver Fig. 6.7), acompañada de una contracción visible por microscopia de calentamiento (Tabla 6.3.) Este efecto podría 
explicar la menor contracción observada en las muestras precalcinadas a 800 ${ }^{\circ} \mathrm{C}$.

El comportamiento de BOHAl y $\mathrm{BOHZr}$ con y sin pretratamiento se observa en la Fig. 6.16. En comparación con la muestra B (Fig. 6.15), las curvas de la muestras precalcinadas no presentan la contracción inicial hasta $200{ }^{\circ} \mathrm{C}$, se aprecia un aumento de contracción a temperaturas mayores a1000 ${ }^{\circ} \mathrm{C}$, así como la ausencia de la expansión observada a partir de 1000 y $1100{ }^{\circ} \mathrm{C}$ en las muestras B y B pretratadas, respectivamente, indicando la mayor estabilidad térmica hasta $1300{ }^{\circ} \mathrm{C}$. El menor tamaño de partícula de BOHAl-cm y BOHZrcm favoreció el sinterizado de las mismas, alcanzando una contracción mayor que las respectivas muestras naturales y precalcinadas.
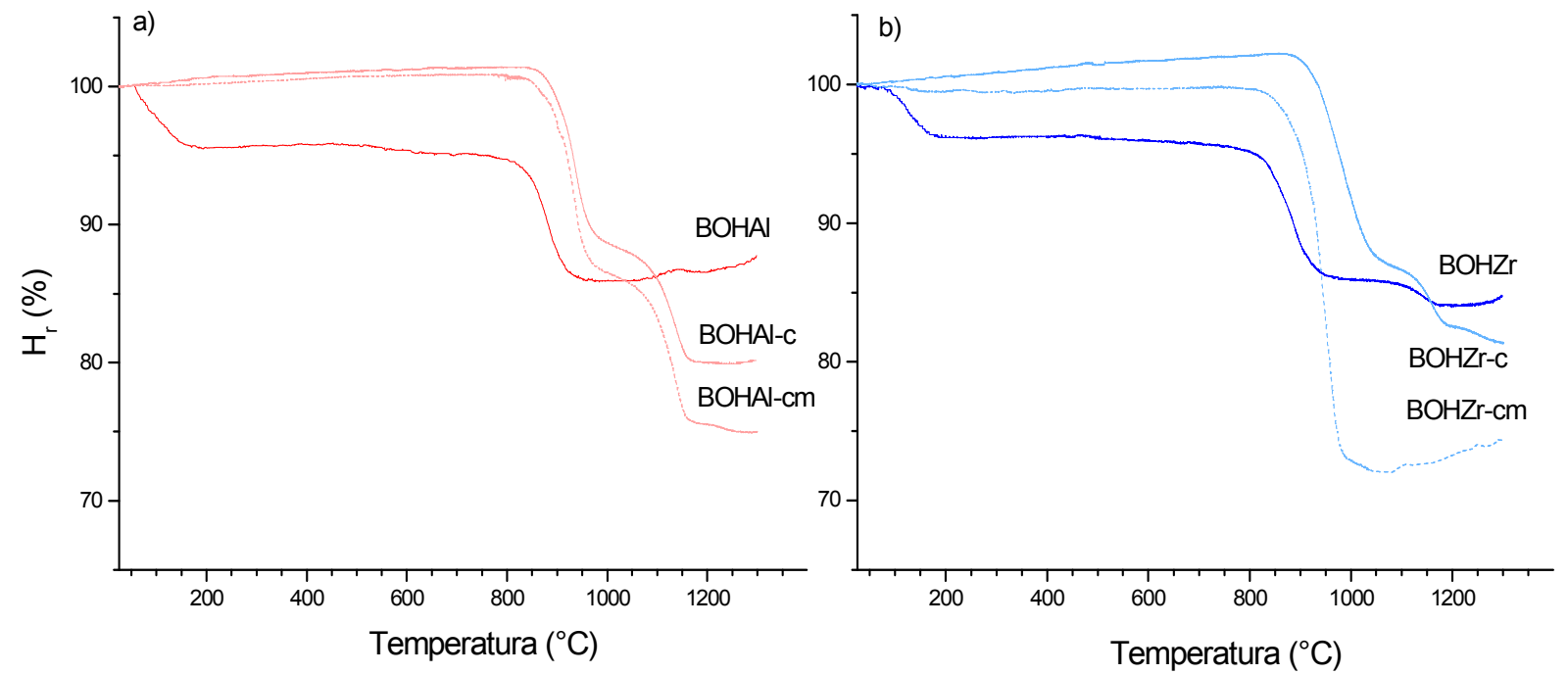

Fig. 6.16. Evolución de Hr vs temperatura de probetas de a) BOHAl, B- OHAl-c, BOHAl-cm y b) BOHZr, B- OHZr-c, BOHZr-cm

La curva de BOHAl-c evidencia dos etapas de contracción entre 800-1000 y entre 1000-1200 ${ }^{\circ} \mathrm{C}$ (sinterización). Esto marca una diferencia respecto a la muestra BOHAl, la cual solo posee etapa de contracción entre 800 y $900{ }^{\circ} \mathrm{C}$, y denota una ligera expansión entre $1000-1200{ }^{\circ} \mathrm{C}$. La misma presentó $\mathrm{Hr}$ de $80 \%$ (contracción) a $1200^{\circ} \mathrm{C}$. El comportamiento de la muestra BOHAl-cm molida fue similar, aunque alcanzando $\mathrm{Hr} 75,1 \%$ (mayor contracción) a 1250 ${ }^{\circ} \mathrm{C}$. 
Para la muestra $\mathrm{BOHZr}$, se observa que el precalcinado y molienda (BOHZr$\mathrm{cm}$ ) modificó el comportamiento desplazando las etapas de contracción a temperaturas ligeramente superiores con contracción de la muestra hasta $\mathrm{Hr}$ de $81,4 \%$. La muestra BOHZr-cm demostró una única etapa de contracción (sinterización), acotada entre $800-1000{ }^{\circ} \mathrm{C}$, alcanzando $\mathrm{Hr}$ el $72,1 \%$ a $1050^{\circ} \mathrm{C}$.

Las imágenes de las secciones transversales de las muestras de ANs modificadas (extraídas de tabla 6.2.), así como de las ANs pretratadas se muestran en la Tabla 6.4 .

Tabla 6.4 Evolución de la sección transversal de muestras pretratadas de $\mathrm{BOHAl}$ y $\mathrm{BOHZr}$ por tratamiento térmico en microscopio de calentamiento

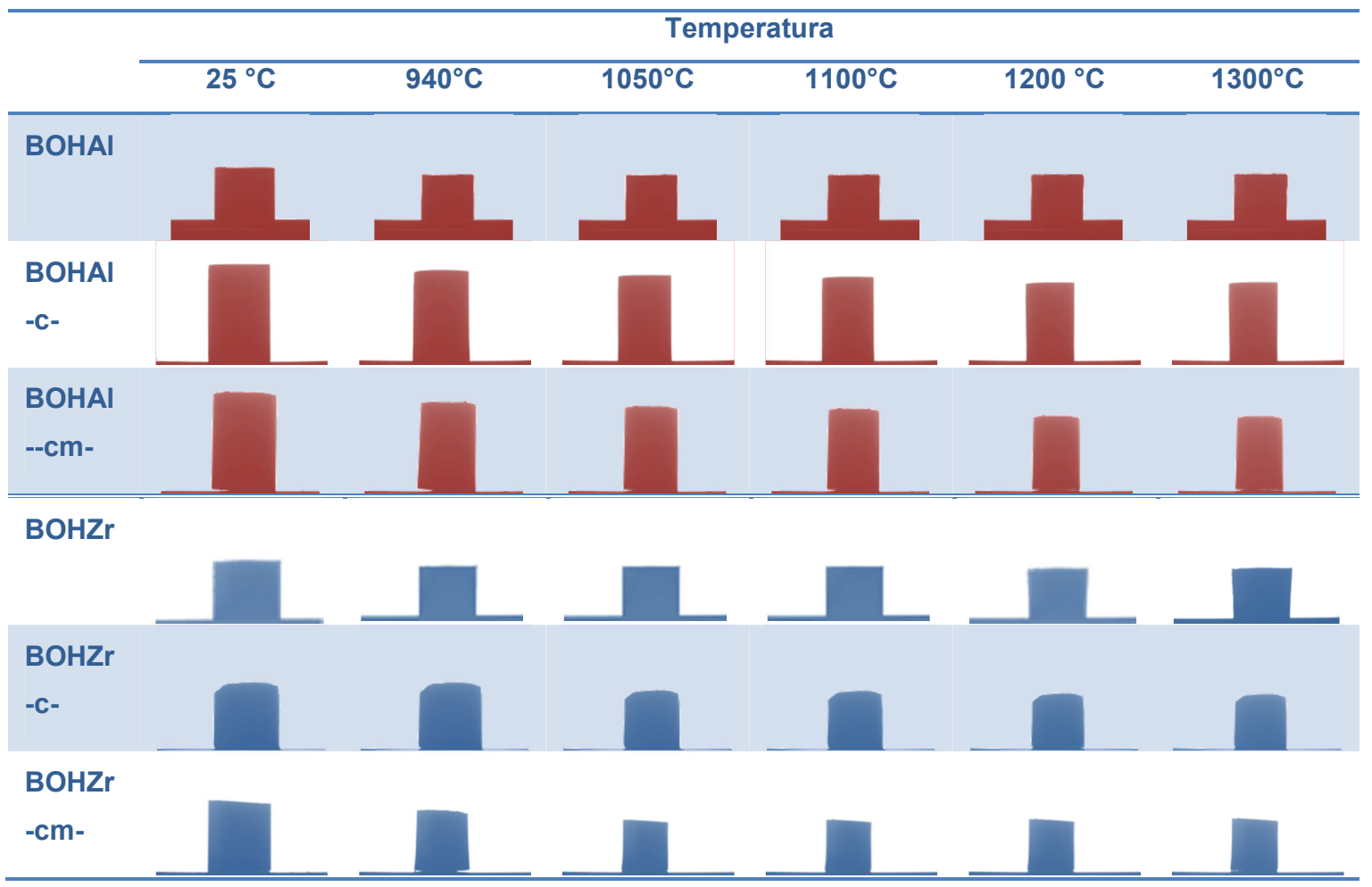

Se observa en la misma que las muestras pretratadas (c y $\mathrm{cm}$ ), como sus precursoras, no denotan la deformación de la pieza original observada en las muestras de B a altas temperaturas (Fig. 6.3). Esto indica la mayor estabilidad térmica de las piezas a altas temperaturas, posibilitando su uso para el conformado de piezas densas a altas temperaturas. 
La Fig. 6.17 muestra los difractogramas de la bentonita original, B, precalcinada (B-C) y con posterior molienda $(B-c m)$ tratada térmicamente a $1000{ }^{\circ} \mathrm{C}$. Así como la muestra sin pretratamientos, las muestras B-c y B-cm mostraron la presencia de aluminosilicato de magnesio y espinela, con cantidades minoritarias de feldespato y cuarzo. El pretratamiento térmico y la molienda no afectaron considerablemente las fases cristalinas desarrolladas por la muestra.

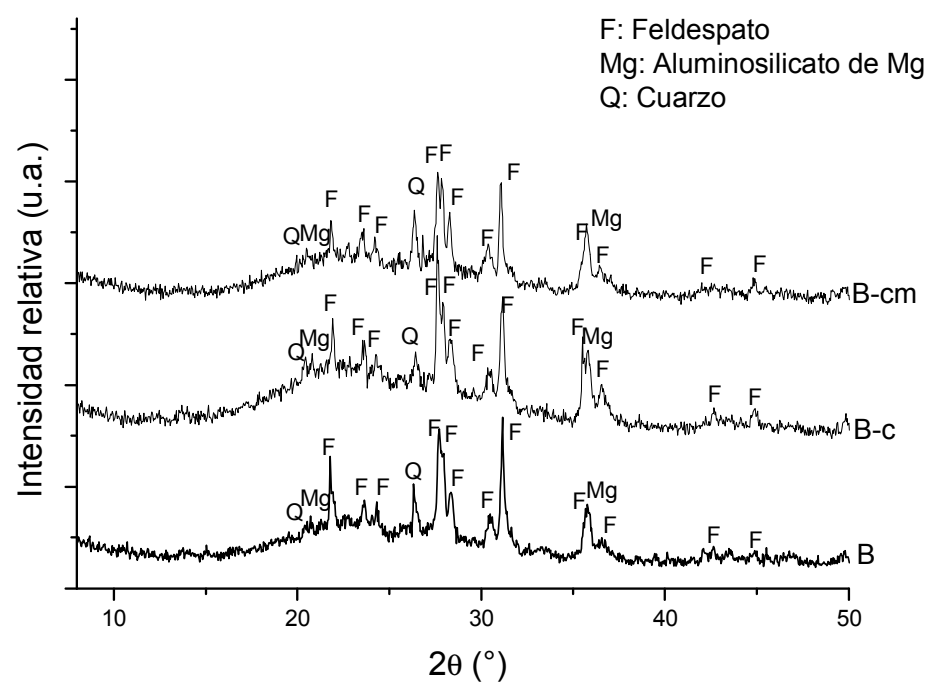

Fig. 6.17. Difractogramas de B, B-c y B-cm calcinadas a $1000{ }^{\circ} \mathrm{C}$

La Fig. 6.18 muestra los difractogramas de $\mathrm{BOHAl}$ y $\mathrm{BOHZr}$ sin pretratamientos; precalcinadas y molidas; y posterior calcinación a $1200{ }^{\circ} \mathrm{C}$. Los difractogramas de la muestra BOHAl (Fig. 6.18a.) demuestran que, así como en la bentonita precursora, el pretratamiento térmico y molienda no originaron cambios apreciables en la estructura cristalina del material al ser posteriormente tratado térmicamente a $1200^{\circ} \mathrm{C}$, exceptuando una pequeña reducción en la intensidad de los picos de cordierita para la muestra BOHAl-c. 


\section{a)}

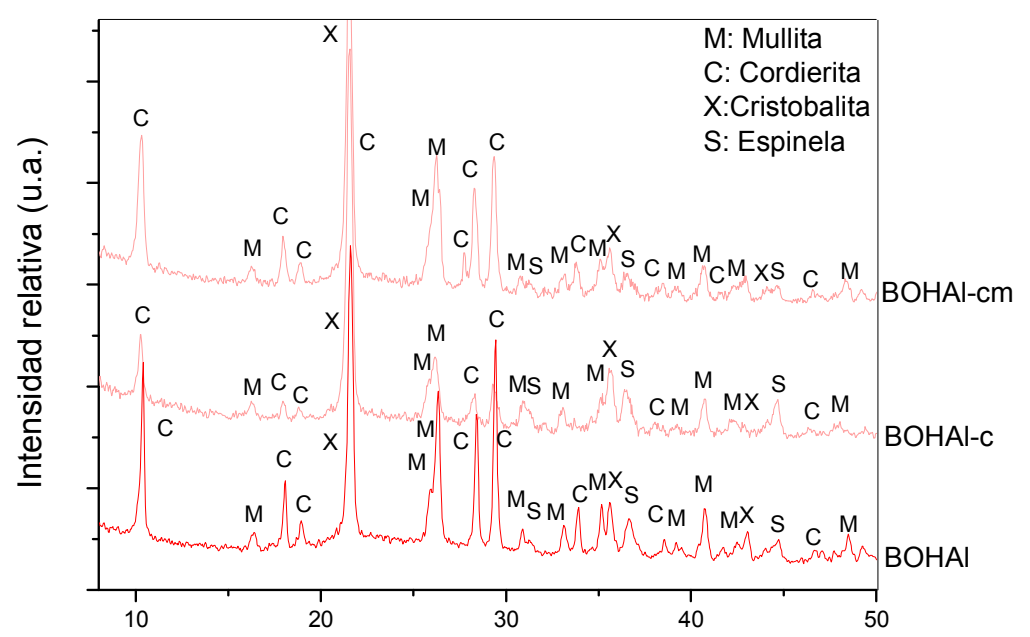

b)

$2 \theta\left({ }^{\circ}\right)$

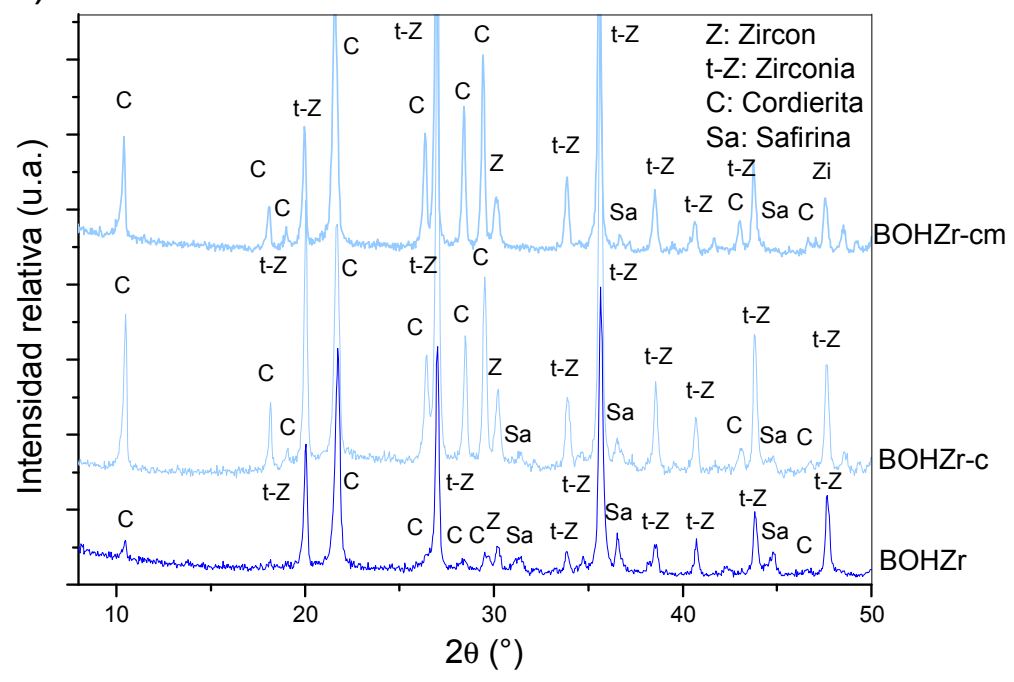

Fig. 6.18. Difractogramas de muestras calcinadas a $1200^{\circ} \mathrm{C}$ de a) $\mathrm{BOHAl}$, BOHAl-c y BOHAl-cm y b) BOHZr, BOHZr-c y BOHZr-cm

Para las muestras de $\mathrm{BOHZr}$ calcinadas a $1200{ }^{\circ} \mathrm{C}$ (Fig. 6.18b), los difractogramas indican leves diferencias de composición de fases. El precalcinado a $800{ }^{\circ} \mathrm{C}$ favoreció el desarrollo de cordierita comparativamente con la muestra $\mathrm{BOHZr}$, viéndose este hecho reflejado en un aumento relativo de intensidad de los picos correspondientes a esta fase con respecto a los de zircón.

Tomando en cuenta las curvas de sinterización de las muestras, se eligió una temperatura de $1000^{\circ} \mathrm{C}$ para las probetas preparadas con $\mathrm{B}$, y de $1200^{\circ} \mathrm{C}$ para las $\mathrm{BOHAl}$ y $\mathrm{BOHZr}$, para realizar el análisis por SEM. Estas temperaturas elegidas son cercanas a la de temperatura de máxima contracción de las 
muestras, eligiendo una temperatura menor para las muestras obtenidas a partir de B por la deformación de las piezas a mayores temperaturas, como fuera observado y comentado anteriormente

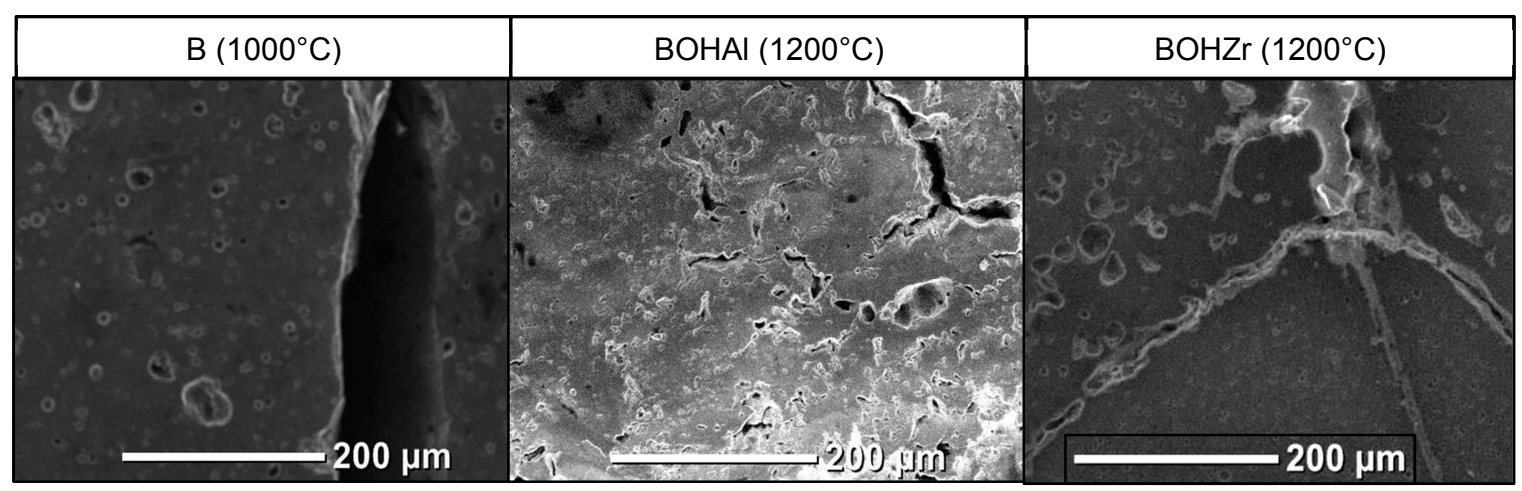

Fig. 6.19. Imágenes SEM de piezas sinterizadas a partir de $\mathrm{B}\left(1000^{\circ} \mathrm{C}\right), \mathrm{BOHAl}$

$$
\text { y BOHZr }\left(1200^{\circ} \mathrm{C}\right)
$$

A las probetas sinterizadas se les midieron diversas propiedades, entre ellas porosidad abierta y densidad aparente. La porosidad de los cerámicos preparados con BOHAl y BOHZr (sin pretratamiento) no se pudo medir debido al agrietamiento superficial de las piezas (ver Fig. 6.19), atribuido a la deshidratación-deshidroxilación de las especies poliméricas intercaladas, que conducen a una contracción rápida y elevada de las piezas a bajas temperaturas (Fig. 6.15 y 6.16).

En la Fig. 6.20 se observan las piezas obtenidas a partir de las muestras precalcinadas y molidas de B y AN modificadas. En las mismas se observa, en general, la ausencia del agrietamiento observado en las muestras obtenidas a partir del material sin pretratar (Fig. 6.19). Asimismo, se observa para las tres muestras obtenidas a partir de $B$ y $A N$ precalcinadas y molidas $(\mathrm{cm})$ una reducción del tamaño de los poros respecto a su contraparte sin moler (c). 


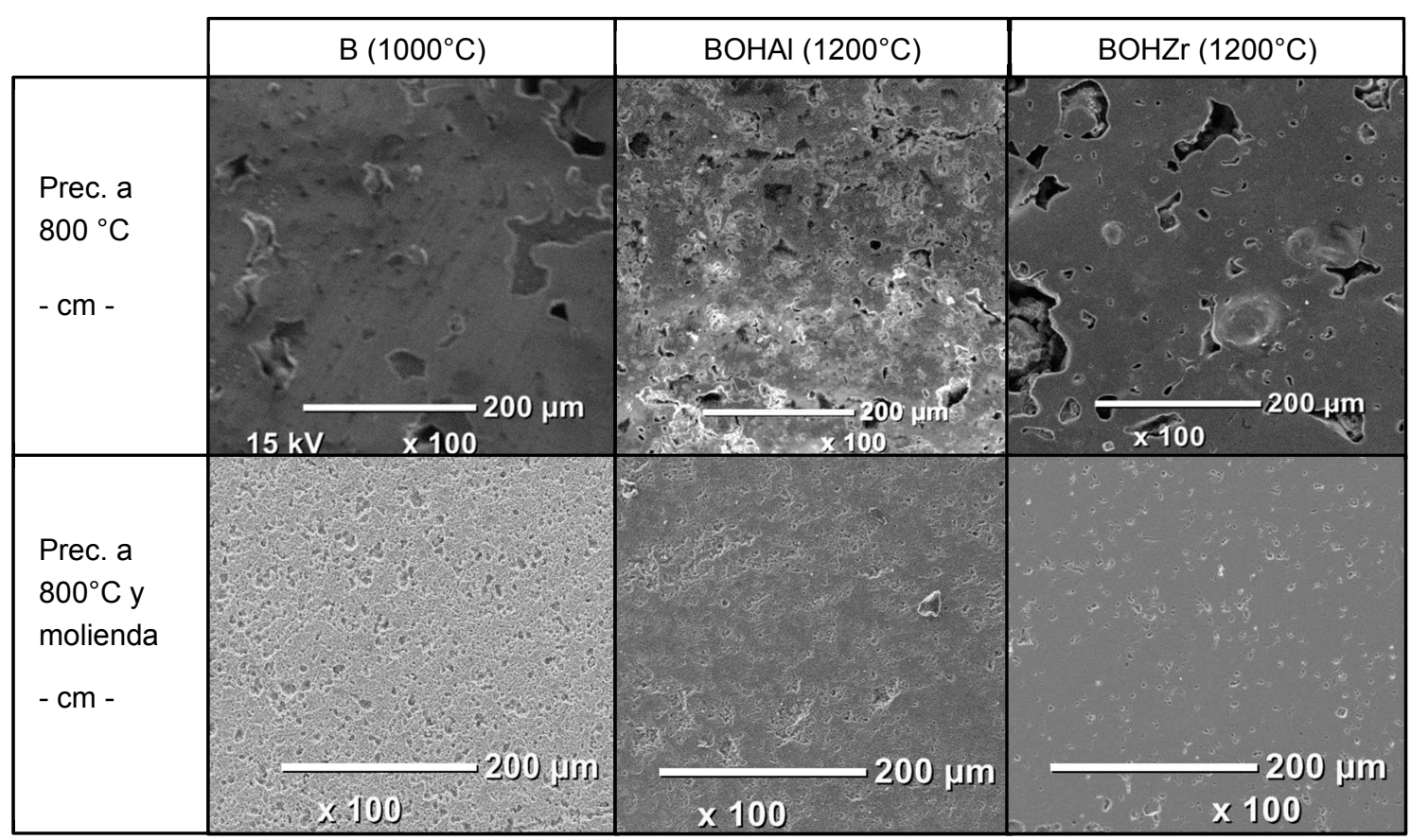

Fig. 6.20. Imágenes SEM de piezas sinterizadas a partir de B, BOHAl y BOHZr precalcinadas $(-\mathrm{c})$ y molidas $(-\mathrm{cm})$

La Tabla 6.5 muestra los valores de porosidad abierta y densidad aparente, determinadas por el método de Arquímedes.

Tabla 6.5. Porosidad abierta y densidad aparente de piezas sinterizadas

\begin{tabular}{lcccc}
\hline & \multicolumn{2}{c}{ Precalcinación a $\mathbf{8 0 0 ^ { \circ } \mathbf { C } - \mathbf { c } -}$} & \multicolumn{2}{c}{ Precalcinación a $\mathbf{8 0 0} \mathbf{}^{\circ} \mathbf{C}$ y molienda-cm- } \\
\cline { 2 - 5 } & $\begin{array}{c}\text { Porosidad } \\
\text { abierta }(\%)\end{array}$ & $\begin{array}{c}\text { Densidad } \\
\text { aparente }\left(\mathbf{g} / \mathbf{c m}^{3}\right)\end{array}$ & $\begin{array}{c}\text { Porosidad abierta } \\
(\%)\end{array}$ & $\begin{array}{c}\text { Densidad } \\
\text { aparente }\left(\mathbf{g} / \mathbf{c m}^{3}\right)\end{array}$ \\
\hline $\mathbf{B}\left(\mathbf{1 0 0 0}{ }^{\circ} \mathbf{C}\right)$ & 2,3 & 1,7 & 2,0 & 1,9 \\
\hline $\mathbf{B O H A l}\left(\mathbf{1 2 0 0}{ }^{\circ} \mathbf{C}\right)$ & 0,7 & 2,0 & $<0,1$ & 2,5 \\
\hline $\mathbf{B O H Z r}\left(\mathbf{1 2 0 0}{ }^{\circ} \mathbf{C}\right)$ & 52,6 & 1,2 & $<0,1$ & 1,7 \\
\hline
\end{tabular}

Las piezas sinterizadas, obtenidas a partir de B y BOHAl precalcinadas y molidas denotaron una leve disminución en la porosidad abierta (de 2,3 a 2 \% y de 0,7 a menos de $0,1 \%$ respectivamente), acompañado con un incremento de la densidad aparente (de 1,7 a $1,9 \mathrm{~g} / \mathrm{cm}^{3}$ y de 2,0 a $2,5 \mathrm{~g} / \mathrm{cm}^{3}$, respectivamente), respecto a su contraparte sin moler (c). Para la muestra $\mathrm{BOHZr}$, este efecto fue mucho mayor, disminuyendo de valores de porosidad abierta de 52,6 \% a $<0,1 \%$, y aumentando su densidad aparente de 1,2 a 1,7; efecto que se condice con la contracción más elevada de esta muestra 
respecto a su contraparte sin moler, observada por microscopia de calentamiento (Fig. 6.16).

La Tabla 6.6 muestra los valores de dureza de los cerámicos obtenidos. La muestra $\mathrm{BOHZr}$ no fue medida debido a que la alta porosidad de la misma no permitió su adecuada medición. A fines de comparación, se determinó además la dureza de cerámicos obtenidos a partir de las arcillas que se utilizaron como sustrato de los recubrimientos, sinterizados a $1200^{\circ} \mathrm{C}$. Dichos cerámicos (LG y $P G)$ fueron obtenidos por prensado uniaxial y posterior sinterizado a $1200^{\circ} \mathrm{C}$ durante $1 \mathrm{~h}$.

Tabla 6.6. Dureza Vickers (GPa) de cerámicos sinterizados a $1200{ }^{\circ} \mathrm{C}$

\begin{tabular}{lccc}
\hline & \multicolumn{3}{c}{ Dureza Vickers (GPa) } \\
\cline { 2 - 4 } & Sin pretratamiento & $\begin{array}{c}\text { Precalcinado a } 800^{\circ} \\
-c-\end{array}$ & $\begin{array}{c}\text { Precalcinado+Molienda } \\
\text {-cm- }\end{array}$ \\
\hline B & & $5,0 \pm 0,4$ & $5,8 \pm 0,4$ \\
BOHAI & $4,9 \pm 0,3$ & $5,7 \pm 0,5$ & $6,7 \pm 0,4$ \\
BOHZr & - & - & $6,5 \pm 0,7$ \\
PG & $5,3 \pm 0,9$ & & \\
LG & $4,9 \pm 0,7$ & & \\
\hline
\end{tabular}

En general, se observa que los valores de dureza Vickers de las muestras precalcinadas y molidas fueron superiores que lo de las muestras sin pretratamiento y precalcinadas, siendo este valor afectado por la menor porosidad (Tabla 6.5.). Se observa además, que el cerámico procesado con BOHAl pretratada presentó una dureza superior a la de la bentonita B y a los cerámicos utilizados como sustratos para aplicar los recubrimientos. La mejora de la dureza de los cerámicos densos obtenidos con las AN (precalcinados y molidas) respecto a los preparados con bentonita $\mathrm{B}$ evidencia el efecto favorable de la formación de fases cristalinas tales como mullita en BOHAl y zircón en BOHZr que se caracterizan por sus buenas propiedades mecánicas. La formación de estas fases no se vio afectada por el proceso de precalcinación y molienda (Fig. 6.18).

Koseski y col (2008) midieron los valores de dureza de muestras de agentes de sostén a base de andesita, amorfos y tratados térmicamente para favorecer la

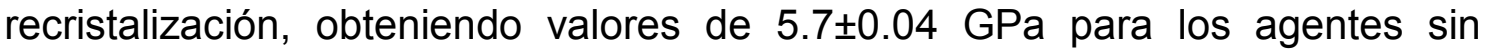


pretratamientos y valores oscilando entre $5,62 \pm 0.04-6,46 \pm 0.14 \mathrm{GPa}$ para los tratados térmicamente.

Luscher y col (2006) midieron la dureza de agentes de sostén a partir de caolines y bauxita, observando en los mismos valores de dureza Vickers de 7,16 GPa y 8,4 GPa respectivamente. Si bien los valores de las muestras de AN analizadas en este ensayo fueron ligeramente menores que los obtenidos por estos autores, puede resaltarse en forma positiva que la densidad aparente de los materiales obtenidos en esta tesis son menores $\left(1,7-2,5 \mathrm{~g} / \mathrm{cm}^{3}\right)$ que las de los autores mencionados $\left(2,74\right.$ y $3,22 \mathrm{~g} / \mathrm{cm}^{3}$ respectivamente).

\subsubsection{Consideraciones parciales}

$\checkmark$ Las fases cristalinas desarrolladas por tratamiento térmico para la bentonita natural, B, por DRX concuerdan con lo esperado para una esmectita con predominio de magnesio octaédrico (montmorillonita tipo Cheto). El análisis permite relacionar el pico endo-exotérmico con el colapso de la estructura de la montmorillonita, formación de silicato de Mg y espinela. Se observó a $120{ }^{\circ} \mathrm{C}$ desarrollo de cordierita y safirina (probablemente a expensas de espinela) y escasa cristobalita, en tanto que el cuarzo y el feldespato se reduce. Se evidencia el crecimiento relativo de la banda asociada al contenido de fase amorfa (no cristalina) con el aumento de la temperatura, que corrobora formación considerable de fase liquida a altas temperaturas.

$\checkmark$ A diferencia de lo expuesto para la bentonita B, se observa que la misma muestra tratada con especies poliméricas de $\mathrm{OH}-\mathrm{Al}, \mathrm{BOHAl}$, calcinada a $1000{ }^{\circ} \mathrm{C}$ se identifica sólo la formación de espinela con cuarzo y feldespato residuales. A $1100{ }^{\circ} \mathrm{C}$, se registra la formación de mullita y principalmente de cristobalita. A $1200^{\circ} \mathrm{C}$ ocurre aumento significativo del desarrollo de mullita mientras que se reducen los picos de espinela y se detecta escasa cordierita. A $1300^{\circ} \mathrm{C}$, mullita pasa a ser la fase cristalina mayoritaria, acompañada de cristobalita y cordierita. Cabe destacar la reducción importante de la intensidad de la banda correspondiente a la fase amorfa con el aumento de la temperatura. 
$\checkmark$ Las fases cristalinas presentes en la bentonita tratada con especies $\mathrm{OHZr}, \mathrm{BOHZr}$, calcinada a $1000^{\circ} \mathrm{C}$ son comparables con la BOHAl. Se destaca la formación de $\mathrm{t}-\mathrm{ZrO}_{2}$. A $1100{ }^{\circ} \mathrm{C}$ se acentúa el desarrollo de t$\mathrm{ZrO}_{2}$, presencia espinela y formación de cristobalita, y se detecta Zircón. Es relevante la formación de zircón a $1200{ }^{\circ} \mathrm{C}$ en tanto que la fase $\mathrm{t}-\mathrm{ZrO}_{2}$ se reduce considerablemente. La muestra $\mathrm{BOHZr}$ tratada a $1300^{\circ} \mathrm{C}$ se compone principalmente de zircón, cordierita y cristobalita, y bajo desarrollo de fase amorfa.

$\checkmark$ Los análisis por IR de B calcinada en el rango $1000-1200{ }^{\circ} \mathrm{C}$, indicaron un cambio relevante de su estructura. Las bandas propias de la montmorillonita desaparecieron. Se observaron intensas bandas de Si$\mathrm{O}-\mathrm{Si}$ y de uniones tipo Al-O atribuidas a nuevas fases. La muestra de bentonita con OHAl incorporado (BOHAl), posterior a los tratamientos térmicos evidenciaron bandas propias de la mullita. Por otro lado, la incorporación de $\mathrm{OHZr}$ a la bentonita $(\mathrm{BOHZr})$ y posterior tratamiento térmico hasta $1100{ }^{\circ} \mathrm{C}$ evidenció bandas características de $\mathrm{t}-\mathrm{ZrO}_{2}$, en tanto que a $1200{ }^{\circ} \mathrm{C}$ se observó la aparición de bandas propias de zircón.

$\checkmark$ Se realizó el ensayo dilatométrico hasta $1300{ }^{\circ} \mathrm{C}$ de muestras (precalcinadas a $800^{\circ} \mathrm{C}$ y molidas) con tamaño de partícula $\mathrm{d}_{50}$ de $4,3.8$ y $5 \mu \mathrm{m}$ para $\mathrm{B}, \mathrm{BOHAl}$ y $\mathrm{BOHZr}$, respectivamente. A diferencia de la bentonita $\mathrm{B}$, el comportamiento dilatométrico de estas muestras presenta la tendencia de contracción más pronunciada debida al avance sinterización y ausencia de la expansión a temperaturas mayores a 1100 ${ }^{\circ} \mathrm{C}$ propia de la vitrificación superficial (Bloating). No se observó influencia del precalcinación y molienda en composición de fases presentes en los cerámicos obtenidos con respecto a las muestras sin tratar

$\checkmark$ Se determinaron las propiedades de cerámicos a partir de las BOHAl y $\mathrm{BOHZr}$ conformados por prensado uniaxial y sinterizados a $1200{ }^{\circ} \mathrm{C}$. 
Ambos cerámicos presentan porosidad aparente nula, densidad de 1,7 y $2,5 \mathrm{~g} / \mathrm{cm}^{3}$ y similar microestructura SEM caracterizada por porosidad fina y bien distribuida en el interior del cerámico, sin fisuras y pocas heterogeneidades. La dureza Vickers resultó 6,5-6,7 GPa. Los resultados han sido satisfactorios demostrando la posibilidad de preparar recubrimiento y cerámicos con estos materiales acondicionados como polvos finos. 


\subsection{Compositos obtenidos por recubrimiento de sustratos con BOHAI por inmersión en suspensiones}

Debido a las diferentes variables involucradas en el proceso de recubrimiento de sustratos por inmersión, a saber, propiedades del sustrato (porosidad y tamaño de poro, rugosidad superficial); de la suspensión (viscosidad, concentración de sólidos, densidad) y condiciones experimentales (velocidad de inmersión y de extracción, tiempo de inmersión en suspensión), se vuelve necesario un proceso de análisis de las variables experimentales a fin de obtener un procedimiento adecuado para lograr recubrimientos estables de AN modificadas sobre sustratos estudiados, el cual se incluye en el presente inciso.

Los resultados del análisis realizado de las condiciones experimentales para la obtención de recubrimientos a partir de BOHAl se muestran en el inciso 6.3.1. Como parte del proceso de evaluación de las condiciones experimentales aptas para realizar los recubrimientos con las arcillas modificadas sobre sustratos, en una primera etapa se determinaron las propiedades reológicas y electrocinéticas de las suspensiones de BOHAl (6.3.1.1).

Los ensayos preliminares de recubrimientos sobre sustratos seleccionados, se realizaron en todos los casos utilizando suspensiones de BOHAl, en donde se evaluaron: influencia de distintas variables del proceso (sinterizado, secado, tiempo de inmersión) así como de los materiales utilizados (concentración de suspensión, sustratos utilizados, etc.). Los resultados de esta etapa se encuentran en el apartado 6.3.1.2.

Como primera aproximación, y con el fin de observar las características de los recubrimientos obtenidos, se seleccionaron las mismas condiciones experimentales optimas establecidas con la muestra BOHAl para aplicar los recubrimientos de $\mathrm{BOHZr}$ sobre el sustrato arcilloso. Los resultados de este ensayo se muestran en el apartado 6.3.2. 


\subsubsection{Recubrimiento de BOHAl sobre sustratos}

\subsubsection{Evaluación de propiedades de suspensiones de BOHAI}

Como parte del proceso de evaluación de las condiciones experimentales aptas para realizar los recubrimientos con BOHAl sobre sustratos, en esta primera etapa se muestran los resultados de los estudios sobre las propiedades reológicas y electrocinéticas de suspensiones de BOHAl.

\subsection{Viscosidad}

Las propiedades de flujo de suspensiones acuosas de BOHAI $(40 \% \mathrm{~m} / \mathrm{m})$ y su variación con el agregado de poliacrilato de sodio (NaPA) respecto al contenido de BOHAl entre 0.7 y $4.2 \% \mathrm{~m} / \mathrm{m}$ BOHAl en peso se muestran en la Fig. 6.21.a.

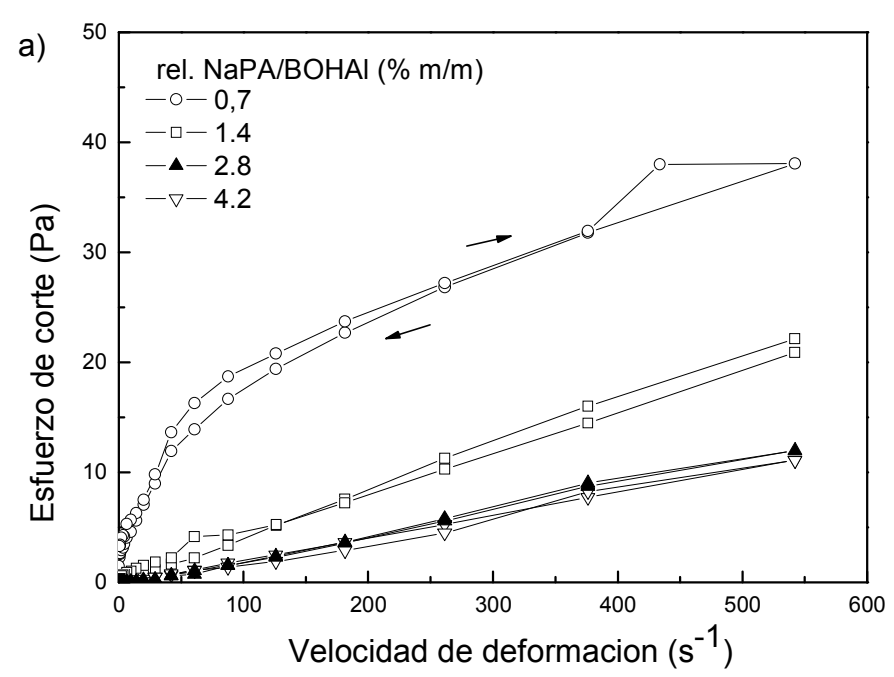

b)

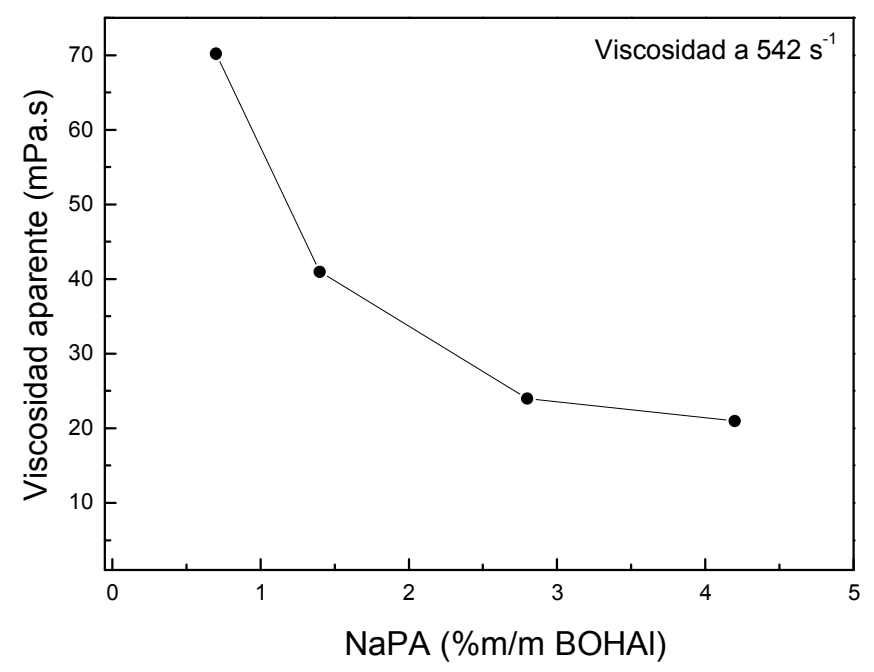

Fig. 6.21.a) Curvas de flujo y b) viscosidad aparente de suspensiones de $\mathrm{BOHAl}$ con distintos agregados de $\mathrm{NaPA}$ (expresados en \% $/ \mathrm{mBOHAl}$ ) 
La curva de flujo de la suspensión BOHAl preparada sin agregado de poliacrilato de sodio, NaPA, no se pudo medir debido a que presentó alta consistencia, probablemente asociada a la coagulación de las partículas. La coagulación se explica por la neutralización de la carga negativa de la superficie arcillosa por la adsorción de policationes de Al y/o heterocoagulación - contactos entre dichas especies y partículas por atracción entre cargas opuestas. Los aglomerados de partículas (flóculos) originan alta resistencia al flujo causando un aumento de viscosidad. Esto se condice con lo observado por Vercauteren y col. (1998b), quienes reportaron que a altas concentraciones, las partículas floculadas en suspensión se conectan entre si y pueden dar lugar a la formación de una estructura continua tipo gel El cambio en las propiedades reológicas podría interferir en la formación de recubrimientos por inmersión.

La suspensión con $0,7 \% \mathrm{~m} / \mathrm{m}$ de NaPA exhibió valores de esfuerzo de corte relativamente altos (es decir, alta viscosidad aparente) y un comportamiento similar al de un fluido pseudoplástico con una dependencia no lineal del esfuerzo con la velocidad de deformación, en el que la viscosidad aparente disminuye al aumentar la velocidad de deformación.

Por otra parte, la adición de $1,4 \% \mathrm{~m} / \mathrm{m}$ de NaPA redujo significativamente los valores de esfuerzo de corte y cambio el comportamiento de flujo a Newtoniano. En este caso, el esfuerzo de corte resulta linealmente proporcional a la velocidad de deformación y la viscosidad (pendiente) es aproximadamente constante. Para 2,8 y $4,2 \% \mathrm{~m} / \mathrm{m}$ de NaPA, el comportamiento Newtoniano se mantiene, con viscosidades comparativamente menores que las de la suspensión con 1,4\% m/m NaPA. La Fig. 6.21.b muestra una marcada reducción en la viscosidad para contenidos de hasta 2,8 \%m/m NaPA, en tanto que presentó un valor similar para 4,2 \% NaPA. Por lo tanto, la adición de 2,8 $\% \mathrm{~m} / \mathrm{m}$ de NaPA fue la óptima requerida para obtener un mínimo de viscosidad de $22 \mathrm{mPa}$.s indicando claramente una suspensión bien estabilizada por efecto de la adsorción del dispersante. La adsorción especifica de anión poliacrilato en los grupos superficiales de las partículas y en las especies policatiónicas de aluminio retenidas, conduce a la neutralización de los sitios positivos y a reducir y revertir la floculación (Van Olphen, 1964). 


\subsection{Efecto de NaPA en la movilidad electroforética}

El efecto de la adición de 2,8 \%NaPA sobre la movilidad electroforética de las partículas de BOHAl se muestra en la Fig. 6.22. Se observa que las partículas de BOHAI con NaPA adsorbido desarrollan mayor movilidad electroforética negativa en todo el rango de $\mathrm{pH}$ estudiado, que implica mayor carga superficial negativa con respecto a la muestra BOHAI.

Como ya se discutió (inciso 3.2.1.2.3.), a pH entre 4,5 y 12, las moléculas de $\mathrm{NaPA}$ en solución están completamente ionizadas. Los grupos $\mathrm{COO}^{-}$poseen fuerte afinidad por los grupos $\mathrm{Al}-\mathrm{OH}$, localizados tanto en borde de la partícula arcillosa así como en las especies policatiónicas de aluminio, de modo que el polielectrolito aniónico se adsorbe específicamente, contribuyendo al aumento de la carga superficial negativa de BOHAI. El aumento de la movilidad electroforética negativa, incrementa la repulsión electrostática entre partículas $y$, consecuentemente, mejora el grado de dispersión de las partículas suspendidas.

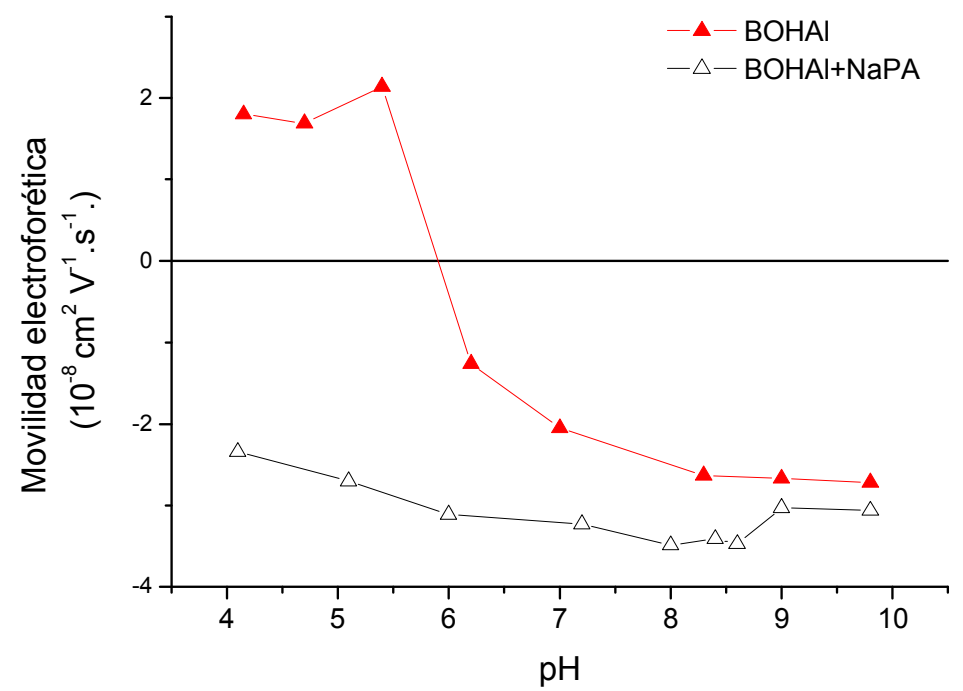

Fig. 6.22. Movilidad electroforética de BOHAl en suspensión acuosa; con y sin agregado de $2,8 \% \mathrm{~m} / \mathrm{m} \mathrm{NaPA}$

Aunque varios autores han reportado que la adsorción de las moléculas de NaPA en la superficie del mineral arcilloso es comparativamente más baja en las montmorillonitas (Siffert y Espinasse, 1980), las moléculas de NaPA 
interactúan electrostáticamente con especies de $\mathrm{OH}-\mathrm{Al}$ con carga positiva; especies que, para estas arcillas modificadas, son aportadas por las especies OH-Al intercaladas. (Choon, 2010; Mathieu y col., 2008).

La ligera reducción en la movilidad electroforética negativa de las partículas a pH>8 puede explicarse por reducción de la adsorción de las moléculas de NaPA debido a un aumento de repulsión electrostática entre el grupo $\mathrm{COO}^{-}$del polielectrolito ionizado y los sitios superficiales negativamente cargados de BOHAl (Siffert y Espinasse, 1980). Tal como lo indica el aumento de movilidad electroforética negativa, la cantidad relativa de estos sitios negativos de BOHAl aumenta con el aumento del $\mathrm{pH}$ para $\mathrm{pH}$ mayores que el $\mathrm{pH}$ correspondiente al punto isoeléctrico.

\subsubsection{Ensayos preliminares de recubrimientos por inmersión.}

El análisis anterior se centró en el comportamiento al flujo de la suspensión de BOHAl con y sin dispersante, clave para la aplicación de recubrimientos sobre sustratos, a fin de obtener compositos cerámicos por tratamiento térmico. En este apartado se aborda un análisis del proceso de recubrimiento de un sustrato arcilloso por inmersión en suspensiones BOHAI. En principio, el estudio consistió en establecer las condiciones experimentales más adecuadas para cubrir la superficie del sustrato con una capa delgada de BOHAI, posterior secado y sinterización. A fin de mejorar el procedimiento se obtuvieron recubrimientos sobre sustratos de distinta porosidad en diferentes condiciones operativas.

\subsection{Efecto del pretratamiento térmico del sustrato y temperatura del sustrato en la inmersión}

En esta etapa se presentan los resultados de la influencia de dos factores: pretratamiento térmico del sustrato (a 800 y $1100{ }^{\circ} \mathrm{C}$ ) y la temperatura del sustrato (Ts) al momento de realizar la inmersión (ambiente y a $90^{\circ} \mathrm{C}$ ). 
El sustrato seleccionado correspondió a una arcilla comercial, compuesta mayoritariamente por caolinita, cuarzo, feldespato y alúmina, el cual fue denominada LG en el presente trabajo (ver inciso 5.2.1.1.). En la Fig. 6.23 se muestra la curva termogravimétrica de dicho sustrato, realizado para conocer la magnitud de la pérdida de masa del mismo con el tratamiento térmico.

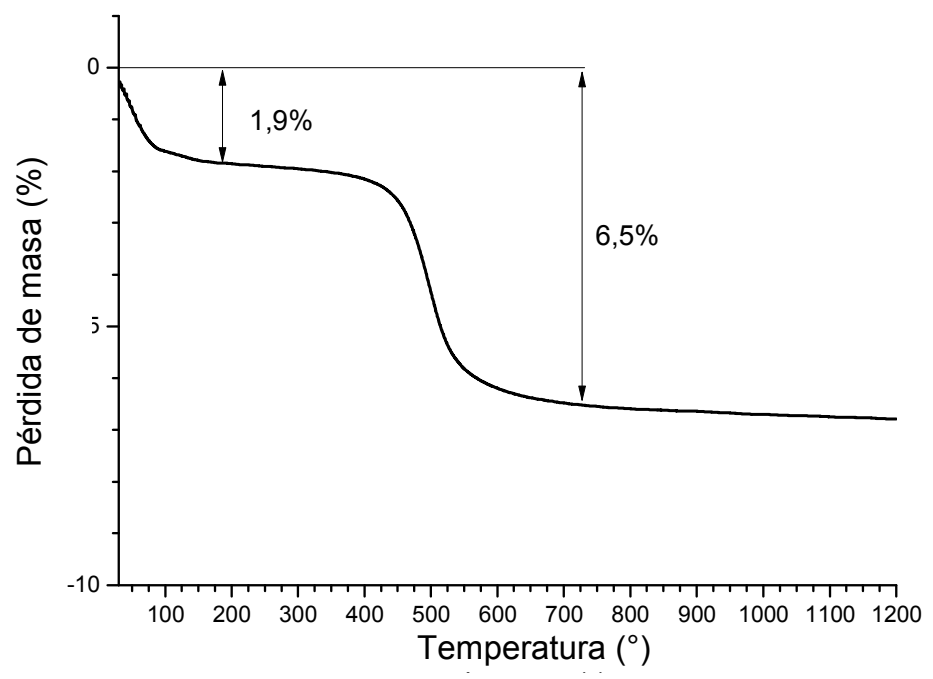

Fig. 6.23. Curva termogravimétrica del sustrato LG

La pérdida de masa observada hasta $200{ }^{\circ} \mathrm{C}(1,9 \%)$ se debe a la pérdida del agua adsorbida del mineral arcilloso (caolinita), mientras que la pérdida de masa entre $400-600{ }^{\circ} \mathrm{C}(6,5 \%)$ está asociada a la deshidroxilación de dicho mineral. No se observaron pérdidas de masa adicionales para el sustrato LG hasta $1200{ }^{\circ} \mathrm{C}$.

A fin de analizar la influencia de la porosidad del sustrato sobre los recubrimientos, se prepararon piezas por prensado uniaxial, en condición seca, calcinadas a 800 y $1100{ }^{\circ} \mathrm{C}$, y denominadas LG, LG8 y LG11, respectivamente. Las pérdidas de masa entre la temperatura de precalcinado más baja $\left(800^{\circ} \mathrm{C}\right)$ y la máxima evaluada en este ensayo $\left(1200^{\circ} \mathrm{C}\right)$ es $<0,2 \%$, por lo cual es considerada despreciable para futuros cálculos.

Las curvas de distribución de tamaño de poros de las muestras compactadas LG8 y LG11, obtenidas por porosimetría por intrusión de mercurio, se muestra en la Fig. 6.24. 

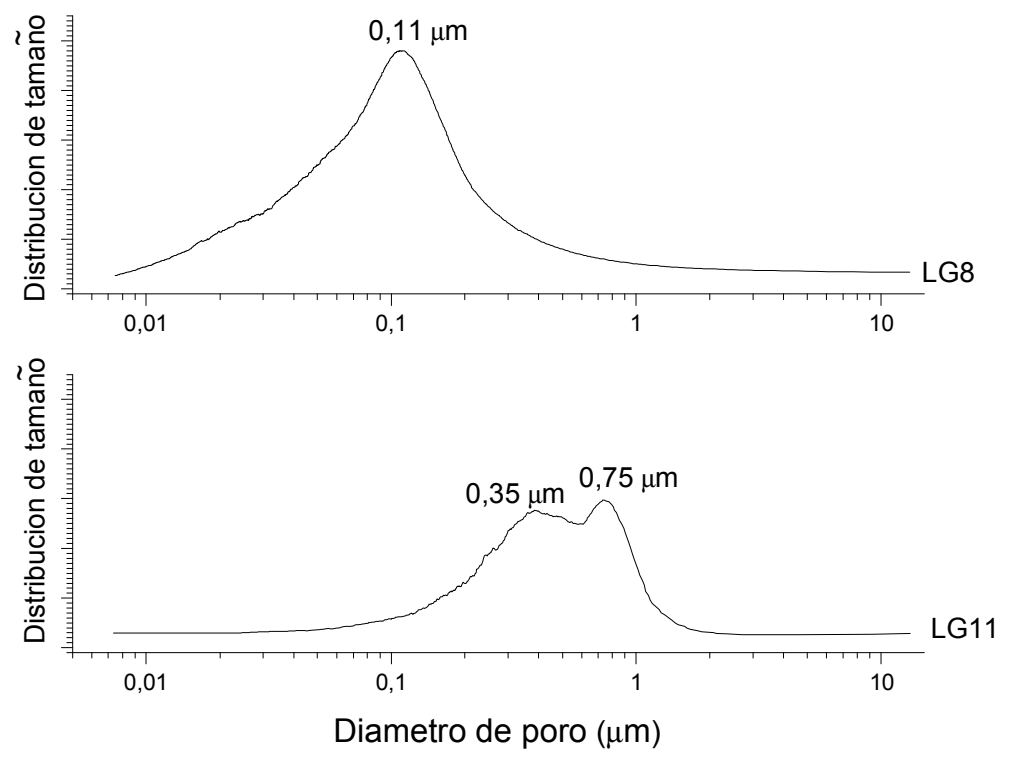

Fig. 6.24. Distribución de tamaño de poros de los sustratos LG sinterizados a 800 (LG8) y $1100^{\circ} \mathrm{C}($ LG11)

La muestra LG8 mostró una distribución unimodal, centrada en valores de diámetro de poro de $110 \mathrm{~nm}$, mientras que la muestra sinterizada a $1100{ }^{\circ} \mathrm{C}$ denotó una distribución bimodal, con valores de tamaños centrados en 350 y $750 \mathrm{~nm}$. La porosidad abierta de ambos sustratos, obtenidos por el mismo método fueron 32,1 y $18,1 \%$ para las muestras LG8 y LG11, respectivamente. La porosidad del sustrato sin precalcinar, LG, no pudo medirse por este método debido a que las elevadas presiones desarrolladas dentro del porosímetro comprimen la muestra sin calcinar, lo cual impide su medición ya que uno de los requisitos de este método es la ausencia de deformación del material durante la medición, condición que modificaría la porosidad del sustrato, invalidando los resultados obtenidos.

Los ensayos iniciales de recubrimientos por inmersión de los sustratos LG, LG8 y LG11 se realizaron sumergiendo cada uno de ellos a velocidad controlada en dos suspensiones acuosas de BOHAl (3 y $6 \% \mathrm{~m} / \mathrm{m}$ ) durante $10 \mathrm{~s}$, para su posterior extracción y dejando secar a temperatura ambiente las piezas previas a cada inmersión. Este proceso se repitió diez veces para las piezas sumergidas en la suspensión al $3 \% \mathrm{~m} / \mathrm{m}$ y cinco veces en la suspensión al 6 
$\% \mathrm{~m} / \mathrm{m}$. A fin de evaluar la influencia de la temperatura del sustrato en los recubrimientos obtenidos, se repitieron los ensayos bajo las mismas condiciones excepto que luego de cada inmersión el secado fue realizado en estufa a $90{ }^{\circ} \mathrm{C}$ durante $15 \mathrm{~min}$. Este tiempo fue elegido acorde a medidas preliminares, en las cuales se encontró que a este tiempo de secado, la variación de masa del recubrimiento fue nula, asegurando el secado completo del recubrimiento. Los compositos resultantes fueron sinterizados en horno eléctrico a $1100{ }^{\circ} \mathrm{C}$ durante $1 \mathrm{~h}$, temperatura de la primera aparición de picos de difracción de mullita en la muestra BOHAI (ver Fig. 6.11).

En la Fig. 6.25 se muestran las imágenes de los diferentes sustratos (LG, LG8 y LG11) recubiertos con suspensiones de BOHAl y sinterizados a $1100{ }^{\circ} \mathrm{C}$ durante $1 \mathrm{~h}$, para la diferentes condiciones de ensayos (concentraciones de las suspensiones y temperatura de secado entre inmersiones).

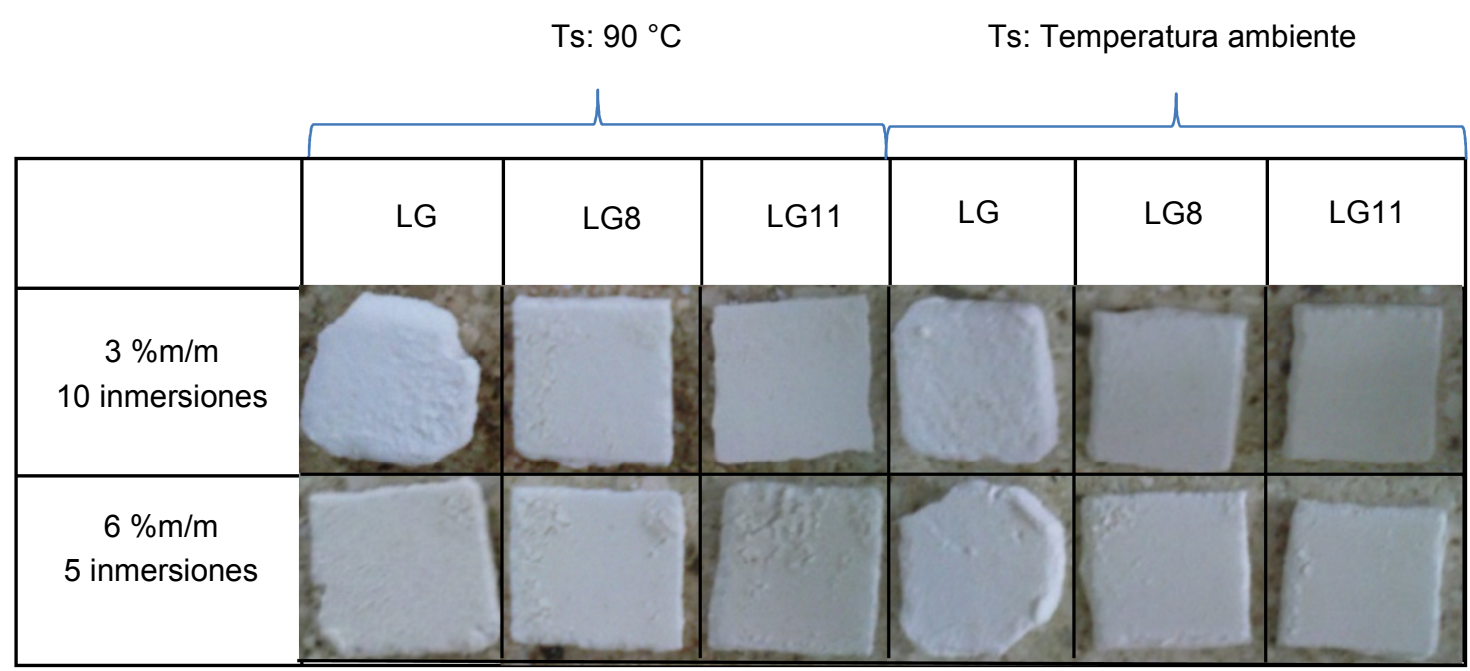

Fig. 6.25. Imagen de compositos sinterizados a $1100^{\circ} \mathrm{C}$ obtenidos por recubrimiento de LG con BOHAI

Como se observa en la Fig. 6.25 los compositos preparados con el sustrato sin tratamiento térmico (LG) han perdido su forma inicial, debido a la disgregación del sustrato crudo al exponerse a repetidas inmersiones. Este fenómeno es esperado en arcillas sin tratamiento térmico y expuestas en medio acuoso (Lagaly y Dékány, 2013). Por otra parte, los sustratos precalcinados a 800 y $1100{ }^{\circ} \mathrm{C}$ conservan su forma. Si bien todas las piezas sinterizadas muestran claramente agrietamiento superficial macroscópico en los bordes, se hace más notable en las piezas que fueron sumergidas inmediatamente después del 
secado en estufa a $90^{\circ} \mathrm{C}$ entre etapas de inmersión. Este tipo de agrietamiento fue observado durante el secado de las piezas, y las grietas generadas conservaron su morfología tras el sinterizado de los compositos.

No se observaron diferencias importantes en el aspecto de los recubrimientos obtenidos sobre los sustratos precalcinados a 800 y a $1100{ }^{\circ} \mathrm{C}$.

En la Fig. 6.26 se representa la masa de recubrimiento de BOHAl $\left(\mathrm{mg} / \mathrm{cm}^{2}\right)$ en los compositos sinterizado, preparados con diez y cinco inmersiones en suspensiones de 3 y $6 \% \mathrm{~m} / \mathrm{m}$ de $\mathrm{BOHAl}$, respectivamente, utilizando los sustratos LG previamente calcinados, LG8 y LG11.

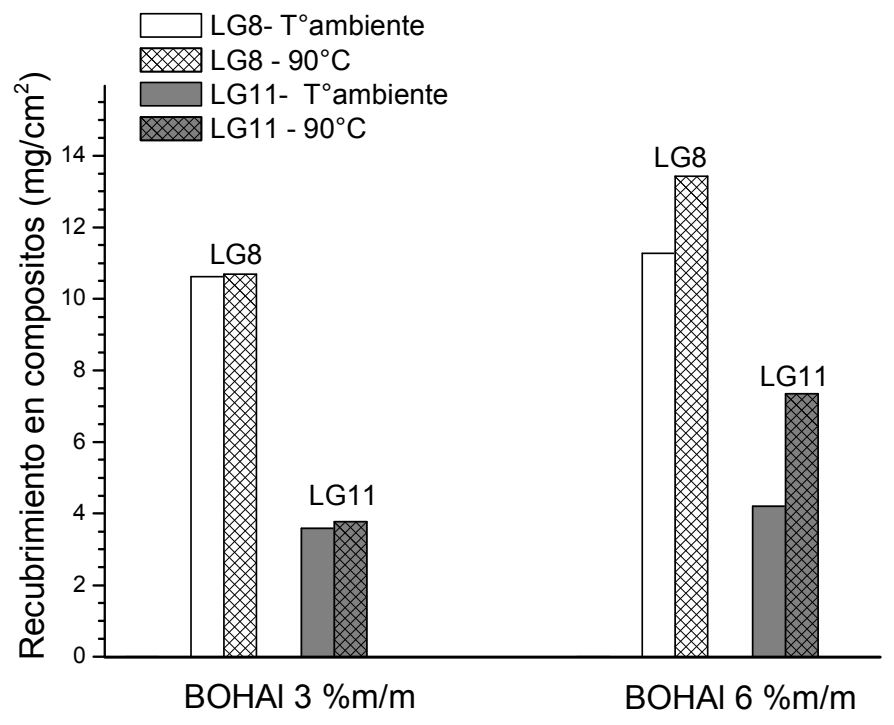

Fig. 6.26. Recubrimiento en compositos obtenidos por inmersión en suspensión de BOHAI $6 \% \mathrm{~m} / \mathrm{m}$ de sustratos LG8 y LG11, secados a temperatura ambiente y a $90{ }^{\circ} \mathrm{C}$, sinterizados a $1100^{\circ} \mathrm{C}$

Debido a la desintegración que sufre el sustrato LG (sin tratamiento térmico) no se pudo realizar una medida satisfactoria de la cantidad de recubrimiento sobre el mismo. La Fig. 6.26 muestra que los compositos preparados utilizando sustratos de mayor porosidad abierta y menor diámetro de poro (LG8) retuvieron mayores cantidades de BOHAl que el sustrato con menor porosidad y mayor diámetro de poro (LG11) para ambas concentraciones de las suspensiones BOHAl. Este resultado se asocia con el mecanismo de formación de recubrimiento por succión capilar (ver inciso 3.2.2.1), según el cual, manteniendo constantes las otras condiciones experimentales, sustratos con 
mayor porosidad abierta y menor diámetro de poro generan recubrimientos de mayor espesor (Gu y Meng, 1999).

Si bien la influencia del número de etapas de inmersión en la masa de recubrimiento depositada en los sustratos para el caso de recubrimiento con suspensiones arcillosas, no ha sido suficientemente examinada en los estudios consultados, las experiencias realizadas permiten extraer varias conclusiones. Considerando que el recubrimiento formado en etapa de inmersión anterior es un nuevo sustrato con propiedades texturales distintas para la siguiente etapa de inmersión, se estima que las sucesivas inmersiones producirían recubrimientos con un espesor que se incrementa con el tiempo hasta un valor estacionario (Moon, 2012). Suponiendo que los ciclos sucesivos cierran la estructura porosa, entonces la capa siguiente debería ser cada vez más fina. El espesor de dicho recubrimiento puede determinar la existencia de defectos en el mismo.

Estudios relacionados mostraron que el grado de agrietamiento depende del espesor de la capa formada. Tirumkudulu y Russel (2005) realizaron mediciones de evolución de tensiones y espaciado de grietas en el secado de films de suspensiones con esferas de polímeros variando el espesor (h) de los films. Empleando el criterio de Griffin (Griffith, 1921) para el equilibrio de propagación de grietas, los autores hallaron un modelo para predecir la tensión crítica para la nucleación de una grieta aislada, la cual depende del espesor $f\left(h^{-}\right.$ ${ }^{2 / 3}$ ). Este modelo predice que espesores demasiado gruesos de recubrimientos favorecerán la formación de grietas. Se demuestra que existe un espesor crítico, $h_{c}$, por debajo del cual no se generarán grietas. Este tipo de comportamiento ha sido observado por varios autores en el secado de recubrimientos cerámicos (Chen y col., 2017; Chiu y col., 1993; Holmes y col., 2006). Colina y Roux (2000) realizaron un análisis cuantitativo del agrietamiento de capas de arcilla depositadas sobre vidrios petri, sugiriendo la existencia de una relación entre espesor mínimo de las láminas formadas y el agrietamiento, definiendo un espesor crítico por debajo del cual no se desarrollan grietas macroscópicas. Estos trabajos previos sugieren que el agrietamiento observado se debe a que el espesor final de la capa de BOHAI excede dicho espesor crítico. La deshidratación y deshidroxilación durante el 
calentamiento de esta muestra y la contracción de la capa formada por el sinterizado, a su vez originan esfuerzos en la capa y en el sustrato. Es evidente que estos esfuerzos son significativos y que deben minimizarse para reducir el agrietamiento.

Con respecto a la influencia de la inmersión del sustrato en caliente a $90^{\circ} \mathrm{C}$, sobre los recubrimientos resultantes, la Fig. 6.26 muestra que ocurrió un leve aumento de la masa de recubrimiento, siendo notable cuando se utilizó la suspensión más concentrada. Sin embargo, debido a la mayor temperatura del sustrato es posible que se haya producido, al contacto con la suspensión acuosa, la formación de pequeñas burbujas en la superficie del mismo debido a la evaporación del agua. De acuerdo con Bonekamp (1996) la presencia de burbujas en la suspensión origina agrietamiento y "huecos" sin recubrimiento, hecho que se demostró en las piezas obtenidas por recubrimientos de alúmina sobre sustratos comerciales. La presencia de burbujas en la suspensión, debido a este efecto o por mala de-aireación de la suspensión, se vuelve perjudicial para la integridad del recubrimiento. Este fenómeno dificulta la adhesión del recubrimiento, y favorece el agrietamiento de los mismos si alguna de las burbujas queda atrapada en el film.

Goehring y col. (2010) estudiaron el secado de barbotinas de bentonita, y encontraron que las películas formadas se agrietaban con facilidad. Este fenómeno probablemente es producido por el comportamiento de hinchamiento de determinados tipos de bentonitas, que al secarse producen elevadas contracciones.

\subsection{Efecto del tiempo de inmersión y propiedades de la suspensión precursora}

Conforme a lo determinado en el inciso 6.3.2.2.1, el agrietamiento en verde observado se atribuye a un espesor de recubrimiento muy alto. De acuerdo con un mecanismo de formación de recubrimiento por succión capilar del sustrato, la cinética de crecimiento de la capa consolidada de partículas se describe como el flujo de un líquido Newtoniano a través de un lecho poroso y según este modelo el espesor de la capa obtenida depende del tiempo de inmersión con una dependencia de $f\left(t^{1 / 2}\right)$ (Landau y Levich, 1942). La dependencia 
observada de la masa de BOHAl con la porosidad y con el tamaño de poro del sustrato también indicó que probablemente este mecanismo sea el que gobierna la formación del recubrimiento.

Por ello, en este apartado se examina el efecto del tiempo de inmersión en la masa de BOHAl depositada y en el agrietamiento superficial del recubrimiento sinterizado. Teniendo en cuenta que el comportamiento de flujo de las suspensiones precursoras de recubrimiento es importante para un buen procesamiento, se evaluó experimentalmente el efecto del contenido de sólidos y diversos aditivos en las propiedades reológicas de dichas suspensiones.

El agregado de aditivos de procesamiento (espesantes, dispersantes, etc.) a suspensiones para el control de sus propiedades reológicas es una práctica usual en la industria. En particular, se ha estudiado extensivamente el uso de polímeros como modificadores de las propiedades reológicas de las suspensiones de bentonitas, debido principalmente al uso de estas suspensiones como lodos de arrastre de perforación en la producción de petróleo (Abu-Jdayil y Ghannam, 2014; Menezes y col., 2010). Sin embargo, los estudios referidos a las propiedades de suspensiones de arcillas intercaladas con especies poliméricas de aluminio son más limitados (Avena y col., 1990; Harsh y col., 1988).

En este estudio, las experiencias se realizaron aplicando el recubrimiento en las condiciones más adecuadas definidas anteriormente (i.e. sustrato precalcinado y sumergido a temperatura ambiente) y variando el tiempo de inmersión. Se prepararon cuatro suspensiones con 3 y $6 \% \mathrm{~m} / \mathrm{m}$ de $\mathrm{BOHAl}$, sin aditivos y con agregado de $1 \% \mathrm{~m} / \mathrm{m}$ sólido de carboximetilcelulosa (CMC). Utilizando estas suspensiones, se recubrieron por inmersión los sustratos LG8 y LG11 durante tiempos de inmersión variables $(5,10,20$ y 40 s), y retirados a la misma velocidad, para su posterior secado en estufa. Se repitió el proceso seis y tres veces para cada concentración, respectivamente, y luego los sustratos recubiertos fueron sinterizados a 1100 y $1200{ }^{\circ} \mathrm{C}$.

En la Fig. 6.27 se presentan las imágenes de la superficie de los compositos recubiertos a mayor tiempo de inmersión (40 s) sinterizados a 1100 y a 1200 ${ }^{\circ} \mathrm{C}$. 


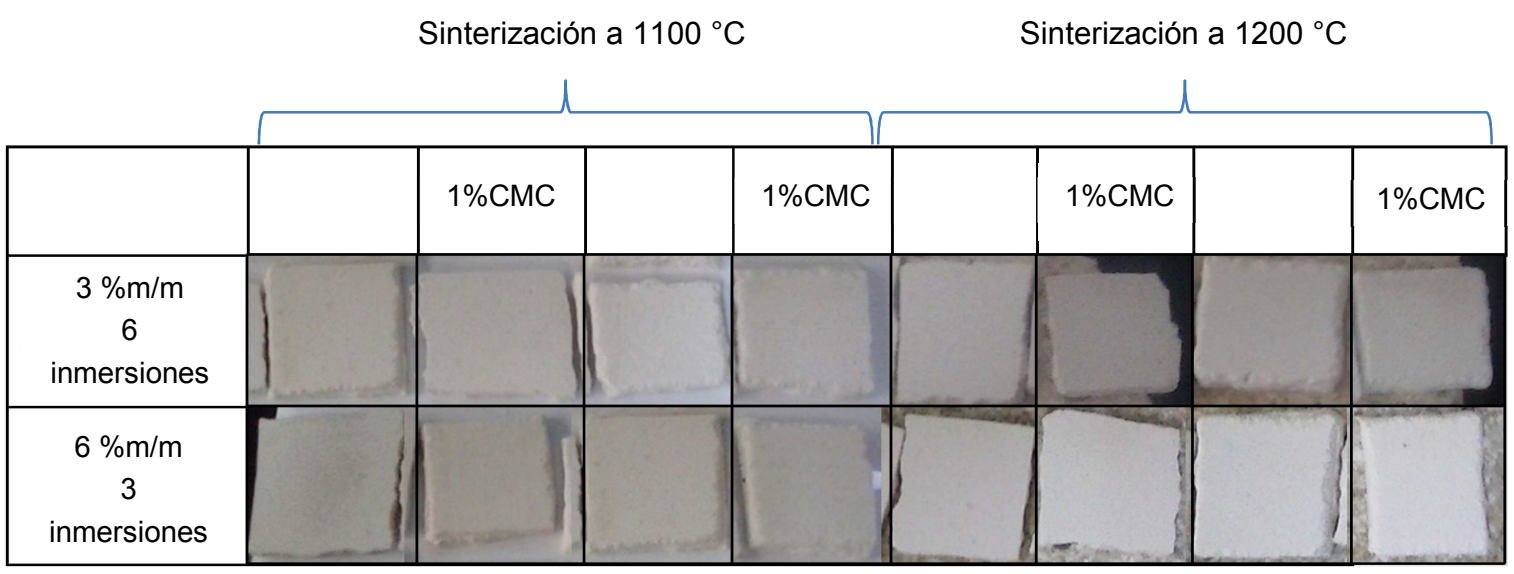

Fig. 6.27. Compositos obtenidos por recubrimiento de sustratos LG8 y LG11 en suspensiones de BOHAI sin aditivos y con CMC $1 \%$.

En general, ninguno de los recubrimientos obtenidos con este tiempo de inmersión (40 s) o menores denotaron el macroagrietamiento superficial observado en los recubrimientos del inciso anterior, presentando también una buena adherencia sin delaminación del recubrimiento, independiente de la suspensión de BOHAl utilizada y del sustrato empleado. La estabilidad del recubrimiento fue independiente además de la temperatura del sinterizado, observándose la ausencia de defectos macroscópicos para ambas temperaturas de sinterizado estudiadas.

La Fig. 6.28 muestra la variación de la cantidad de BOHAl retenida en función el tiempo de inmersión para diferentes sustratos (LG8 y LG11) utilizando suspensiones de BOHAl, con y sin CMC, y sinterización a 1100 y $1200{ }^{\circ} \mathrm{C}$. No se observa una correlación directa entre la cantidad de recubrimiento y el tiempo de inmersión en los distintos ensayos. Esto indicaría que el tiempo mínimo de inmersión utilizado (5 s) fue suficiente para alcanzar un valor estacionario de espesor (Moon, 2012), y, para cada caso, la variación de espesor registrada deriva de posibles errores experimentales y/o por la variación intrínseca del método de recubrimiento empleado. 


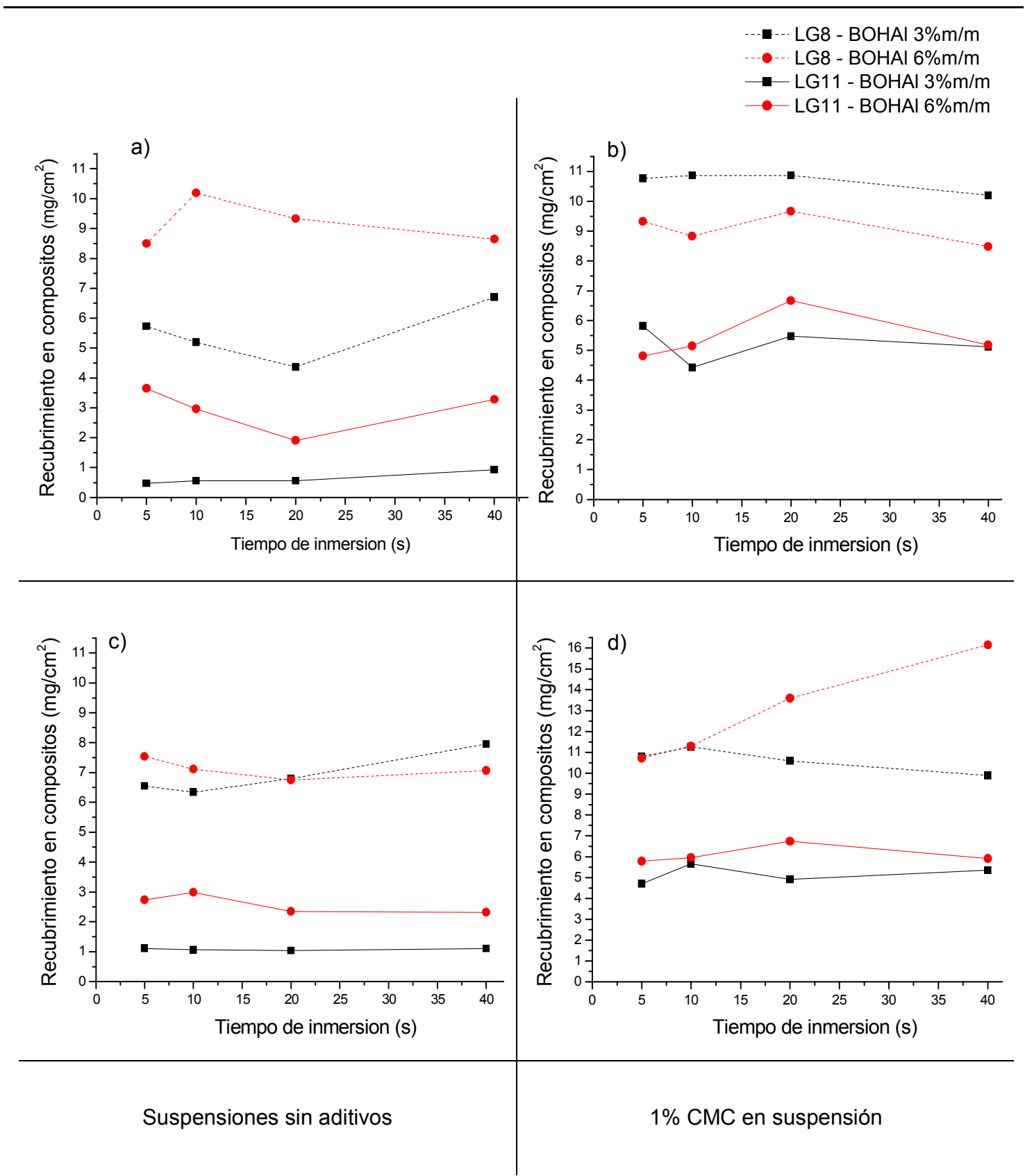

Fig. 6.28. Recubrimiento en compositos obtenidos por inmersión en distintas suspensiones de BOHAI de sustratos LG8 y LG11, sinterizados a), b) 1100 y

$$
\text { c),d) } 1200^{\circ} \mathrm{C} \text {. }
$$

Tal como fue descrito en el inciso 6.3.1.2.1, se confirma que la mayor cantidad de recubrimiento $\left(\mathrm{mg} / \mathrm{cm}^{2}\right)$ se encontró para LG8. El agregado de CMC a la suspensión resultó, en general, en mayores cantidades de recubrimiento en relación a las correspondientes sin aditivos. Cabe mencionar que durante el proceso de crecimiento de la capa consolidada tiene lugar el mecanismo de adherencia por arrastre además de la succión capilar que sería responsable del aumento en la cantidad depositada de BOHAl. Probablemente, la CMC actúa 
como espesante y aglomerante, como el polímero disuelto imparte mayor viscosidad y favorece la adherencia de la suspensión a la superficie.

Se ha reportado (Conceição y col., 2003) que la adición de CMC a suspensiones de arcilla provee mayor estabilidad, es decir impide la segregación de las partículas en suspensión.

Si bien en las condiciones ensayadas se logró eliminar las grietas macroscópicas presentes en las piezas (ver inciso 6.3.2.2.1), la observación de los recubrimientos mediante microscopía óptica (Fig. 6.29) evidenció la aparición de grietas en la superficie de todas las piezas sinterizadas a $1100{ }^{\circ} \mathrm{C}$.
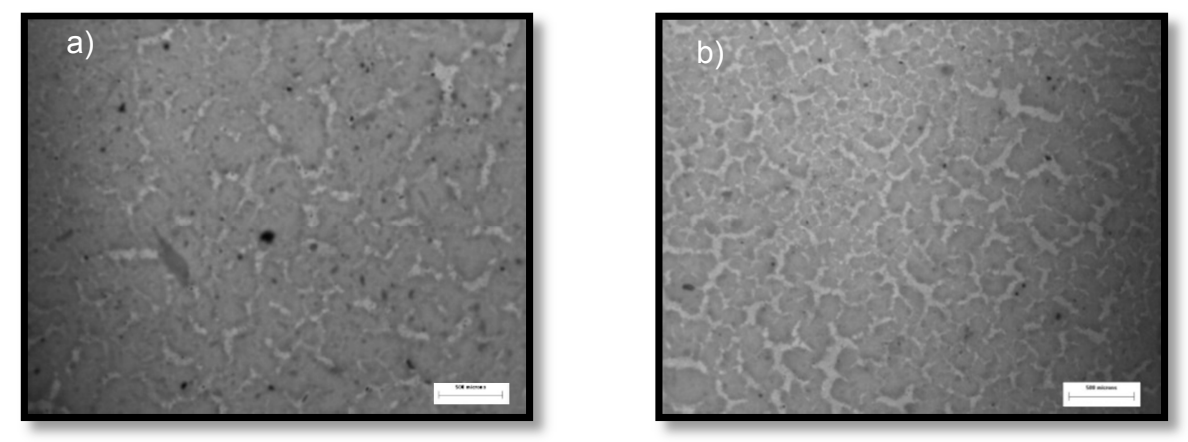

Fig. 6.29. Vista superior de compositos obtenidos por inmersión de a) LG8 y b) LG11 en suspensión $6 \% \mathrm{~m} / \mathrm{m}$ de BOHAl (t=10 s) sinterizados a $1100{ }^{\circ} \mathrm{C}$ (Barra: $500 \mu \mathrm{m})$

De acuerdo con lo explicado en el Capítulo 3, cuando un film densifica debido al sinterizado en un sustrato rígido, el recubrimiento estará sujeto a una tensión biaxial por el sustrato, y la densificación solo podrá ocurrir en dirección perpendicular a la superficie del sustrato. Según Green y col. (2008), las tensiones internas generadas, si bien presentes en todo el proceso de sinterizado, surgen principalmente durante la etapa de enfriamiento.

\subsection{Efecto de la temperatura de secado entre etapas sucesivas y de la temperatura de sinterizado}

Las etapas de secado y sinterizado pueden ser particularmente importantes para conseguir recubrimientos por inmersión sin defectos superficiales (agrietamiento, desprendimiento de recubrimiento, etc.). Las tensiones que 
surgen debido a las distintas velocidades de densificación y en etapas posteriores (i.e: diferentes coeficientes de expansión térmica durante el enfriamiento) pueden inducir a la delaminación, el agrietamiento y/o el "alabeo" del recubrimiento.

Para lograr el sinterizado adecuado de los compositos, definir el ciclo térmico tiene especial relevancia. Una velocidad de calentamiento muy alta puede causar un gradiente térmico excesivo en la pieza, derivando en posibles agrietamientos, distorsión de forma y/o microestructuras no homogéneas en la pieza final (Salamon y col., 2012). Además, surgen esfuerzos adicionales importantes durante la etapa de enfriamiento desde la temperatura de sinterizado, derivados de los distintos coeficientes de expansión térmica de las fases presentes en el cerámico.

Con el fin de obtener recubrimientos estables y bien adheridos, en este apartado se analizó la influencia del tipo de secado y del ciclo térmico de calentamiento y enfriamiento en las características superficiales de los recubrimientos obtenidos, hasta $1100^{\circ} \mathrm{C}$, de acuerdo a la Tabla 6.7. Para ello se prepararon recubrimientos en el sustrato LG8 utilizando suspensiones de 6 $\% \mathrm{~m} / \mathrm{m}$ de $\mathrm{BOHAl}$ sin aditivos, sumergiendo el sustrato durante $10 \mathrm{~s}$ con posterior secado, repitiendo tres veces la inmersión para finalmente completar el proceso con la sinterización.

Tabla 6.7: Condiciones de tratamiento térmico hasta 1100 y $1200^{\circ} \mathrm{C}$

\begin{tabular}{|c|c|c|c|}
\hline Tratamiento & \multicolumn{2}{|c|}{ Condiciones experimentales } & Denominación \\
\hline \multirow{2}{*}{ Secado } & \multicolumn{2}{|l|}{-a temperatura ambiente } & $\mathrm{Ta}$ \\
\hline & \multicolumn{2}{|l|}{-en estufa a $90^{\circ} \mathrm{C}$} & T90 \\
\hline \multirow{7}{*}{ Sinterizado } & \multicolumn{2}{|c|}{-calentamiento a $5^{\circ} \mathrm{C} / \mathrm{min}$ hasta temperatura final. Meseta $1 \mathrm{~h}$} & C5 \\
\hline & \multicolumn{2}{|c|}{-calentamiento a $2{ }^{\circ} \mathrm{C} / \mathrm{min}$ con 5 mesetas } & $\mathrm{C} 2 \mathrm{~m}$ \\
\hline & i. & $30 \min$ a $150^{\circ} \mathrm{C}$ & \\
\hline & ii. & $30 \min$ a $250^{\circ} \mathrm{C}$ & \\
\hline & iii. & $30 \min$ a $400{ }^{\circ} \mathrm{C}$ & \\
\hline & iv. & $30 \min$ a $550{ }^{\circ} \mathrm{C}$ & \\
\hline & v. & $1 \mathrm{~h}$ a temperatura final & \\
\hline \multirow[t]{2}{*}{ Enfriamiento } & \multicolumn{2}{|c|}{$\begin{array}{l}\text {-enfriamiento a } 2{ }^{\circ} \mathrm{C} / \mathrm{min} \text { desde temperatura final hasta } 600{ }^{\circ} \mathrm{C} \text {, y sin } \\
\text { regular hasta temperatura ambiente }\end{array}$} & E2 \\
\hline & \multicolumn{2}{|c|}{ - enfriamiento no regulado hasta temperatura ambiente } & Enr \\
\hline
\end{tabular}


La Fig. 6.30 se muestra la superficie de los compositos obtenidos posterior a tratamientos de secado y posterior sinterizado a $1100{ }^{\circ} \mathrm{C}$

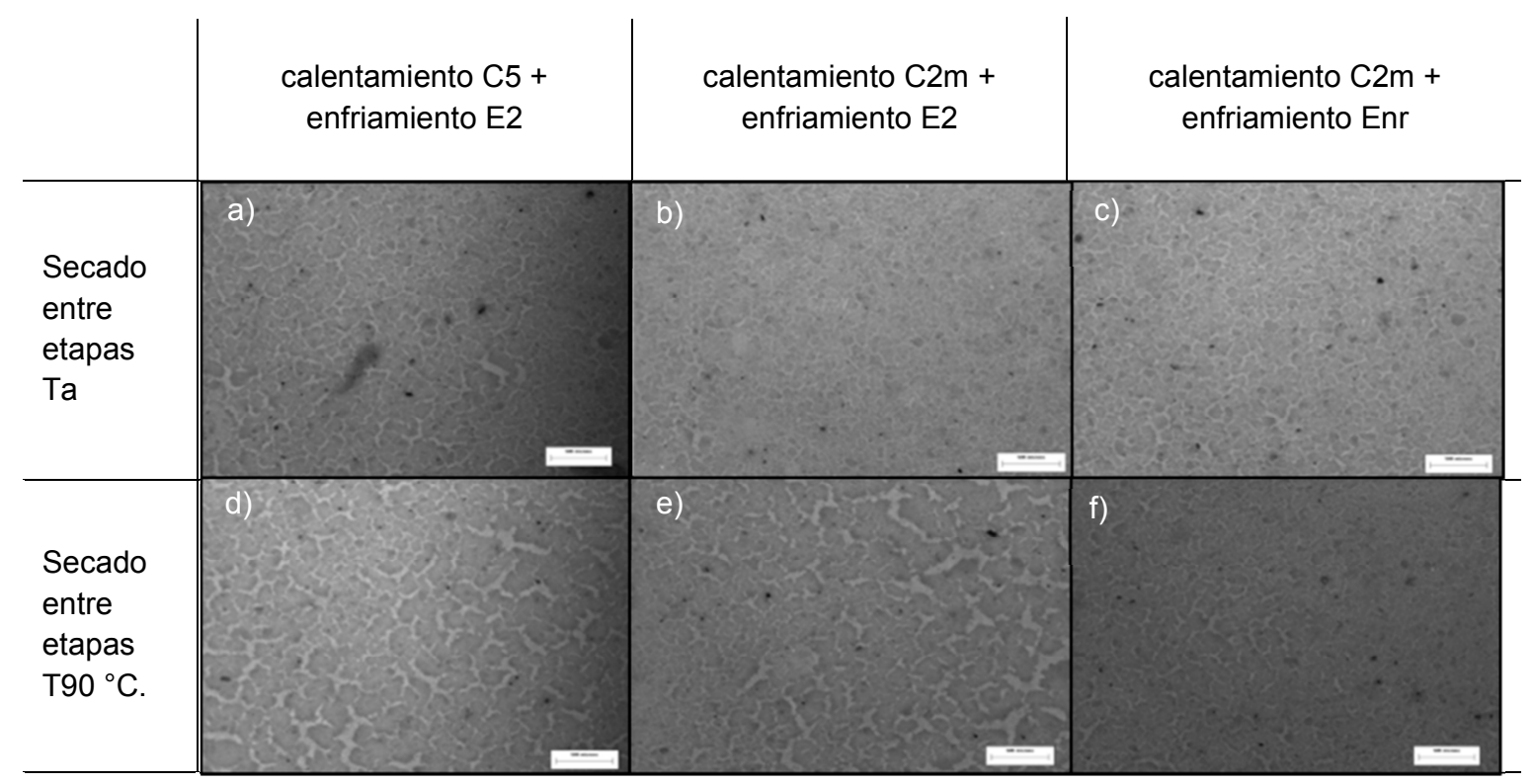

Fig. 6.30. Vista superior de compositos obtenidos por inmersión de sustratos LG8 en suspensión de $6 \% \mathrm{~m} / \mathrm{m}$ BOHAl sinterizados a $1100^{\circ} \mathrm{C}$ (Barra: $500 \mu \mathrm{m}$ )

En general, todos los compositos presentaron agrietamiento superficial aunque el secado de las muestras entre etapas sucesivas a temperatura ambiente (Fig. 6.30.a-c) condujo un tamaño de grieta mucho menor que la de piezas secas a $90{ }^{\circ} \mathrm{C}$ en estufa (Fig. 6.30.d-f). Según Scherer (1990), la formación de grietas en cuerpos porosos se debe principalmente a los esfuerzos a que está sometida la pieza debido al secado. Durante el mismo, el frente de líquido evaporándose alcanza la superficie del sólido.

Debido a que esto causaría un incremento de la energía del sistema debido a la tensión superficial de la interfaz sólido-aire que quedaría descubierta, el líquido tiende a fluir hacia la superficie para prevenir la exposición de la superficie del sólido. El flujo del líquido causa que el mismo se encuentre en tensión, lo cual es compensado por esfuerzos de compresión en el interior del recubrimiento, que conducen a la contracción del mismo. Si dicho esfuerzo compresivo aumenta (por ejemplo, debido a una alta velocidad de secado) el sólido puede agrietarse. A la vez, durante el secado de la pieza, el líquido alojado en los poros se evapora de manera diferencial (poros de mayor tamaño 
se vacían primero). La tensión capilar resultante comprime a los poros más pequeños, causando la aparición de esfuerzos locales que pueden derivar en el agrietamiento del recubrimiento.

Respecto a los recubrimientos sinterizados a baja velocidad de calentamiento (C2m) (Fig. 6.30.b y c), se observa que comparativamente el agrietamiento superficial es menor que cuando la sinterización se lleva a cabo a mayor velocidad de calentamiento (C5) (Fig. 6.30.a) indicando que una velocidad de calentamiento rápido no sería aceptable. El desajuste entre los coeficientes de expansión térmica (CET) del sustrato y del recubrimiento originarían esfuerzos de tensión, los cuales pueden relajarse por diferentes mecanismos, entre ellos, el agrietamiento y delaminación del recubrimiento (Salamon y col., 2012). Estas tensiones se ven incrementadas al aumentar la velocidad de calentamiento (Binner y col., 2008).

El efecto de la velocidad de enfriamiento se pudo observar en las muestras sinterizadas a velocidad de calentamiento lento, $\mathrm{C} 2 \mathrm{~m}$, en tanto que ocurrió un agrietamiento leve (Fig. 6.30.e) cuando la velocidad de enfriamiento fue controlada (E2), observado en la Fig. 6.30.b. Dicho efecto se puede relacionar con el alto contenido de fase vítrea (o fase no cristalina proveniente de la fase líquida presente a altas temperaturas) que se desarrolla en las piezas arcillosas por tratamiento térmico. De acuerdo con un estudio previo sobre preparación de agregados livianos a partir de arcillas (Bernhardt y col, 2014), el enfriamiento rápido favorece la formación de microgrietas en el cerámico, mientras que el enfriamiento lento mejora las propiedades mecánicas de los agregados obtenidos. Según estos autores, las microgrietas se pueden atribuir al alto contenido de fase vítrea en los cerámicos. La fase vítrea es susceptible al "choque térmico" por enfriamiento rápido, efecto que habría originado este agrietamiento. Sin embargo, en este estudio no se observa dicho efecto en las piezas sinterizadas a bajas velocidades de calentamiento (Fig. 6.30.e y f). Probablemente, la menor velocidad de calentamiento haya favorecido el desarrollo de fases con mayor cristalinidad, (i.e: un menor contenido de fase vítrea), aumentando la resistencia térmica y mecánica del material. 


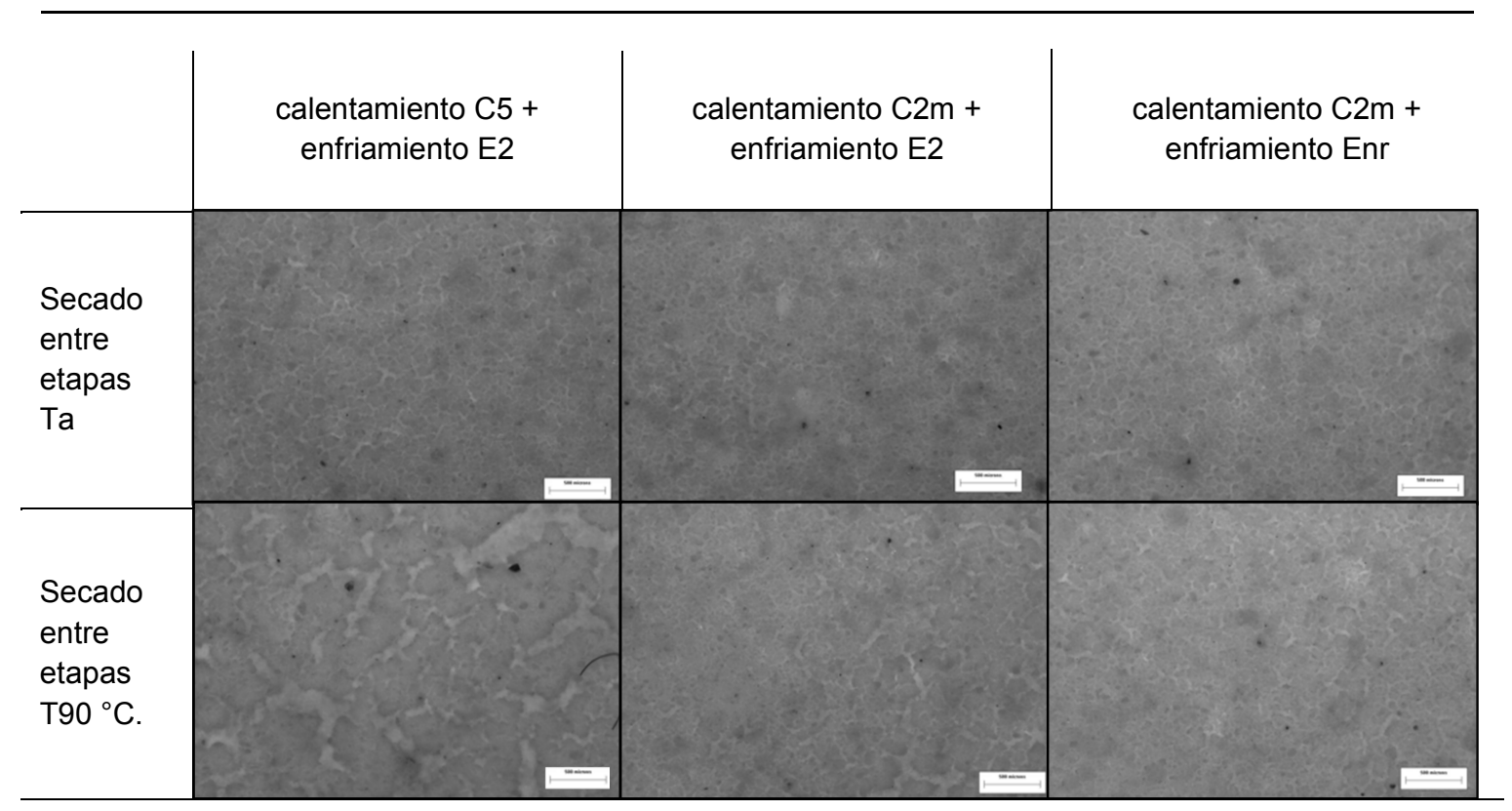

Fig. 6.31. Vista superior de compositos obtenidos por inmersión de sustratos

LG8 en suspensión de $6 \% \mathrm{~m} / \mathrm{m} \mathrm{BOHAl}$ sinterizados a $1200{ }^{\circ} \mathrm{C}$. (Barra: 500

$\mu \mathrm{m})$

La Fig. 6.31, similar a la Fig. 6.30, muestra imágenes de compositos, en este caso sinterizados a $1200{ }^{\circ} \mathrm{C}$. Si bien las tendencias observadas respecto al agrietamiento de los recubrimientos se mantiene, el aumento de la temperatura del sinterizado de BOHAl conduce a un producto con mayor desarrollo de mullita (compuesto de bajo coeficiente de expansión térmica) así como con menor proporción de fase vítrea (Fig. 6.11); esto resultaría favorable para el aumento de las propiedades mecánicas de los recubrimientos sinterizados a esta temperatura.

En base a los resultados obtenidos, se definieron las condiciones de secado y sinterizado más adecuadas para la obtención de recubrimientos de BOHAl por inmersión en suspensiones, a saber:

- Secado entre etapas de recubrimiento sucesivas a temperatura ambiente hasta peso constante.

- Sinterización a velocidad de calentamiento de $2{ }^{\circ} \mathrm{C} / \mathrm{min}$ con 5 mesetas hasta la temperatura máxima. En este caso, no se necesita una velocidad el enfriamiento controlada, ya que no se detectó una influencia en el agrietamiento superficial de los recubrimientos obtenidos 


\subsection{Ensayos de recubrimiento con suspensiones modificadas con diferentes aditivos}

Teniendo en cuenta las condiciones de secado y sinterización definidas anteriormente, que minimizan el agrietamiento de los recubrimientos por inmersión, en el presente estudio se analizó la posibilidad de mejorar estos compositos a partir del uso de poliacrilato de sodio (NaPA) como dispersante y/o carboximetilcelulosa (CMC) como espesante-ligante de suspensiones de BOHAl.

Estudios anteriores (Martinez y col., 2017c) demostraron que el agregado de NaPA a suspensiones de BOHAl mejora el grado de dispersión de las partículas suspendidas, a través de un mecanismo electrostérico, (Capítulo 6) evitando la formación de flóculos. Por otra parte, los agentes espesantes aumentan la viscosidad de la suspensión e inciden en la estabilidad (i.e: evitando la sedimentación rápida), requisito necesario para la formación de recubrimientos por inmersión. Un espesante efectivo para modificar las propiedades reológicas de suspensiones de bentonita es la CMC (Abu-Jdayil y Ghannam, 2014; Menezes y col., 2010).

Para llevar adelante esta etapa, se prepararon cuatro tipos de suspensiones acuosas $6 \% \mathrm{~m} / \mathrm{m}$ de BOHAl conteniendo los aditivos ya mencionados. Las suspensiones obtenidas se denominaron:

- Suspensión B: Sin agregado de aditivos.

- Suspensión D: 2,8 \% m/m NaPA

- Suspensión T: 2,8 \% m/m NaPA + 1\% m/m CMC

- Suspensión C: $1 \% \mathrm{~m} / \mathrm{m} \mathrm{CMC}$ 
Los recubrimientos sobre los sustratos LG8 y LG11, se aplicaron por inmersión en la suspensión (B, D, T y C) durante $10 \mathrm{~s}$, extracción a velocidad controlada; las piezas recubiertas se secaron a temperatura ambiente hasta peso constante. Esta etapa se repitió tres veces, y posteriormente las piezas recubiertas se sinterizaron siguiendo el ciclo de calentamiento previamente definido, es decir velocidad de calentamiento a $2{ }^{\circ} \mathrm{C} / \mathrm{min}$ y enfriamiento a 2 ${ }^{\circ} \mathrm{C} / \mathrm{min}$ (ver 6.3.2.2.3). En la Fig. 6.32 se muestra la masa total de BOHAl depositada en los compositos sinterizados a 1100 y $1200{ }^{\circ} \mathrm{C}$, preparados con suspensiones de BOHAl conteniendo diferentes aditivos.

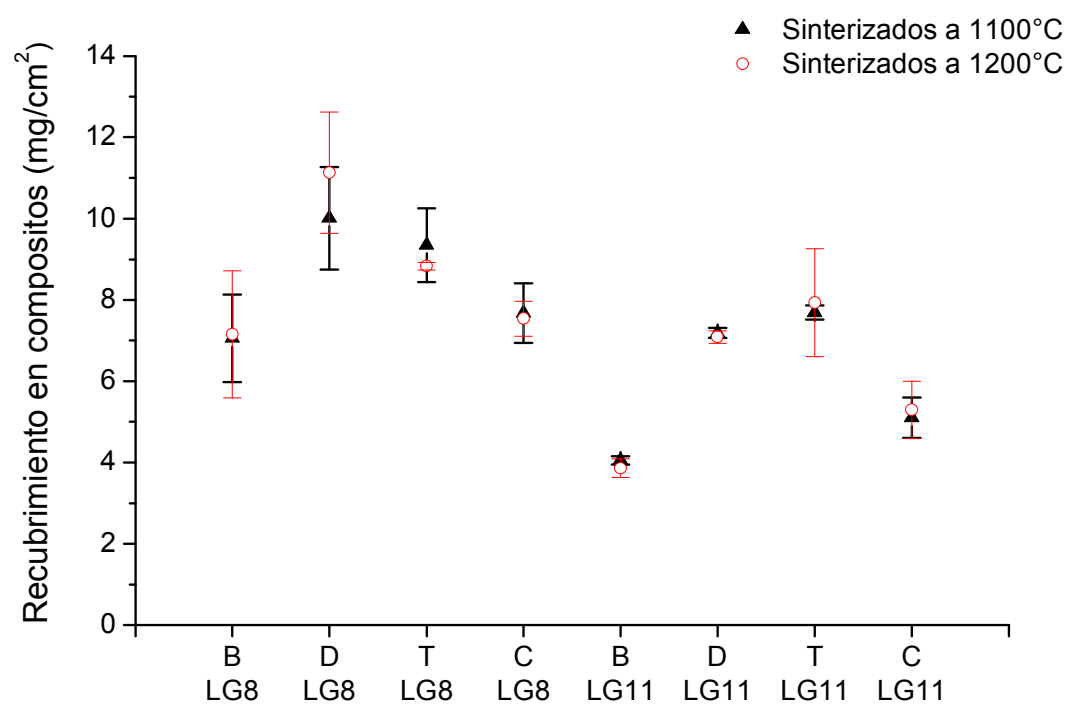

Fig. 6.32. Recubrimiento en compositos obtenidos por inmersión en suspensiones de BOHAI (B,D,T y C) de sustratos LG8 y LG11, con posterior sinterización a 1100 y $1200^{\circ} \mathrm{C}$

Así como en otros ensayos anteriores (Fig. 6.26 y 6.28), para una dada suspensión se cumple que la cantidad de recubrimiento en el sustrato LG8 es mayor que la correspondiente al sustrato LG11, debido a su mayor porosidad y menor tamaño de poro (inciso 6.1.3.1). A la vez, se encontró que la temperatura de sinterizado no afecta notablemente la cantidad de recubrimiento, lo cual es acorde con lo determinado por termogravimetría para BOHAl y para el sustrato (Fig. 6.7 y 6.23, respectivamente); donde no se aprecia pérdida de masa entre 1100 y $1200{ }^{\circ} \mathrm{C}(<0,1 \%)$. 
Respecto a la influencia de NaPA y CMC como modificadores de la suspensión (suspensiones $\mathrm{D}$ y $\mathrm{C}$ ), se observa que estos aditivos ayudaron a incrementar la cantidad de recubrimiento. Probablemente, con la suspensión bien dispersa lograda con el NaPA (i.e: ruptura de flóculos) se haya alcanzado un empaquetamiento de partículas más denso en la capa formada. Tanto la desaglomeración causada por el dispersante, así como el efecto espesante de la CMC (ver inciso 6.3.1.4) derivaron en mayores cantidades de recubrimiento en los compositos respecto a la muestra obtenida a partir de la suspensión sin aditivos.

Sin embargo, el efecto combinado de CMC y NaPA (suspensión C) produjo compositos con una cantidad de BOHAI menor o similar a los obtenidos con la suspensión con dispersante (para ambos sustratos). Esto se debe este tipo de compuestos se adsorbe en superficie de las partículas suspendidas. Probablemente, ambos compuestos compitan por los sitios de adsorción, derivando en menores cantidades adsorbidas de estos aditivos en superficie del sólido. Estudios referidos a la adsorción de CMC sobre arcillas (Husband, 1998) pretratadas con NaPA demuestran dichas especies competirían entre sí por los sitios de adsorción sobre las partículas de arcilla.

En la Fig. 6.33 se presentan micrografías SEM de la superficie de los recubrimientos BOHAl con $y$ sin aditivos sobre sustratos y posterior sinterización a $1100^{\circ} \mathrm{C}$. En general, existe microagrietamiento superficial de los recubrimientos. 


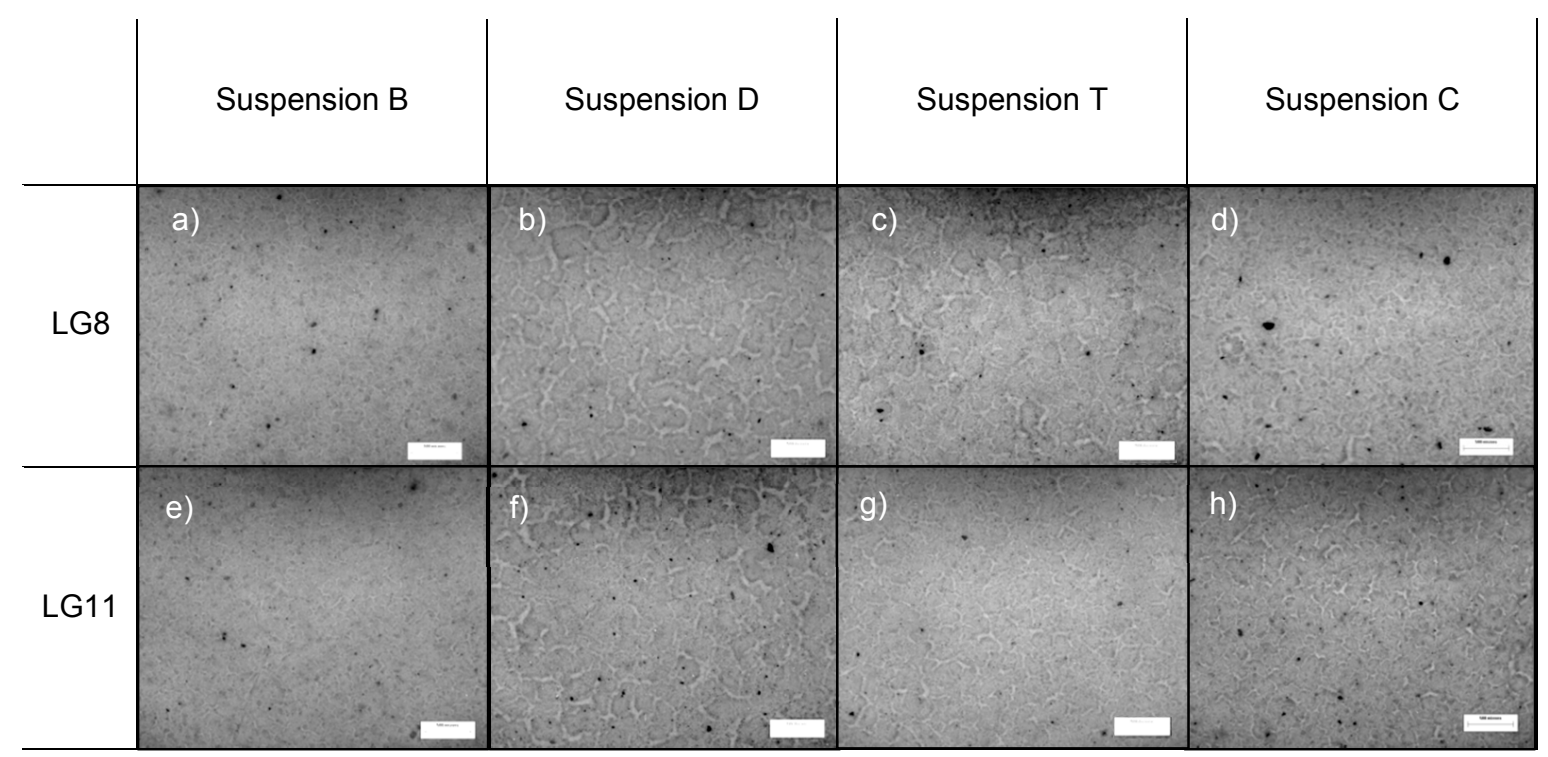

Fig. 6.33. Vista superior de compositos obtenidos por inmersión de sustratos en suspensiones de $6 \% \mathrm{~m} / \mathrm{m} \mathrm{BOHAl}$ con y sin aditivos, sinterizados a $1100{ }^{\circ} \mathrm{C}$.

(Barra: $500 \mu \mathrm{m}$ )

Dicho fenómeno depende de diversos factores, entre ellos presenta una influencia marcada del esfuerzo térmico originado por la diferencia entre los coeficientes de expansión térmica del sustrato y el recubrimiento por lo que resulta necesaria la determinación de ambos coeficientes de expansión. Por ello, utilizando los datos extraídos de las curvas dilatométricas obtenidas por microscopia de calentamiento, se determinaron los coeficientes de dilatación térmica del soporte y el recubrimiento. En la Fig. 6.34.a y b se muestra la variación del coeficiente de expansión térmica con la temperatura para sustrato y recubrimiento, ambos sinterizados a 1100 y $1200{ }^{\circ} \mathrm{C}$. El comportamiento también es diferente. Los valores del soporte sinterizado a 1100 y $1200{ }^{\circ} \mathrm{C}$ (LG1100 y LG1200) presentan un considerable aumento a $570{ }^{\circ} \mathrm{C}$ a partir del cual el coeficiente comienza gradualmente a reducirse, en tanto que el coeficiente de los recubrimientos sinterizados (BOHAl-11 y BOHAl-12) no presenta grandes variaciones con la temperatura lo que puede producir esfuerzos suficientes para generar las grietas. 

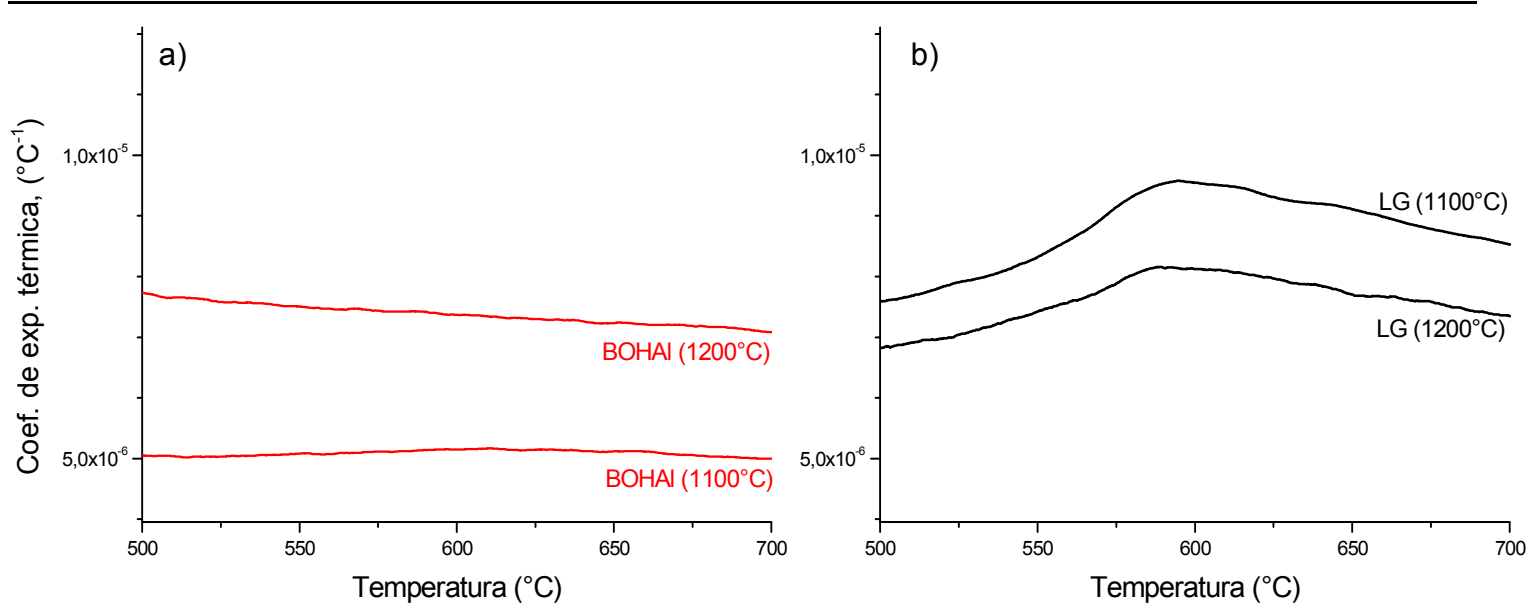

Fig. 6.34. Coeficiente de expansión térmica vs temperatura para a ) BOHAl y b) sustrato LG sinterizados, a 1100 y $1200^{\circ} \mathrm{C}$.

Así, durante enfriamiento desde la temperatura de sinterización, recubrimiento se ve sometido a un esfuerzo térmico debido al incremento del coeficiente de expansión del sustrato en este rango de temperaturas. Esto se debe a las partículas de cuarzo proveniente del soporte LG. Dicha fase cristalina posee una reacción de transformación de fase al enfriarse (cuarzo $\beta \rightarrow$ cuarzo $\alpha$ ), la cual genera una rápida contracción a $573{ }^{\circ} \mathrm{C}$ (Worrall, 2013) durante el enfriamiento de las piezas en el sinterizado (Fig. 6.34.b). En general, se encontró mayor tamaño de grietas para recubrimientos obtenidos a partir de las suspensiones con aditivos (suspensiones $\mathrm{D}, \mathrm{T}$ y $\mathrm{C}$ ) en comparación con los compositos obtenidos a partir de la suspensión sin aditivos. Es probable que la eliminación del aditivo orgánico en el calentamiento genere comparativamente mayor contracción que daría lugar a un agrietamiento mayor.

En la Fig. 6.35 se observa la superficie de los recubrimientos obtenidos sinterizados a $1200^{\circ} \mathrm{C}$. 


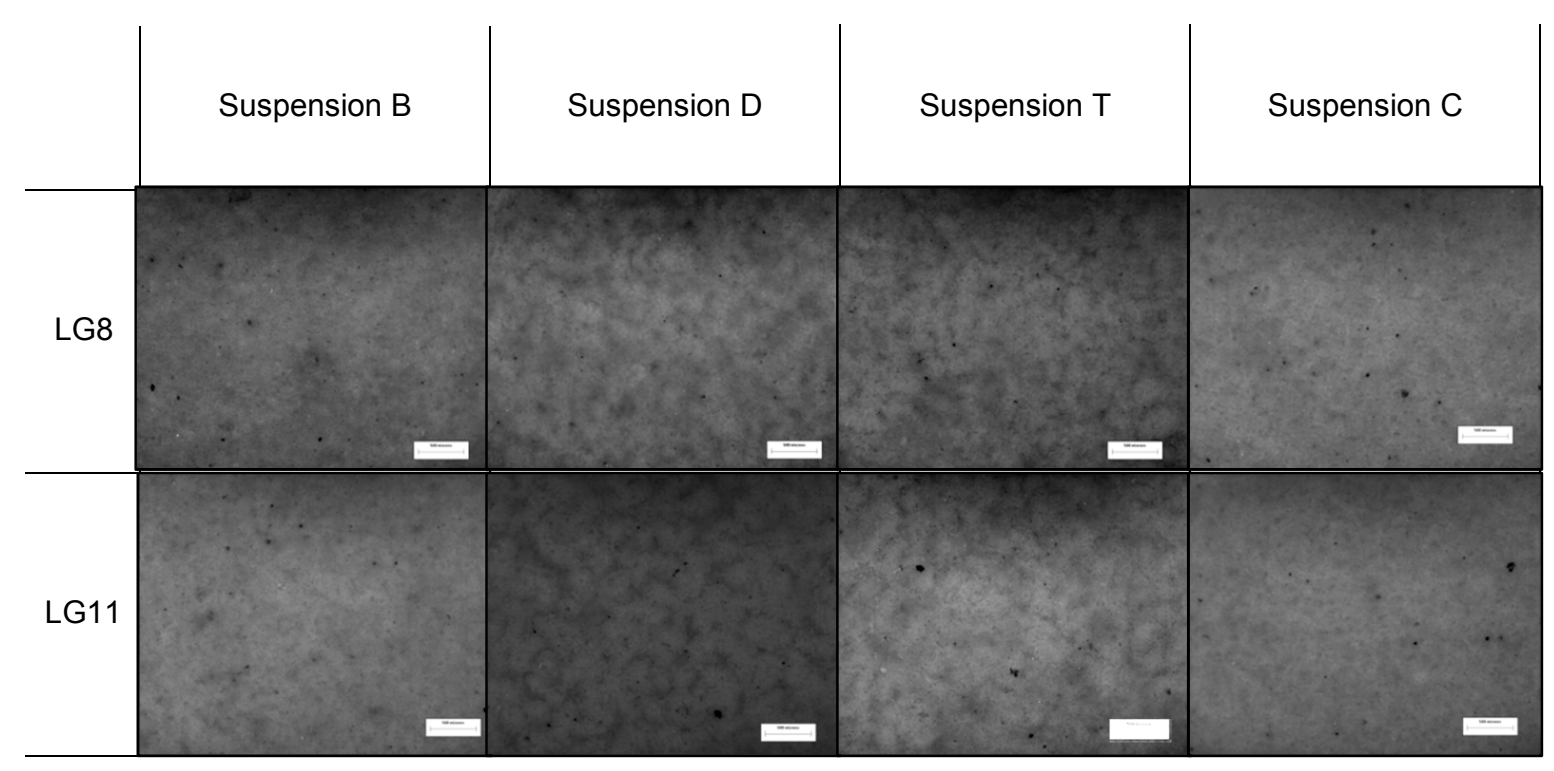

Fig. 6.35. Vista superior de compositos obtenidos por inmersión de sustratos LG8 y LG11 en suspensiones de $6 \% \mathrm{~m} / \mathrm{m}$ BOHAl con y sin aditivos sinterizados a $1200{ }^{\circ} \mathrm{C}$. (Barra: $\left.500 \mu \mathrm{m}\right)$

Así como en los compositos sinterizados a $1100{ }^{\circ} \mathrm{C}$, no se observa influencia apreciable del sustrato utilizado en el aspecto superficial de los recubrimientos. El agrietamiento de las muestras sinterizadas a $1200{ }^{\circ} \mathrm{C}$ (áreas oscuras en imágenes) procesadas a partir de las suspensiones con NaPA (suspensiones D y T) se incrementó, mientras que los recubrimientos obtenidos a partir de las suspensiones B y C presentaron agrietamiento similar al de las piezas respectivas sinterizadas a $1100{ }^{\circ} \mathrm{C}$. La temperatura de sinterizado no afectó la tendencia al agrietamiento; y el hecho de poder realizar el sinterizado a 1200 ${ }^{\circ} \mathrm{C}$, es favorable para el desarrollo de mullita como producto de reacción de BOHAl (Martinez y col., 2017c), y en consecuencia, mejorar sus propiedades mecánicas. Así, en general se comprueba que los recubrimientos con mayor cantidad retenida (i.e. espesor) producen un agrietamiento mayor. 
El efecto de los aditivos NaPA y CMC en la densificación de la muestra BOHAl, precursora de los recubrimientos, se examinó en discos conformados por colado en yeso de las suspensiones B, D, T y C. En la Fig. 6.36 se presenta la porosidad abierta y densidad aparente de piezas sinterizadas a 1000, 1100 y $1200{ }^{\circ} \mathrm{C}$ durante $1 \mathrm{~h}$.
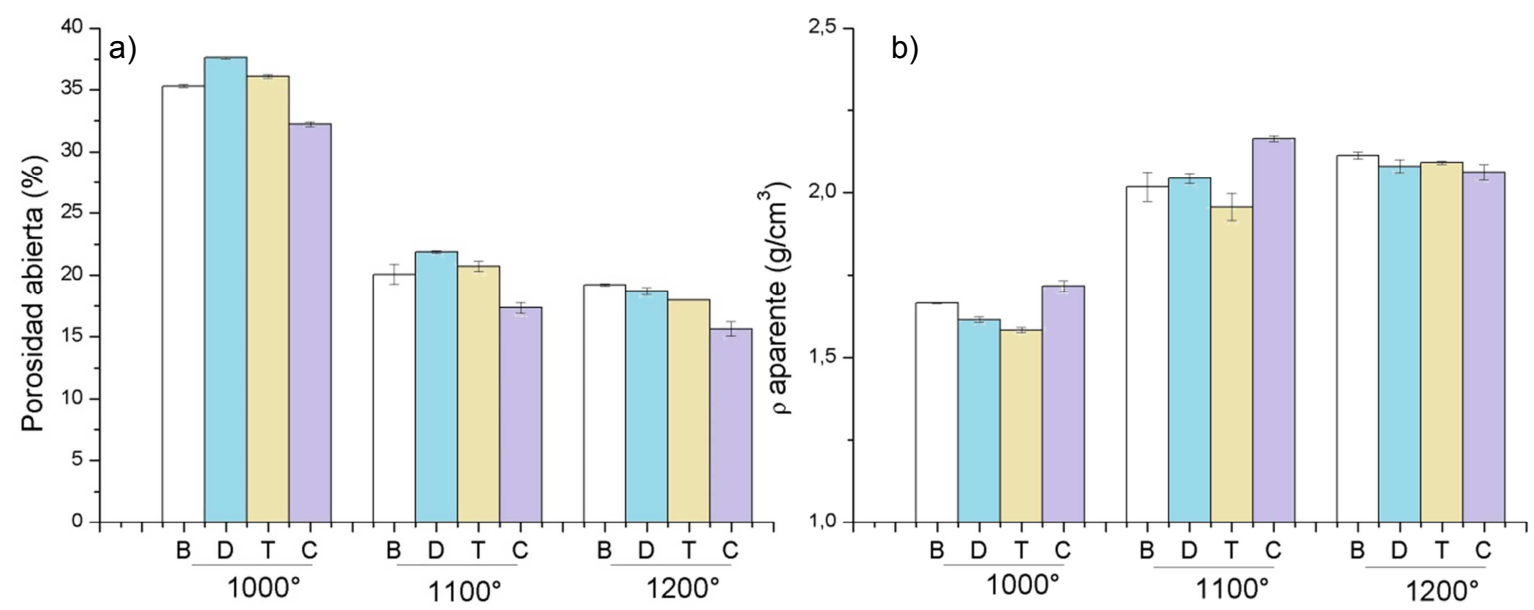

Fig. 6.36.a) Porosidad abierta y b) densidad aparente de piezas BOHAl sinterizadas obtenidas por colado de suspensiones de $6 \% \mathrm{~m} / \mathrm{m}$.

La densificación de las piezas va acompañada con disminución de la porosidad abierta, debido al avance del sinterizado al elevar la temperatura de $1000{ }^{\circ} \mathrm{C}$ a $1100{ }^{\circ} \mathrm{C}$. La porosidad abierta menor correspondió a las piezas obtenidas a partir de la suspensión C. Este efecto se entiende por el aumento de viscosidad que provee la CMC a dicha suspensión, el cual impediría la segregación de las impurezas de feldespato y cuarzo, fases constituyentes en la bentonita B. La segregación de dichas partículas, de mayor tamaño, provocaría un empaquetamiento de partículas deficiente en las suspensiones $\mathrm{D}$ y $\mathrm{T}$, resultando piezas con mayor porosidad abierta.

Si bien estas experiencias demostraron que los cerámicos obtenidos a partir de la suspensión con CMC poseen menor porosidad abierta y densidad aparente similar o mayor que las correspondientes a la suspensión sin aditivos (B), los recubrimientos con $\mathrm{CMC}$ poseen un agrietamiento mayor y una masa de BOHAl depositada similar. Por ello, en los ensayos posteriores se optó por realizar los recubrimientos sin el agregado de aditivos en la suspensión BOHAl. 
Debido a que el cuarzo presente en la composición del sustrato contribuye a la formación de microgrietas durante el sinterizado, en los ensayos posteriores se utilizan sustratos preparados con la arcilla caolinítica PG, que comparativamente exhibe una variación menor del coeficiente de expansión térmica en este rango de temperaturas (Fig. 6.37).

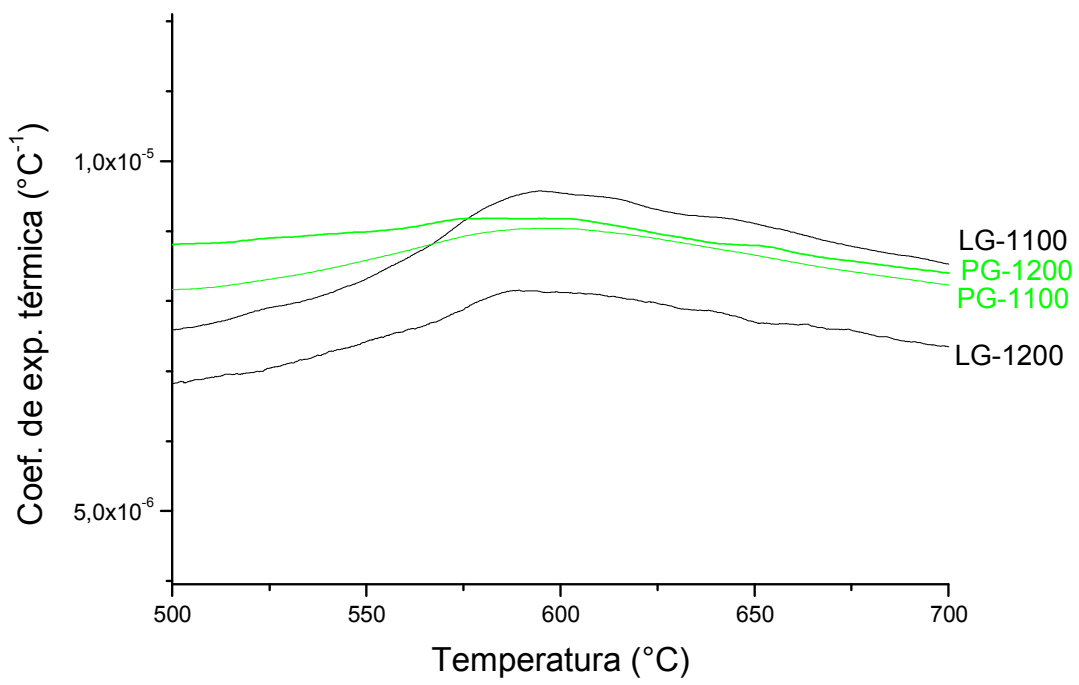

Fig. 6.37. Coeficiente de expansión térmica vs temperatura de sustratos $P G$ y

LG sinterizados a 1100 y $1200^{\circ} \mathrm{C}$

\subsection{Ensayos de recubrimiento sobre sustratos PG}

Tal como se indicó precedentemente, a fin de evaluar la posibilidad de minimizar los defectos en los recubrimientos, se procedió a la aplicación de recubrimientos sobre sustratos de arcilla PG presentado en el inciso 5.2.1.1.

El sustrato seleccionado fue preparado utilizando una arcilla comercial, compuesta principalmente por caolinita, cuarzo y feldespato, la cual fue denominada $P G$ en el presente trabajo (ver inciso 5.2.1.1.). En la Fig. $6.38 \mathrm{se}$ muestra la curva termogravimétrica de dicho sustrato. 


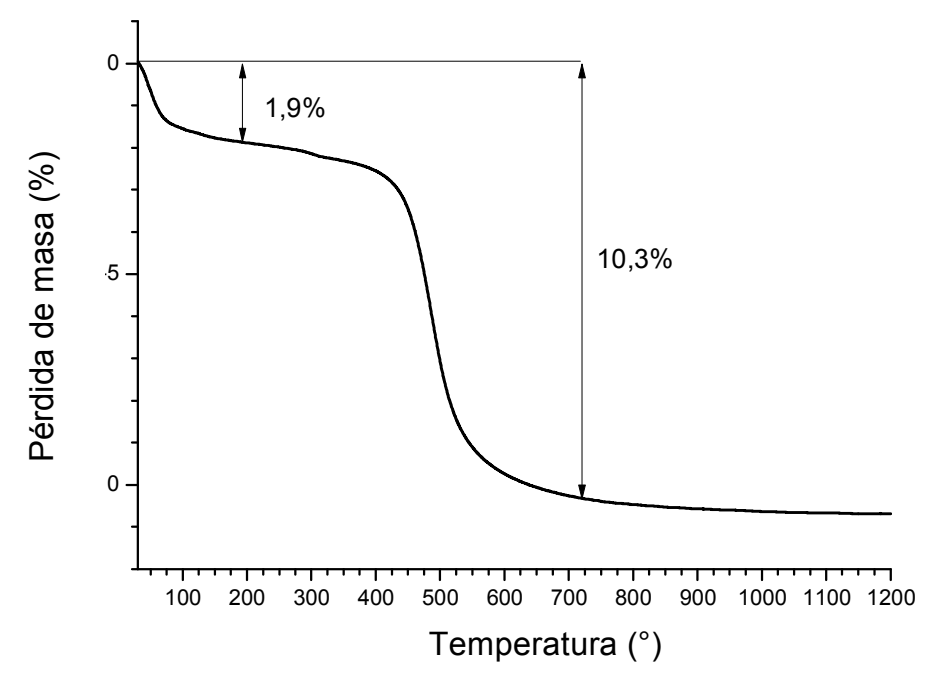

Fig. 6.38. Curva termogravimétrica del sustrato PG

Los resultados del inciso anterior además demostraron que el agregado de aditivos a las suspensiones precursoras, si bien ayuda a la preparación de una suspensión estable, no mejora sustancialmente las propiedades de los recubrimientos, ni disminuye el agrietamiento observado. Por ello, en esta etapa, se utilizaron los sustratos PG calcinados a 1000 y $1100{ }^{\circ} \mathrm{C}$ (denominados PG10 y PG11) los cuales poseen una porosidad abierta total de $33,0 \%$ para PG10 y $21,1 \%$ para PG11. Dichos valores de porosidad abierta son similares a las de los sustratos LG8 (32,1\%) y LG11 $(18,1 \%)$ respectivamente. En la Fig. 6.39 se muestra la distribución de tamaño de poros de los sustratos PG10 y PG11, así como de los sustratos antes utilizados (LG8 y LG11). 

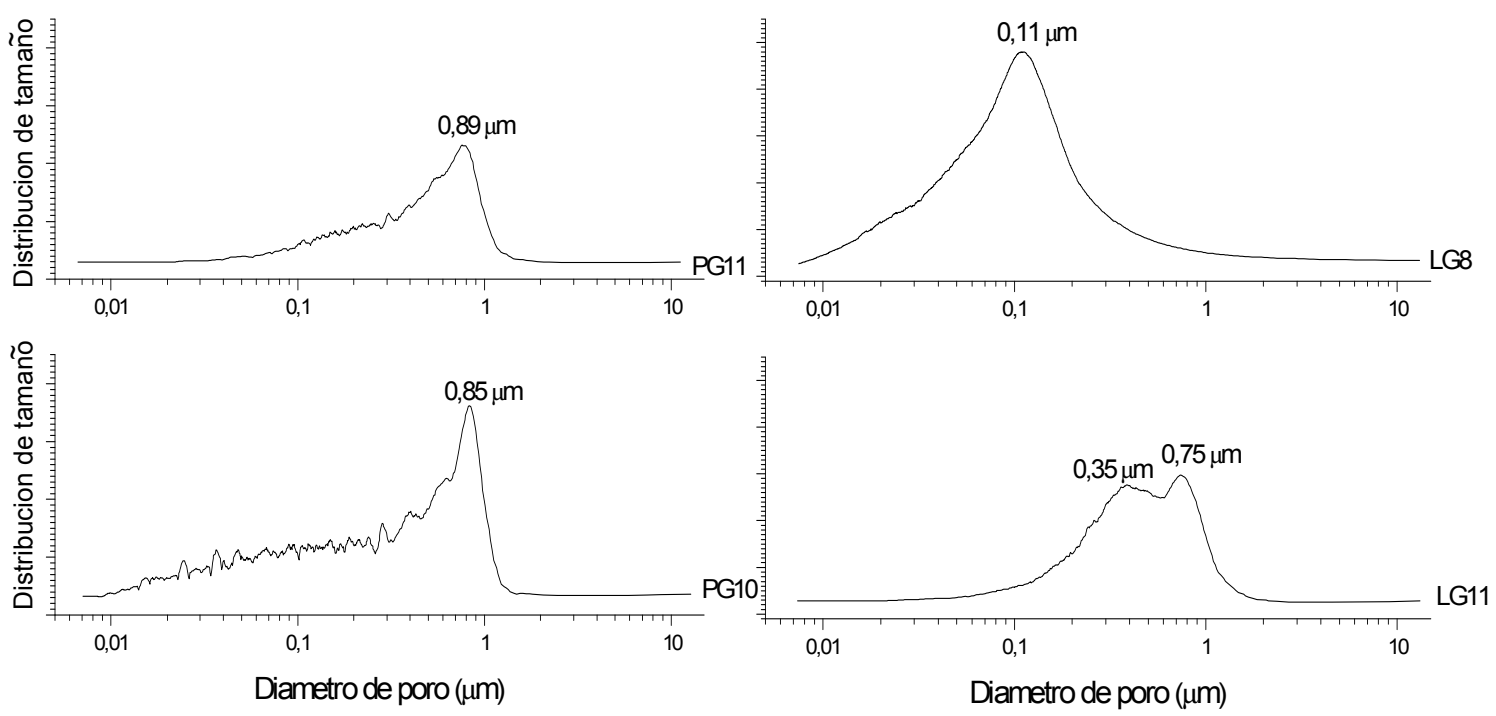

Fig. 6.39. Distribución de tamaño de poros en sustratos

Se observa que los sustratos PG10 y PG11 poseen valores de diámetro de poro más frecuente cercanos a los valores del sustrato LG11; aunque denotan una distribución unimodal con una asimetría hacia menores valores de diámetro de poro.

Los recubrimientos se obtuvieron por inmersión de ambos sustratos en suspensiones de BOHAl al $6 \% \mathrm{~m} / \mathrm{m}$, por $10 \mathrm{~s}$, extracción a velocidad controlada, secado a temperatura ambiente hasta peso constante, repitiendo este procedimiento tres veces. Posteriormente, las piezas recubiertas se sinterizaron siguiendo el ciclo térmico definido anteriormente, velocidad de calentamiento a $2{ }^{\circ} \mathrm{C} / \mathrm{min}$ hasta $1100{ }^{\circ} \mathrm{C}$ y $1200^{\circ} \mathrm{C}$, con enfriamiento regulado (ver 6.2.2.3).

En la Fig. 6.40 se muestran la cantidad de recubierta en los compositos sinterizados a 1100 y $1200{ }^{\circ} \mathrm{C}$. 


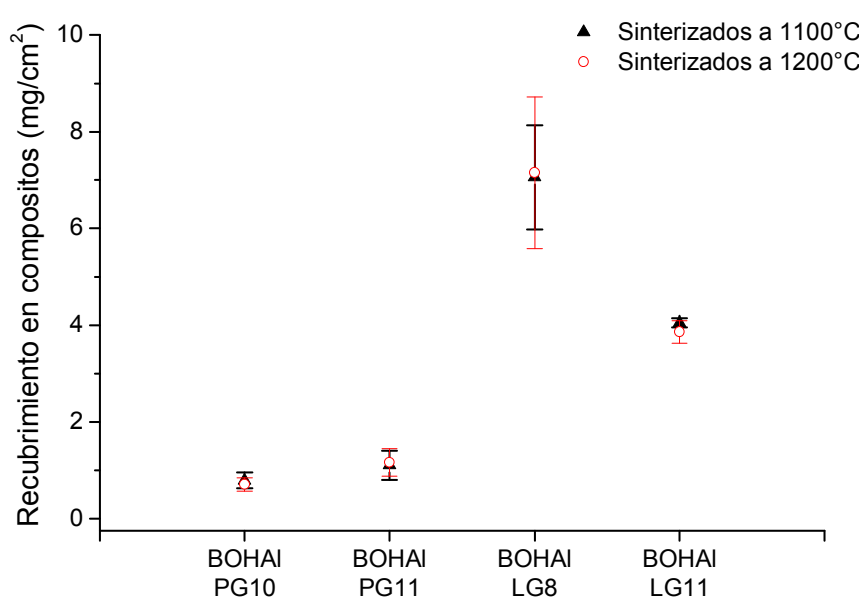

Fig. 6.40. Recubrimiento en compositos obtenidos por inmersión en suspensión de BOHAl de sustratos PG10 y PG11 sinterizados a 1100 y $1200{ }^{\circ} \mathrm{C}$

A diferencia de los compositos obtenidos con el sustrato LG, no se observó una variación apreciable entre la cantidad de recubrimiento sobre los compositos modificando la temperatura de pretratamiento del sustrato PG. Asimismo, las cantidades de recubrimiento total depositadas fueron menores $\left(\sim 1 \mathrm{mg} / \mathrm{cm}^{2}\right)$ que las depositadas en los LG, mostradas en la Fig. 6.40 para comparación. Probablemente, otras características superficiales como la rugosidad, ángulo de mojado suspensión-sustrato y/o tensión superficial del sustrato PG sean menos favorables para la formación de recubrimientos.

Imágenes por microscopía óptica, Fig. 6.41 que muestran superficie de los compositos obtenidos con sustratos PG10 y PG11 con y sin recubrimiento de BOHAl, después de la sinterización a 1100 y $1200^{\circ} \mathrm{C}$. 


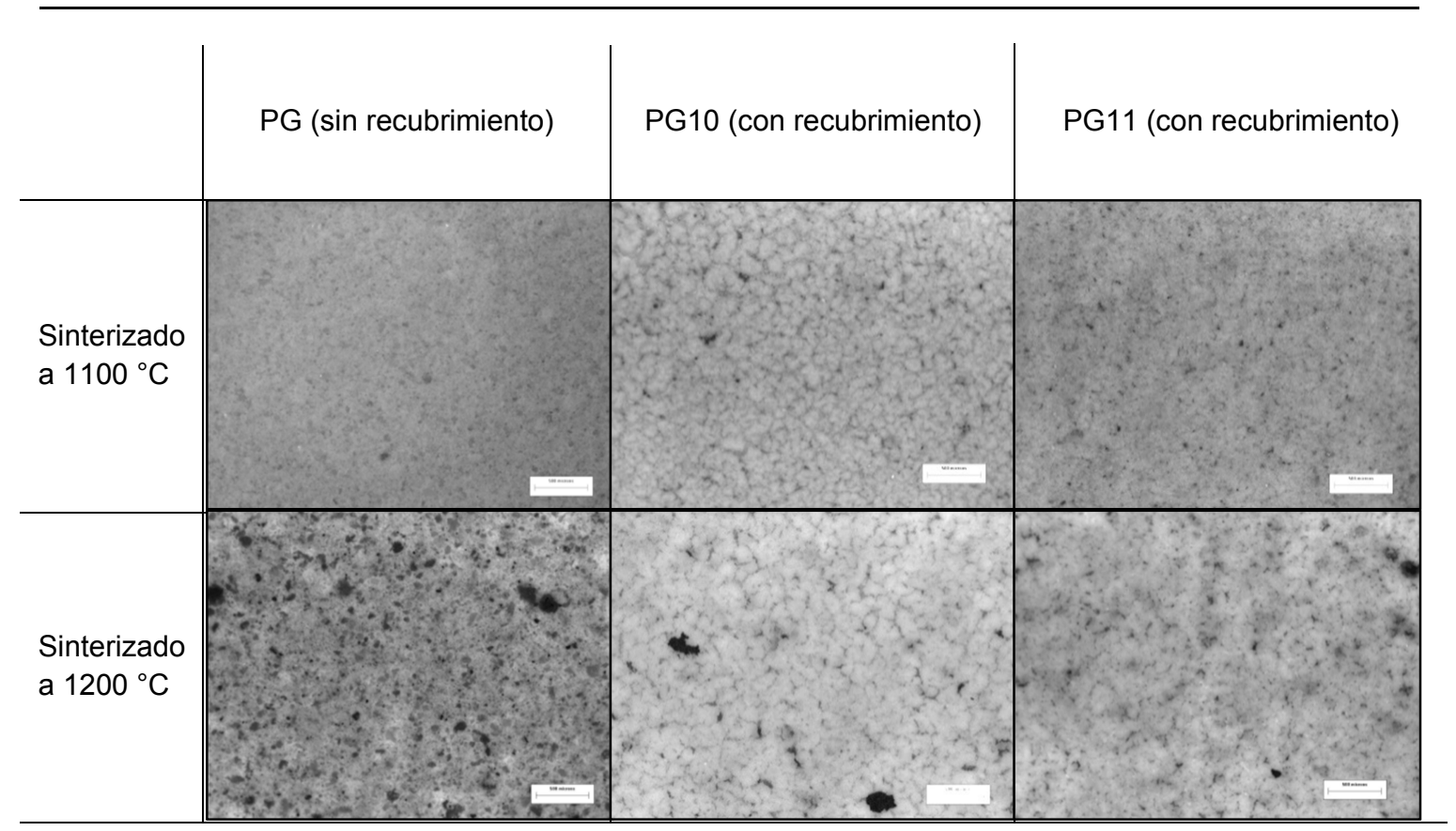

Fig. 6.41. Vista superior de compositos obtenidos por inmersión de sustratos PG en suspensiones de $6 \% \mathrm{~m} / \mathrm{m} \mathrm{BOHAl}$ sinterizados a 1100 y $1200{ }^{\circ} \mathrm{C}$.

(Barra: $500 \mu \mathrm{m}$ )

En general se observa que en compositos sinterizados a $1100{ }^{\circ} \mathrm{C}$, los recubrimientos sobre PG10 presentan un agrietamiento similar al observado en las compositos obtenidos a partir del sustrato LG, mientras que los obtenidos a partir del sustrato PG11 demuestran un menor grado de agrietamiento. Esto podría interpretarse en función de la distribución ancha de tamaño de poros del sustrato en PG10 (Fig. 6.39) donde persiste una fracción de poros finos, (mayor capilaridad) que origina un frente de mojado irregular en el proceso de mojado; generando en última instancia recubrimientos de espesor irregular. En este caso, el agrietamiento se mantuvo similar en los recubrimientos sinterizados a $1200^{\circ} \mathrm{C}$.

Probablemente, esto se explique por las tensiones internas desarrolladas por el composito al ser sinterizado de manera restringida (Ver capítulo 2), las cuales tienen diversos orígenes. Los esfuerzos de tracción generados por la diferencia de coeficientes de expansión térmica entre sustrato $(P G)$ y recubrimiento (BOHAl), siendo en este caso de tracción ( $\mathrm{CET}_{\mathrm{BOHAl}}>\mathrm{CET} \mathrm{T}_{\mathrm{PG}}$ ) para ambas temperaturas de sinterizado (ver Fig. 6.37), lo cual favorece el agrietamiento del recubrimiento, pero evita la delaminación del recubrimiento, confirmándose 
esto por la buena adherencia de los mismos. (Restrepo y col., 2016). Asimismo, los cambios de fase del sustrato (i.e: cuarzo en sustrato LG y en menor medida, $P G$ ) o del recubrimiento (cristobalita en BOHAI), dependiendo de las fases generadas, pueden generar una contracción/expansión brusca durante el enfriamiento.

\subsubsection{Recubrimientos de BOHZr sobre sustratos PG}

Como fuera antes mencionado, la formación de un recubrimiento estable y sin defectos superficiales requeriría un estudio de optimización adecuado. Si bien la arcilla bentonítica utilizada para la preparación de BOHAl y $\mathrm{BOHZr}$ es la misma, el comportamiento de dichas partículas en suspensión (inciso 6.1.4) así como el comportamiento térmico (inciso 6.1.5) y las fases cristalinas desarrolladas a alta temperatura (inciso 6.2.1.1.) denotan una fuerte diferencia entre el comportamiento de dichos materiales, tanto en crudo como después de ser tratados térmicamente.

En base a los resultados obtenidos de recubrimientos de BOHAl sobre los sustratos de PG, en el presente inciso se evaluó la obtención de recubrimientos de suspensiones de BOHZr sobre el mismo tipo de sustrato, PG, a fin de realizar una comparación de los sustratos obtenidos con las condiciones óptimas para BOHAl.

En esta etapa, así como el ensayo del inciso 6.3.1.2.5, se utilizaron los sustratos PG10 y PG11, obteniendo recubrimientos a partir de suspensiones acuosas de $\mathrm{BOHZr} 6 \% \mathrm{~m} / \mathrm{m}$ de concentración. El procedimiento seguido fue similar al de dicho inciso, variando únicamente la $\mathrm{AN}$ en suspensión para formar los recubrimientos, por inmersión de los sustratos en la suspensión durante 10 segundos, extracción a velocidad controlada, secando el soporte recubierto a temperatura ambiente hasta peso constante y repitiendo este procedimiento tres veces. Posteriormente, las piezas fueron sometidas a tratamiento térmico a velocidad "controlada" (ver 6.2.2.3) hasta 1100 y $1200{ }^{\circ} \mathrm{C}$ durante $1 \mathrm{~h}$.

En la Fig. 6.42 se muestran la cantidad de $\mathrm{BOHZr}$ retenido en los compositos sinterizados a 1100 y $1200{ }^{\circ} \mathrm{C}$. A modo de comparación, se muestran los 
valores obtenidos sobre los mismos sustratos a partir de suspensiones de BOHAl.

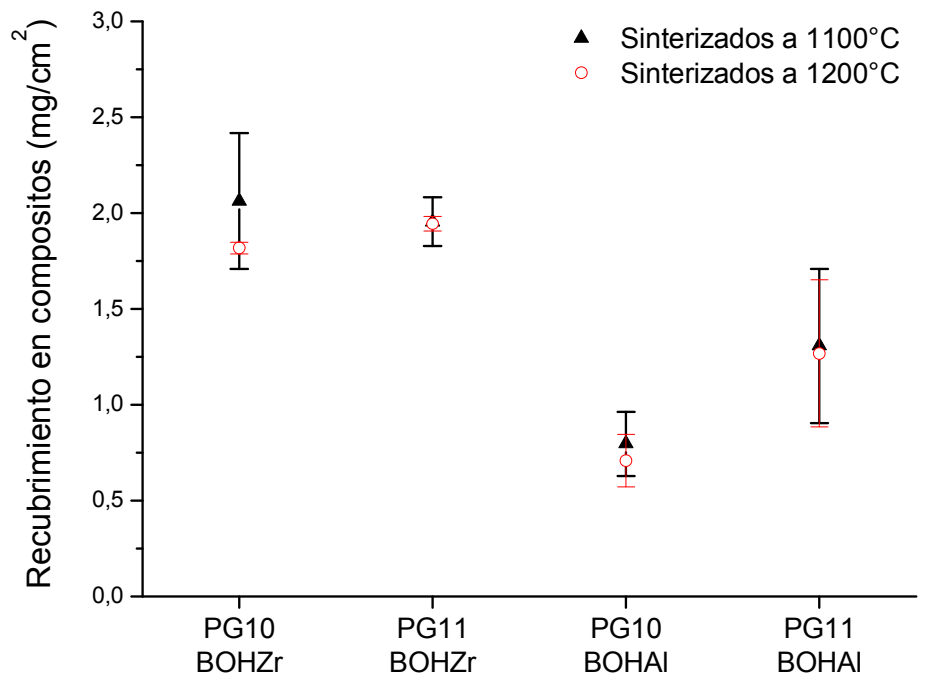

Fig. 6.42. Recubrimiento en compositos obtenidos por inmersión en suspensión de $\mathrm{BOHZr}$ y $\mathrm{BOHAl}$ de sustratos PG10 y PG11 sinterizados a 1100 y $1200{ }^{\circ} \mathrm{C}$

Se observa que la cantidad de recubrimiento en los compositos fue similar para ambos sustratos, no observándose una dependencia del peso del recubrimiento del tipo de sustrato utilizado. En general, los recubrimientos con $\mathrm{BOHZr}$ obtenidos fueron del doble de masa que los resultantes a partir de suspensiones de BOHAl en condiciones similares.

En la Fig. 6.43 se observa la superficie de los recubrimientos y sustratos sin recubrir sinterizados, obtenidos por microscopía óptica. 


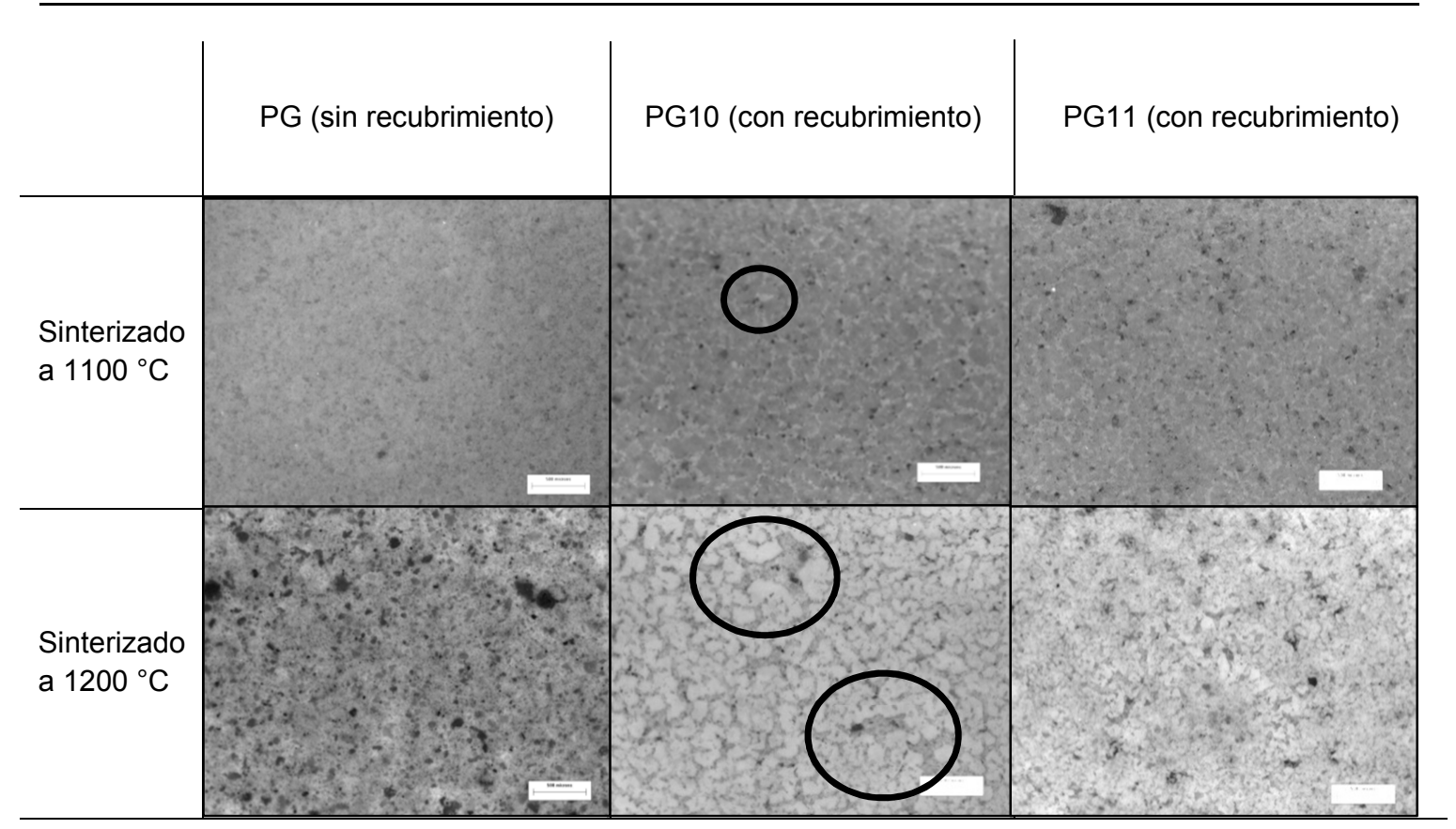

Fig. 6.43. Vista superior de compositos obtenidos por inmersión de sustratos PG en suspensiones de $6 \% \mathrm{~m} / \mathrm{m} \mathrm{BOHZr}$ sinterizados a 1100 y $1200{ }^{\circ} \mathrm{C}$.

(Barra: $500 \mu \mathrm{m}$ )

Se observa que, si bien la cantidad de recubrimiento en cada composito fue similar, el agrietamiento observado fue distinto para los compositos sinterizados a $1200{ }^{\circ} \mathrm{C}$, siendo mayor el obtenido a partir del sustrato PG10, y observándose en estos el delaminado del recubrimiento; indicando la influencia del sustrato en la generación de defectos superficiales en la superficie de los recubrimientos. Estos desprendimientos no habrían sido observados para los recubrimientos de $\mathrm{BOHAl}$, reflejando una menor adherencia de los recubrimientos de $\mathrm{BOHZr}$ sobre el sustrato $\mathrm{PG}$. Asimismo, esto puede haber sido causado por un espesor excesivo de recubrimiento de $\mathrm{BOHZr}$, como sucediera en ciertos recubrimientos de BOHAl del inciso 6.1.2.3

Esta generación de defectos superficiales sigue la tendencia observada en los recubrimientos de $\mathrm{BOHAl}$; el sustrato PG10 genera recubrimientos más defectuosos que los que se obtienen sobre el sustrato PG11.

Veytizou y col (2002) observaron que la formación de zircón a partir de precursores amorfos producía piezas agrietadas en todas las condiciones de tratamiento térmico estudiadas. Los autores atribuyen la formación de grietas a la presencia de esfuerzos inherentes a la morfología del zircón sintetizado. 
Así, se observa una tendencia similar del grado de agrietamiento de los recubrimientos de $\mathrm{BOHZr}$ respecto a los recubrimientos obtenido por inmersión de sustratos PG sobre suspensiones de BOHAl en función del sustrato. Sin embargo, se encontraron diferencias en cuanto a la masa de recubrimiento y la influencia de temperatura de tratamiento térmico. Para este sistema es necesario adecuar las condiciones experimentales de procesamiento debido a que los diferentes iones polinucleares intercalantes del recubrimiento producen materiales con composición y características marcadamente distintas por tratamiento térmico a altas temperaturas, indicando la necesidad de realizar este proceso.

\subsubsection{Consideraciones parciales}

- Se desarrollaron compositos utilizando sustratos de base arcillosa por dip coating en suspensiones de BOHAl. Los sustratos fueron precalcinados a fin de evitar su disgregación en suspensiones acuosas.

- Se definieron las condiciones reológicas más adecuadas, así como ciclo térmico de los compositos, encontrándose que el secado a temperatura ambiente, sinterización con rampa de calentamiento lento $\left(2^{\circ} \mathrm{C} / \mathrm{min}\right)$ y con cinco mesetas hasta $1200{ }^{\circ} \mathrm{C}$, contribuye a minimizar el agrietamiento.

- Se determinaron los coeficientes de expansión térmica del sustrato y del recubrimiento de BOHAl sinterizados. El comportamiento expansivo del sustrato LG atribuido a la presencia de cuarzo sería el responsable de las diferencias entre ambos coeficientes

- La cantidad de recubrimiento fue dependiente del aumento de la porosidad y el menor tamaño de poro del sustrato (mayor presión capilar).

- El agregado de aditivos, si bien mejora la estabilidad de las suspensiones y produce mayor cantidad de recubrimiento, origina un mayor agrietamiento, deteriorando los recubrimientos.

- Los recubrimientos obtenidos sobre PG11 sinterizados a 1100 y $1200^{\circ} \mathrm{C}$ presentaron las superficies con menor cantidad de agrietamiento.

- Los recubrimientos obtenidos sobre sustratos PG a partir de BOHZr (en iguales condiciones experimentales que los obtenidos con BOHAl) 
poseen comparativamente un mayor grado de agrietamiento. Por lo mismo, para la optimización a partir de esta AN modificada, se requieren estudios adicionales que permitan establecer las mejores condiciones experimentales de procesamiento. 


\subsection{Procesamiento y evaluación del material granular obtenido en mezcladora de alta intensidad con y sin aplicación de recubrimientos de AN.}

En este inciso se presentan los resultados del desarrollo de pellets cerámicos utilizando una mezcladora de alta intensidad. Tal como se describió en el Capítulo 5, la metodología seguida para la obtención de estos pellets se basó en dos procesos básicos: conformado en mezcladora de alta intensidad (granulación del sustrato, con recubrimiento de AN) y sinterización. El primero consiste en la transformación de un polvo fino en un material granular con agregados individuales de mayor tamaño. La granulación en este equipo requiere la adición de un ligante para el conformado de los pellets. Una vez conformado, el pellet húmedo puede ser recubierto en el mismo equipo mediante el agregado de polvo y rotación del tambor. La sinterización a alta temperatura permite que estos agregados de partículas finas se conviertan en pellets cerámicos densos y resistentes.

En este apartado se analizó la factibilidad de la mezcladora de alta intensidad para la obtención de pellets esferoidales con tamaño entre 400 y $850 \mu \mathrm{m}$, así como se determinó la posibilidad de recubrir dichos pellets con una capa de AN y establecer la influencia del recubrimiento en las características de los gránulos y la resistencia a la compresión del lecho de pellets cerámicos. Para la evaluación de las propiedades mecánicas de los pellets cerámicos se siguieron los lineamientos indicados en la norma API 19C, para determinar la aptitud de un material granular como agente de sostén cerámico.

Teniendo en cuenta un estudio citado previamente sobre obtención de agentes de sostén recubiertos con una capa fina de arcillas bentoníticas y posterior sinterizado (Pisklak y col., 2011), se decidió llevar a cabo este desarrollo de pellets esféricos usando gránulos arcillosos como núcleos o soportes y un recubrimiento con AN. Como primer paso, se procedió a formular pellets en una mezcladora de alta intensidad utilizando la arcilla caolinítica PG, caracterizada en el apartado 6.1, para establecer las mejores condiciones experimentales para su conformado. En base a estos resultados y a fin de evaluar la influencia de un recubrimiento en las características del pellet en el siguiente inciso 
(6.4.1) se estudió el desarrollo de materiales granulares preformados con PG a los que se les realizó la aplicación posterior de una capa de $20 \%$ en masa de $B$ (precursora de las AN intercaladas). Subsecuentemente, ambos tipos de pellets fueron sinterizados a diferentes temperaturas, evaluando las propiedades de los productos cerámicos resultantes.

Como fuera analizado en el inciso 6.2.2.1, el tamaño de partícula de las materias primas es determinante en las propiedades del material cerámico final. Con esto en vista, se realizó un estudio adicional sobre pellets de PG partiendo en este caso de arcilla finamente molida, y recubrimiento de BOHAl. Motiva la elección de esta AN para su uso en recubrimiento sus buenas propiedades mecánicas (Tabla 6.6), las fases cristalinas desarrolladas y el tamaño de partícula adecuado que favorece el sinterizado del material. Asimismo, la modificación de AN por intercalación de especies poliméricas de aluminio ha sido más extensivamente estudiada, y se han reportado estudios de escalado para la producción de la misma (Aouad y col., 2005; Olaya y col., 2009; Sanabria y col., 2009). Teniendo esto en cuenta, y puesto que para su posible aplicación en la preparación de agentes de sostén se necesitaría un volumen considerable de ese material, en el inciso 6.4.2 se muestran los resultados alcanzados sobre la preparación y caracterización de pellets cerámicos compuestos de sustrato PG molida, y recubrimiento de BOHAI precalcinada y finamente molida.

Esto permitió concretar un estudio comparativo entre las propiedades de los pellets cerámicos obtenidos con PG recubiertos con bentonita y las de otros materiales desarrollados partir de arcilla PG molida como soporte con un recubrimiento de $10 \%$ en masa de BOHAl precalcinada y finamente molida. Estos resultados se presentan en el inciso 6.4.3

Finalmente, en el inciso 6.4.4 se muestran los resultados del ensayo de crush a $35 \mathrm{MPa}(5000 \mathrm{psi})$ de los pellets que denotaron mayor resistencia al ensayo de crush a 28 MPA (4000 psi). 


\subsubsection{Obtención y evaluación de cerámicos granulares a partir de arcilla PG y bentonita}

Tal como fue mencionado, en primer lugar se procedió a obtener material granular a partir de la arcilla caolinítica (PG) utilizándola en las condiciones disponibles comercialmente, es decir con un tamaño de partícula medio $d_{50}$ de $4,9 \mu \mathrm{m}$, como se muestra en la Fig. 6.44.

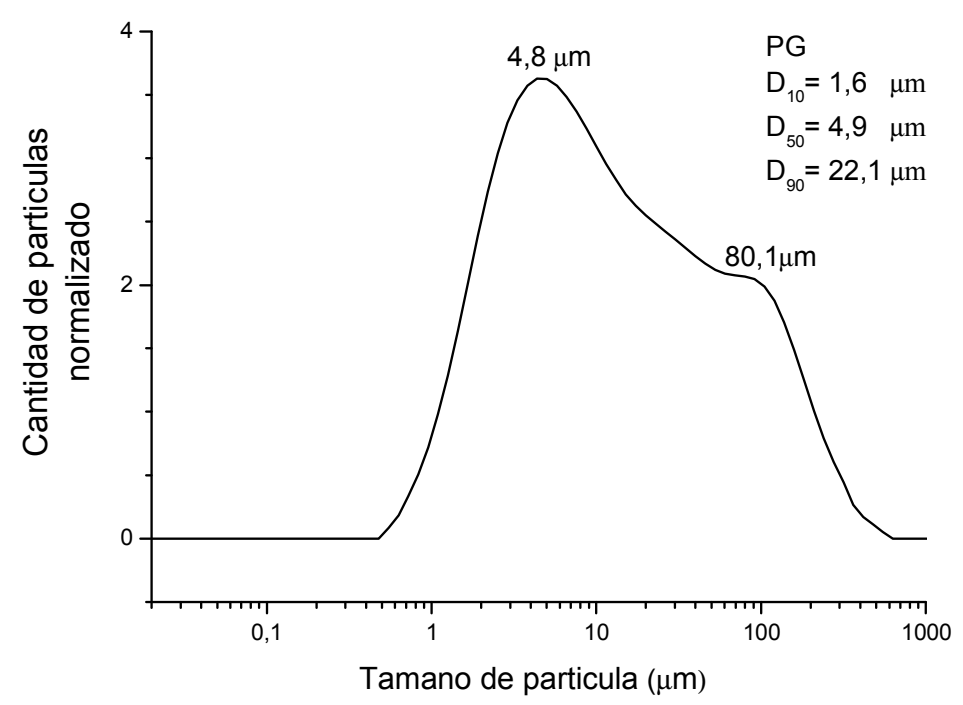

Fig. 6.44: Distribución de tamaños de partícula de la arcilla PG

En ensayos preliminares se establecieron las condiciones experimentales de la granuladora (granulometría de las materias primas, humedad, se ensayaron diferentes velocidades de rotación, y duración de las etapas de mezclado, nucleación y esferizado de los gránulos, etc.) requeridas para la obtención del material granular con y sin recubrimiento de bentonita.

El ensayo de granulación consistió en el agregado de la arcilla PG $(1 \mathrm{~kg})$ en el tambor rotativo (cuba) de la granuladora (Fig. 5.3) y se humectó hasta un 18 $\% \mathrm{~m} / \mathrm{m}$. Los pellets se conformaron por mezclado intensivo de la mezcla húmeda empleando un eje con paletas (rotor) que gira a alta velocidad (4800 rpm) con rotación simultánea del tambor en el sentido contrario durante 5 min. A continuación, se prosiguió con las etapas el crecimiento y esferización de los gránulos por rotación a baja velocidad (1200 rpm) y rotación simultánea del tambor durante $3 \mathrm{~min}$. Los pellets así obtenidos fueron denominados PG. En el 
caso del conformado de los pellets recubiertos con bentonita, el agregado de la bentonita se realizó al comienzo de esta etapa. Los pellets recubiertos obtenidos fueron denominados PG@B.

El sinterizado se llevó a cabo en horno eléctrico con una rampa de calentamiento de $5^{\circ} \mathrm{C} \mathrm{min}^{-1}$ hasta diferentes temperatura máxima $(1050,1100$, 1150,1200 y $1250^{\circ} \mathrm{C}$ ) durante $2 \mathrm{~h}$. Se obtuvieron así dos clases de materiales granulares (PG con y sin recubrimiento de bentonita) que fueron sinterizados a las diferentes temperaturas. En la Tabla 6.8 se indica la denominación de cada muestra.

Tabla 6.8 Nomenclatura de los diferentes pellets obtenidos

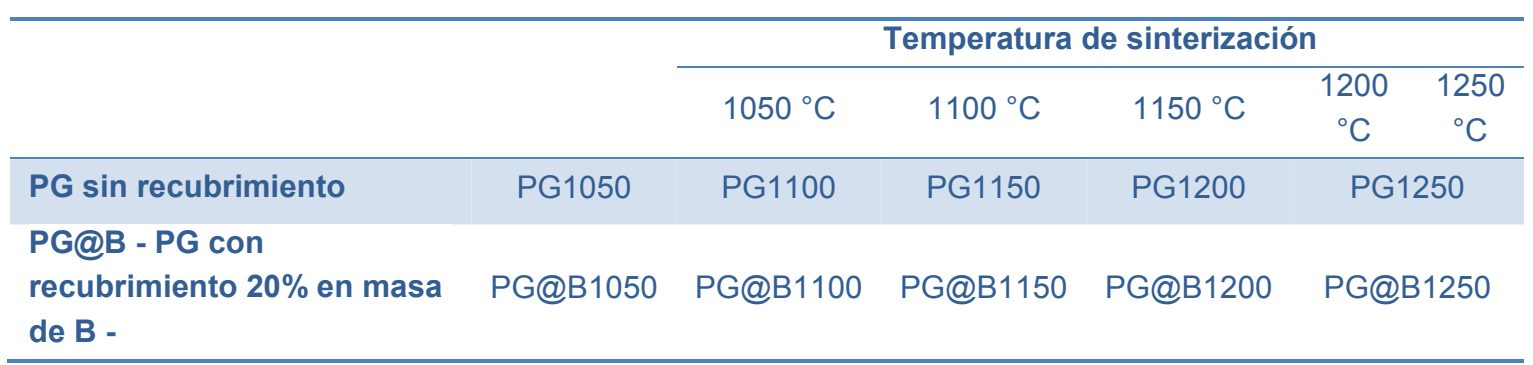

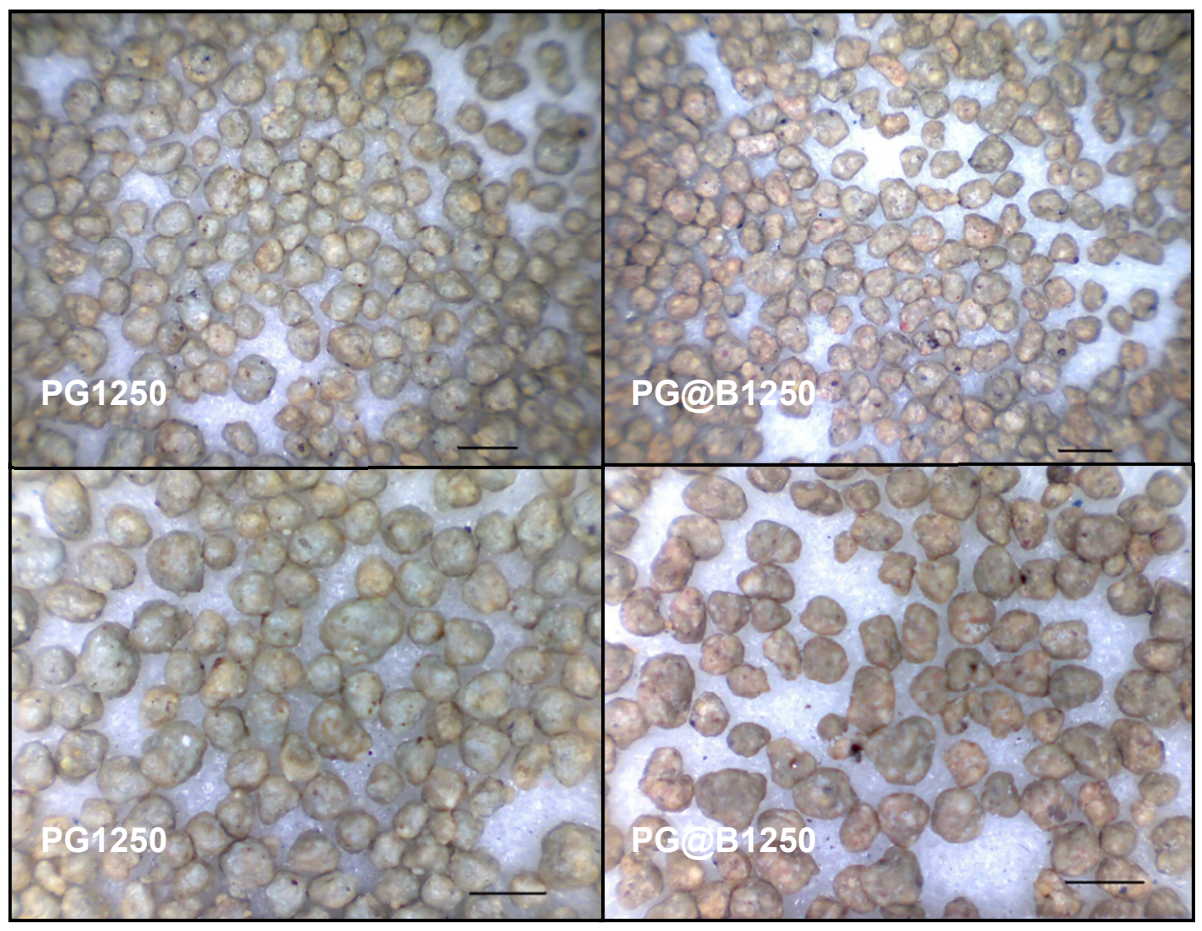

Fig. 6.45 Fotografías de material granular PG y PG@B sinterizados a 1250 C (Barra: $1 \mathrm{~mm}$ ) 
En la Fig. 6.45 se muestran imágenes tomadas de los materiales granulares obtenidos, posterior al tamizado y sinterizado a $1250{ }^{\circ} \mathrm{C}$, donde se puede observar la forma esferoide de dichos pellets. Para la caracterización se seleccionó el material granular M: 20/40 correspondiente a la fracción de tamaños comprendida entre tamices M: 20 (abertura 0,850 mm) y M: 40 (abertura 0,425 mm). Este rango de tamaños es uno de los usuales de los agentes de sostén cerámicos para la industria del petróleo y gas. En la Fig. 6.46 se muestran los difractogramas de los materiales granulares sinterizados a diferentes temperaturas.
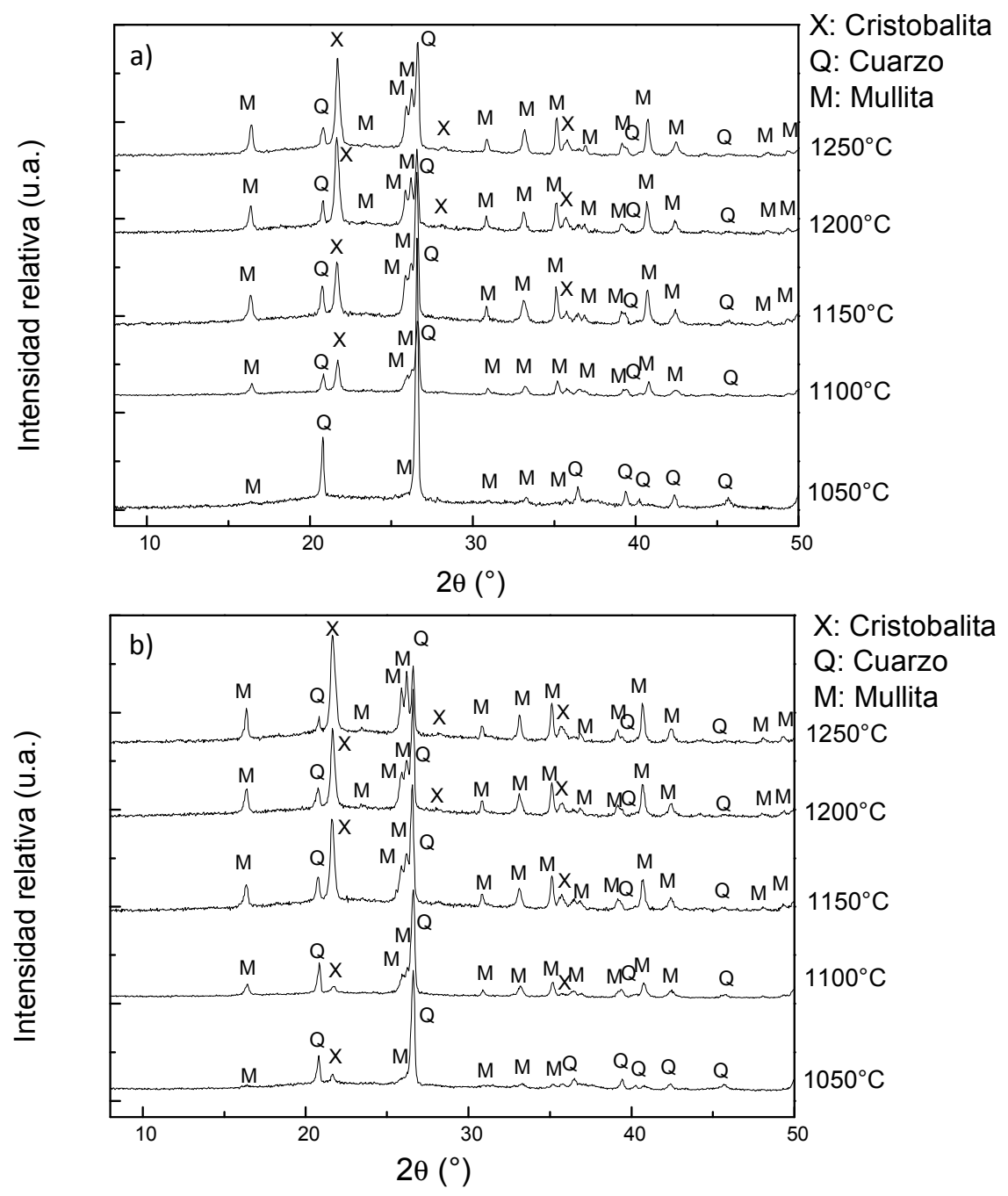

Fig. 6.46. Difractogramas de las muestras a) PG y b) PG@B calcinadas entre 1050 y $1250^{\circ} \mathrm{C}$.

Respecto a los pellets procesados sólo con arcilla PG (Fig. 6.46.a) sinterizados a $1050{ }^{\circ} \mathrm{C}$ se componen de cuarzo como fase cristalina principal, y se observa 
la formación de mullita. A $1100{ }^{\circ} \mathrm{C}$, se incrementa el desarrollo de mullita y de cristobalita, en tanto que el contenido de cuarzo se reduce ligeramente. A 1150 ${ }^{\circ} \mathrm{C}$ se mantiene la tendencia de aumento de mullita y cristobalita, mientras que cuarzo disminuye. En particular, las fases cristalinas concuerdan con lo esperado por la transformación de la caolinita, presente en el sustrato PG, y que puede describirse a través de la siguiente reacción:

$$
\begin{aligned}
3\left(\mathrm{Al}_{2} \mathrm{O}_{3} 2 \mathrm{SiO}_{2} 2 \mathrm{H}_{2} \mathrm{O}\right) & \rightarrow 3\left(\mathrm{Al}_{2} \mathrm{O}_{3} 2 \mathrm{SiO}_{2}\right)+6 \mathrm{H}_{2} \mathrm{O} \\
\text { caolinita } & \\
3\left(\mathrm{Al}_{2} \mathrm{O}_{3} 2 \mathrm{SiO}_{2}\right) & \rightarrow 3 \mathrm{Al}_{2} \mathrm{O}_{3} 2 \mathrm{SiO}_{2}+4 \mathrm{SiO}_{2} \\
& \text { mullitar cristobalita }
\end{aligned}
$$

Los difractogramas de los pellets PG sinterizados a $1200{ }^{\circ} \mathrm{C}$ y a $1250{ }^{\circ} \mathrm{C}$ presentaron composiciones de fases cristalinas similares.

Los difractogramas correspondientes a los pellets recubiertos con bentonita (PG@B) mostraron una composición de fases cristalinas similar a la del material granular PG (Fig. 6.46.b). Sin embargo, las diferencias de composición se observaron para los cerámicos PG@B sinterizados a $1050^{\circ} \mathrm{C}$, en los que se aprecia además de cuarzo, la presencia de una pequeña cantidad de mullita y de cristobalita. En los pellets PG@B sinterizados a $1150{ }^{\circ} \mathrm{C}$ es notable el crecimiento de mullita y cristobalita a medida que disminuye el contenido de cuarzo. Estos cambios sugieren que la cristobalita se ha transformado a expensas del cuarzo y de los minerales arcillosos, los cuales, a temperaturas $\sim 1100^{\circ} \mathrm{C}$, comienzan a desarrollar cristobalita y mullita.

Además, los difractogramas de los materiales obtenidos a bajas temperaturas presentan una banda centrada en $22,5^{\circ} 2 \theta$ que indica la presencia de fase amorfa (no cristalina) rica en sílice. Se determinó semicuantivamente por el método de Ohlberg que contenido de la fase amorfa es importante (45-50\%) (Fig. 6.47). Para los pellets obtenidos sólo con PG, el contenido de fase amorfa aumentó levemente con la temperatura. Para el material PG@B, se observó que el contenido de fase amorfa presentó un máximo a $1150{ }^{\circ} \mathrm{C}(56,6 \%)$, y se redujo con el aumento de la temperatura a $1250^{\circ} \mathrm{C}$. 
Comparativamente, los pellets PG@B tuvieron mayor contenido de fase amorfa que los PG sin recubrir. Esto concuerda con el análisis por DRX realizado sobre la bentonita de recubrimiento (precursora de las AN modificadas) calcinada a temperaturas mayores a $1000{ }^{\circ} \mathrm{C}$, donde se evidencia un considerable aumento de fase amorfa con la temperatura de sinterización hasta los $1300^{\circ} \mathrm{C}$ (Martinez y col., 2016).

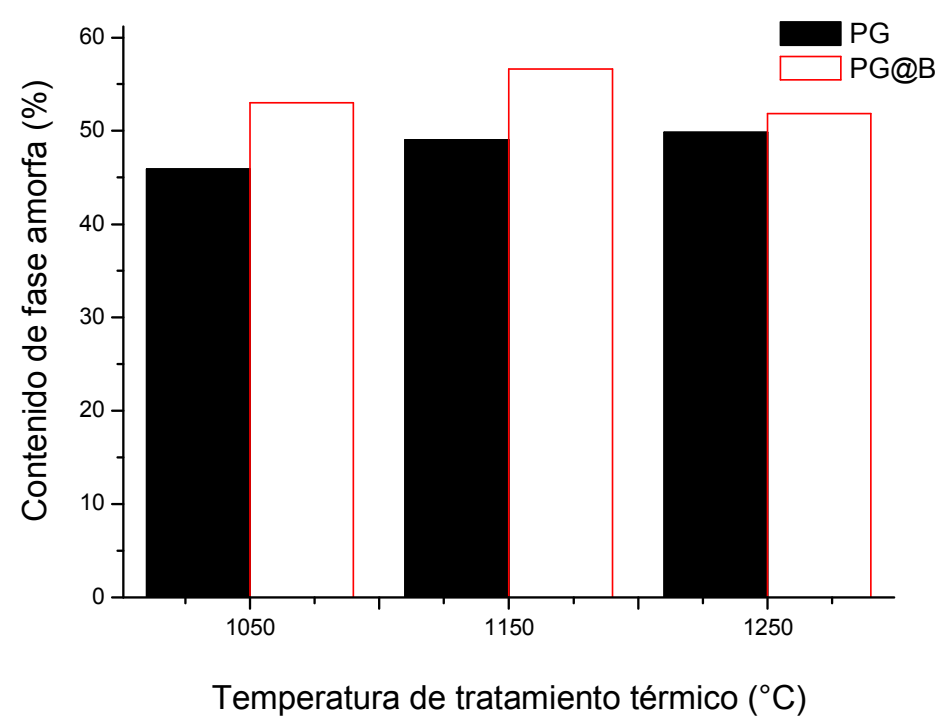

Fig. 6.47. Contenido de fase amorfa calculado por el método de Ohlberg en granulares después de sinterización a 1050,1150 y $1250^{\circ} \mathrm{C}$

Es importante remarcar que si bien las fases cristalinas presentes en ambos casos no varían significativamente, el alto contenido de fase amorfa en cerámicos puede tener importancia debido a que es uno de los factores responsables de las propiedades mecánicas finales del composito (Sun y col., 2014). En el contexto del comportamiento a la compresión del lecho de agentes de sostén (ensayo crush), se conoce bien que materiales vítreos de composición similar a los comerciales originan por fragmentación astillas de polvo fino, a diferencia de agentes de sostén cerámicos que, al fracturarse, se convierten en fragmentos equivalentes a la mitad o la cuarta parte del tamaño del gránulo (o más pequeños), generando una menor proporción de finos que los de vidrio (Mader, 1989). Por este motivo, agentes de sostén obtenidos a partir de ciertos materiales vítreos han caído en desuso en la industria del petróleo. 
Por otro lado, se debe tener en cuenta la influencia que ejercen otras variables como la composición mineralógica, química y la microestructura en las propiedades de los materiales granulares. Así, se ha reportado la reducción de la resistencia mecánica de agentes de sostén derivados de caolinita tras el sinterizado a $1460{ }^{\circ} \mathrm{C}$ que coincide con un aumento del contenido cristobalita y con una microestructura más gruesa (Luscher y col., 2006). En general, la devitrificación, así como la introducción de una segunda fase o cristalitos dispersos en la composición del cerámico resultan en mejoras debido a la actuación de mecanismos de refuerzo (por deflexión, y ramificación de grietas, tenacidad, disipación de energía de fractura, etc.).

Las imágenes de la Fig. 6.48 muestran la morfología de los materiales granulares M20/40 PG y PG@B sinterizados a $1200{ }^{\circ} \mathrm{C}$, se puede verificar que los mismos poseen una forma esferoidal. No se aprecian diferencias en el aspecto superficial que presentan los gránulos individuales, aunque en la estructura de algunos de ellos se visualiza la unión de varios aglomerados más finos.

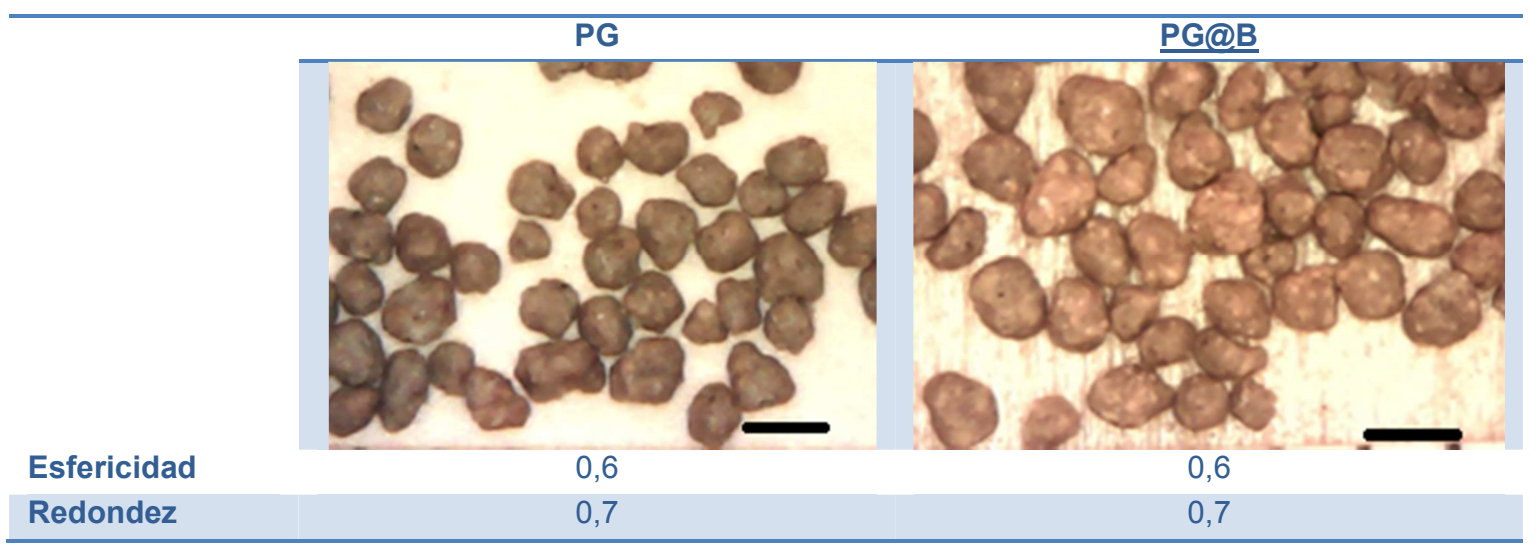

Fig. 6.48: Imágenes por microscopía óptica, esfericidad y redondez de materiales granulares PG y PG@B sinterizados a $1250{ }^{\circ} \mathrm{C}$. (Barra: $1 \mathrm{~mm}$ )

La Fig. 6.48 indica que presentan moderada esfericidad (S) y buena redondez (R). La norma establece valores de $S \geq 0,7$ y $R \geq 0,7$ para los agentes de sostén cerámicos. Estos parámetros para los pellets PG y PG@B resultaron ligeramente inferiores a los valores que poseen habitualmente los agentes de sostén cerámicos 
La Tabla 6.9 muestra los valores de diámetro medio de poro, densidad aparente y porosidad abierta de los pellets obtenidos.

Tabla 6.9. Diámetro medio de poro, densidad aparente y porosidad abierta y densidad del lecho de los materiales granulares obtenidos.

\begin{tabular}{|c|c|c|c|c|c|c|c|c|c|c|}
\hline & \multicolumn{5}{|c|}{ PG } & \multicolumn{5}{|c|}{ PG@B } \\
\hline $\begin{array}{l}\text { Temperatura de } \\
\text { sinterización }\left({ }^{\circ} \mathrm{C}\right)\end{array}$ & 1050 & 1100 & 1150 & 1200 & 1250 & 1050 & 1100 & 1150 & 1200 & 1250 \\
\hline $\begin{array}{l}\text { Diametro medio de } \\
\text { poro }(\mathrm{nm})\end{array}$ & 87,6 & 101,4 & 143,4 & 155,3 & 212,3 & 113,1 & 122,3 & 134,6 & 278,9 & 104,3 \\
\hline $\begin{array}{l}\text { Densidad aparente } \\
\left(\mathrm{g} / \mathrm{cm}^{3}\right)\end{array}$ & 2,40 & 2,53 & 2,50 & 2,46 & 2,56 & 2,38 & 2,44 & 2,49 & 2,56 & 2,60 \\
\hline $\begin{array}{l}\text { Porosidad abierta por } \\
\mathrm{Hg}(\%)\end{array}$ & 15,5 & 13,3 & 9,3 & 3,6 & 3,6 & 19,8 & 14,1 & 8,6 & 3,3 & 3,3 \\
\hline $\begin{array}{l}\text { Densidad de lecho } \\
\left(\mathrm{g} / \mathrm{cm}^{3}\right)\end{array}$ & 1,09 & 1,26 & 1,28 & 1,29 & 1,33 & 1,08 & 1,21 & 1,26 & 1,31 & 1,35 \\
\hline
\end{tabular}

Para los pellets PG, se observa una tendencia general de aumento del diámetro medio de poro y densidad, con el aumento de temperatura, en tanto que presentan una reducción de la porosidad abierta desde $15.5 \%$ a $1150{ }^{\circ} \mathrm{C}$ hasta $3.6 \%$ a $1250{ }^{\circ} \mathrm{C}$. Para los materiales recubiertos PG@B, la porosidad abierta se redujo de manera similar, llegando al 3,3\%.

La densidad aparente de las muestras PG es levemente mayor que la respectiva de PG@B hasta $1150{ }^{\circ} \mathrm{C}$, esta tendencia se revierte con el aumento de la temperatura, siendo la densidad de PG@B1200 mayor que las muestras sin recubrimiento. Asimismo, la porosidad abierta muestras PG@ B se reduce en relación a las del material PG a partir de los $1150{ }^{\circ} \mathrm{C}$. Estos resultados indicarían la vitrificación superficial de los pellets recubiertos por bentonita, que originaría un efecto de "sellado" sobre los poros abiertos del mismo; aumentando su densidad aparente (Pisklak y col., 2011).

Exceptuando a la muestra PG1200, para ambos tipos de materiales se observó una tendencia del aumento de la densidad aparente con el aumento de la temperatura de sinterizado, manteniéndose los valores dentro del rango de 2,38-2,60 g/ $/ \mathrm{cm}^{3}$ para PG@B y 2,40-2,56 g/ $\mathrm{cm}^{3}$ para PG. Estos valores de densidad se aproximan a los valores usuales de los agentes de sostén cerámicos livianos, de 2,6-2,65 g/ $/ \mathrm{cm}^{3}$. (Cannan y Palamara, 2006; Lunghofer, 1992). 
En la Fig. 6.49 se observan las imágenes obtenidas por SEM. Las fotografías no muestran una diferencia muy marcada de microestructura entre los materiales recubiertos y sin recubrir sinterizados a distintas temperaturas, exceptuando a la muestra PG1250, la cual posee una escasa cantidad de defectos y menor porosidad interna en la zona central de los pellets.

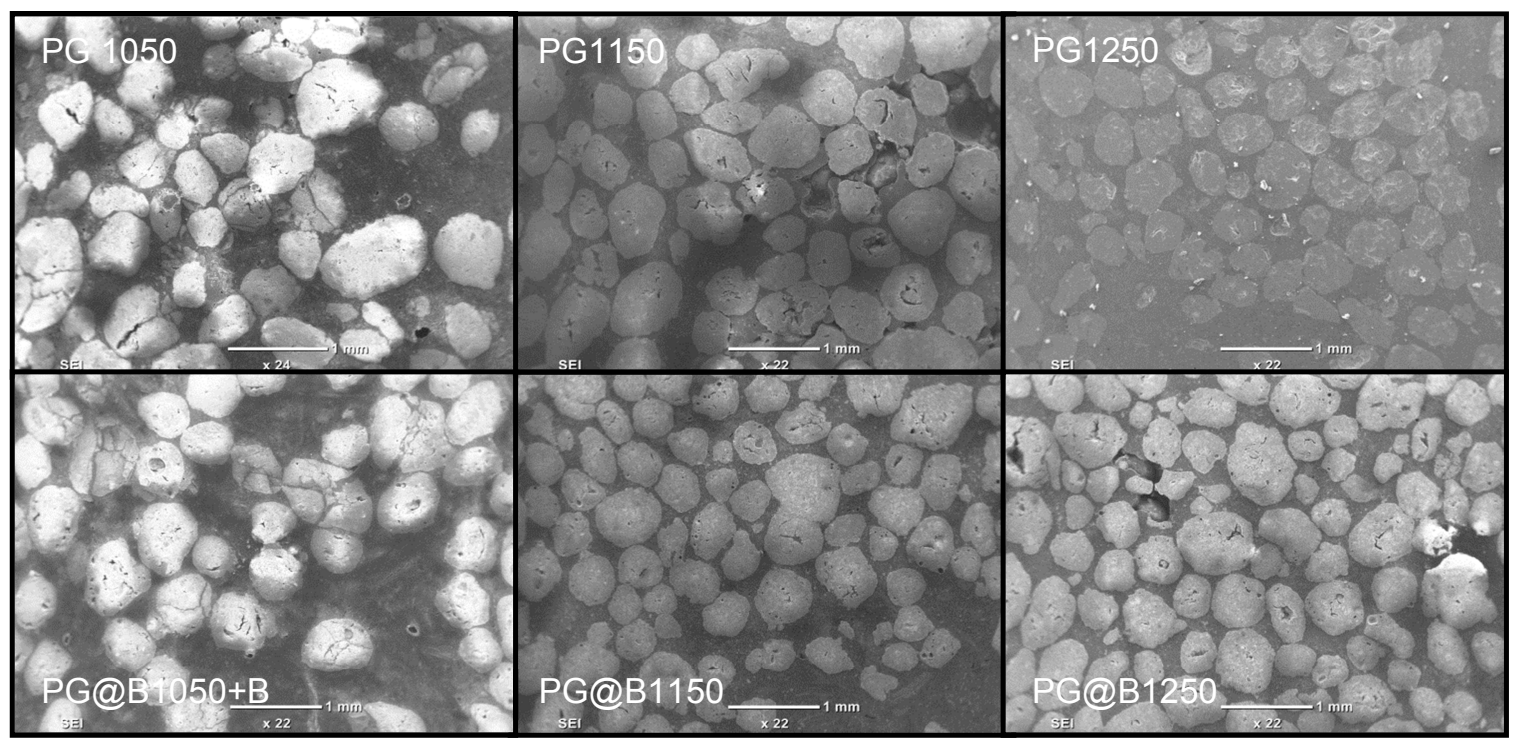

Fig. 6.49: Imágenes SEM de granulados M: 20/40 sinterizados a 1050, 1150 y $1250{ }^{\circ} \mathrm{C}$

Se observa, además, que es mayor la cantidad de gránulos fracturados en las muestras sinterizadas a $1050{ }^{\circ} \mathrm{C}$. La fractura de estos pellets incluidos en resina probablemente ocurrió durante el desbastado y pulido de las probetas. En este caso, se aprecia claramente en la microestructura también la presencia de poros internos de formas irregulares/ grietas (áreas en negro visibles en el interior de los gránulos) y defectos de empaquetamiento de partículas debidos probablemente a la distribución de tamaños gruesos de partícula de la arcilla utilizada como materia prima.

Los poros de mayor tamaño que los granos que componen el cerámico resultan difíciles de eliminar durante el sinterizado. Ello podría explicar la elevada porosidad detectada en las fotografías, resultado que concuerda con un bajo grado de densificación debido a la baja temperatura de sinterizado. El aumento de temperatura de sinterizado conduce a una reducción significativa de la porosidad abierta. 
En la Tabla 6.9 se muestran los valores de densidad del lecho de pellets, calculada según norma API 19c. Se encontraron valores variables entre 1,1 y $1,35 \mathrm{~g} / \mathrm{cm}^{3}$ y similares para las muestras PG y PG@B. Para ambos casos, se observó una tendencia al aumento de este valor con el incremento de la temperatura de sinterizado que correspondería al incremento de la densidad aparente de los gránulos con el tratamiento térmico, ya que no se observó una variación apreciable en la forma (esfericidad, redondez) de los pellets individuales que pudiera afectar su densidad de empaquetamiento.

En la Fig. 6.50 se presentan los resultados del ensayo de crush a una presión de 28 MPa (4000 psi) realizado con muestras de PG y PG@B sinterizados a distintas temperaturas.

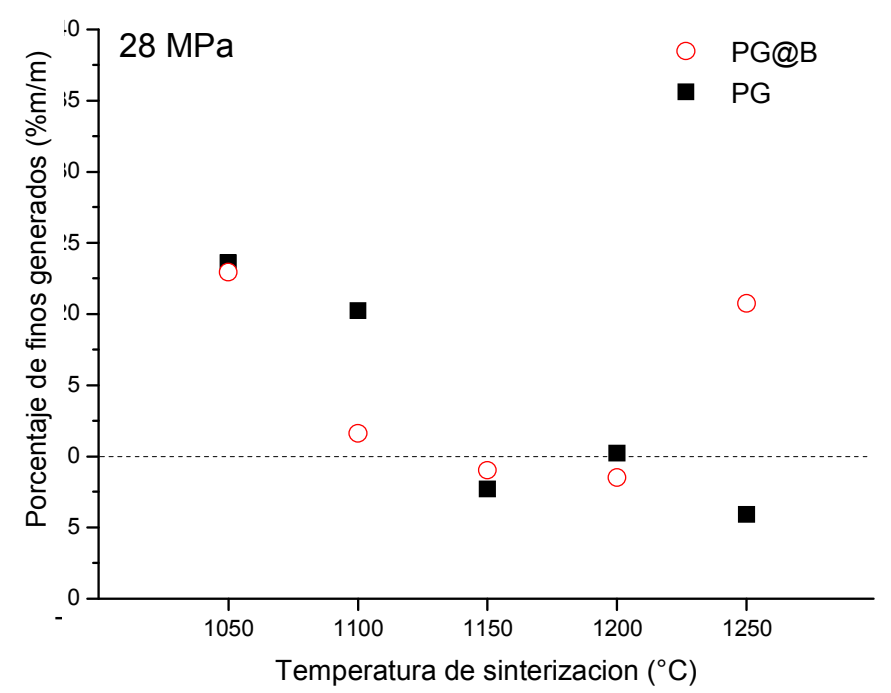

Fig. 6. 50: Porcentaje de finos generados en ensayo de crush a $28 \mathrm{MPa}$ de materiales granulares sinterizados a $1050,1100,1150,1200$ y $1250{ }^{\circ} \mathrm{C}$

Cabe recordar que dicho ensayo se considera satisfactorio cuando el porcentaje de finos generados es menor al $10 \% \mathrm{~m} / \mathrm{m}$ del peso del lecho de pellets analizado. El valor de crush informado corresponde al promedio de tres medidas.

En el primer caso, aunque la porosidad del pellet se reduce con el aumento de la temperatura desde 1150 a $1250{ }^{\circ} \mathrm{C}$, no se observaron mejoras en el comportamiento al crush. Los resultados evidencian que hay una incidencia 
importante de la microestructura interna de los pellets en la resistencia al crush de las muestras. La Tabla 6.9, muestra que el volumen de poros fue eliminado gradualmente con el aumento de la temperatura de sinterización. La reducción de la porosidad puede explicar la densificación de los pellets, incrementando la resistencia a la compresión del lecho.

Si bien la densidad aparente de los pellets sinterizados a $1250^{\circ} \mathrm{C}$ es mayor para PG@B que para PG, los resultados de crush indican una menor resistencia a la compresión del lecho de dichos materiales. El incremento en la generación de finos de las muestras PG@B a temperaturas de sinterizado mayores a $1150^{\circ} \mathrm{C}$ se atribuye a la fase amorfa (vítrea) presente en el cerámico (originada a partir de enfriamiento de fase líquida desde temperatura de sinterizado) debido al agregado de bentonita (Ver Fig. 6.15). Como fuera descrito en el inciso 6.2., la bentonita expande a altas temperaturas, debido a la retención de gases dentro de la fase vítrea de elevada viscosidad formada, que, a su vez, podría provocar una disminución en la resistencia a la compresión (Ma y col., 2018). Asimismo, la localización preferencial de fase vítrea en el borde de grano condiciona la resistencia mecánica del cerámico ya que su presencia favorecería la fractura intergranular.

Por otra parte, el trabajo de Pisklak y col. 2011) reporta que se consiguieron mejoras de la resistencia a la compresión de ciertos agentes de sostén fabricados por recubrimiento de bentonita sobre piedra pómez. En ese caso, la porosidad es un factor que hay que tener en cuenta y es probable que las mejoras estén relacionadas con las bajas propiedades mecánicas del núcleo más poroso (i.e. piedra pómez) con respecto a las de bentonita sinterizada. Por otro lado, en ese trabajo se informa que la temperatura de sinterización utilizada fue de $1200^{\circ} \mathrm{C}$ que coincide con la temperatura a la cual los pellets de PG@B producen una cantidad de finos ligeramente menor que PG. 
Tabla 6.10. Contenido de fases presentes en los materiales granulares determinado por el método de Rietveld

\begin{tabular}{lcccc}
\hline & \multicolumn{2}{c}{ PG1250 } & \multicolumn{2}{c}{ PG@B1200 } \\
\cline { 2 - 5 } Fase cristalina & $\% \mathrm{~m} / \mathbf{m}$ & desvío & $\% \mathrm{~m} / \mathrm{m}$ & desvío \\
\hline Mullita & 32,6 & 0,8 & 25,6 & 0,7 \\
Cristobalita & 10,8 & 0,6 & 8,2 & 0,4 \\
Cuarzo & 11,5 & 0,6 & 13,3 & 0,5 \\
Fase amorfa & 45,2 & 2,0 & 52,9 & 1,6 \\
\hline
\end{tabular}

Para realizar la cuantificación de las fases presentes en los pellets que denotaron mejores resultados en el ensayo de crush a $28 \mathrm{MPa}$, es decir, los que presentaron menor porcentaje de finos pasantes M:40 (Fig. 6.50), se utilizó el método de Rietveld para el cálculo de contenido de fases cristalinas. Asimismo, la fase amorfa fue cuantificada por el método de patrón externo, ambas metodologías previamente explicadas en el inciso 4.1.1.

De los resultados de la Tabla 6.10 se comprueba que mullita y cristobalita constituyen las fases mayoritarias, siendo el porcentaje de mullita de la muestra PG1250 mayor que el de PG@B1200 y cercano al 36,4 \% que es el valor estimado según el contenido de caolinita proveniente de la arcilla PG. El contenido de cuarzo determinado fue similar en ambas muestras y la fase amorfa alcanzó 45 y 53 \% para PG y PG@B respectivamente. Así, la incorporación de $20 \%$ bentonita conduce a menor formación de mullita debido a la reducción en caolinita junto con mayor desarrollo de fase amorfa asociado al menor contenido relativo de $\mathrm{Al}_{2} \mathrm{O}_{3}$ y aumento de óxidos fundentes $\left(\mathrm{Na}_{2} \mathrm{O}, \mathrm{K}_{2} \mathrm{O}\right.$, $\mathrm{Fe}_{2} \mathrm{O}_{3}, \mathrm{CaO}$ ) en la composición de BOHAI.

En la Fig. 6.51 se muestran imágenes SEM de pellets cerámicos de PG y PG@B sinterizados a 1150 y $1250{ }^{\circ} \mathrm{C}$. En ambos casos, se observa la presencia de defectos microestructurales (agrietamientos y porosidad interna). 


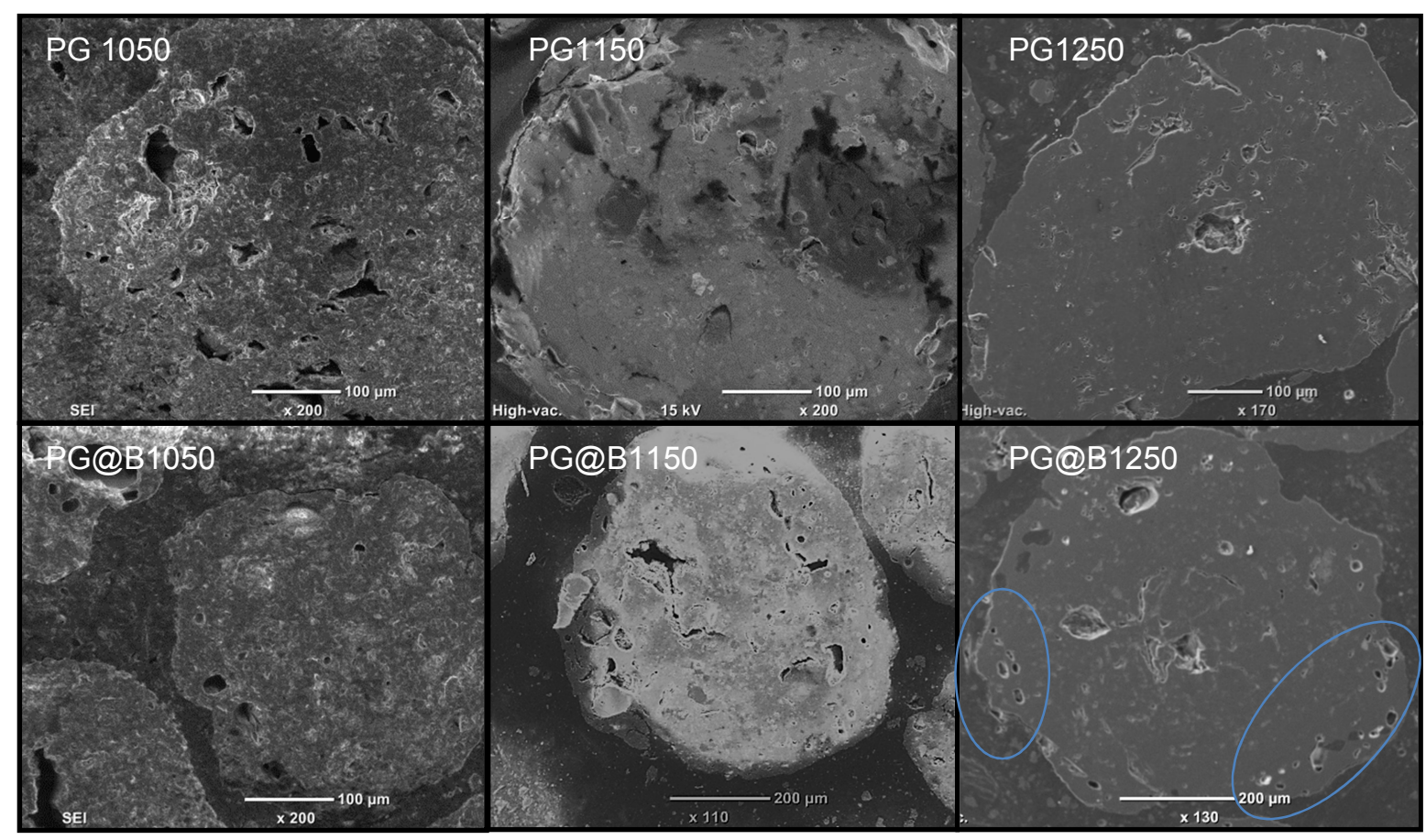

Fig. 6.51: Imágenes SEM de pellets PG y PG@B sinterizados a 1150, 1200 y $1250^{\circ} \mathrm{C}$

Adicionalmente, en el borde del pellet PG@B sinterizado a $1250{ }^{\circ} \mathrm{C}$ se observa microporosidad atribuida a la vitrificación superficial que dificulta la eliminación del aire/porosidad interna de la bentonita, que se expande, tal como fuera descrito en el inciso 6.1. Esta porosidad adicional probablemente sea perjudicial en las propiedades mecánicas/resistencia al crush del lecho en comparación con el material sin recubrir.

Los finos obtenidos de los ensayos de crush, es decir, el material pasante M: 40, fue adicionalmente clasificado por un tamiz M: $100(<149 \mu \mathrm{m})$ a fin de cuantificar el porcentaje de polvo más fino generado. De acuerdo con la Fig. 6.52, para la muestra recubierta (PG@B), el aumento de temperatura de sinterizado desde 1050 hasta $1150{ }^{\circ} \mathrm{C}$ produce una disminución del material pasante M: 100 desde $17 \%$ hasta un mínimo del $12 \%$ en peso, respectivamente. Aumentando la temperatura de sinterizado, el contenido fase vítrea y a su vez, el material pasante M: 100 también aumenta. Para la muestra PG, dicho contenido se mantiene relativamente constante (15-16 \%). 


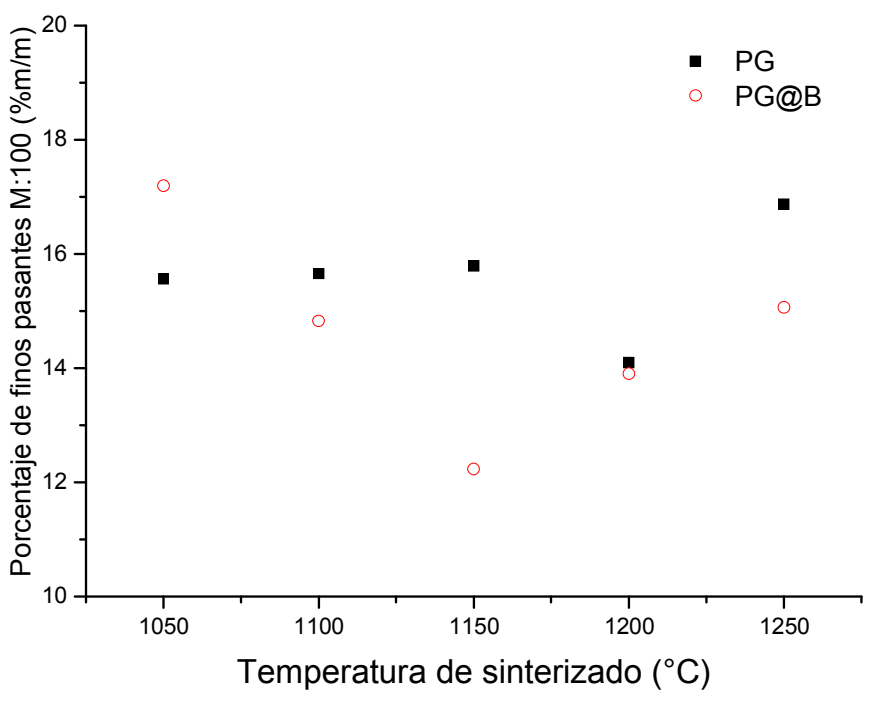

Fig. 6.52: Porcentaje de material pasante M100 obtenido a partir de finos de ensayo de Crush de materiales granulares sinterizados entre 1050 y $1250^{\circ} \mathrm{C}$

En la Fig. 6.53 se observan imágenes de las fracciones finas resultantes de pellets PG1250 y PG@B1200.

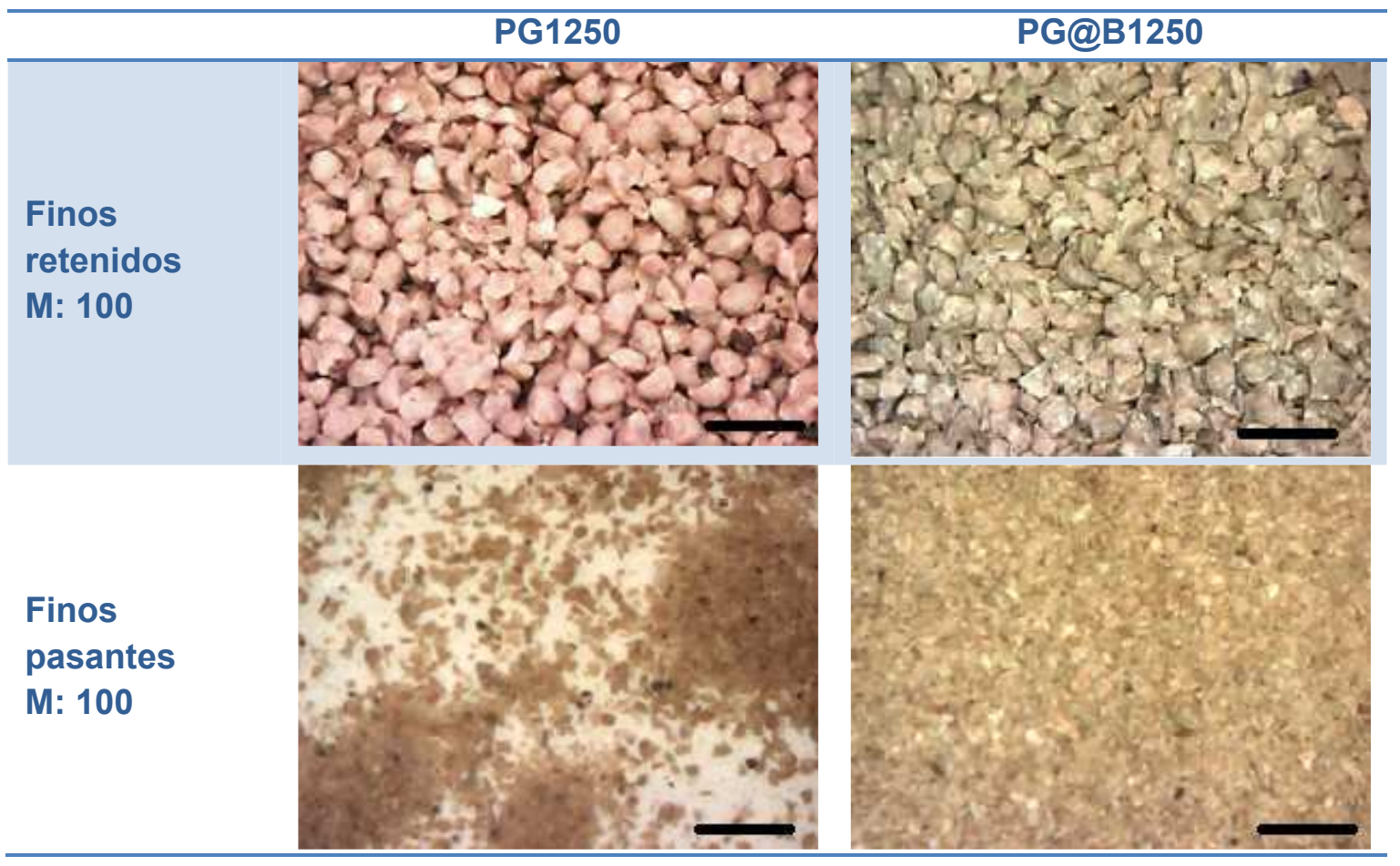

Fig. 6.53 Imágenes de las fracciones de finos de ensayo de Crush retenidas y pasantes M: 100 de pellets PG1250 y PG@B1200 por microscopia óptica. (Barra: $1 \mathrm{~mm}$ ) 
Por otra parte, la formación de líquido a elevadas temperaturas podría ser favorable para el desarrollo de mullita, fase con buenas propiedades mecánicas. En el caso de la muestra PG, por DRX se comprobó la presencia de mullita a partir de $1100{ }^{\circ} \mathrm{C}$, además de $\mathrm{Fe}_{2} \mathrm{O}_{3}$ y óxidos alcalinos provenientes de impurezas (illita) propician su desarrollo a $1150^{\circ} \mathrm{C}$, que es una temperatura relativamente baja. Asimismo, la fase líquida actúa sobre la morfología de los cristales de mulita así como en la microestructura del cerámico. Sin embargo, y como fue discutido anteriormente, la fase vítrea puede ser una desventaja ya que contribuye a la fractura frágil, típica de materiales vítreos, que es una causa probable del aumento de finos generados en el ensayo de crush.

Exceptuando la muestra PG1250, los pellets en general desarrollaron defectos internos (i.e: poros, fisuras) que seguramente son determinantes de la resistencia al crush de los mismos.

La reducción de la porosidad abierta de los pellets cerámicos con el aumento del tratamiento térmico, así como el incremento de la densidad aparente fue comparable para ambas familias de pellets (PG y PG@B). Sin embargo, el comportamiento de ambos pellets respecto a su resistencia al crush fue claramente distinto. En general, para los pellets PG, el aumento de temperatura de sinterizado produjo un aumento de la resistencia al crush, adjudicable a la densificación (sinterizado) de los mismos. Sin embargo, para los pellets PG@B recubiertos, la resistencia al crush alcanzó un máximo a temperaturas de 1150$1200{ }^{\circ} \mathrm{C}$. Condice lo observado con que estos pellets fueron los que menor cantidad de finos generaron en el mencionado ensayo $(5,9 \% \mathrm{~m} / \mathrm{m})$. A temperaturas superiores el porcentaje de finos generados $(20,7 \% \mathrm{~m} / \mathrm{m})$ excedió el $10 \%$ requerido por el ensayo.

\subsubsection{Obtención y evaluación de cerámicos granulares derivados de arcilla PG con recubrimiento de arcilla nanoestructurada BOHAI.}

Este estudio se llevó a cabo para mejorar la microestructura de los pellets en comparación con los obtenidos precedentemente, y controlar la formación de defectos internos (poros, fisuras) que reducen la resistencia mecánica del lecho de material granular y conducen a una baja reproducibilidad de los resultados, 
en particular de los pellets sinterizados a bajas temperaturas. Para ello, se procedió a la molienda de la arcilla PG en molino de bolas, alterando el tamaño de partícula de la muestra, como se refleja en la Fig. 6.54.

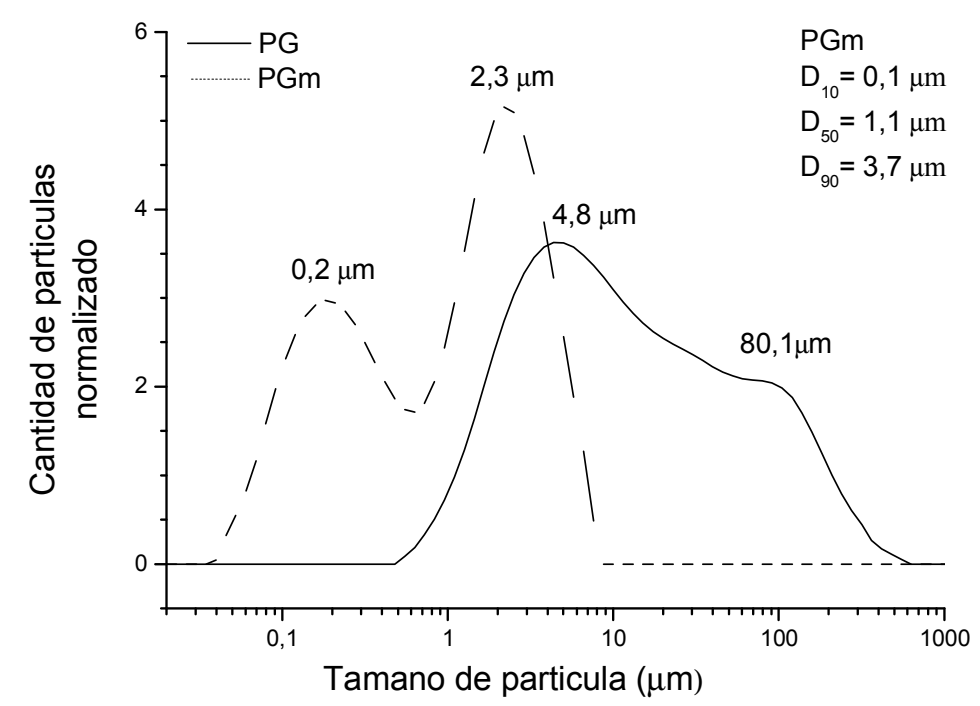

Fig. 6.54: Distribución de tamaños de partícula de la arcilla PG molida (PGm). Comparación con distribución de tamaño de partícula de PG.

La molienda produjo una reducción en el $d_{50}$ de la arcilla PG, desde 4,9 $\mu \mathrm{m}$ a 1,1 $\mu \mathrm{m}$ posterior a dicho proceso. Se conservó el carácter bimodal de la distribución de la arcilla molida (PGm), si bien se observó una distribución más estrecha, reflejada en los valores de $d_{10} y d_{90}$, que se redujeron desde 1,6 y $22,1 \mu \mathrm{m}$ para la muestra sin moler a 0,1 y $3,7 \mu \mathrm{m}$ respectivamente en la muestra molida

El cambio en la distribución de tamaños de partícula de la arcilla PGm (Fig. 6.54) requirió la adecuación de la cantidad de agua adicionada en el proceso de granulación. En particular, para la elaboración de estos pellets fue necesario incrementar la cantidad de agua desde el $18 \%$ hasta el $28 \% \mathrm{~m} / \mathrm{m}$. Además, se seleccionó la temperatura de sinterizado de 1250 y $1300{ }^{\circ} \mathrm{C}$ en base a la baja porosidad abierta determinada por intrusión de $\mathrm{Hg}$ de los materiales previamente obtenidos (inciso 6.4.1).

Se elaboró otra serie de gránulos recubiertos con $10 \%$ en masa de BOHAl. Para ello se procedió a utilizar la muestra BOHAI molida y precalcinada, debido a su mejor resistencia térmica (en comparación a la bentonita $B$ ), menor 
tamaño de partícula, y mayor desarrollo de fases cristalinas de interés (mullita). La precalcinación a $800{ }^{\circ} \mathrm{C}$ y posterior molienda en molino planetario de BOHAl se realizó según lo analizado en el inciso 6.2.

La nomenclatura de los pellets obtenidos se detalla en la Tabla 6.11

Tabla 6.11 Nomenclatura de los pellets obtenidos a partir de PG molida

\begin{tabular}{lcc}
\hline & \multicolumn{2}{c}{ Temperatura de sinterización } \\
\cline { 2 - 3 } & $\mathbf{1 2 5 0 ^ { \circ } \mathrm { C }}$ & $\mathbf{1 3 0 0 ^ { \circ } \mathrm { C }}$ \\
\hline PG molida & PGm1250 & PGm1300 \\
PG molida con recubrimiento 10\% de BOHAl & PGm@BOHAl1250 & PGm@BOHAl1300 \\
\hline
\end{tabular}

En la Fig. 6.55 se muestran imágenes de los pellets preparados a partir material granular preformado con $P G$ molida con y sin recubrimiento de BOHAI (bentonita intercalada con policationes de $\mathrm{Al}$ ). Cabe mencionar que el material granular seleccionado, así como el del inciso anterior, corresponde a la fracción retenida entre los tamices M: 20/40.

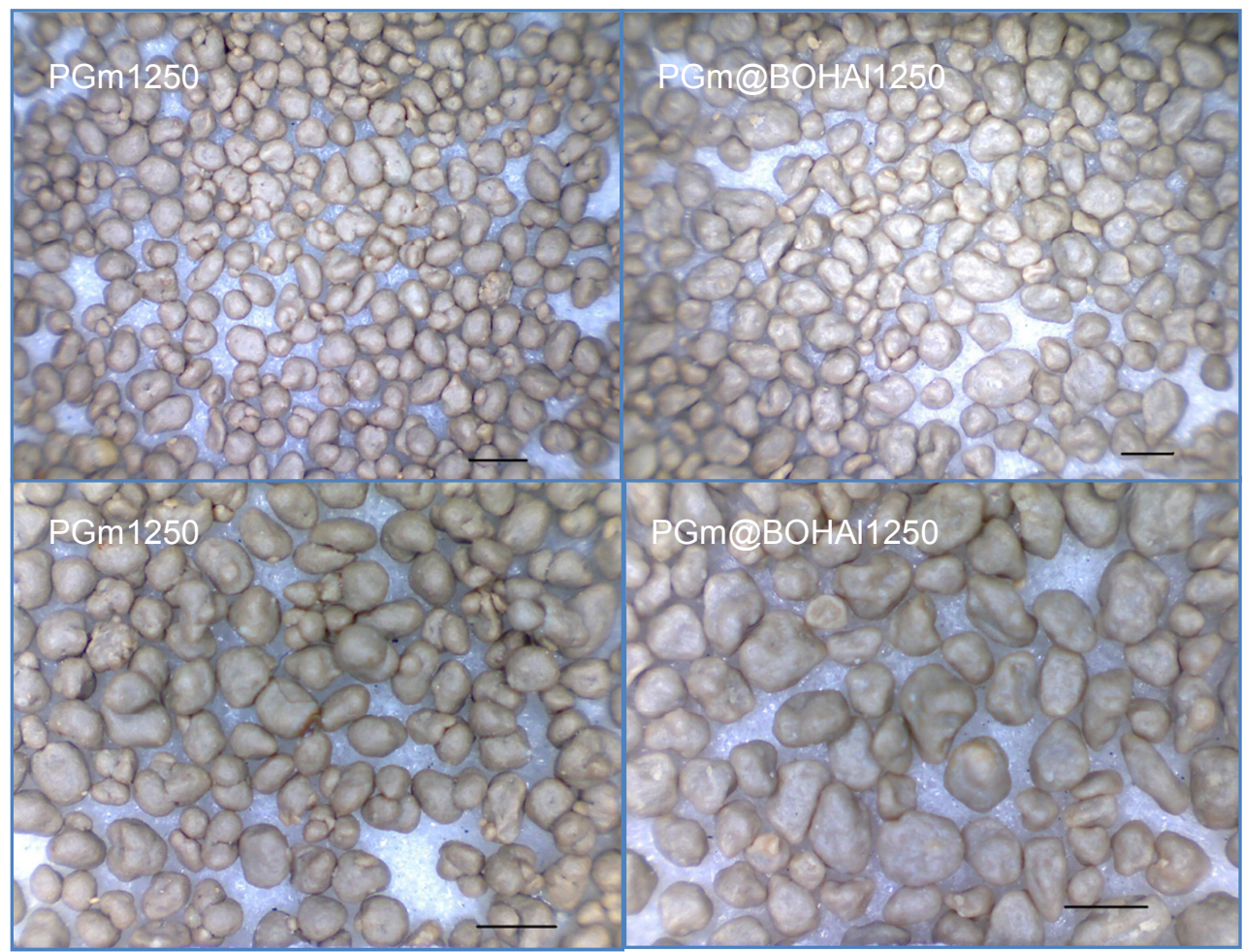

Fig. 6.55 Fotografías de material granular PGm y PGm@BOHAl sinterizados a $1250^{\circ} \mathrm{C}$ (Barra: $\left.1 \mathrm{~mm}\right)$ 
Comparando con los pellets presentados en el inciso anterior, se observa una forma más redondeada en ambos pellets con y sin recubrimiento. La Fig. 6.56 muestra que los 2 tipos de pellets (PGm y PGm@BOHAl) presentan una superficie lisa, y se observa que la temperatura de sinterizado no modificó apreciablemente la textura superficial.

No obstante, se distingue que los pellets de PGm se componen de gránulos pequeños adheridos a la superficie (estructura tipo "frutilla"). El menor tamaño de partícula del polvo PG molido utilizado como materia prima requirió un mayor agregado de agua para el conformado de los mismos. Probablemente, en la etapa de esferización, donde la energía entregada por las paletas del rotor es menor (menor velocidad de giro), en vez de lograr la esferización de los pellets se haya inducido el crecimiento de pellets por la adhesión de gránulos más pequeños a los pellets grandes, que durante el sinterizado terminaron de unirse resultando pellets más irregulares.

\begin{tabular}{l}
$\begin{array}{l}\text { Temperatura de } \\
\text { sinterizado }\end{array}$ \\
\hline $1250{ }^{\circ} \mathrm{C}$ \\
$1300{ }^{\circ} \mathrm{C}$
\end{tabular}

Fig. 6.56: Imágenes por microscopia óptica de materiales granulares PGm y PGm@BOHAl sinterizados a distintas temperaturas (Barra: $1 \mathrm{~mm}$ )

En los pellets PGm@BOHAl no se observa el efecto mencionado de adhesión de gránulos pequeños. Esto demuestra no sólo la influencia del agregado de 
recubrimiento en las propiedades del material final, sino además su efecto como agente de partición, durante el conformado de los pellets, regulando la forma de los mismos durante la etapa de esferización.

Respecto a la esfericidad y redondez, los pellets recubiertos poseen valores ligeramente mayores que los preparados sin recubrimiento. Asimismo, los pellets PGm@BOHAl cumplen con los valores requeridos para su uso como agentes de sostén cerámicos (API 19C).

Los difractogramas de los pellets obtenidos se muestran en la Fig. 6.57. Para los pellets $\mathrm{PGm}$, se observa principalmente el desarrollo de mullita y cristobalita, junto con escasa cantidad de cuarzo. El tratamiento térmico a 1300 ${ }^{\circ} \mathrm{C}$ no modificó apreciablemente la intensidad de los picos. Los pellets recubiertos (PGm@BOHAI) se componen de las mismas fases cristalinas que los respectivos sin recubrimiento, y además cordierita, producto de reacción de BOHAl a alta temperatura (Martinez et al, 2017). La cordierita presenta la mejor relación de densidad teórica respecto a su resistencia mecánica en las fases cristalinas usualmente encontradas en agentes de sostén cerámicos, lo cual la hace una fase interesante para su uso en el desarrollo de agentes de sostén livianos (Burst, 1991).

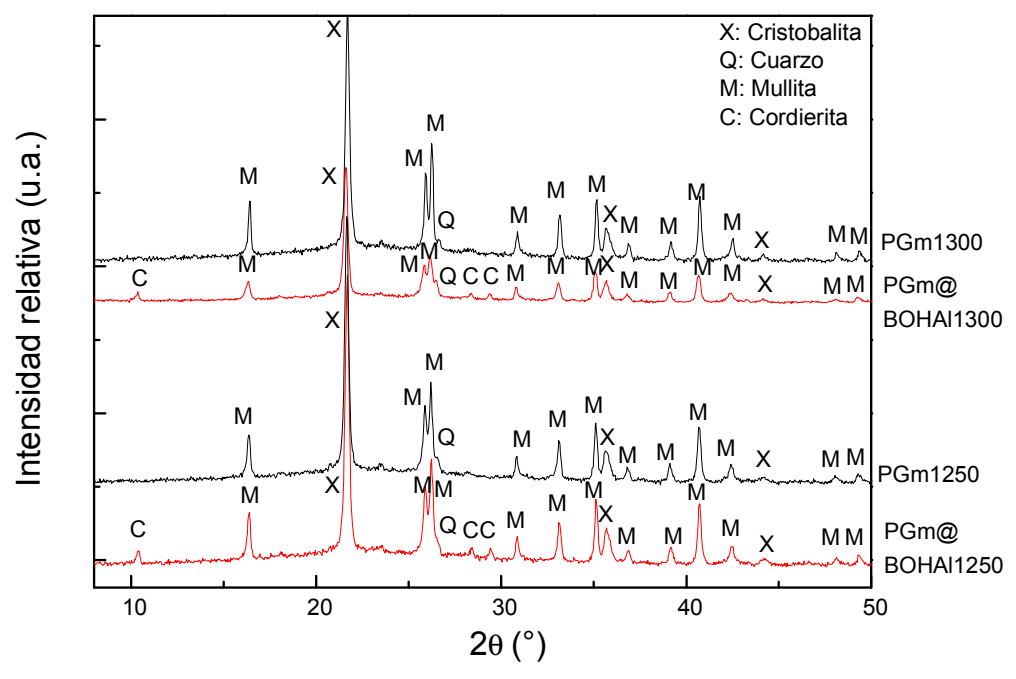

Fig. 6.57. DRX de los pellets obtenidos

Respecto a la composición de las fases de los pellets obtenidos, se procedió a analizar los difractogramas por el método Rietveld para cuantificar el contenido 
de las fases cristalinas presentes y el de fase amorfa (no cristalina), los resultados de dicho análisis se incluyen en la Tabla 6.12

Tabla 6.12. Contenido de fases cristalinas presentes en los pellets y de fase amorfa (no cristalina) determinadas aplicando Rietveld

\begin{tabular}{|c|c|c|c|c|c|c|c|c|}
\hline \multirow{3}{*}{$\begin{array}{l}\text { Temperatura } \\
\text { de sinterizado } \\
\text { Fases } \\
\text { cristalinas }\end{array}$} & \multicolumn{4}{|c|}{ PGm } & \multicolumn{4}{|c|}{ PGm@ BOHAI } \\
\hline & \multicolumn{2}{|c|}{$1250^{\circ} \mathrm{C}$} & \multicolumn{2}{|c|}{$1300^{\circ} \mathrm{C}$} & \multicolumn{2}{|c|}{$1250^{\circ} \mathrm{C}$} & \multicolumn{2}{|c|}{$1300^{\circ} \mathrm{C}$} \\
\hline & $\% \mathrm{~m} / \mathrm{m}$ & desvío & $\% m / m$ & desvío & $\% \mathrm{~m} / \mathrm{m}$ & desvío & $\% \mathrm{~m} / \mathrm{m}$ & desvío \\
\hline Mullita & 30,8 & 1,3 & 30,9 & 1,4 & 29,0 & 1,3 & 32,3 & 1,6 \\
\hline Cordierita & - & - & - & - & 2,2 & 0,6 & 2,7 & 0,7 \\
\hline Cristobalita & 16,6 & 0,7 & 16,3 & 0,6 & 16,5 & 0,6 & 18,1 & 0,7 \\
\hline Cuarzo & 0,8 & 0,3 & 0,9 & 0,3 & 1,9 & 0,4 & 0,5 & 0,5 \\
\hline Amorfo & 51,7 & 2,3 & 52,0 & 2,4 & 50,3 & 2,9 & 46,4 & 3,5 \\
\hline
\end{tabular}

En general se observa que en la composición de PGm predominan mullita y cristobalita acompañadas de un pequeño porcentaje de cuarzo y abundante fase amorfa. El efecto de la temperatura de sinterizado no es apreciable en la composición de los pellets $P G m$. Existe una leve reducción del contenido de mullita y aumento de cristobalita de $\mathrm{PGm}$ en relación al material PG. Comparativamente, la molienda del material conduce a menor porcentaje de cuarzo y aumento del contenido de cristobalita y de fase amorfa.

A la vez, en la Tabla 6.12 se aprecia para el material PGm@BOHAl que los contenidos de mullita y cristobalita son similares a los de PGm y además posee un bajo porcentaje de cordierita. En este caso, la formación de cordierita se explica por la adición BOHAl y consecuentemente el aporte de MgO. El desarrollo de cordierita ha limitado el avance de la reacción a mullita por el consumo de $\mathrm{Al}_{2} \mathrm{O}_{3}$. En esta muestra, no es significativo el efecto de la temperatura de sinterizado en la formación de mullita y en la disminución del contenido de fase amorfa. No obstante, para ambos tipos de materiales, la fase amorfa representó un alto porcentaje (46-52 \%) siendo el menor para PGm@BOHAl. En coincidencia con los resultados de la Tabla 6.12, obtenidos por el método de patrón interno, mediante el método de Ohlberg se determinó semicuantitativamente que el porcentaje de fase amorfa fue menor en los 
pellets PGm y PGm@BOHAl sinterizados a $1250{ }^{\circ} \mathrm{C}$ en relación a los respectivos de las muestras PG (51\%) y PG@B (49 \%).

En la Tabla 6.13 se muestran los valores de diámetro medio de poro, porosidad abierta y densidad aparente medidos por intrusión de $\mathrm{Hg}$ y picnometría, respectivamente, y la densidad de lecho de los pellets fue determinada siguiendo el método de la norma API 19C. La porosidad abierta fue casi nula $(<0.6 \%)$ para todas las muestras, indicando un alto grado de sinterización , debido al material finamente molido utilizado para el conformado de los pellets, acompañada por reducción de tamaño de poros con el aumento de la temperatura.

Tabla 6.13 Diámetro medio de poro, densidad aparente, porosidad abierta y densidad de lecho de los materiales granulares obtenidos.

\begin{tabular}{lcc|cc}
\hline & \multicolumn{2}{c|}{ PGm } & \multicolumn{2}{c}{ PGm@BOHAl } \\
\hline Temperatura de sinterizado $\left({ }^{\circ} \mathrm{C}\right)$ & 1250 & 1300 & $1250{ }^{\circ} \mathrm{C}$ & $1300{ }^{\circ} \mathrm{C}$ \\
\hline Diametro medio de poro $(\mathbf{n m})$ & 729 & 336 & 283 & 107 \\
\hline Densidad aparente $\left(\mathbf{g} / \mathrm{cm}^{3}\right)$ & 2,61 & 2,59 & 2,59 & 2,62 \\
\hline Porosidad abierta $(\%)$ & 0,1 & 0,3 & 0,2 & 0,6 \\
\hline Densidad de lecho $\left(\mathbf{g} / \mathrm{cm}^{3}\right)$ & 1,36 & 1,36 & 1,45 & 1,47 \\
\hline
\end{tabular}

Esto explica que la densidad aparente del pellet $\left(\sim 2,6 \mathrm{~g} / \mathrm{cm}^{3}\right)$ sea comparativamente mayor que la de los pellets obtenidos en el inciso anterior. Esta densidad, si bien mayor, está comprendida en el rango usual de los agentes de sostén cerámicos livianos, de 2,6 $-2,65 \mathrm{~g} / \mathrm{cm}^{3}$. Se observa que a pesar de tener densidades aparentes similares, la densidad del lecho de pellets sin recubrimiento es menor que las de los pellets recubiertos. Esto es indicativo de un empaquetamiento de gránulos menos eficiente que se alcanza con los pellets sin recubrimiento, adjudicado a la baja esfericidad y redondez, así como a su estructura tipo "frutilla" (gránulos de menor tamaño adheridos en la superficie del pellet), como fuera observado en la Fig. 6.56. La mayor densidad aparente y porosidad abierta casi nula, indican una mejor densificación en ambos tipos de pellets.

La Fig. 6.58 muestra imágenes de la sección transversal de los pellets obtenidas por SEM. Se distinguen escasos poros casi esféricos en el interior, y la microestructura es más densa que la correspondiente a los pellets PG. En la 
imagen de pellets PGm1300 se destaca la presencia de gránulos de menor tamaño al definido por el tamizado. Probablemente, durante la inclusión en la resina, los gránulos más pequeños adheridos a los pellets grandes se hayan separado, indicando una baja resistencia de estos materiales.

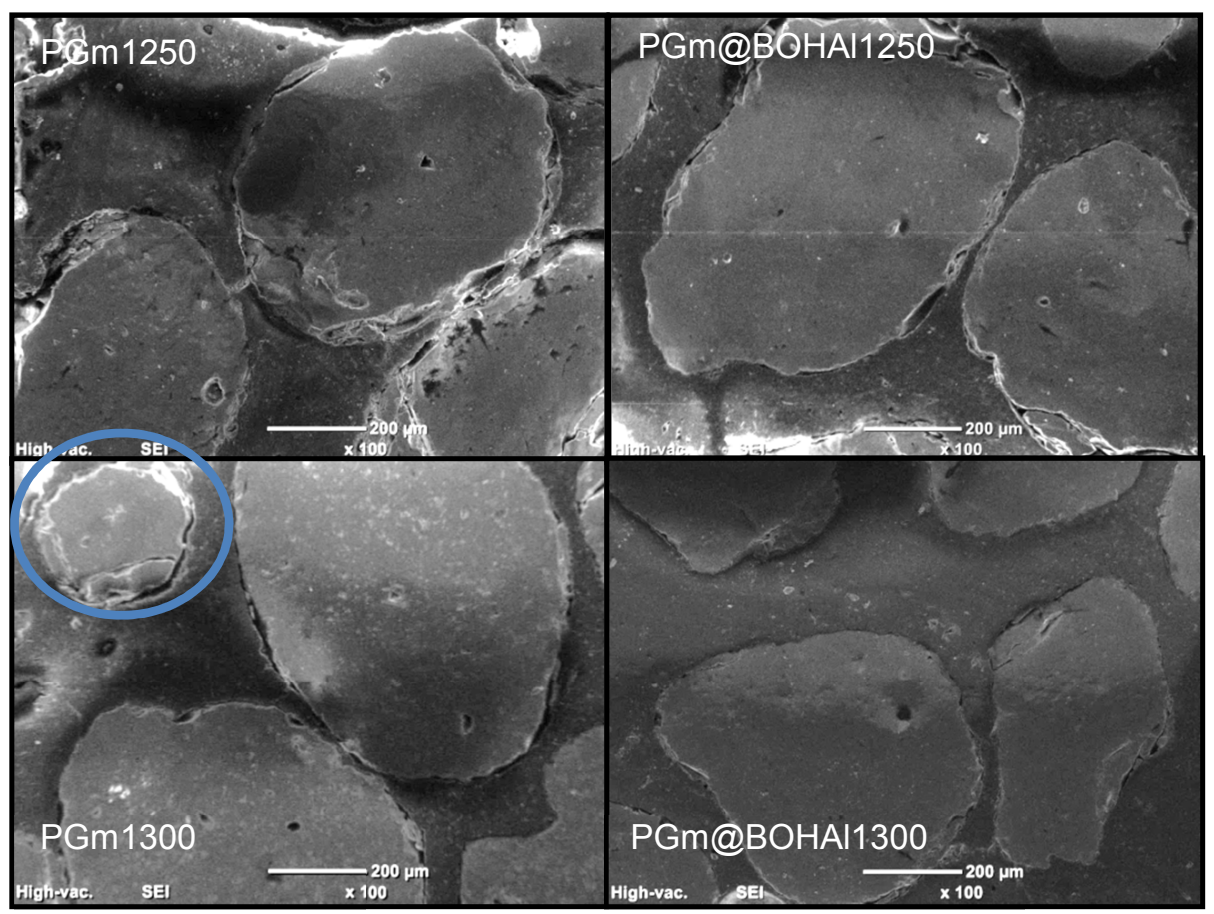

Fig. 6.58: Imágenes SEM de pellets PGm y PGm@BOHAI sinterizados a 1250 y 1300 ${ }^{\circ} \mathrm{C}$

En la Fig. 6.59 se presentan los resultados del ensayo de crush a $28 \mathrm{MPa}$ (4000 psi) realizado para PGm y PGm@BOHAl. En primera instancia se observa que para PGm, el porcentaje de finos generados es $<10 \%$, aunque mayor al de las muestras PG sin moler. Si bien los pellets PGm poseen una densidad aparente mayor y porosidad abierta menor, la estructura de estos pellets (compuestos de gránulos pequeños adheridos) es perjudicial en este ensayo.

Debido a la compresión uniaxial ejercida mediante el émbolo de la celda en el ensayo de crush, estas partículas adheridas (de menor tamaño que la abertura del tamiz M: 40 utilizado) se desprenden causando un aumento en la cantidad de finos generados en el ensayo y una menor resistencia a la compresión del lecho. El aumento de temperatura de sinterizado a $1300{ }^{\circ} \mathrm{C}$ disminuyó levemente $(1 \%)$ la cantidad de finos generados. 


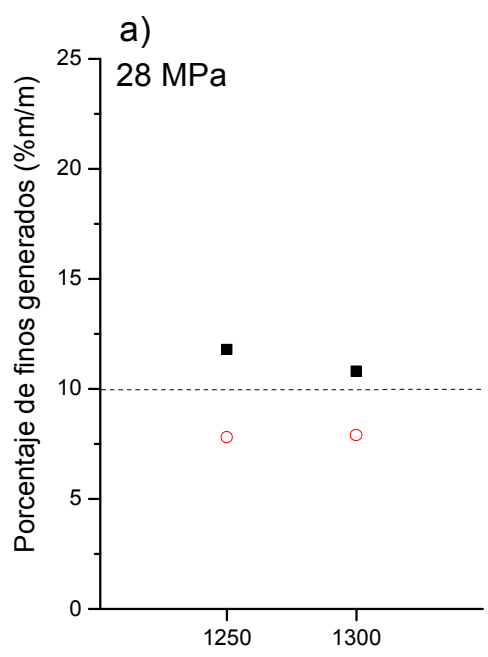

Temperatura de sinterizacion $\left({ }^{\circ} \mathrm{C}\right)$

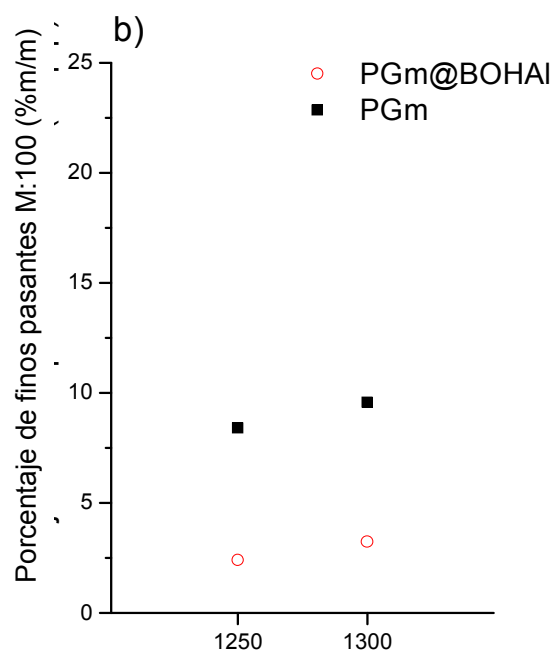

Temperatura de sinterizacion $\left({ }^{\circ} \mathrm{C}\right)$

Fig. 6.59 Resultados de ensayo de Crush a $28 \mathrm{MPa}$ de pellets sinterizados a 1250 y $1300{ }^{\circ} \mathrm{C}$ : a) porcentaje de finos $\mathrm{M}: 40$ y b) porcentaje de finos pasantes M: 100

Para la muestra PGm@BOHAl, el porcentaje de finos generados es $<10 \%$ para ambas temperaturas de sinterizado. Los resultados de los ensayos de crush son similares respecto a los de pellets PG obtenidos a partir de arcilla sin moler. No obstante, se evidencia una mejora considerable en el incremento en la densificación del material y se destaca una mínima presencia de defectos internos tales como poros y fisuras, observados por microscopía SEM en Fig. 6.13 y superficiales (menor porosidad abierta).

Asimismo, en la Fig. 6.59.b se muestra la incidencia del recubrimiento en la proporción de finos pasantes M100, observándose una notable disminución hasta 2,4 y $3,2 \% \mathrm{~m} / \mathrm{m}$ para los pellets con recubrimiento de bentonita intercalada con aluminio con respecto a los de PGm (8,5 y 9,7 \%m/m). Estos resultados demuestran un aumento en la resistencia a la compresión del lecho de pellets cerámicos.

\subsubsection{Correlación entre resistencia al crush y propiedades del material granular}

A pesar de la influencia simultánea que ejercen diferentes variables en la resistencia al crush del lecho de pellets, el objetivo de este apartado es 
establecer posibles correlaciones que existan entre características del pellet individual y la resistencia a la compresión/generación de finos.

A continuación en la Tabla 6.14 se realiza una comparación entre las propiedades de los pellets PG1250, PG@B1200, PGm1300 y PGm@BOHAl1250 y 1300 con un comportamiento satisfactorio al crush (28 $\mathrm{MPa}$

Tabla 6.14 .Densidad aparente, porosidad abierta, esfericidad y redondez de los pellets y densidad del lecho de los materiales granulares.

\begin{tabular}{lccccc}
\hline & PG & PG@B & PGm & PGm@BOHAI & PGm@BOHAI \\
& $\mathbf{1 2 5 0}$ & $\mathbf{1 2 0 0}$ & $\mathbf{1 3 0 0}$ & $\mathbf{1 2 5 0}$ & $\mathbf{1 3 0 0}$ \\
\hline Densidad aparente $\left(\mathbf{g} / \mathbf{c m}^{3}\right)$ & 2.56 & 2,56 & 2,59 & 2,59 & 2,62 \\
Porosidad abierta (\%) & 3,6 & 3,3 & 0,3 & 0,2 & 0,6 \\
Densidad de lecho $\left(\mathbf{g} / \mathbf{c m}^{3}\right)$ & 1,33 & 1,31 & 1,36 & 1,45 & 1,47 \\
Esfericidad (ad) & 0,6 & 0,6 & 0,5 & 0,7 & 0,7 \\
Redondez $(\mathbf{a d})$ & 0,8 & 0,7 & 0,6 & 0,7 & 0,7 \\
\hline
\end{tabular}

En cuanto a la composición de fases cristalinas, que es uno de los principales factores determinantes, se estableció que los pellets PG1250 y PG@B1200 están mayoritariamente constituidos por mullita, cristobalita y cuarzo. En el caso PG@B1200, se verifica que disminuye la proporción de mullita, aumenta el de fase amorfa del cerámico debido a que la incorporación de $20 \%$ de B que reduce el contenido de caolinita de la composición. Según lo estimado por Rietveld, con el proceso de molienda, los pellets poseen similares contenido de mullita en tanto se redujo notablemente el porcentaje de cuarzo y aumentó el de cristobalita. El recubrimiento de BOHAl derivó en formación de 2-3 \% de cordierita y por lo tanto se reduce la conversión a mullita en relación a los preparados sólo con PG molida. PGm@BOHAl1300 presenta el más bajo contenido de fase amorfa.

La Tabla 6.14 muestra que la densidad aparente se aproxima a $2,6 \mathrm{~g} / \mathrm{cm}^{3}$ para materiales preparados con PG molida, siendo estos valores mayores que los preparados a partir de PG. Las muestras preparadas utilizando PG molida poseen menor porosidad abierta que los pellets PG. Comparativamente, PGm y PGm@BOHAl presentan características texturales adecuadas (porosidad abierta casi nula) y un alto grado de sinterización, y microestructura densa con 
baja porosidad interna (observada por microscopía SEM). Sin embargo, los resultados del ensayo de crush indicaron que la muestra $\mathrm{PGm}$ posee una menor resistencia a la compresión (Fig. 6.59). Estos resultados se pueden relacionar al proceso de formación de gránulos en la esferizadora: en la etapa de crecimiento el aumento de tamaño de algunos pellets se asocia a la unión de gránulos más pequeños que originan una estructura de gránulo débil que es perjudicial para la resistencia mecánica. En tanto que, la incorporación de BOHAl como recubrimiento actúa como agente de partición, inhibiendo la adhesión entre los pellets húmedos, y evitando así la formación de estructura tipo "frutilla" (pellets más pequeños adheridos a pellets de mayor tamaño).

Las densidades de lecho de los pellets PG y PG@B son similares, entendiéndose por la densidad aparente levemente menor respecto a las de pellets PGm. Con las muestras PG@BOHAl1250 y PG@BOHAl1300 se consigue una densidad de lecho ligeramente mayor, probablemente asociada a la mayor densidad aparente de los pellets individuales, debido a que no se observan distinciones importantes en los valores de esfericidad y redondez de dichas muestras (es decir, esfericidad y redondez similares.

Si bien los pellets PGm1300 poseen una densidad aparente similar a las muestras PG@BOHAl1250 y PG@BOHAl1300, alcanzan comparativamente una densidad menor de empaquetamiento de lecho. Como fue explicado, esto proviene de su forma no completamente esférica ( $\mathrm{y}$ de la estructura tipo "frutilla") que impide un empaquetamiento más compacto.

Respecto a su posible aplicación como agentes de sostén, las muestras PG@BOHAl1250 y 1300 cumplen los valores de esfericidad y redondez estipulados por la norma $(S \geq 0,7 ; R \geq 0,7)$. 


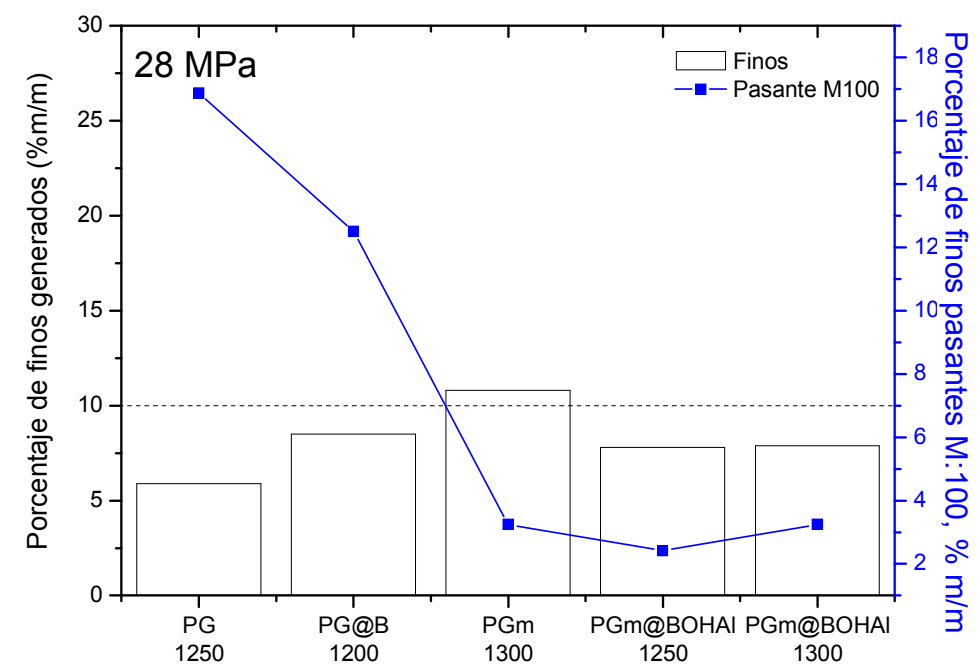

Fig. 6.60. Comparación ensayo de Crush de materiales granulares sinterizados a 1250 y $1300^{\circ} \mathrm{C}$ : a) porcentaje de finos $\mathrm{M}: 40$ y b) porcentaje de finos pasantes M: 100.

Se determinó además que, pellets $\mathrm{PG} 1250^{\circ} \mathrm{C}$ y PG@B1200 con una resistencia al crush satisfactoria (finos pasantes M: $40<10 \%$ ), originan el 27 y el $18 \%$ de material pasante M: 100 respectivamente, en tanto que este contenido fue sólo de 3,2, 2,4 y 3,3 \% para PGm1300, PGm@BOHAl1250 y PGm@BOHAl1300 respectivamente (Fig. 6.60). Este resultado se asocia a las mejoras en densificación y microestructura de los pellets PGm y PGm@BOHAl. No obstante, la presencia de pellets PGm con baja esfericidad y estructura poco adecuada disminuyen su desempeño respecto al crush en comparación con el material PGm con buena esfericidad y redondez.

Así, el recubrimiento con BOHAl no sólo mejora la esfericidad y redondez y aumenta la resistencia al crush sino que reduce considerablemente el porcentaje de material pasante $M$ : 100, esto último seria potencialmente beneficioso puesto que los gránulos además deben ser capaces de conservar una buena permeabilidad del lecho. 


\subsubsection{Ensayo de resistencia al crush a $35 \mathrm{MPa}$ (5000 psi) de materiales PG1250, PG@B1200,PGm@BOHAl1250 y PGm@BOHAl1300}

Los pellets sinterizados que alcanzaron adecuada resistencia al ensayo crush a $28 \mathrm{MPa}(4000 \mathrm{psi})$ fueron sometidos adicionalmente al ensayo crush a $35 \mathrm{MPa}$ psi (5000 psi). Los resultados se presentan en la Fig. 6.61.

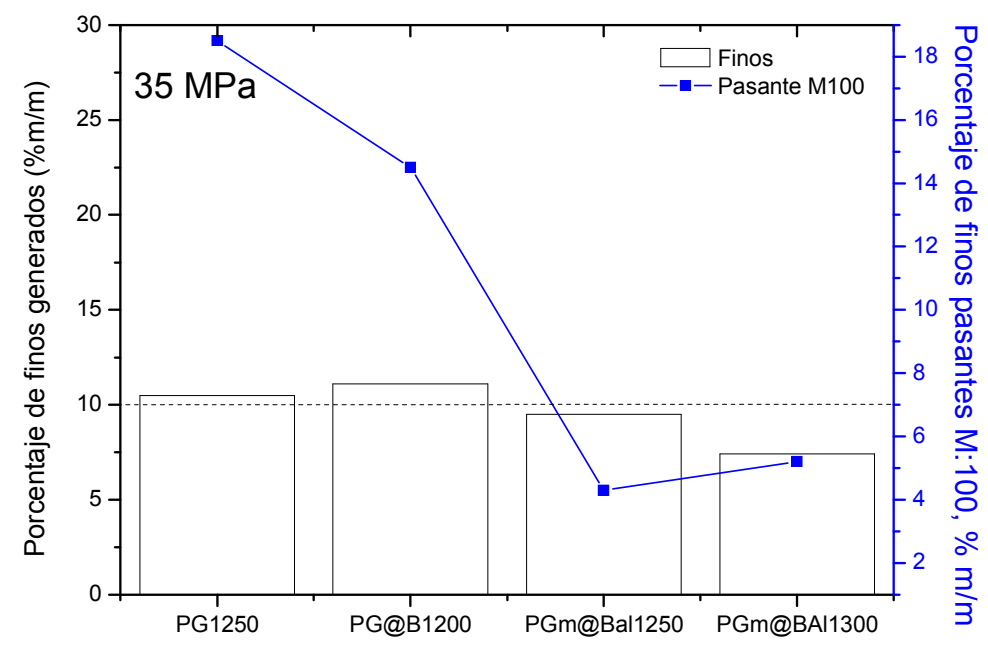

Fig. 6.61: Porcentaje de finos ( $<M: 40)$ y material pasante M: 100 generados en ensayo de Crush a $35 \mathrm{MPa}$ de materiales granulares

El ensayo a $35 \mathrm{MPa}$ muestra que los pellets PG1250 y PG@B1200 no resultaron aceptables, obteniéndose una cantidad de finos mayor a la estipulada por el ensayo. En tanto que las muestras PGm@BOHAl1250 y PGm@BOHAl1300 demostraron una mayor resistencia a la compresión, obteniéndose valores de finos $<10 \%$ tal como estipula la norma.

\subsubsection{Consideraciones parciales}

- Se conformaron pellets cerámicos M20/40 a partir de una arcilla caolinítica PG disponible comercialmente en una mezcladora de alta energía y posterior sinterizado a $1050-1250{ }^{\circ} \mathrm{C}$. Se preparó otra serie de pellets (PG@B) a partir de material granular preformado con PG como núcleo y posterior aplicación de un recubrimiento de $20 \%$ de bentonita $B$ (precursora de ANs modificadas). Los pellets así obtenidos se sinterizaron en el mismo rango de temperaturas. 
- Ambos tipos de pellets M20/40 presentaron buena esfericidad y redondez, cercanos a los valores estipulados por la norma API19C. Por sinterización a $1250{ }^{\circ} \mathrm{C}$, desarrollaron mullita y cristobalita con cuarzo y abundante fase amorfa. Ambos tipos de gránulos poseen $3,5 \%$ de porosidad abierta y densidad próxima a $2,6 \mathrm{~g} / \mathrm{cm}^{3}$. Sin embargo, en la microestructura SEM se distinguen poros grandes y defectos/ grietas.

- La caracterización mecánica por el ensayo de crush a 28 MPa psi de estos pellets cerámicos sinterizados a $1250{ }^{\circ} \mathrm{C}$ indicó que la resistencia fue satisfactoria para ambos productos con y sin recubrimiento de bentonita, siendo menor el porcentaje de finos para PG.

- En una segunda etapa, se definió como variable a modificar la distribución de tamaños de partícula de los materiales de partida para mejorar la microestructura y se optimizó la metodología para la elaboración de pellets en la mezcladora de alta energía por combinación de material granular preformado de arcilla caolinítica molida como núcleos y una capa de $10 \%$ en peso de BOHAl como recubrimiento.

- Estos pellets PGm@BOHAl sinterizados a 1250 y $1300{ }^{\circ} \mathrm{C}$, rango de temperatura relativamente bajo, se componen mayoritariamente de mullita (29$32 \%$ en peso) y cristobalita (16-18\%) con escasa cordierita (2-3\%), escaso cuarzo residual, siendo elevado el contenido de fase amorfa (46-50 \%) A la vez, exhiben una microestructura densa, con escasos poros y sin grietas.

- Los pellets desarrollados M: 20/40 presentan buena esfericidad y redondez de 0.7 y 0.7 respectivamente, densidad cercana a $2,6 \mathrm{~g} / \mathrm{cm}^{3}$ y porosidad abierta $<0.6 \%$, que concuerdan con los valores especificados para proppants comerciales. Estos materiales presentan adecuada resistencia al crush a 35 $\mathrm{MPa}$, requerida para su aplicación como agentes de sostén cerámicos livianos para fracturación. 


\section{CONCLUSIONES}

En este trabajo de Tesis se desarrollaron y caracterizaron compositos cerámicos a partir de arcillas nanoestructuradas $A N$, modificadas por intercalación de especies policatiónicas de aluminio o zirconio (BOHAl y $\mathrm{BOHZr}$ ) en el mineral arcilloso de una bentonita. Existen limitados antecedentes sobre transformaciones térmicas de dichas AN químicamente modificadas, así como su uso como precursores para el procesamiento de cerámicos en comparación con las fases formadas y aplicaciones de arcillas naturales y fue por ello que se planteó este estudio.

Se conformaron dos tipos de compositos a partir de dichas AN modificadas: sustratos cerámicos recubiertos por inmersión en suspensiones (dip coating) de BOHAl y BOHZr, y pellets cerámicos (núcleo@cáscara) recubiertos con BOHAI en polvo utilizando mezcladora de alta energía.

\subsection{Acerca de las arcillas nanoestructuradas, AN, obtenidas y su caracterización}

Se caracterizó la arcilla natural utilizada como materia prima: bentonita nacional, por análisis químico, difracción de rayos $X$, espectroscopia de infrarrojo, análisis térmicos (ATD-TG) y se verificó la presencia de esmectita tipo montmorillonita con importante contenido de magnesio octaédrico, acompañada de impurezas de cuarzo y feldespato.

La caracterización de $\mathrm{BOHAl}$ y $\mathrm{BOHZr}$ fue realizada utilizando las técnicas antes mencionadas, y posibilitó confirmar la retención de las especies poliméricas de $\mathrm{OH}-\mathrm{Al}$ y $\mathrm{OH}-\mathrm{Zr}$ y su ubicación en el espaciado interlaminar de la montmorillonita.

La intercalación de las especies catiónicas en el mineral arcilloso modificó el comportamiento en suspensión de las partículas de AN modificadas, aumentando la carga superficial positiva de las mismas. Para BOHAl se determinó un punto isoeléctrico cercano a $\mathrm{pH}$ 6. El poliacrilato de sodio fue un dispersante adecuado que permitió preparar suspensiones acuosas con suficiente contenido de sólidos y buena fluidez. 
Se observaron diferencias en las transformaciones térmicas de ambas AN modificadas hasta $1300{ }^{\circ} \mathrm{C}$ por DRX y microscopía de calentamiento, estableciendo que dependen del tipo de catión intercalado y de la temperatura. Durante el tratamiento térmico se evidenciaron numerosas reacciones y transformaciones, tales como deshidratación y deshidroxilación de la montmorillonita, transformación de especies retenidas a óxidos, destrucción estructural de la montmorillonita y reacción entre productos de descomposición de la esmectita y óxidos incorporados, formación de nuevas fases cristalinas y amorfa, etc., algunas de ellas tienen lugar con importantes pérdidas de peso y cambios de volumen.

La estabilidad térmica de las AN intercaladas aumentó notablemente, debido al enriquecimiento en $\mathrm{Al}_{2} \mathrm{O}_{3} \circ \mathrm{ZrO}_{2}$ y la disminución de contenido de fundentes por sustitución de los cationes de intercambio $\left(\mathrm{Na}_{2} \mathrm{O}, \mathrm{K}_{2} \mathrm{O}\right.$ y CaO). En tanto que con la bentonita ocurrió la fusión parcial del sistema y la subsecuente expansión debida al fenómeno de bloating a relativa baja temperatura $\left(\sim 1050^{\circ} \mathrm{C}\right)$, que no se observó con las BOHAl y BOHZr presumiblemente por la menor presencia de líquido a elevadas temperatura.

Las AN intercaladas desarrollaron un menor contenido de fase amorfa, respecto a la sin tratar. La evolución de las fases cristalinas con la temperatura dependió fuertemente de la composición química. Para BOHAl se obtuvo espinela a $1000{ }^{\circ} \mathrm{C}$ y aumento progresivo en el desarrollo de mullita y cristobalita hasta $1200{ }^{\circ} \mathrm{C}$, acompañadas de cordierita a $1300^{\circ} \mathrm{C}$. Para BOHZr, se formó $\mathrm{t}-\mathrm{ZrO}_{2}$ a $1000{ }^{\circ} \mathrm{C}$, transformándose a $1200{ }^{\circ} \mathrm{C}$ en $\mathrm{ZrSiO}_{4}$ por reacción entre $\mathrm{ZrO}_{2}$ y $\mathrm{SiO}_{2}$. A partir de $1300{ }^{\circ} \mathrm{C}$ coexistieron cordierita, $\mathrm{ZrSiO}_{4}$ y cristobalita. Las fases desarrolladas a altas temperaturas (mullita, $\mathrm{t}-\mathrm{ZrO}_{2}$ y $\left.\mathrm{ZrSiO}_{4}\right)$ se destacan por sus altos puntos de fusión y buenas propiedades mecánicas y junto con las mejoras en la estabilidad térmica resultan favorables para la aplicación en cerámicos.

\subsection{Acerca del procesamiento de cerámicos obtenidos a partir de AN modificadas}

La obtención de cerámicos de baja porosidad a partir de BOHAl y BOHZr, requirió la pre-calcinación y molienda de dichas muestras. En las piezas 
cerámicas conformadas por prensado uniaxial y sinterización, se verificó que el pretratamiento no alteró las fases cristalinas formadas. Por su parte, el cerámico preparado con la bentonita natural presentó deformación y expansión a temperaturas mayores a $1100^{\circ} \mathrm{C}$.

Los cerámicos obtenidos por tratamiento térmico de $\mathrm{BOHAl}$ y $\mathrm{BOHZr}$ permanecieron térmicamente estables hasta $1300{ }^{\circ} \mathrm{C}$. Los cerámicos sinterizados a $1200{ }^{\circ} \mathrm{C}$, presentaron porosidad abierta casi nula y densidades aparentes de 1,7 y $2,5 \mathrm{~g} / \mathrm{cm}^{3}$, respectivamente. Las micrografías SEM evidenciaron que microestructura de ambos cerámicos es homogénea y la porosidad interna que presentan aparece bien distribuida. Ambos cerámicos exhibieron buena dureza Vickers, alcanzándose valores de 6,5-6,7 GPa. Dichos valores son cercanos a la dureza de los agentes de sostén mencionados en bibliografía para densidades aparentes similares.

Comparativamente, los dos sustratos (LG y PG) utilizados para el conformado de compositos cerámicos denotaron una dureza Vickers menor (4,9 y 5,3 GPa, respectivamente); demostrando la potencialidad de los recubrimientos de AN para la mejora de la dureza de compositos.

\subsection{Acerca de los compositos obtenidos por recubrimiento de sustratos con AN por inmersión en suspensiones (dip coating) y caracterización}

Los resultados sobre las propiedades de los cerámicos obtenidos a partir de las AN modificadas fueron promisorios en la obtención de compositos, por lo que en este caso se presentan las conclusiones sobre el procesamiento de compositos constituidos de sustratos recubiertos con AN por inmersión en suspensiones (dip coating) de BOHAl y BOHZr

Utilizando BOHAl, se optimizaron las variables que intervienen en obtención de recubrimientos por esta técnica, estableciendo las características más adecuadas de la suspensión (condiciones reológicas y aditivos en suspensión), así como la influencia de las propiedades texturales del sustrato y de los ciclos de tratamiento térmico. En general, la cantidad de AN retenida en el sustrato resultó dependiente de la porosidad y del menor tamaño de poro del sustrato, debido a la succión capilar generada por estos poros. Para el sustrato LG se 
determinó más adecuado el uso de suspensión de BOHAl sin aditivos, sinterización con rampa de calentamiento lento $\left(2^{\circ} \mathrm{C} / \mathrm{min}\right)$ y cinco mesetas hasta $1200{ }^{\circ} \mathrm{C}$, a fin de minimizar el agrietamiento de los recubrimientos. Los coeficientes de expansión térmica del sustrato y del recubrimiento de BOHAI sinterizados arrojaron que el comportamiento expansivo del sustrato LG es causado por el contenido de cuarzo, lo que conlleva diferencias importantes entre ambos coeficientes (sustrato y recubrimiento), derivando esto en la formación de microgrietas en el recubrimiento. Sustratos con menor contenido cuarzo y características texturales similares condujeron a recubrimientos con menor microagrietamiento superficial. Este resultado se deriva de una menor diferencia entre los coeficientes de expansión térmica del sustrato y del recubrimiento. Sin embargo, los compositos procesados a partir del mismo sustrato y recubrimiento de $\mathrm{BOHZr}$ por dip coating, en las condiciones experimentales óptimas establecidas para el caso de $\mathrm{BOHAl}$, poseen comparativamente un mayor grado de agrietamiento. Esto remarca la dependencia del tipo de catión intercalante en las AN en la formación de recubrimientos. De modo que, para la obtención de recubrimientos estables es preciso realizar estudios de condiciones experimentales específicos para cada tipo de catión intercalante.

\subsection{Acerca de los compositos obtenidos por granulación y recubrimiento} de BOHAl utilizando una mezcladora de alta intensidad y caracterización

Respecto a los materiales granulares, en una primera etapa se desarrollaron a partir de una arcilla sin recubrimiento y luego con recubrimiento de bentonita natural (composito tipo núcleo@cáscara), denominados PG y PG@B, respectivamente, y fueron de importancia para establecer los valores apropiados de las variables más importantes del proceso granulación en la mezcladora de alta intensidad. Estos pellets sinterizados a $1050-1250{ }^{\circ} \mathrm{C}$ están constituidos principalmente de cristobalita, mullita y cuarzo con abundante fase amorfa, siendo esta última mayor en las muestras PG@B. Ambos tipos de gránulos mostraron baja porosidad abierta (<3.5 \%) y densidad aparente $\sim 2,6 \mathrm{~g} / \mathrm{cm}^{3}$. Por microscopía SEM se identificó, en la microestructura de los pellets individuales, la presencia de poros grandes y defectos. Estos materiales 
granulares M: $20 / 40$ sinterizados a 1200 y $1250{ }^{\circ} \mathrm{C}$ presentaron adecuada resistencia mecánica, evaluada por el ensayo de crush según Norma API 19C, a $28 \mathrm{MPa}$ (4000 psi); asimismo presentan valores de esfericidad y redondez cercanos a los aceptados por la normativa. Posteriormente, mediante la reducción del tamaño de partícula de la arcilla usada en la conformación del material granular que representa el sustrato, se logró eliminar los poros grandes y defectos observados en la microestructura, Los pellets sinterizados a $1250-1300{ }^{\circ} \mathrm{C}$ tuvieron composición de fases cristalinas similar a la obtenida en la primera etapa con apreciable reducción del porcentaje de cuarzo con respecto al de cristobalita.

El recubrimiento con BOHAl en la obtención de compositos por granulación se aplicó usando polvo finamente molido de la muestra BOHAl precalcinada, debido a la baja porosidad y buena densificación que mostraron los cerámicos. En este material granular recubierto, se encontró una leve reducción en el contenido de mullita por formación de 2-3\% de cordierita, una microestructura densa, con escasos poros y sin grietas. Los defectos de conformado de los pellets sin recubrimiento (estructura tipo "frutilla") no se detectaron con el recubrimiento de $\mathrm{BOHAl}$, que actuaría como agente de partición durante el conformado de los mismos.

Los pellets (M: 20/40) procesados con PG molida y recubrimiento de BOHAI (PGm@BOHAl) mostraron valores de esfericidad y redondez acordes a la Norma $(\geq 0,7)$, densidad cercana a $2,6 \mathrm{~g} / \mathrm{cm}^{3}$ y porosidad abierta $<0.6 \%$; valores que concuerdan con los especificados para agentes de sostén livianos comerciales. Estos materiales presentan adecuada resistencia al crush a 35 MPa (5000 psi), requerida para su aplicación como agentes de sostén cerámicos livianos para estimulación hidráulica.

En síntesis, este trabajo de Tesis permitió analizar y establecer las posibilidades de uso de las arcillas nanoestructuradas (ANs) intercaladas con polihidroxicationes de $\mathrm{Al} \circ \mathrm{Zr}$ como materias primas para el desarrollo de compositos cerámicos. El tratamiento de intercalación realizado modificó las propiedades de la arcilla original. Se mejoró la dureza y resistencia térmica de los cerámicos obtenidos a partir de las ANs intercaladas con respecto a la 
bentonita natural. Respecto a los compositos desarrollados, la optimización de los sistemas sustrato-recubrimiento por dip coating derivó en compositos con recubrimientos de buena adherencia, en los cuales se minimizó el microagrietamiento superficial. Asimismo, pudo confirmarse la capacidad de los materiales nucleo@cáscara obtenidos por granulación y recubrimiento de AN en polvo en mezcladora de alta intensidad como agentes de sostén cerámicos, evaluando las propiedades mecánicas y morfológicas de los mismos según Norma API. Estudios adicionales serán requeridos (permeabilidad, ataque ácido, etc.) para confirmar la aptitud de estos materiales como agentes de sostén cerámicos. 


\section{REFERENCIAS}

Abu-Jdayil, B., Ghannam, M., 2014. The Modification of Rheological Properties of Sodium Bentonite-water Dispersions with Low Viscosity CMC Polymer Effect. Energy Sources, Part A: Recovery, Utilization, and Environmental Effects 36, 1037-1048.

Aceman, S., Lahav, N., Yariv, S., 1997. XRD study of the dehydration and rehydration behaviour of Al-pillared smectites differing in source of charge. Journal of thermal analysis 50, 241-256.

Aceman, S., Lahav, N., Yariv, S., 2000. A thermo-XRD study of Al-pillared smectites differing in source of charge, obtained in dialyzed, non-dialyzed and washed systems. Applied Clay Science 17, 99-126.

Al-Malki, N., Pourafshary, P., Al-Hadrami, H., Abdo, J., 2016. Controlling bentonite-based drilling mud properties using sepiolite nanoparticles. Petroleum Exploration and Development 43, 717-723.

Álvarez-Pinazo, G., Cuesta, A., García-Maté, M., Santacruz, I., Losilla, E.R., De la Torre, A.G., León-Reina, L., Aranda, M.A., 2012. Rietveld quantitative phase analysis of Yeelimite-containing cements. Cement and Concrete Research 42, 960-971.

Allo, W.A., Murray, H.H., 2004. Mineralogy, chemistry and potential applications of a white bentonite in San Juan province, Argentina. Applied Clay Science 25, 237-243.

Aouad, A., Mandalia, T., Bergaya, F., 2005. A novel method of Al-pillared montmorillonite preparation for potential industrial up-scaling. Applied Clay Science 28, 175-182.

API19C, Measurement of Properties of Proppants Used in Hydraulic Fracturing and Gravel-packing Operations, May 2008, Washington, DC: API.

Aranda, M.A., De la Torre, A.G., León-Reina, L., 2012. Rietveld quantitative phase analysis of OPC clinkers, cements and hydration products. Reviews in Mineralogy and Geochemistry 74, 169-209.

Arcos, D., Vallet-Regí, M., 2013. Bioceramics for drug delivery. Acta Materialia 61, 890-911.

Avena, M.J., Cabrol, R., De Pauli, C.P., 1990. Study of some physicochemical properties of pillared montmorillonites: acid-base potentiometric titrations and electrophoretic measurements. Clays and clay minerals 38, 356-362.

Basu, B., 2005. Toughening of yttria-stabilised tetragonal zirconia ceramics. International Materials Reviews 50, 239-256.

Beckhoff, B., Kanngießer, B., Langhoff, N., Wedell, R., Wolff, H., 2007. Handbook of practical X-ray fluorescence analysis. Springer Science \& Business Media.

Bergaya, F., Aouad, A., Mandalia, T., 2006. Pillared clays and clay minerals. Handbook of clay science 1, 393-421.

Bergaya, F., Lagaly, G., 2013. Handbook of Clay Science. Elsevier Science. 
Bernhardt, M., Tellesbø, H., Justnes, H., Wiik, K., 2014. The effect of heat treatment and cooling rate on the properties of lightweight aggregates. Journal of the European Ceramic Society 34, 1353-1363.

Binner, J., Annapoorani, K., Paul, A., Santacruz, I., Vaidhyanathan, B., 2008. Dense nanostructured zirconia by two stage conventional/hybrid microwave sintering. Journal of the European Ceramic Society 28, 973-977.

Blanton, T., Majumdar, D., Chatterjee, D., 2000. The use of Smectite Clays for Formation of a Ceramic Case Surrounding a Tetragonal Zirconium Dioxide Core. The Rigaku Journal 17, 4-8.

Bonekamp, B., 1996. Preparation of asymmetric ceramic membrane supports by dip-coating, Membrane Science and Technology. Elsevier, pp. 141-225.

Bottero, J., Bruant, M., Cases, J., 1988. Interactions Between HydroxyAluminium Species and Homoionic $\mathrm{Na}$ - and $\mathrm{Ca}$-Montmorillonite Particles, as Manifested by $\zeta$ Potential, Suspension Stability and X-ray Diffraction. Clay minerals 23, 213-224.

Bragg, W.L., 1913. The diffraction of short electromagnetic waves by a crystal. Proc. Cambridge Phil. Soc. 17, 43-57.

Brigatti, M., Galanb, E., Thengc, B., 2013. Structure and Mineralogy of Clay Minerals, Handbook of Clay Science, p. 21.

Budworth, D.W., Arthur, G., 2016. An Introduction to Ceramic Science: The Commonwealth and International Library: Materials Science and Technology (Ceramics Division). Elsevier Science.

Burst, J.F., 1991. The application of clay minerals in ceramics. Applied Clay Science 5, 421-443.

Busquets, M.D.J. 2009. Apuntes de Curso de Fundamentos de Ciencia de Materiales. Universitat Politècnica de València. Extraído de https://www.upv.es/materiales

Cannan, C.D., Palamara, T.C., 2006. Low density proppant. U.S. Patent No 7,036,591.

Carter, C.B., Norton, M.G., 2007. Ceramic materials: science and engineering. Springer Science \& Business Media.

Clearfield, A., Vaughan, P.A., 1956. The crystal structure of zirconyl chloride octahydrate and zirconyl bromide octahydrate. Acta Crystallographica 9, 555558.

Cleaves, H.J., 2011. Isoelectric Point, in: Gargaud, M., Amils, R., Quintanilla, J.C., Cleaves, H.J., Irvine, W.M., Pinti, D.L., Viso, M. (Eds.), Encyclopedia of Astrobiology. Springer Berlin Heidelberg, Berlin, Heidelberg, pp. 858-858.

Colina, H., Roux, S., 2000. Experimental model of cracking induced by drying shrinkage. The European Physical Journal E 1, 189-194.

Conceição, S.I., Velho, J.L., Ferreira, J.M.F., 2003. Influence of deagglomeration and carboxymethyl cellulose binders on rheological behaviour of kaolin suspensions. Applied Clay Science 23, 257-264. 
Conconi, M., Rendtorff, N., Aglietti, E., 2011. Evaluation of Non Crystalline Phase in AZS Refractories by XRD Methods. New Journal of Glass and Ceramics 1, 28.

Cullity, B.D., Stock, S.R., 2001. Elements of X-Ray Diffraction 3ra ed.

Chen, Z., Burtovyy, R., Kornev, K.G., Luzinov, I., Peng, F., 2017. Dense and crack-free mullite films obtained from a hybrid sol-gel/dip-coating approach. Journal of Materials Research 32, 1665-1673.

Chiu, R.C., Garino, T., Cima, M., 1993. Drying of granular ceramic films: I, effect of processing variables on cracking behavior. Journal of the American Ceramic Society 76, 2257-2264.

Chlup, Z., Boccaccini, D.N., Leonelli, C., Romagnoli, M., Boccaccini, A.R., 2006. Fracture behaviour of refractory ceramics after cyclic thermal shock. Ceramics Silikaty 50, 245.

Chlup, Z., Salamon, D., 2010. Properties of porous multi-layered free-standing ceramic microchannels. Scripta materialia 63, 597-600.

Choon, O.B., 2010. Surface Forces Arising from Polymers and Small Ionic Additives-Yield Stress and Zeta Potential Relationship.

De León, M.A., De Los Santos, C., Latrónica, L., Cesio, A.M., Volzone, C., Castiglioni, J., Sergio, M., 2014. High catalytic activity at low temperature in oxidative dehydrogenation of propane with $\mathrm{Cr}-\mathrm{Al}$ pillared clay. Chemical Engineering Journal 241, 336-343.

Delgado, A., Gonzalez-Caballero, F., Bruque, J., 1986. On the zeta potential and surface charge density of montmorillonite in aqueous electrolyte solutions. Journal of colloid and interface science 113, 203-211.

Díaz-Parralejo, A., Ortiz, A.L., Caruso, R., 2010. Effect of sintering temperature on the microstructure and mechanical properties of $\mathrm{ZrO}_{2}-3 \mathrm{~mol} \% \mathrm{Y}_{2} \mathrm{O}_{3}$ sol-gel films. Ceramics International 36, 2281-2286.

Escarria J.D.V., López H.J.A., Fuertes O.I., 2012. Apuntes de Curso de Metalografía. Universidad Tecnológica de Pereira. Extraído de http://blog.utp.edu.co/metalografia/3-cristalografia/

Farmer, V., 1968. Infrared spectroscopy in clay mineral studies. Clay minerals 7, 373-387.

Figueras, F., 1988. Pillared clays as catalysts. Catalysis Reviews Science and Engineering 30, 457-499.

Framinan, J.M., Leisten, R., Ruiz García, R., 2014. A Case Study: Ceramic Tile Production, Manufacturing Scheduling Systems: An Integrated View on Models, Methods and Tools. Springer London, London, pp. 371-395.

Galisteo, A.J.L., 2007. Comportamiento frente a corrosión y desgaste de recubrimientos de sílice sol-gel sobre material compuesto Al-SiC. Universidad Rey Juan Carlos.

Gallagher, P.K., Brown, M.E., Kemp, R., 1998. Handbook of thermal analysis and calorimetry. Elsevier. 
Gandía, L.M., Gil, A., Vicente, M.A., Belver, C., 2005. Dehydrogenation of ethylbenzene on alumina-pillared Fe-rich saponites. Catalysis Letters 101, 229 234.

Ganjaee Sari, M., Ramezanzadeh, B., Shahbazi, M., Pakdel, A.S., 2015. Influence of nanoclay particles modification by polyester-amide hyperbranched polymer on the corrosion protective performance of the epoxy nanocomposite. Corrosion Science 92, 162-172.

Garrido, L.B., Aglietti, E.F., 2001. Zircon based ceramics by colloidal processing. Ceramics International 27, 491-499.

Gavin, P., Chevrier, V., Ninagawa, K., Gucsik, A., Hasegawa, S., 2013. Experimental investigation into the effects of meteoritic impacts on the spectral properties of phyllosilicates on Mars. Journal of Geophysical Research: Planets $118,65-80$.

Goehring, L., Conroy, R., Akhter, A., Clegg, W.J., Routh, A.F., 2010. Evolution of mud-crack patterns during repeated drying cycles. Soft Matter 6, 3562-3567.

Gonçalves, W., Silva, V., Gomes, J., Menezes, R., Neves, G., Ferreira, H., Santana, L., 2014. Avaliação da influência de diferentes tratamentos térmicos sobre as transformações de fases esmectitas. Cerâmica 60, 316-322.

Green, D.J., Guillon, O., Rödel, J., 2008. Constrained sintering: A delicate balance of scales. Journal of the European Ceramic Society 28, 1451-1466.

Griffith, A.A., 1921. The phenomena of rupture and flow in solids. Philosophical Transactions of the Royal Society of London. Series A, containing papers of a mathematical or physical character 221, 163-198.

Grim, R.E., Kulbicki, G., 1961. Montmorillonite-high temperature reactions and classification. American Mineralogist 46, 1329-1369.

Grim, R.E., Rowland, R.A., 1942. Differential thermal analyses of clay minerals and other hydrous materials. Report of investigations no. 085.

Groisman, L., Rav-Acha, C., Gerstl, Z., Mingelgrin, U., 2004. Sorption of organic compounds of varying hydrophobicities from water and industrial wastewater by long- and short-chain organoclays. Applied Clay Science 24, 159-166.

Gu, Y., Meng, G., 1999. A model for ceramic membrane formation by dipcoating. Journal of the European Ceramic Society 19, 1961-1966.

Guggenheim, S., Martin, R., 1995. Definition of clay and clay mineral: joint report of the AIPEA nomenclature and CMS nomenclature committees. Clays and clay minerals $43,255-256$.

Hellmann, J.R., Scheetz, B.E., Luscher, W.G., Hartwich, D.G., Koseski, R.P., 2014. Proppants for shale gas and oil recovery. American Ceramic Society Bulletin 93, 28-35.

Hevia, R., 2007. Bentonitas. Propiedades y usos industriales. Cuaderno Tecnológico, Proyecto INTI-SEGEMAR-Unión Europea.

Hoggard, D.B., Park, H.-K., Morrison, R., Slasor, S., 1990. Zirconia and its refractory application. American Ceramic Society Bulletin 69, 1163-1166. 
Holmes, D.M., Vasant Kumar, R., Clegg, W.J., 2006. Cracking during lateral drying of alumina suspensions. Journal of the American Ceramic Society 89, 1908-1913.

Hsu, P.H., 1989. Aluminum hydroxides and oxyhydroxides. Minerals in soil environments, 331-378.

Huijsmans, J.P.P., 2001. Ceramics in solid oxide fuel cells. Current Opinion in Solid State and Materials Science 5, 317-323.

Husband, J.C., 1998. Adsorption and rheological studies of sodium carboxymethyl cellulose onto kaolin: effect of degree of substitution. Colloids and Surfaces A: Physicochemical and Engineering Aspects 134, 349-358.

Iveson, S.M., Litster, J.D., Hapgood, K., Ennis, B.J., 2001. Nucleation, growth and breakage phenomena in agitated wet granulation processes: a review. Powder technology 117, 3-39.

Jagota, S., Harmer, M.A., Lemon, M.F., Jagota, A., McCarron, E.M., 1995. Pillared Smectite Clay Coatings for Ceramic-Matrix Composites. Journal of the American Ceramic Society 78, 2243-2247.

Jenei, I.Z., 2012. Scanning electron microscopy (SEM) analysis of tribofilms enhanced by fullerene-like nanoparticles. Department of Physics, Stockholm University.

Jung, H., Paek, S.-M., Yoon, J.-B., Choy, J.-H., 2007. Zr K-edge XAS study on ZrO2-pillared aluminosilicate. Journal of Porous Materials 14, 369-377.

Kaiser, A., Lobert, M., Telle, R., 2008. Thermal stability of zircon ( $\mathrm{ZrSiO} 4)$. Journal of the European Ceramic Society 28, 2199-2211.

Kastyl, J., Chlup, Z., Clemens, F., Trunec, M., 2015. Ceramic core-shell composites with modified mechanical properties prepared by thermoplastic coextrusion. Journal of the European Ceramic Society 35, 2873-2881.

Kaya, C., 2003. $\mathrm{Al}_{2} \mathrm{O}_{3}-\mathrm{Y}-\mathrm{TZP} / \mathrm{Al}_{2} \mathrm{O}_{3}$ functionally graded composites of tubular shape from nano-sols using double-step electrophoretic deposition. Journal of the European Ceramic Society 23, 1655-1660.

Kincaid, K.P., Snider, P.M., Herring, M., Mahoney, R.P., Soane, D., 2013. Selfsuspending proppant, SPE Hydraulic Fracturing Technology Conference. Society of Petroleum Engineers.

Kingery, W.D., 1976. Introduction to ceramics.

Kloprogge, J., 1998. Synthesis of smectites and porous pillared clay catalysts: A review. Journal of Porous Materials 5, 5-41.

Koch, D., 2002. Bentonites as a basic material for technical base liners and site encapsulation cut-off walls. Applied Clay Science 21, 1-11.

Koep, E., Truong, H., Truong, J.P., 2017. Methods To Make Ceramic Proppants. U.S. Patent Application No. 15/514,335.

Koseski, R.P., 2008. Manupulation of microstructure, phase evolution and mechanical properties by devitrification of andesite for use as proppant. The Pennsylvania State University. 
Labanda, J., Llorens, J., 2005. Influence of sodium polyacrylate on the rheology of aqueous Laponite dispersions. Journal of Colloid and Interface Science 289, 86-93.

Lagaly, G., 1989. Principles of flow of kaolin and bentonite dispersions. Applied Clay Science 4, 105-123.

Lagaly, G., Dékány, I., 2013. Colloid clay science. Developments in Clay Science 5: Handbook of Clay Science 5, 243-345.

Landau, L., Levich, B., 1942. Dragging of a liquid by a moving plate. Acta Physiochim 17.

Li, K., Lei, J., Yuan, G., Weerachanchai, P., Wang, J.-Y., Zhao, J., Yang, Y., 2017. Fe-, Ti-, Zr-and Al-pillared clays for efficient catalytic pyrolysis of mixed plastics. Chemical Engineering Journal 317, 800-809.

Liang, F., Sayed, M., Al-Muntasheri, G.A., Chang, F.F., Li, L., 2016. A comprehensive review on proppant technologies. Petroleum 2, 26-39.

López Anadón, E., Casalotti, V., Halperin, F., 2015. El abecé de los hidrocarburos en reservorios no convencionales. Ciudad Autónoma de Buenos Aires: Instituto Argentino del Petróleo y del Gas.

Luckham, P.F., Rossi, S., 1999. The colloidal and rheological properties of bentonite suspensions. Advances in Colloid and Interface Science 82, 43-92.

Lunghofer, E.P., 1992. Hydraulic fracturing propping agent. U.S. Patent No. $5,120,455$.

Luscher, W.G., Hellmann, J.R., Scheetz, B.E., Wilson, B.A., 2006. Strength enhancement of aluminosilicate aggregate through modified thermal treatment. International journal of applied ceramic technology 3, 157-165.

Lussier, R., Magee, J., Vaughan, D., 1980. Pillared interlayered clay catalyst preparation and properties, Preprint 7th Can. Symp. Catal.

Lyle, D., 2011. Proppants Open Production Pathways. Schlumberger Ind. Artic, 1-6.

Ma, H., Tian, Y., Zhou, Y., Li, G., Wang, K., Bai, P., 2018. Effective reduction of sintering temperature and breakage ratio for a low-cost ceramic proppant by feldspar addition. International Journal of Applied Ceramic Technology, 15:191196.

Ma, L., Zhu, J., Xi, Y., Zhu, R., He, H., Liang, X., Ayoko, G.A., 2015. Simultaneous adsorption of $\mathrm{Cd}$ (II) and phosphate on $\mathrm{Al}_{13}$ pillared montmorillonite. RSC Advances 5, 77227-77234.

Mackenzie, R., Caillere, S., 1979. Thermal analysis, DTA, TG, DTG. Data Handbook for Clay Materials and other Non-metallic Minerals 442, 243-284.

Madejová, J., 2003. FTIR techniques in clay mineral studies. Vibrational spectroscopy $31,1-10$.

Mader, D., 1989. Hydraulic proppant fracturing and gravel packing. Elsevier.

Magliano, M., Pandolfelli, V., 2010. Mulitização em refratários utilizando diferentes fontes precursoras-revisão (Refractories mullitization with different sources of reactants-review). Cerâmica 56, 368-375. 
Martinez, J.M., Volzone, C., Garrido, L.B., 2017a. Thermal transformations up to $1200{ }^{\circ} \mathrm{C}$ of Al-pillared montmorillonite precursors prepared by different $\mathrm{OH}-\mathrm{Al}$ polymers. Journal of Thermal Analysis and Calorimetry 128, 61-69.

Martinez, J.M., Volzone, C., Garrido, L.B., 2017b. Fases cristalinas and comportamiento térmico de bentonita intercalada con policationes de zirconio, IX Congreso Argentino de Ingeniería Química, Centro Científico Tecnológico Conicet ,Bahia Blanca, Argentina.

Martinez, J.M., Volzone, C., Garrido, L.B., 2017c. Evaluation of polymeric Almodified bentonite for its potential application as ceramic coating. Applied Clay Science 149, 20-27.

Mathieu, Y., Rigolet, S., Valtchev, V., Lebeau, B., 2008. Investigations of a Sodium-Polyacrylate-Containing System Yielding Nanosized Boehmite Particles. The Journal of Physical Chemistry C 112, 18384-18392.

McCarron III, E.M., Harmer, M.A., Jagota, S., 2000. Mullite-containing coatings for inorganic fibers and ceramic matrix composites. U.S. Patent No. 6,022,621.

McDaniel, R. R., McCarthy, S. M., \& Smith, M., 2010. Methods and compositions for determination of fracture geometry in subterranean formations. U.S. Patent No. 7,726,397.

Menezes, R.R., Marques, L.N., Campos, L.A., Ferreira, H.S., Santana, L.N.L., Neves, G.A., 2010. Use of statistical design to study the influence of CMC on the rheological properties of bentonite dispersions for water-based drilling fluids. Applied Clay Science 49, 13-20.

Miranda, C.M., Laverde, D., Avella, V., Ballesteros, D.Y.P., 2015. Adsorción de iones $\mathrm{Ni}$ (II) sobre una arcilla bentonítica peletizada/Adsorption of $\mathrm{Ni}$ (II) ions on pellets of benthonitic clay/Adsorção de iões $\mathrm{Ni}$ (II) em grânulos de argila bentonita. Revista Ion 28, 61.

Mishra, M., Bora, J.J., Goswamee, R.L., 2011. Improvement of the mechanical strength of alumina preforms by coating with montmorillonite/LDH gels. Applied Clay Science 53, 8-14.

Mitra, N.K., Maitra, S., 2001. Pillared Interlayered Clays-An Overview. Transactions of the Indian Ceramic Society 60, 121-125.

Moon, H.J., 2012. Development of thin film inorganic membranes for oxygen separation. Forschungszentrum Jülich.

Moore, D.M., Reynolds, R.C., 1989. X-ray Diffraction and the Identification and Analysis of Clay Minerals. Oxford university press Oxford.

Moya, J., Requena, J., 1998. El desafío de los materiales cerámicos. Boletín de la Sociedad Española de Cerámica and Vidrio 37, 319-326.

Murray, H.H., 2000. Traditional and new applications for kaolin, smectite, and palygorskite: a general overview. Applied Clay Science 17, 207-221.

Murray, M., 2009. Cracking in coatings from colloidal dispersions: An industrial perspective. Proceedings Rideal Lecture, London.

Olaya, A., Moreno, S., Molina, R., 2009. Synthesis of pillared clays with aluminum by means of concentrated suspensions and microwave radiation. Catalysis Communications 10, 697-701. 
Ono, Y., Hattori, H., 2012. Solid base catalysis. Springer Science \& Business Media.

Özkurt, Z., Kazazoğlu, E., 2011. Zirconia dental implants: a literature review. Journal of oral implantology 37, 367-376.

Palisch, T., Chapman, M., Leasure, J., 2015. Novel Proppant Surface Treatment Yields Enhanced Multiphase Flow Performance and Improved Hydraulic Fracture Clean-up, SPE Liquids-Rich Basins Conference-North America. Society of Petroleum Engineers.

Paluszkiewicz, C., Holtzer, M., Bobrowski, A., 2008. FTIR analysis of bentonite in moulding sands. Journal of Molecular Structure 880, 109-114.

Panna, W., Szumera, M., Wyszomirski, P., 2016. The impact of modifications of the smectite-bearing raw materials on their thermal expansion ability. Journal of Thermal Analysis \& Calorimetry 123.

Perry, R.H., Green, D.W., Maloney, J.O., 1999. Perry's Chemical Engineers' Handbook. McGraw-Hill.

Pisklak, T.J., Stevens, J.R.F., Qu, Q., Morillo, E.G., 2011. Light-weight proppant from heat-treated pumice. U.S. Patent No 8,796,188.

Plee, D., Borg, F., Gatineau, L., Fripiat, J., 1985. High-resolution solid-state aluminum-27 and silicon-29 nuclear magnetic resonance study of pillared clays. Journal of the American Chemical Society 107, 2362-2369.

Rahaman, M.N., 2003. Ceramic processing and sintering. CRC press.

Rahman, M.K., Murtaza, M., Al-Majed, A.A., Al-zahrani, M.M., 2017. Nanoclay as an additive for high pressure and high temperature well cementing. U.S. Patent No. 9,650,296.

Rendtorff Birrer, N.M., 2009. Materiales cerámicos del sistema Mullita Zirconia Zircón; propiedades mecánicas, de fractura y comportamiento frente al choque térmico. Tesis Doctoral. Facultad de Ciencias Exactas, Universidad Nacional de La Plata.

Restrepo, E., Monsalve, M., Gonzalez, A., Vargas, F., Latorre, G., López, E., 2016. Influencia de los esfuerzos residuales en la adherencia de recubrimientos de Al2O3-40\% TiO2 depositados mediante proyección térmica por combustión. Boletín de la Sociedad Española de Cerámica y Vidrio 55, 219-227.

Rietveld, H.M., 1969. A profile refinement method for nuclear and magnetic structures. Journal of applied Crystallography 2, 65-71.

Roca, M. (22 de junio de 2013). El debate sobre el fracking. Defonline. Extraído de http://www.defonline.com.ar/

S, N., Joseph, S., 2018. Effect of unmodified and modified montmorillonite on the properties of $\mathrm{PCL}$ based ultrafiltration membrane for water treatment applications. Journal of Water Process Engineering 21, 61-68.

Sadik, C., El Amrani, I.-E., Albizane, A., 2014. Recent advances in silicaalumina refractory: A review. Journal of Asian Ceramic Societies 2, 83-96. 
Salamon, D., Maca, K., Shen, Z., 2012. Rapid sintering of crack-free zirconia ceramics by pressure-less spark plasma sintering. Scripta Materialia 66, 899902.

Sanabria, N., Centeno, M., Molina, R., Moreno, S., 2009. Pillared clays with Al$\mathrm{Fe}$ and $\mathrm{Al}-\mathrm{Ce}-\mathrm{Fe}$ in concentrated medium: synthesis and catalytic activity. Applied Catalysis A: General 356, 243-249.

Sastry, K.V., Fuerstenau, D., 1973. Mechanisms of agglomerate growth in green pelletization. Powder Technology 7, 97-105.

Scherer, G.W., 1990. Theory of drying. Journal of the American Ceramic Society 73, 3-14.

Siffert, B., Espinasse, P., 1980. Adsorption of organic diacids and sodium polyacrylate onto montmorillonite. Clays and Clay Minerals 28, 381.

Sjöberg, M., Bergström, L., Larsson, A., Sjöström, E., 1999. The effect of polymer and surfactant adsorption on the colloidal stability and rheology of kaolin dispersions. Colloids and Surfaces A: Physicochemical and Engineering Aspects 159, 197-208.

Smykatz-Kloss, W., Warne, S.S.J., 2006. Thermal Analysis in the Geosciences. Springer Berlin Heidelberg.

Speyer, R., 1993. Thermal analysis of materials. CRC press.

Stábile, F.M., Piccico, M., Serra, M.F., Rafti, M., Súarez, G., Rendtorff, N.M., 2015. Viscosity and Thermal Evolution of Density and Wetting Angle of a Commercial Glaze by Means of Hot Stage Microscopy. Procedia Materials Science 9, 563-570.

Suárez, G., Acevedo, S., Rendtorff, N.M., Garrido, L.B., Aglietti, E.F., 2015. Colloidal processing, sintering and mechanical properties of zircon ( $\mathrm{ZrSiO} 4)$. Ceramics International 41, 1015-1021.

Sun Kou, M.R., Mendioroz, S., Guijarro, M.I., 1998. A thermal study of Zrpillared montmorillonite. Thermochimica Acta 323, 145-157.

Ting-Hsiang, C., Yuan, T., Y., W.D.L., Hongliang, R., Po-Yen, C., 2018. Crumpling and Unfolding of Montmorillonite Hybrid Nanocoatings as Stretchable Flame-Retardant Skin. Small 14, 1800596.

Tirumkudulu, M.S., Russel, W.B., 2005. Cracking in drying latex films. Langmuir 21, 4938-4948.

Van Olphen, H., 1964. Internal mutual flocculation in clay suspensions. Journal of Colloid Science 19, 313-322.

Van Olphen, H., 1977. An introduction to clay colloid chemistry: for clay technologists, geologists, and soil scientists.

Vaughan, D., Lussier, R., 1980. Preparation of molecular sieves based on pillared interlayered clays (PILC), Proceedings of the 5th International Conference on Zeolites. Heyden, London, pp. 94-101.

Vercauteren, S., Keizer, K., Vansant, E.F., Luyten, J., Leysen, R., 1998 a. Porous Ceramic Membranes: Preparation, Transport Properties and Applications. Journal of Porous Materials 5, 241-258. 
Vercauteren, S., Vayer, M., Van Damme, H., Luyten, J., Leysen, R., Vansant, E.F., 1998b. The preparation and characterization of ceramic membranes with a pillared clay top layer. Colloids and Surfaces A: Physicochemical and Engineering Aspects 138, 367-376.

Veytizou, C., Quinson, J.F., Jorand, Y., 2002. Preparation of zircon bodies from amorphous precursor powder synthesized by sol-gel processing. Journal of the European Ceramic Society 22, 2901-2909.

Vidal, N., Volzone, C., 2012. Influence of organobentonite structure on toluene adsorption from water solution. Materials Research 15, 944-953.

Volzone, C.,1997. Síntesis y caracterización de esmectitas con pilares de $\mathrm{Cr}$ (Cr-PILCs). Tesis Doctoral. Facultad de Ingeniería, Universidad Nacional de La Plata.

Volzone, C., 2001. Pillaring of different smectite members by chromium species (Cr-PILCs). Microporous and mesoporous materials 49, 197-202.

Volzone, C., Cesio, A., 2004. Fired products of Cr-smectite clays in nitrogen. Brazilian Journal of Chemical Engineering 21, 593-599.

Volzone, C., Garrido, L., 2001. Retention of OH-Al complexes by dioctahedral smectites, 36, 1, 115-123.

Volzone, C., Garrido, L., 2012. High temperature structural modifications of intercalated montmorillonite clay mineral with $\mathrm{OH}-\mathrm{Al}$ polymers. Procedia Materials Science 1, 164-171.

Volzone, C., Garrido, L.B., 2008. Use of modified hydroxy-aluminum bentonites for chromium (III) removal from solutions. Journal of environmental management 88, 1640-1648.

Volzone, C., Hipedinger, N.E., 1999. Influence of hydrolyzed zirconium solutions on the $\mathrm{OH}-\mathrm{Zr}$-montmorillonite. Clays and clay minerals 47, 109-111.

Wachtman, J.B., Cannon, W.R., Matthewson, M.J., 2009. Mechanical properties of ceramics. John Wiley \& Sons.

Wang, Y.X., Zhang, S., 2014. Toward hard yet tough ceramic coatings. Surface and Coatings Technology 258, 1-16.

Washburn, E.W., 1921. The Dynamics of Capillary Flow. Physical Review 17, 273-283.

Worrall, W.E., 2013. Ceramic Raw Materials: Institute of Ceramics Textbook Series. Elsevier Science.

Zhou, J., Wu, P., Dang, Z., Zhu, N., Li, P., Wu, J., Wang, X., 2010. Polymeric $\mathrm{Fe} / \mathrm{Zr}$ pillared montmorillonite for the removal of $\mathrm{Cr}(\mathrm{VI})$ from aqueous solutions. Chemical Engineering Journal 162, 1035-1044. 